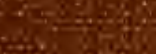




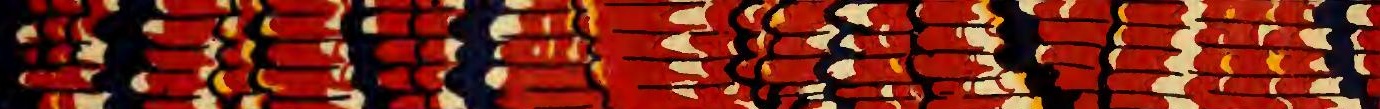

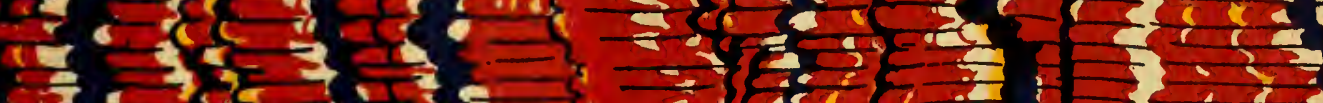

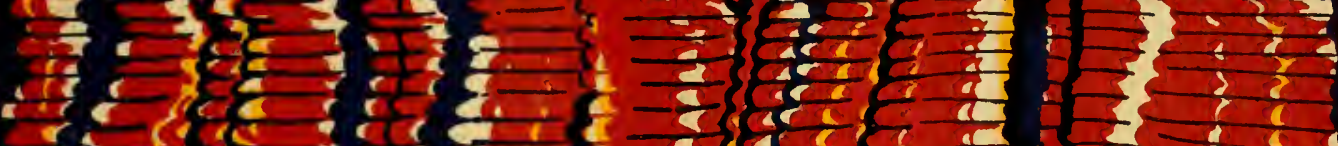

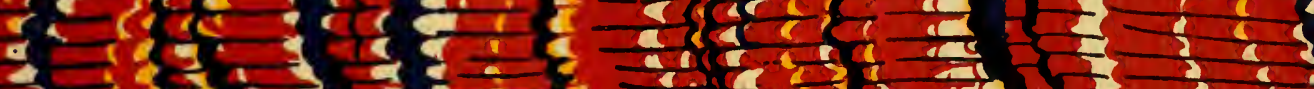

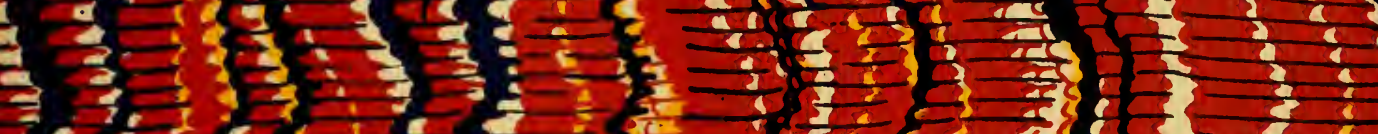

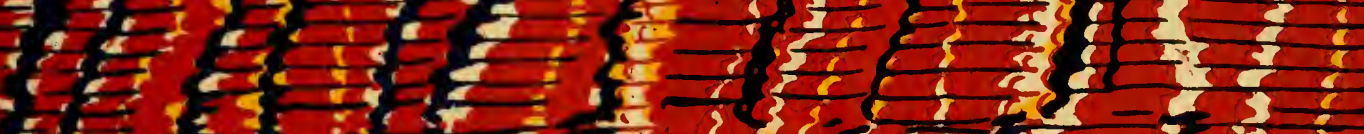

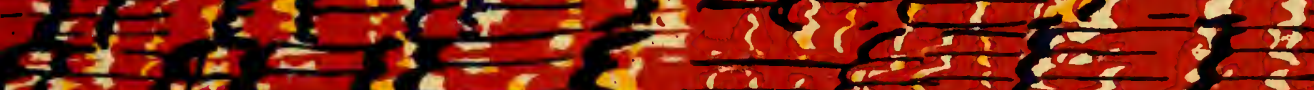

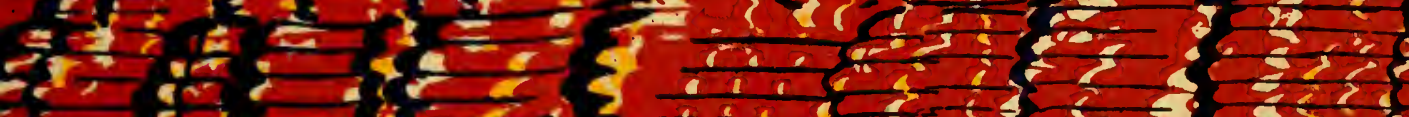

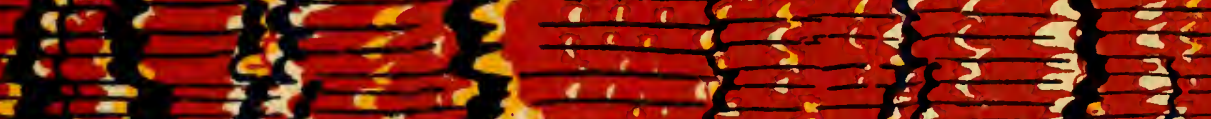

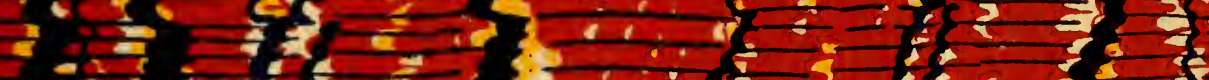

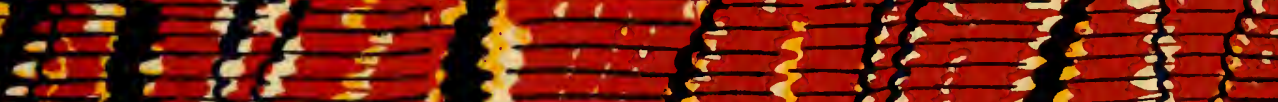

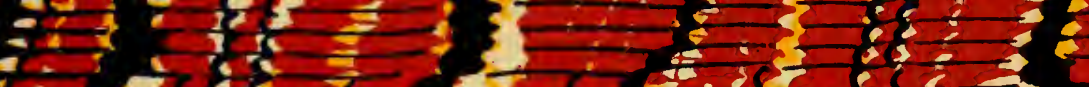

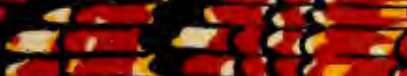

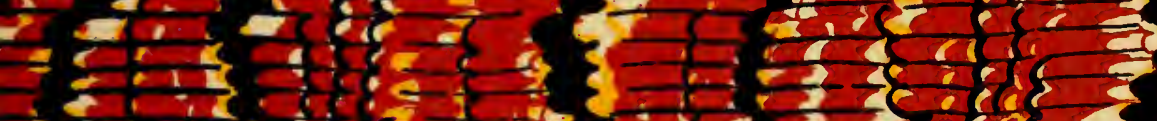

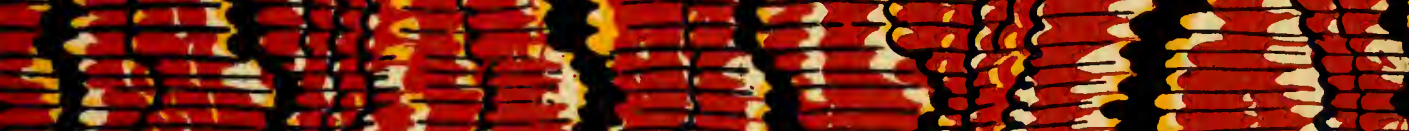

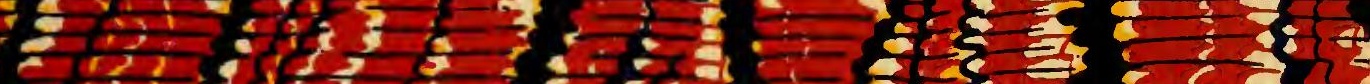

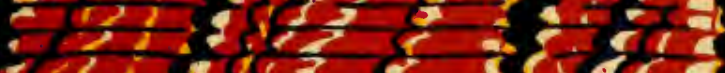

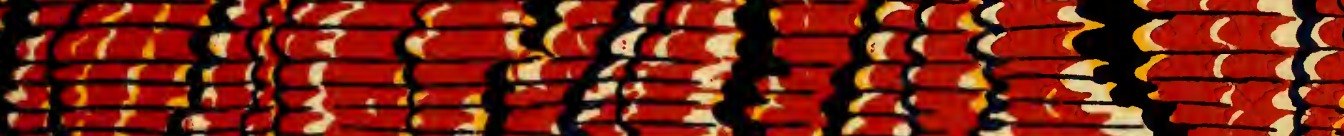
i.

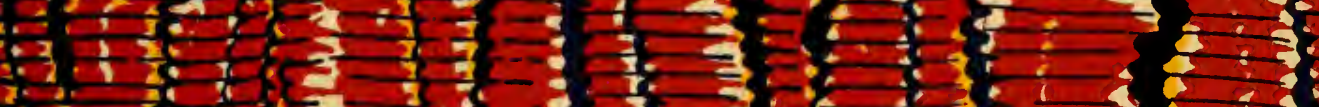

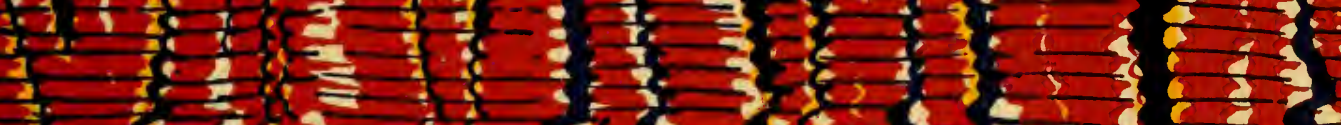

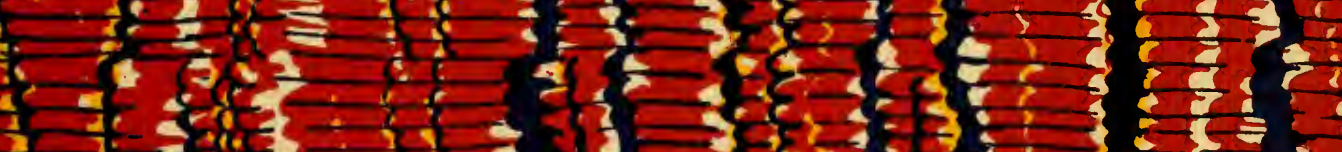

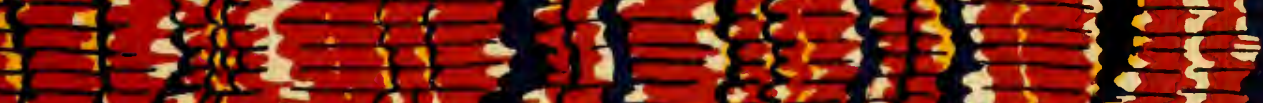

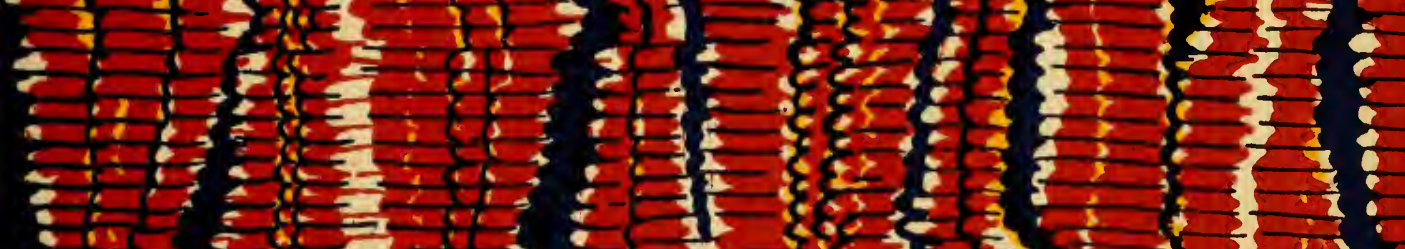

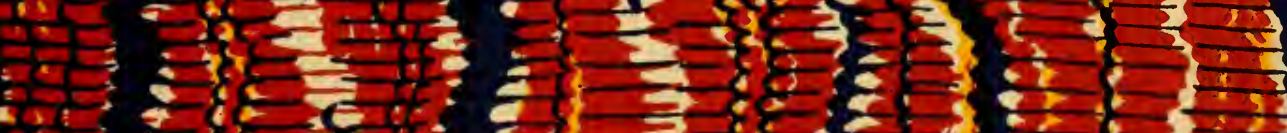

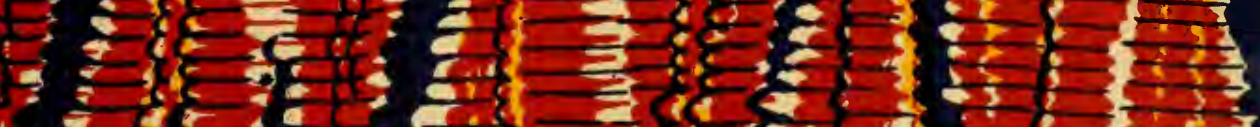

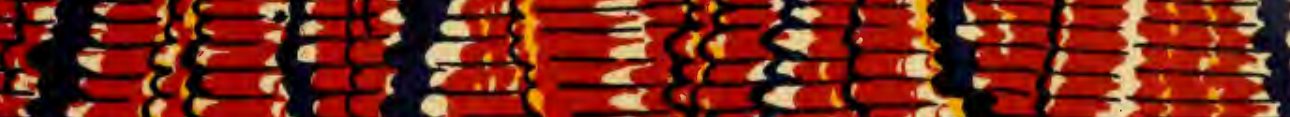

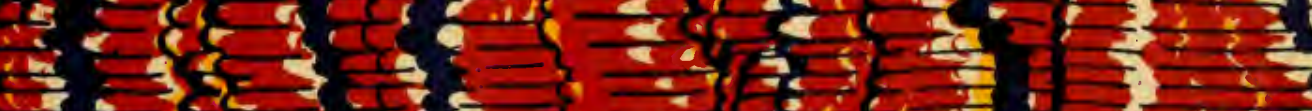

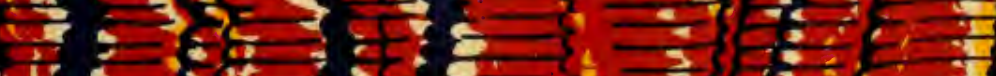

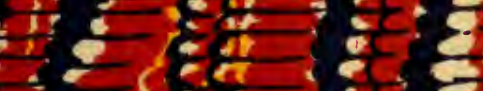

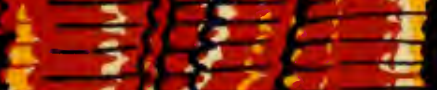

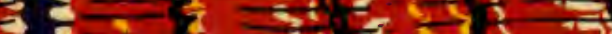









\title{
SELECTION IN CLADOCERA ON THE BASIS OF A PHYSIOLOGICAL CHARACTER
}

\author{
BY ARTHUR M. BANTA
}

\section{INVERTERATE ZODLOGY Crustacen}

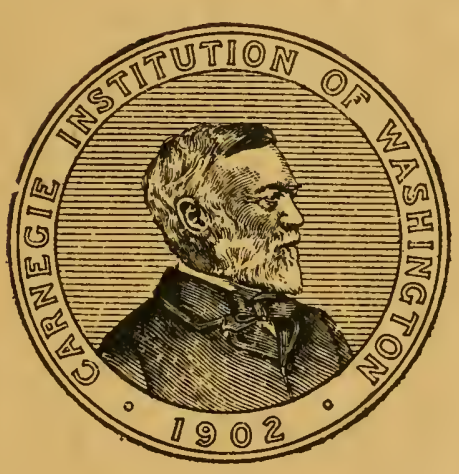

INVERTERT: ZOOLOGY Crustacen

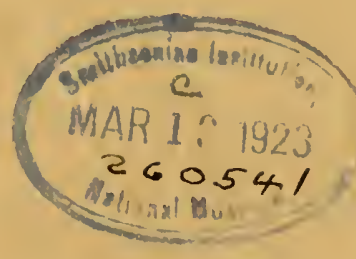

Published bx the Carnegie Institution of Washington WASHINGTON, 1921 



\section{SELECTION IN CLADOCERA ON THE QH BASIS OF A PHYSIOLOGICAL CHARACTER}

By ARTHUR M. BANTA

CRUSTACEA LIBRARY SMITHSONIAN INST. RETURN TO W-119

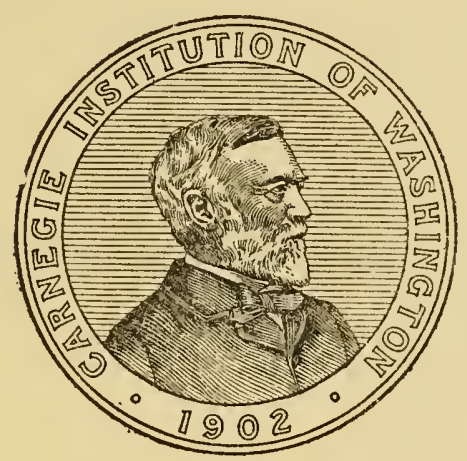

260541 e

Prional haseuts

Published by the Carnegie Institution of Washington WASHINGTON, 1921 


\section{CARNEGIE INSTITUTION OF WASHINGTON.}

Publication No. 305.

Paper No. 33 of the Department of Genetics. 


\section{CONTENTS.}

General statement. . . . . . . . . . . . Page

Source of material. . ............. 6

Culture methods................ 8

Pedigreo records.................. 11

Method of selection.............. 13

General procedure............... 13

Environmental influences and reactiontime $\ldots \ldots \ldots \ldots \ldots \ldots \ldots$

Test series. . . . . . . . . . . . . . .

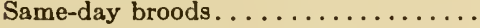

Possible criticisms of methods of selection...................

Nature of swimming movements of $\mathrm{Cla}$ docera species used in selection.

Behavior of young of the different species when released in the experimental tank..................

Relation between environmental conditions and reproductive age.....

Statistical treatment of data...........

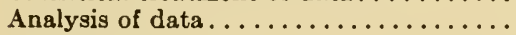

Line $695 \ldots \ldots \ldots \ldots \ldots \ldots \ldots \ldots$

Presentation of data...........

Analysis of data for effect of selection

Relation between reproductive vigor and reactiveness to light.......

Line $689 \ldots \ldots \ldots \ldots \ldots \ldots \ldots \ldots \ldots$

Line $691 \ldots \ldots \ldots \ldots \ldots \ldots \ldots \ldots . . . \ldots$

Line $711 \ldots \ldots \ldots \ldots \ldots \ldots \ldots \ldots \ldots \ldots$

Line $713 \ldots \ldots \ldots \ldots \ldots \ldots \ldots$

Line $714 \ldots \ldots \ldots \ldots \ldots \ldots \ldots \ldots$

Line $719 \ldots \ldots \ldots \ldots \ldots \ldots \ldots \ldots$

Line $751 \ldots \ldots \ldots \ldots \ldots \ldots \ldots$

Line $762 \ldots \ldots \ldots \ldots \ldots \ldots \ldots$

Line $766 \ldots \ldots \ldots \ldots \ldots \ldots \ldots \ldots$

Line $768 \ldots \ldots \ldots \ldots \ldots \ldots \ldots \ldots$

General introduction for Simocephalus exspinosus lines.............

Line $794 \ldots \ldots \ldots \ldots \ldots \ldots \ldots \ldots$

Line $795 \ldots \ldots \ldots \ldots \ldots \ldots \ldots \ldots \ldots \ldots \ldots$

Line $796 \ldots \ldots \ldots \ldots \ldots \ldots \ldots \ldots \ldots \ldots \ldots \ldots \ldots$

Line $740 \ldots \ldots \ldots \ldots \ldots \ldots \ldots \ldots$

Line $757 \ldots \ldots \ldots \ldots \ldots \ldots \ldots \ldots \ldots$

Presentation of data............

Detailed analysis of data for Line 757

Reaction-time means compared by longer periods............ 97

Other features of the data........ 104

Relation between relative vigor and mean reaction-time......... 108
Analysis of data-Continued.

Line 757-Continued.

Special features of the reaction-time curves................ 115

Extent of the change in reactiveness of the Line 757 plus strain..... 116

Reactiveness of both strains of Line 757 modified through selection. 118

Conclusion regarding effect of selection in Line $757 \ldots \ldots \ldots \ldots \ldots \ldots$

Environmental conditions as affecting reaction-time and vigor of stock 128

1. Temperature influences.......... 128

2. Influence of substances exhaled from observer's breath. . . . . . . . . 130

3. Relatively temporary chemical (?) differences in water used in experimental tank........... 131

4. Occurrence of negatively reacting individuals.............. 132

5. General influences operative through longer periods of time....... 132

Coincident changes in reactiveness. . 133

Seasonal changes in reactiveness... 135

Contemporaneous shifts in reactiontime means............. 135

General increase in reactiveness of Simocephalus exspinosus . . . . . 137

Independent shifts in reaction-time means................. 140

Whether "depression periods" occur. 142

6. Environmental conditions as affecting vigor of stock. . . . . . . 143

Reliability of the reproductive index. 143

Coincident fluctuations in vigor.... 344

Independent fluctuations in vigor. . . 145

Differences between reproductive indices during different parts of experiment .............. 146

Is the increased reactiveness for lines of Simocephalus exspinosus associated with increased vigor?.... 147

Possible divergence in vigor between the two strains of a selected line 148

Statement of results of selection...... 150

Discussion of results............ 152

Summary ................... 163

References................... 169 


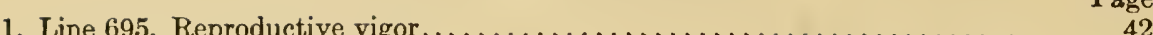

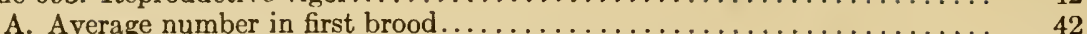

B. Average age of mother at production of first brood.............. 42

C. Reproductive indices, actual values..................... 42

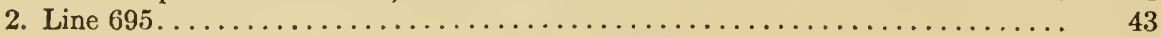

A. Relative rates of descent of the two strains.................. 43

B. Reproductive indices, superiority . . . . . . . . . . . . . 43

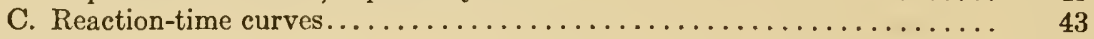

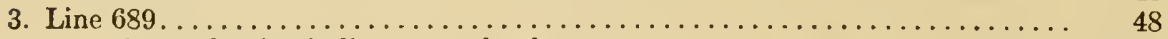

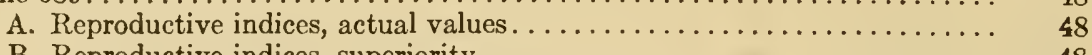

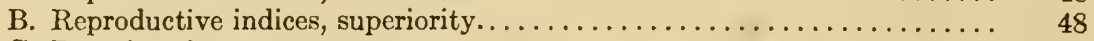

C. Reaction-time curves............................. 48

4. Line 691 . Reaction-time curves.......................... 51

5. Line 711. Reaction-time curves.......................... 53

6. Line 713. Reaction-time curves............................. 55

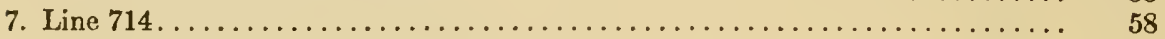

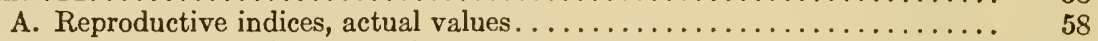

B. Reproductive indices, superiority ................... 58

C. Reaction-time curves............................. 58

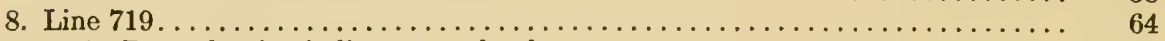

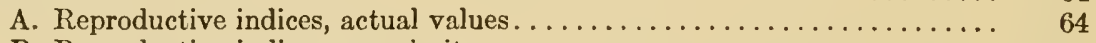

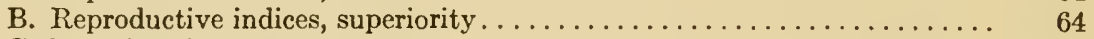

C. Reaction-time curves............................... 64

9. Line 751. Reaction-time curves ........................... 67

10. Reaction-time curves for lines of Daphnia longispina and composite curves for

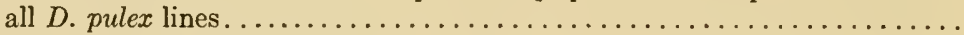

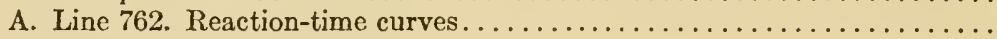

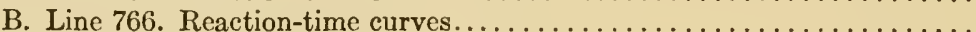

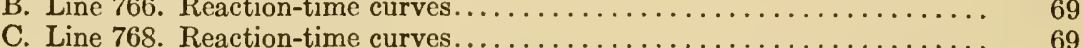

D. Composite curves for all $D$. pulex lines with curves for Line 751 super-

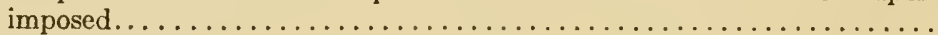

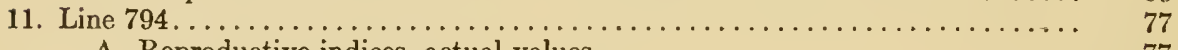

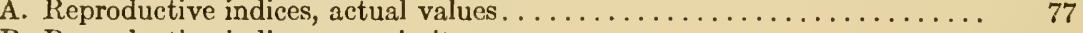

B. Reproductive indices, superiority $\ldots \ldots \ldots \ldots \ldots \ldots \ldots \ldots \ldots \ldots \ldots \ldots \ldots \ldots$

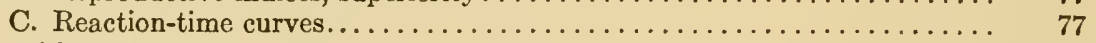

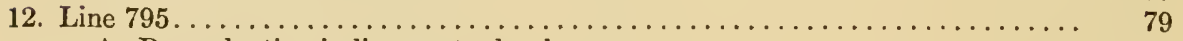

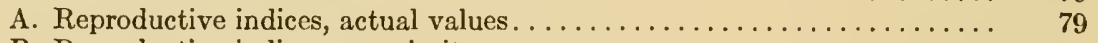

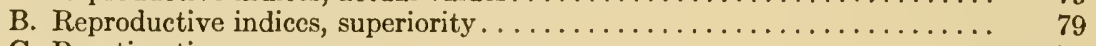

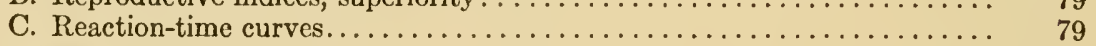

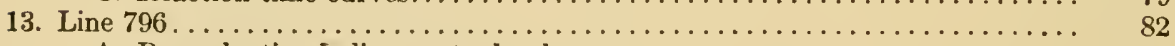

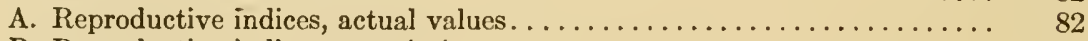

B. Reproductive indices, superiority . . . . . . . . . . . . . . . . 82

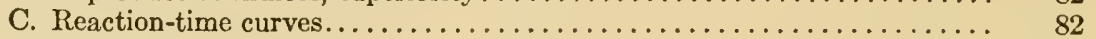

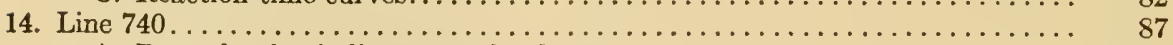

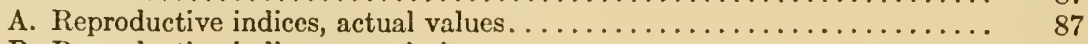

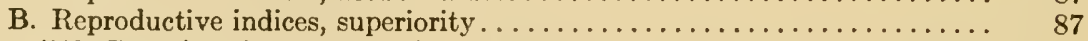

15. Line 740. Reaction-time curves with reaction-time curves for Line 757 super-

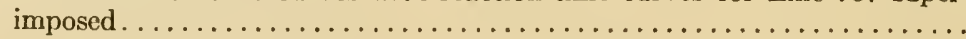

16. Line 757 . Relative rates of d............................. 87

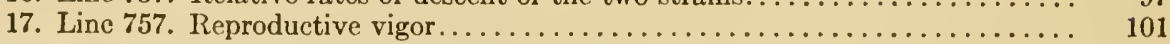

A. Average number in first brood . . . . . . . . . . 101

B. Average age of mother at production of first brood............. 101

C. Reproductive indices, actual values. . . . . . . . . . . . . . . . 101

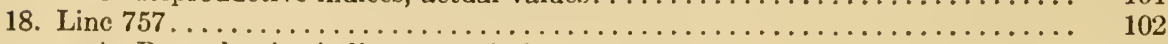

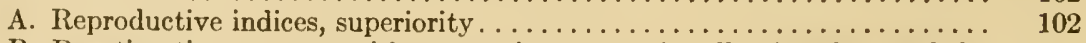

B. Reaction-time curves, with composite curves for all other Simocephalus exspinosus lines superimposed.

19. Line 757. Reaction-time curves by six-month periods with similar curves for

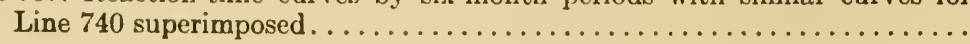




\section{LIST OF TABLES.}

1. History of lines of Cladocera used in selection experiments...

2. Data from an early test series of Line 695 to illustrate differences in general

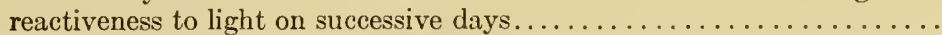

3. Summary of selection data by broods for Line 695 plus................. 29

4. Summary of selection data by broods for Line 695 minus................. 32

5. Selection data summarized by two-month periods for Line 695 plus............ 35

6. Selection data summarized by two-month periods for Line 695 minus . . . . . . . . 36

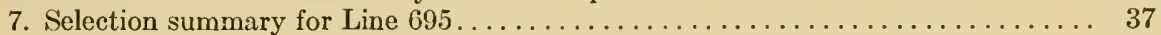

8. Same-day broods. Summary of data for Line $695 \ldots \ldots \ldots \ldots \ldots \ldots \ldots \ldots \ldots \ldots \ldots$

9. Selection data summarized by two-month periods for Line 689 plus . . . . . . . . 46

10. Selection data summarized by two-month periods for Line 689 minus . . . . . . . 46

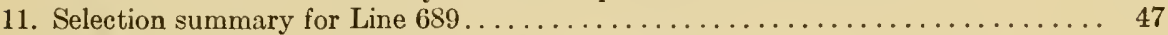

12. Same-day broods. Summary of data for Line $689 \ldots \ldots \ldots \ldots \ldots \ldots \ldots \ldots \ldots$

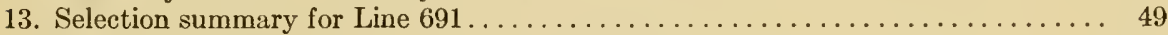

14. Same-day broods. Summary of data for Line $691 \ldots \ldots \ldots \ldots \ldots \ldots \ldots \ldots \ldots \ldots$

15. Selection data summarized by two-month periods for Line 711 plus......... 51

16. Selection data summarized by two-month periods for Line 711 minus . . . . . . . 52

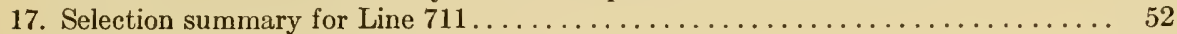

18. Same-day broods. Summary of data for Line $711 \ldots \ldots \ldots \ldots \ldots \ldots \ldots \ldots \ldots$

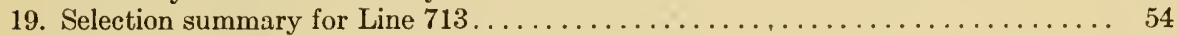

20. Same-day broods. Summary of data for Line $713 \ldots \ldots \ldots \ldots \ldots \ldots \ldots \ldots \ldots$

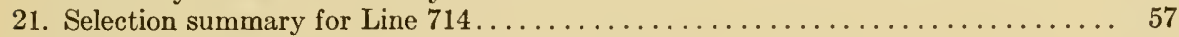

22. Same-day broods. Summary of data for Line $714 \ldots \ldots \ldots \ldots \ldots \ldots \ldots \ldots$

23. Selection data summarized by two-month periods for Line 719 plus . . . . . . . . 61

24. Selection data summarized by two-month periods for Line 719 minus . . . . . . . 61

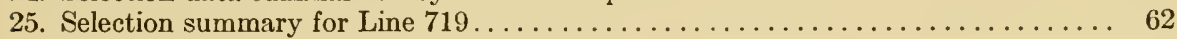

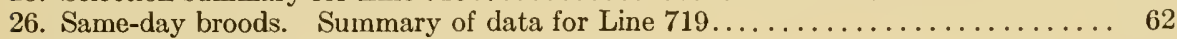

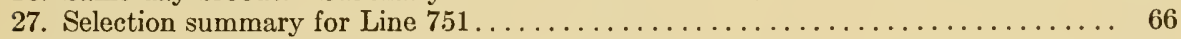

28. Same-day broods. Summary of data for Line $751 \ldots \ldots \ldots \ldots \ldots \ldots \ldots \ldots \ldots$

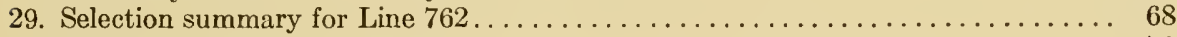

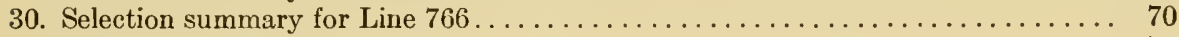

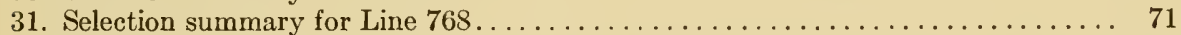

32. Same-day broods. Summary of data for Line $768 \ldots \ldots \ldots \ldots \ldots \ldots \ldots \ldots \ldots$

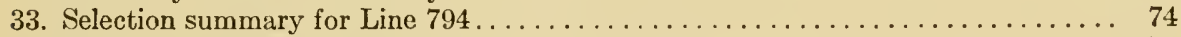

34. Same-day broods. Summary of data for Line $794 \ldots \ldots \ldots \ldots \ldots \ldots \ldots \ldots \ldots$

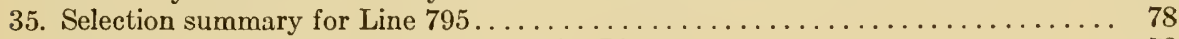

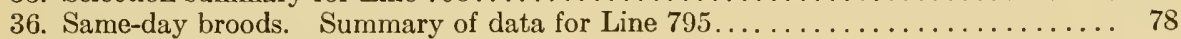

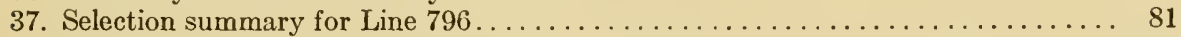

38. Same-day broods. Summary of data for Line $796 \ldots \ldots \ldots \ldots \ldots \ldots \ldots \ldots \ldots$

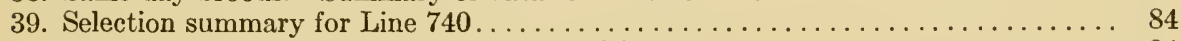

40. Same-day broods. Summary of data for Line $740 \ldots \ldots \ldots \ldots \ldots \ldots \ldots \ldots \ldots$

41. Summary of selection data by broods for Line 757 plus.............. 91

42. Summary of selection data by broods for Line 757 minus . . . . . . . . . . . . 94

43. Selection data summarized by two-month periods for Line 757 plus. . . . . . . . . 98

44. Selection data summarized by two-month periods for Line 757 minus . . . . . . . 99

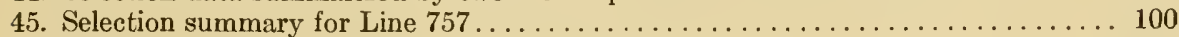

46. Same-day broods. Summary of data for Line $757 \ldots \ldots \ldots \ldots \ldots \ldots \ldots \ldots \ldots$

47. Summary of data for more reactive individuals of Line $757 \ldots \ldots \ldots \ldots \ldots \ldots 107$

48. Comparison of reaction-time means for the plus strain of Line 757 (within which selection was effective) with corresponding means for the plus strains for S. exspinosus lines in which selection was not effective (Line 740) and the shorter $S$. exspinosus lines. Lines 794, 795, and $796 \ldots \ldots \ldots 119$

49. Comparison of reaction-time means for the minus strain of Line 757 (within which selection was effective) with corresponding means for the minus strains for S. exspinosus lines in which selection was not effective (Line 740) and the shorter $S$. exspinosus lines. Lines 794, 795, and 796 



\section{SELECTION IN CLADOCERA ON THE BASIS OF A PHYSIOLOGICAL CHARACTER.}

\section{GENERAL STATEMENT.}

For more than 8 years (January 1920) the writer has been rearing parthenogenetic "pure lines" of Cladocera. The original object of rearing this material was the conducting of experiments on selection within the pure line. These experiments were completed in May 1917. Data bearing on other problems have also been secured from the handling of this material. The selection experiments only will be treated in the present paper.

The writer undertook the selection experiments in order to get additional data on the effects of selection within the pure line. The Cladocera material was chosen for several reasons:

1. It reproduces rapidly.

2. Under favorable conditions it is readily handled in the laboratory.

3. It reproduces parthenogenetically with (under carefully controlled conditions) no possible question as to the occurrence of sexual reproduction.

4. In the maturation of the parthenogenetic eggs of Cladocera there is a single division without reduction (Weismann, 1886; Kühn, 1908). Hence with this material there are presumably no complications of segregation during maturation or of fertilization as with sexually reproducing forms.

5. No selection experiments had been made with a purely physiological character as the basis for selection. Aside from the fact that a physiological character had probably not been used previously as a basis for studies on the effect of selection, a purely physiological character seemed desirable to use for two additional reasons: (a) Physiological differences are frequently readily measurable and measurable in a precise way. Numerical series of measurements provide very usable series of data free from the errors of estimation and personal equation applying to series not directly numerical. The light reactions of Cladocera afford a character perhaps as definitely measurable as any readily handled physiological characteristic. (b) In both the ontogenetic and phylogenetic history of organisms physiological modifications may occur without observed morphological changes, and in the modification of organisms physiological modifications may readily precede distinguishable or measurable morphological changes. This latter consideration (b) had the greatest weight in determining the use of a physiological character as the basis for these experiments. 
The rapidly breeding, easily propagated, parthenogenetic organism possessing a readily measurable physiological character afforded just the material desired.

The experimental object was to attempt to isolate by selection, through a number of generations, a strain more responsive to light than a second strain from the same pure line ${ }^{1}$ selected for its reduced responsiveness to light. ${ }^{2}$

\section{SOURCE OF MATERIAL.}

The Cladocera material to be considered in this paper was obtained from ponds near Cold Spring Harbor. Pond I is a surfacewater pond in an open lot at an altitude of about 160 feet above tidewater. This is a temporary pond, some 60 by 40 feet in dimensions when moderately filled, and contains water only from early winter to May or somewhat later in the summer. Pond II was ${ }^{3}$ a permanent spring-fed pond in a shaded situation in the woods on a northeast slope. It was about one-fourth mile distant from Pond I, at an altitude of about 60 feet, was approximately 18 by 10 feet, and had a depth of only 10 inches. Pond III is another surface-water pond on the upland, three-eighths of a mile from Pond I. It overflows occasionally after excessive rains and frequently becomes dried up in summer. ${ }^{4}$ At its maximum it is approximately 65 by 40 feet, but it ordinarily contains less than a fourth of this area and does not exceed 2 feet in depth at its deepest portion. This pond is near and receives the surface drainage from a barnyard and a pasture lot. Hence it is rich in organic solution constituents. Pond IV is also a shallow surface-water pond. It is on the upland, an eighth of a mile from Pond I, ordinarily has an area of perhaps half an acre, and has become dry only once in the past 7 years. This pond also receives the surface drainage from a barnyard, but because of its larger drainage basin it is not so rich in organic solution constituents as Pond III.

The Daphnia pulex material used in the selection experiments was obtained from Pond I (November 1911 and October 1912) and from Pond II (November 1911). Only two lines $(689,751)$ from Pond I were retained very long. The remainder of the lines of $D$. pulex used in these experiments came from Pond II, the small spring-fed pond in the woods. The D. longispina used in selection were derived from stock from Ponds I and IV. Collections were

1 These were not "pure lines" in the narrowed sense of Johannsen's definition, but were clones in the sense adopted by Johannsen and his followers. The term "pure line" has not in the general mind been restricted to Johannsen's usage, however. Nevertheless, to avoid looseness of expression and possible misunderstanding, it might be wise to abandon this term to Johannsen's limited meaning and for a general term, embracing the Johannsen pure line and the clone, to adopt the term pure lineage or pure descent.

2 Two short noles relating to this series of experiments have been previously published (Banta, 1913, 1919). The references there made to Simocephalus vetulus should read Simocephalus exspinosus = vetulus.

${ }^{3}$ It has since been drained.

It has become empty in the autumn three times in the last 7 years. 
made in October 1912, in Pond I, and in Pond IV in November 1913. The Simocephalus exspinosus material used in selection experiments was obtained from Pond IV, August 1912 and December 1914, and from Pond I, October 1912.

The stock obtained from Pond I, the surface-water pond, had in all probability only recently undergone sexual reproduction. The pond ordinarily remains dry from early summer until October or November. If as much as 3 to 5 weeks had elapsed between the filling of the pond and November 16, when the latest collection from this pond was made, the daphnids could have descended at most only one or two generations, allowing several days for the (fertilized) ephippial eggs (produced before the pond became dried up in the spring) to develop and 2 weeks for each generation at out-door temperature at that season. It is indeed quite probable that the individuals collected were themselves ex-ephippial individuals. There is no safe criterion for determining how long the material obtained from Pond II (the spring-fed pond) may have reproduced parthenogenetically since the stock had last undergone sexual reproduction previous to its being taken into the laboratory. However in this pond and in other small ponds in which this species has been observed it has not ordinarily been found to occur for more than 3 to 5 weeks at a time, so that probably this material had comparatively recently descended from ephippial eggs. There is likewise no way of determining how recently the stock collected from Pond IV had undergone sexual reproduction. D. longispina occurs in this pond occasionally, and, so far as observations go, seems not to continue there long at a time. S. exspinosus, however, is found there the year round. No males or sexual eggs of either species have been found in this pond. ${ }^{1}$

The five lines of $S$. exspinosus originated from five different mothers collected from two ponds and at three different times. There is some evidence (see page 123) that Line 757 (from Pond I, October 1912) at the beginning of selection differed in its reactiveness from Line 740 (from Pond IV, August 1914). The progenitors of these two lines were obtained from different ponds and with a time-interval of about two months. The other lines $(794,795$, and 796, from Pond IV, December 1914) of this species seemed not to differ in their reactiveness from each other or from Line 740 obtained two years earlier from the same pond. Possibly these four lines belonged to the same clone, while Line 757 belonged to a different clone. It is possible that sexual reproduction may not occur in the pond from which these four lines $(740,794,795$, and 796) were obtained, and they may all have come from a common progenitor. While the material was not examined with this point in mind,

\footnotetext{
${ }^{1}$ For the purpose of these experiments it is presumably quite immaterial at what time the last previous sexual reproduction had occurred.
} 
between 60 and 100 collections of $S$. exspinosus material from this pond were made at intervals of several days and no males or ephippial females were found. Males might readily be overlooked in collections not carefully examined microscopically, but ephippial females are unlikely to be overlooked by one who is accustomed to handling Cladocera material. However, sexual reproduction in Cladocera is spasmodic and frequently of short duration, so that the results of the examination of the collections do not entirely preclude the possibility (though making it seem improbable) that sexual reproduction may actually have occurred during the period of frequent examinations of material from this pond.

The same general reactiveness appeared to exist in all $D$. pulex lines (see figs. 2c, 3c, 4, 5, 6, 7c, 8c, 9, and 10D), although they came from two ponds (Pond I and Pond II), were collected at different times, and presumably may have belonged to more than one clone. Sexual reproduction in this species was several times noted in a nearby pond (Pond III) from which the culture-water was obtained.

Table 1 shows in condensed form certain data concerning the lines of Cladocera reared in the laboratory and used for the selection experiments.

\section{CULTURE METHODS.}

The culture-water in which these animals were reared was at first obtained from the spring-fed pond (Pond II). Beginning a year and a half later, it was gotten from Pond III, the barnyard pond. This pond receives all its water from the surface drainage of a small pasture lot and from a barn and barnyard in which live-stock is kept. The amount of organic matter carried into the pond by the surface drainage is relatively large and the water is rich in organic solution constituents. The water is usually heavily colored a reddish or yellowish brown.

In being collected, the culture-water is dipped up in a manner to obtain as much as possible of the loose, fluffy sediment from the bottom of the pond. After being brought into the laboratory it is strained through fine "India linen." The lighter portion of the sediment is gently rubbed through the straining-cloth and the coarser residue is discarded. 'The strained water is then allowed to stand for two days, when it is again (sediment included) strained through India linen. After a second interval of from one to several days the water is thoroughly stirred and a third straining is made through a standard silk bolting-cloth having 130 meshes to the inch. The water is then ready for use as culture-water. The first straining removes any Cladocera or Copepoda which may be in the pondwater and removes most (at least) of their eggs. The second straining removes any young which as eggs may have passed through the 
A PHYSIOLOGICAL CHARACTER.

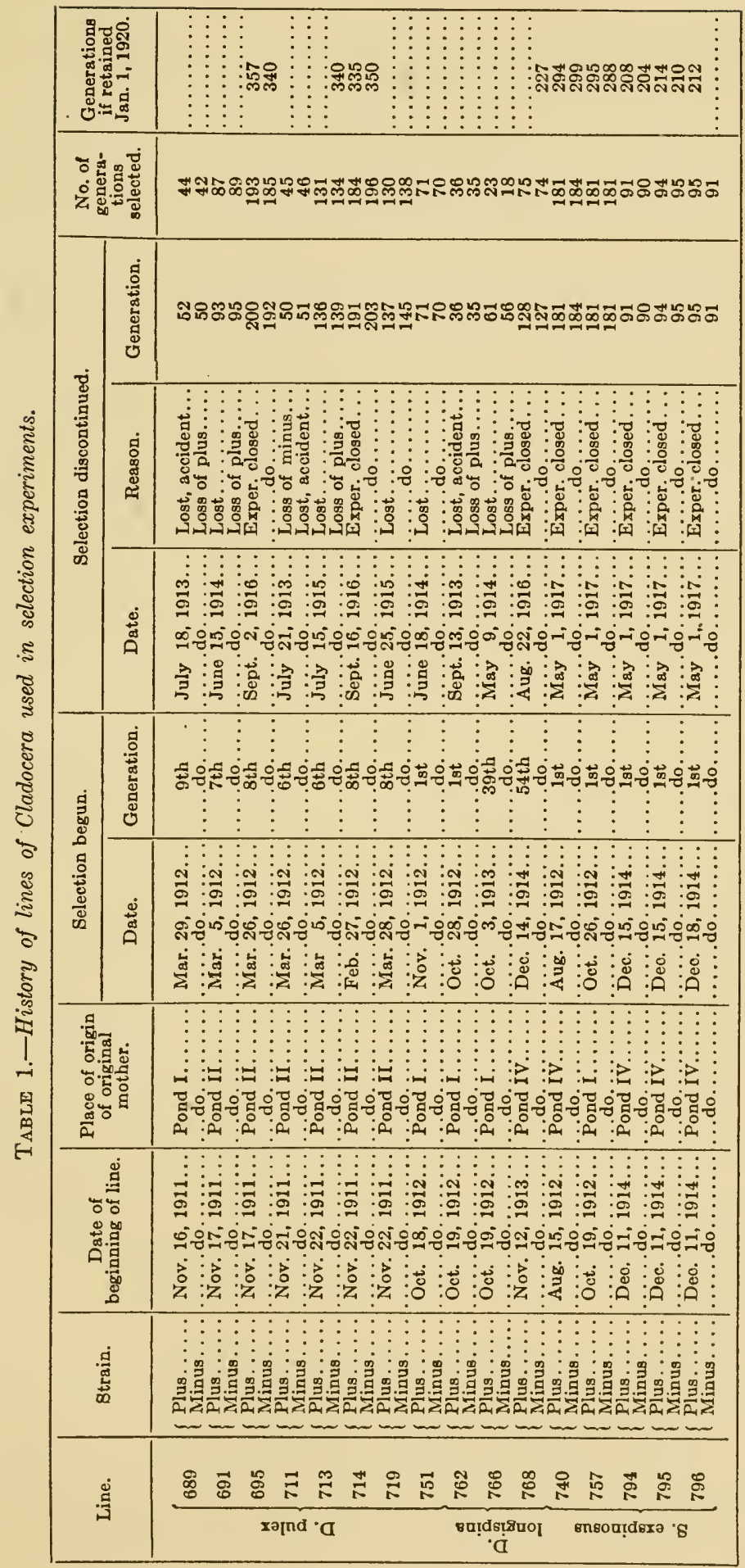


cloth on the first straining, they, meantime, having had time to develop before the later straining. The third straining is probably quite unnecessary, but is used as an added precaution.

The culture-water contains a small amount of the original (now thrice-strained) sediment, has much material in suspension and in solution, and is dull brownish-gray in color. It settles and clears slowly, so that young daphnids placed in the culture-bottles are visible only with difficulty for a day or two.

The animals when collected were isolated in 200-c. c. widemouthed bottles filled to a depth of near $5 \mathrm{~cm}$. (about $100 \mathrm{c}$. c. in quantity) with culture-water. The young of the first brood from the wild mother were transferred during the first day of life to individual bottles. A single individual each was placed in the No. 1 and the No. 2 bottles, while three or more were placed in a third bottle designated as a "prime" bottle to serve as reserve stock. Transfers were made in like manner in subsequent generations, except that Sunday's broods were transferred Monday, when one day old. The bottles of the parent generation were retained as additional reserve stock until a second descendent generation was obtained. The grandmother generation was then discarded, a few individuals being preserved for morphological study if later desired. ${ }^{1}$

For many months after the cultures were begun, and at frequent intervals afterward, large samples of the culture-water, after its three strainings, were set aside in glass jars. Observations were made to determine if daphnids of any sort developed in this water from eggs passing through the straining-cloth or in any way introduced by accident during its handling. None appeared at any time.

In addition to the three strainings of the culture-water and the general precautions observed in handling the stock, the system of handling the material in itself served to check out any possible contamination. The No. 1 and No. 2 bottles each contained a single individual and the prime bottles three or more individuals. Any contamination must have been detected, except in the case of an individual of the same species and very nearly the same age in a No. 1 or No. 2 bottle in which the individual belonging in the bottle died within a day after having been placed therein. The likelihood of the coincidence of the introduction of an inclividual of the same age and of the same species into a bottle in which the rightful individual died within a day is so slight as to arouse little concern. If contamination occurred in a prime bottle, to escape ready detection it would have to be an individual of the same species and of very nearly the same age as the individuals belonging in the bottle. Further, the

I In case the No. 1 individual is lost, young are transferred from the No. 2 bottle, or if the No. 1 and No. 2 are both lost, the transfers are made from the prime bottle. In case the prime too is lost, extra transfers are made from the first or a later brood of the No. 1 or other surviving individual of the parent generation, and young from one of these transfers are used to start the new generation. 
chances would be 3 to 1 (since there are three or more individuals belonging in the prime bottle) against young from the strange individual being used in propagating the line in the unlikely contingency of this bottle being used to continue the line. These facts, combined with the fact that the prime bottles were used only occasionally (when the No. 1 and No. 2 individuals had died) in propagating the strains, make the chances greatly against the perpetuation of a contamination of a pure lime, if such a contamination ever did occur. With a single exception, ${ }^{1}$ which was readily detected, we have every reason to believe that our selection cultures did not at any time become contaminated by the introduction of daphnids in the culturewater or by any other means. ${ }^{2}$

\section{PEDIGREE RECORDS.}

All the descendants of each of the "wild" individuals originally taken into the laboratory are referred to as belonging to a single line, while any subdivisions of the stock within this line are designated as strains. Thus, of each of the lines in which selection on the basis of light reactions was made, there were plus and minus strains, while of certain lines there were several additional strains, all of the strains of any line of course having descended in the laboratory from a single "wild" individual.

In the records each line is referred to by a certain arbitrary number. The generation of its descent since having been brought into the laboratory is indicated by a letter followed by a subscript. The plus and minus strains are indicated by the plus or minus signs. Thus $695 \mathrm{D}_{11}$ - indicates reference to the 264th generation (the letters of the alphabet having been used ten times over and to the letter $\mathrm{D}$ on the eleventh time) of the minus strain of Line $695 .^{3}$

Notes were made on loose-leaf sheets, a sheet being used for the notes for the three bottles (No. 1, No. 2, and "prime") of each generation of each strain. Records on this sheet include the pedigree designation, the pedigree of the mother from which the young were derived, and the date of birth of the young, all made at the time of making the transfer. Later, the date of occurrence and (usually)

1 In one case, early in the course of these experiments, a strange daphnid did appear in one of the culture-bottles. It was a small, rapidly reproducing form, the eggs of which might conceivably be pressed through the straining-cloth, young developed to maturity, and eggs of the next generation produced before the second straining. It was readily recognized as an interloper. Such an appearance, even had it been that of a stray individual of the species under cultivation, would have been readily detected and leads to no great concern as to the purity of our cultures.

${ }^{2}$ In a few instances two individuals were found in a No. 1 or a No. 2 bottle, due to the lifting out in the pipette of two (instead of one) individuals from the mother's bottle or from the experimental tank when making the transfers. The prompt finding of the extra individual added to our confidence in the purity of our cultures, but in every case the bottle in which an extra individual was found was discarded. Since in these cases the extra individual was not of another strain, but marely an extra individual of the same strain, its presence in the bottle did not represent a threatened contamination.

${ }^{3}$ It is to be noted that the minus strains are strains selected for reduced reactiveness to light. No negatively reacting strains occur. 
the number of young in the first brood and the date of occurrence of the second brood from the No. 1 mother were recorded. The transfer of young to the next descendent generation was noted for the appropriate mother, as was also the later discarding of the bottles and the preservation of individuals from the No. 1 bottle. The record of transfers made was given on the mother's as well as the daughter's sheet. This double checking served as a safeguard in case of any deficiency or discrepancy in the notes. Similar, but less complete, records were made for the No. 2 and prime bottles.

The data obtained in conducting the light tests for determining the individuals to be selected was recorded in a separate note-book. Any discrepancy as to the number in a given brood, its pedigree designation, date of birth, etc., could again be checked by reference to this book, so that in reality a three-entry system of note-keeping was utilized. Very few discrepancies or deficiencies in the notes have been found, and these were readily cleared up. ${ }^{1}$

A sample sheet of the loose-leaf notes is appended, and also a page of the experimental-room notes.

Copy of pedigree sheet of loose-leaf notes. $695 \mathrm{~F}_{5}-$ No. 1.

From $695 \mathrm{E}_{5}-$ No. 1. 10/13/14.

Oct. 20,14 young. Distributed to $695 \mathrm{G}_{5}$.

Oct. 23, 2 d brood.

Oct. 31 , preserved.

$695 \mathrm{~F}_{5}-$ No. 2.

Oct. 20,13 young.

Oct. $23,2 \mathrm{~d}$ brood.

Oct. 27 , discarded.

$695 \mathrm{~F}_{5}-$.

Oct. 20 , young.

Oct. 27 , discarded.

Copy of page from experimental note-book.
$695 \mathrm{~F}_{5}-$ No. 1.
$10 / 20 / 14$

Temperature, $19.9^{\circ}$.

Time, $2: 10: 00$.

$$
\begin{aligned}
& 2: 12: 11,+ \\
& 12: 15,+ \\
& 13: 03,+ \\
& 13: 05,+ \\
& 13: 27,+ \\
& 12: 27,+ \\
& 14: 00,+ \\
& 14: 50,+ \\
& 15: 05,+ \\
& 15: 50,+ \\
& 18: 00,+ \\
& 19: 55,+ \\
& \text { over-time. } \\
& \text { over-time. }
\end{aligned}
$$

${ }^{1}$ However, for the sake of complete safety, it was considered wise to keep up the threeentry method of keeping notes. It did not prove unduly laborious. In any case, a new sheet must bo made for each set of three now bottles of the new generation, and naturally the notes on the light tests required the entry of several of the items placed in the experimental note-book. 


\section{METHOD OF SELECTION.}

\section{General Procedure.}

Propagation of the older lines of $D$. pulex had progressed from 5 to 8 generations before the selection experiments were begun. Selection with lines later used was begun at once upon introduction into the laboratory.

The culture-bottles were given uniform treatment so far as possible. The plus and minus strains of the same line were kept side by side on the table. The only obvious environmental differences to which the two strains of the same line were subjected arose from the fact that the young from the two strains were transferred to new food, usually on different days. While every effort was made to provide uniform culture-water, only a moderate degree of uniformity was attainable, but this unavoidable difference in environmental treatment was not differential, and in the long run should have affected the two strains equally.

Unlike the Cladocera material reared under laboratory conditions by many workers, the writer's material produced exclusively asexual young, there being with the material subjected to selection no discovered case in which males or sexual eggs were produced.

The selection tests were conducted in a darkened basement room with dull-black walls. The tank was constructed of plate glass, the bottom being a heavy slab of smooth slate, grooved out to a depth of about $1.5 \mathrm{~cm}$., the grooves being about $2 \mathrm{~cm}$. wide. The plate-glass sides and ends were set in these grooves in an aquarium cement. The grooves were filled with the cement so as to leave a smooth surface continuous with the surface of the slab. The lines of contact of the glass sides and ends were cemented together with thick Canada balsam. After the aquarium cement and balsam had been given several days for hardening, the surface of the cement and the inside of the glass sides of the tank were coated with a mixture of lampblack, balsam, and turpentine. The result was a tank with uniform dull-black sides and bottom and with transparent ends. The tank measured inside $40 \mathrm{~cm}$. by $26.6 \mathrm{~cm}$. and was $7.2 \mathrm{~cm}$. in depth. An improvement on this tank would be made by substituting thin slabs of smooth slate for the plate-glass sides.

The source of light was at first a slender, cylindrical, carbonfilament, incandescent lamp. Later similar carbon-filament lamps could not be obtained and a tungsten lamp was used. The lamps used varied from 43.5 to 75.9 candle-power. They were placed at 
the appropriate distances from the tank to obtain an illumination of 120 candle-meters, calculated to the middle of the tank. ${ }^{1}$

The heat-screen, $4.5 \mathrm{~cm}$. thick, with parallel glass sides and filled with distilled water, was placed at the end of the tank through which the illumination was received. An upright black cardboard screen was placed between the heat-screen and the end of the tank, so as to permit rays of light to enter the end of the tank only in the area between the bottom of the tank and the level of the surface of the water. The water within the tank was filtered pond-water and was maintained at a depth of $1.8 \mathrm{~cm}$. Fresh water was placed in the tank each day and a change of water was made after testing and selecting from each four broods.

The young animals to be tested, consisting of entire first broods, were removed from the mothers' bottles by means of a small pipette, and taken to the experimental room in $10 \mathrm{~mm}$. cylindrical vials. The vials were placed in a wire basket and immersed to about $3 \mathrm{~cm}$. depth in a dish of water of the same temperature as the water in the experimental tank and left about an hour before the tests were begun. The temperature of the experimental room varied from $14^{\circ} \mathrm{C}$. during the coldest weather in winter to sometimes as high as $22^{\circ} \mathrm{C}$. in summer. Very rarely the temperature was as low as $10^{\circ} \mathrm{C}$. or as high as $24^{\circ} \mathrm{C}$.

In preparation for the testing of each brood, the entire brood was (by means of the small pipette) placed in the center of the experimental tank within an upright cylinder of glass $1 \mathrm{~cm}$. in diameter. The experimental light was turned on and all extraneous light was eliminated. The animals were then left undisturbed within this cylinder for 2 minutes, when the cylinder was lifted carefully from the water, thus releasing the animals in the center of the tank; the temperature of water and time of release of the animals were recorded just before the release. The illumination within the water was sufficient to make the young daphnids just visible to the eye of one accustomed to working with them. As soon as a daphnid reached either end of the tank it was removed and the time of its arrival recorded, together with the proper sign to indicate to which end of the tank it had gone (see page 12). The interval between the release of the animal and its arrival at the end of the tank is referred

${ }^{1}$ No allowance was made for the diminution in amount of light due to its passage through the heat-sereen, the plate-glass end of the tank, and the water within, nor was allowance made for the somewhat different results in illumination due to using lamps of different candlepower. While the distances at which the lamps were used were such as to give a caleulated illumination of 120 candle-meters at the middle of the tank, the illumination at the ends of the tank would of course be somewhat different with the lamps differing in candle-power. This fact was not taken into consideration in originally substituting a 60-watt Mazda lamp (about 75.3 eandle-power) for the carbon-filament lamp of 43.5 candle-power. Having for a time used the lamp with the higher candle-power, it was considered wise to continue its use. Any variation in absolute intensity of the light at the different parts of the tank is regrettable, but it should of course be equally effective with the plus and minus strains and presumably could not disturb the course of the experiments. 
to as its reaction-time. ${ }^{1}$ The test was continued for 15 minutes, unless all individuals had reached an end of the tank earlier; any remaining at the end of 15 minutes were removed and arbitrarily assigned a reaction-time of 15 minutes. $^{2}$ Another brood was then tested in a like manner.

In testing a brood of the plus strain, the individual first reaching the positive end of the tank was at once placed in a separate vial and later transferred to the No. 1 bottle of the new generation. The second one to reach the positive end was likewise placed in a separate vial, to be later transferred to the No. 2 bottle. The others were returned to the vial in which they had been conveyed to the experimental room. Three or more of these were later transferred to the "prime" bottle of the new generation. With the broods of the minus strains the procedure was the same, except that the two quickest to reach the negative end, the two which moved farthest toward the negative end, the two moving least toward the positive end of the tank, or the two slowest in reaching the positive end were selected for the No. 1 and No. 2 bottles of the new generation. Negatively reacting individuals did not occur in most of the broods, nor were there usually individuals which showed any tendency to react negatively to light. With $D$. pulex and $D$. longispina few individuals failed to move to the positive end within the limits of the experiment. Hence very frequently in the minus strains the No. 1 and No. 2 individuals selected were respectively the one slowest and the one next slowest in reaching the positive end of the tank.

As with the data for the over-time individuals, the data for the negatively reacting individuals presented some difficulty. The occurrence of negatively reacting individuals was irregular and more or less spasmodic. Table 2 presents some data illustrating this point. Reference to any of the tables presenting the data by broods will show that when negatively reacting individuals occur they are frequently relatively numerous. The writer believes negatively reacting individuals are (usually, at any rate) influenced by some unusual environmental factor and that an individual's swimming

1 The "reaction-time" as recorded in the notes and used in this paper indicates, in seconds, the interval between the release of the young daphnid from the glass cylinder in the middle of the experimental tank and the time at which it reached the end of the tank. Strictly speaking, this is the real reaction-time-the time consumed in the beginning of movement and establishing orientation with reference to the light—plus the time consumed by the animal in swimming to the end of the tank.

2 The arbitrary assumption of 15 minutes as the reaction-time of individuals which as $\mathbf{a}$ matter of fact did not react within that length of time is open to criticism, but no better method of utilizing this significant portion of the data was ascertained. The "over-time" individuals can not be disregarded. The data for them are obviously very significant. In a slightly reactivo strain, such as the minus strain of Line 757 , they constitute a large portion of the individuals tested and represent a striking manifestation of the low responsiveness to light in this as in other strains. As pointed out in another connection, the arbitrary assumption of 900 seconds for their reaction-times greatly minimizes the rightful influence upon mean reaction-time of their slight or non-reactiveness to light. 
to the negative end of the tank does not in most cases really indicate a negative phototropism. Such individuals, if tested a second time, do not ordinarily repeat the behavior. ${ }^{1}$ The best interpretation seemed to be that individuals which reacted negatively were stimulated by the light as their sisters were, but that a "negative" response was ordinarily called forth by some accessory influence. Occasionally this additional influence obviously was accidental mechanical stimulation; but usually negative responses could not be thus accounted for, and often they were certainly not due to this cause.

The data for negatively reacting individuals were treated as though the individuals had reacted positively, except that the number of such occurrences was tabulated and is frequently referred to in the treatment of the data. It is questionable if, in making selections in the minus strains, one was justified in selecting individuals (where such a selection was possible) which went to the negative end of the tank. Cladocera are so generally positive that negative reactions are at once open to a question as to significance, but it is believed that the possibility of an actual change or mutation producing a really negatively reacting individual is sufficient justification for selecting these individuals in the minus strains.

In case a daphnid remained unaccounted for at the end of the test of a brood, the tank was emptied, twice carefully rinsed, and filled to the proper depth with fresh water. At all times in the experiments every conceived precaution was taken to exclude extraneous light, to guard against reflection from any object without or small foreign body within the tank, to eliminate all mechanical stimulation, and particularly to guard against the possible misplacing of an individual daphnid in the handling of the broods. ${ }^{2}$

In brief, in the selection experiments the entire first brood, soon after its release from the mother's brood-pouch, was removed from the culture-bottle, placed in a small vial, taken to a darkened room, and subjected to known and always uniform directive lightstimulation under carefully controlled conditions, the object being to attempt to procure (by selection through many generations) a strain more responsive to light than a second strain from the same

${ }^{1}$ In the plus strain of Line 757 minus individuals occurred in 17 broods out of 172 broods from which selections were made. In 4 of these eases there were more than a single minus individual (19 individuals in 4 broods). In the minus strain of Line 757 minus individuals occurred in 13 of 175 actual selection tests, and in one of these cases there were 3 minus individuals (tuble 42).

${ }^{2}$ Tho pipette in which the daphnids were handled was earefully rinsed after handling each brood. In conducting the selections the vials to receive the selected animals were arranged so that the one nearest at hand was the one in which the next individual removed from the tank was to be placed. A small opening was made in the cardboard screen in order to permit a small amount of light to fall upon the observer's watch and note-book. The pipette could readily be examined in this light and the animal seen within it, in case there was any doubt about the daphnid having been drawn into the pipette when its removal from the tank was attempted. The table on which the experiments were conducted was closed off from the remainder of the room by a black curtain. 
line selected for its less responsiveness to light. In the beginning of this selection the most responsive individual from the first brood of the young mother was selected for the beginning of the plus strain and the least reactive one or, perchance, one reacting negatively and avoiding the light, for the beginning of the minus strain. In the next and later generations selections were made from the first broods (except in cases where the first brood was lost), the two most reactive individuals in the plus and the two least reactive individuals (or negatively reacting individuals if such occurred) in the minus strain being selected to propagate and continue their respective strains.

At certain periods during the course of these experiments the rearing of the various strains was rendered difficult by poor food conditions. Sometimes during such periods selections were not made on the basis of reaction to light, but the individuals used to continue the strains were taken at random from the mother's bottle. In the tables giving the data by broods, such cases (and a few others in which for some reason the selection test was not conducted) are indicated as "random distributions."

\section{Environmental Influences and Reaction-Time.}

The tables of data obtained in making the selections show that there were wide differences in the general reactiveness of different broods tested in making the selections (see tables 3 and 4). Sometimes a brood had an unusually low or an unusually high mean reaction-time, when perhaps the immediately preceding and next succeeding broods of the same strain had a mean near that for the strain as a whole. Sometimes a considerable number of a single brood reacted negatively, although on the whole only a small percentage of the individuals reacted negatively. Occasionally it was noted that all the broods on a certain day responded slowly to light stimulation, while perhaps on the following day all responded promptly. These differences are due to environmental factors. Table 2 illustrates this point, as well as the spasmodic occurrence of negatively reacting individuals. Reference to this table shows that on August 29, 1913, the mean reaction-time of 87 individuals of Line 695 tested was 401 seconds, and 3.5 per cent reacted negatively; on the following day the mean reaction-time was 636 seconds and 1.6 per cent were negative; on the day following this the mean reaction-time was 398 seconds and 28 per cent were negative. Thus, on the second of these three days the individuals of the same strains were slower in their reactions, compared with the other two days, by approximately 60 per cent. And there were twice and 18 times as large percentages of negatively reacting individuals on the first and third as on the second of these days. ${ }^{1}$

1 This is an extreme case, but it illustrates differences such as were repeatedly observed, though usually to a much less marked degree. 
Such differences in response indicate environmental factors of great influence, but what these influences were was in most cases not determined. It was frequently noted, in the tests at the beginning of these experiments, that after the observer had tested several broods in succession the broods tested later reacted less quickly than the earlier ones. This may have been due to the accumulation in the water of $\mathrm{CO}_{2}$ from the observer's breath. The difficulty was obviated by changing the water in the experimental tank after testing each four broods.

These and other factors were much too influential for one to ignore them completely, but their influence was presumably a horizontal one, affecting all the individuals of a brood and of the different strains in the same manner and not in any way influencing selections, except as affecting the reaction-time and in causing a few

TABLE 2.-Data from an early test series of Line 695 to illustrate differences in general reactiveness to light on successive days.

\begin{tabular}{|c|c|c|c|c|c|c|}
\hline & \multirow{2}{*}{ Mother's pedigree. } & \multirow{2}{*}{$\begin{array}{c}\text { No. } \\
\text { of } \\
\text { young. }\end{array}$} & \multirow{2}{*}{$\begin{array}{l}\text { No. of nega- } \\
\text { tively react- } \\
\text { ing } \\
\text { individuals. }\end{array}$} & \multirow{2}{*}{$\begin{array}{l}\text { Percentage } \\
\text { of negative } \\
\text { individuals. }\end{array}$} & \multicolumn{2}{|c|}{$\begin{array}{l}\text { Mean reaction-time in } \\
\text { scconds. }\end{array}$} \\
\hline & & & & & By broods. & By days. \\
\hline \multirow[t]{2}{*}{$\begin{array}{l}\text { Aug. } 29,1913 . \\
\text { Fresh water......... } \\
\text { Fresh water......... }\end{array}$} & \multirow{2}{*}{$\begin{array}{r}695 \mathrm{E}_{3}-\text { No. }{ }^{91} \ldots \\
695 \mathrm{I}_{3}+\text { No. } 5 \ldots \\
695 \mathrm{I}_{3}+\text { No. } 6 \ldots \\
\text { Totals, etc..... }\end{array}$} & $\begin{array}{l}26 \\
23 \\
38\end{array}$ & $\begin{array}{l}1 \\
0 \\
2\end{array}$ & $\begin{array}{c}\ldots \ldots \ldots \ldots \\
\cdots \ldots \ldots \ldots \ldots \\
\cdots \ldots \ldots \ldots\end{array}$ & $\begin{array}{l}448 \\
555 \\
276\end{array}$ & an....... \\
\hline & & 87 & 3 & 3.5 & $\ldots \ldots \ldots$ & 401 \\
\hline $\begin{array}{c}\text { Aug. } 30,1913 . \\
\text { Fresh water......... }\end{array}$ & \multirow[t]{2}{*}{$\begin{array}{r}695 \mathrm{I}_{3}+\text { No. } 9 \ldots \\
695 \mathrm{E}_{3} \text { - No. } 2 \ldots \\
695 \mathrm{E}_{3} \text { - No. } 10 \ldots \\
695 \mathrm{I}_{3}+\text { No. } 12 \ldots \\
695 \mathrm{E}_{3} \text { - No. } 7 \ldots \\
695 \mathrm{I}_{3}+\text { No. } 11 \ldots \\
695 \mathrm{I}_{3}+\text { No. } 13 \ldots \\
695 \mathrm{E}_{3} \text { - No. } 4 \ldots \\
\text { Totals, ete.... }\end{array}$} & $\begin{array}{l}22 \\
21 \\
23 \\
23 \\
27 \\
33 \\
21 \\
20\end{array}$ & $\begin{array}{l}0 \\
0 \\
0 \\
0 \\
1 \\
2 \\
0 \\
0\end{array}$ & 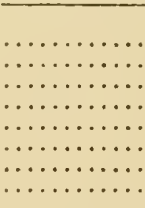 & $\begin{array}{l}346 \\
631 \\
704 \\
710 \\
577 \\
766 \\
761 \\
526\end{array}$ & 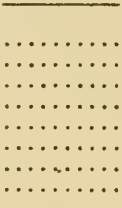 \\
\hline \multirow{3}{*}{$\begin{array}{c}\text { Aug. } 31,1913 \\
\text { Fresh water......... }\end{array}$} & & 190 & 3 & 1.6 & $\ldots \ldots \ldots$ & 636 \\
\hline & \multirow{2}{*}{$\begin{array}{r}695 \mathrm{I}_{3}+\text { No. } 1 \ldots \ldots \\
695 \mathrm{E}_{3}-\text { No. } 9 \ldots \\
695 \mathrm{I}_{3}+\text { No. } 8 \ldots \\
\\
\text { Totals, etc..... }\end{array}$} & $\begin{array}{l}22 \\
17 \\
11\end{array}$ & $\begin{array}{r}10 \\
2 \\
2\end{array}$ & $\begin{array}{c}\ldots \ldots \ldots \ldots \\
\cdots \ldots \ldots \ldots \ldots \\
\ldots \ldots \ldots \ldots \ldots\end{array}$ & $\begin{array}{l}350 \\
396 \\
498\end{array}$ & $\begin{array}{l}\cdots \ldots \ldots \cdots \\
\cdots \cdots \cdots \cdots \\
\cdots \cdots \cdots\end{array}$ \\
\hline & & 50 & 14 & 28.0 & $\ldots \ldots \ldots \ldots$ & 398 \\
\hline
\end{tabular}

${ }^{1}$ This is mother No. 9 of the fifty-8eventh generation of the minus strain of Line 695 .

individuals which otherwise would have been positive to be rendered negative in their reactions. It seems wise to postpone the detailed analysis of the effects of environment upon reaction-time and upon vigor until after the general analysis of the data has been presented (sec pages 128-149).

\section{Test Series.}

Because of the various factors instrumental in influencing the reactions of the different broods of Cladocera, and in order to obtain a critical measure of the effect of selection, if such occurred, so-called 
test series were planned. These test series were conducted under a plan by which large numbers of broods of the plus and the minus strains of the same line were experimented upon on the same day and as nearly as was experimentally possible under precisely the same conditions. The plan was as follows: First, it was necessary to wait until such time as the plus and minus strains of the same line reproduced on the same day. A number of these young, from 12 to 20 , of each of the strains were then transferred to individual bottles, given the same food, kept grouped together on the same table, and in every way treated alike. When their first broods appeared, four broods of equal or nearly equal size--two from the plus and two from the minus strain-were chosen, the choice being limited to broods released from the mother's brood-pouch within 2 or 3 hours of the same time. Thus we had broods containing equal or nearly equal numbers of individuals, of the same age (within 2 or 3 hours), and from mothers of the same age which had themselves received identical treatment from birth; other "quartettes" were selected in like manner. Further, the four broods, constituting a quartette, were handled in a definite order; a plus brood was experimented with first, then a minus brood, then the second minus brood of the quartette, and finally the second plus brood was tested. The tank was then emptied and replenished with fresh water. The second quartette was handled in reverse order: first a minus brood, then (in order) the two plus broods, and the second minus brood. The next quartette was then handled in the order indicated for the first quartette. Still other quartettes of broods were chosen from the second and later broods of the test-series mothers until the numbers of individuals tested from each strain were quite large-in most cases larger than 600 and in several cases in excess of 1,000 .

The test-series, it was hoped, might serve as a means of eliminating most of the disturbing factors unquestionably present during the reaction-tests, due to the fact that the selections in the plus strain and the minus strain of the same line were usually, through necessity, made on different days.

\section{Same-Day Broods.}

The two strains of the same line only occasionally reproduced on the same day, so that consecutive reaction-tests of a brood of each of these two strains were not ordinarily possible; however, during the whole course of the selection experiments, there were a number of selections in the plus and minus strains of the same line on the same days. In addition to the complete tabulation, the data for these "same-day" broods are tabulated separately. Such a tabulation for the two strains of Line 695 is given in table 8 . Such a comparison of the mean reaction-times of the same-day broods ought perhaps to afford a safer criterion of the effectiveness of 
selection (if an effect be obtained) than a summary of the entire selection data. The difficulty is that the amount of this data is so limited. For example, there are only 41 of these same-day broods for Line 695, out of a total of 192 broods of the plus strain and 180 broods of the minus strain for which data were secured.

\section{Possible Criticisms of Methods of Selection.}

Certain possible criticisms of the methods used in the selection experiments occurred to the writer and doubtless may occur to others.

1. Was there assurance that the individual daphnids selected were really the most and the least positively reacting individuals in their respective broods? (a) Was there reason to think that the individual daphnid first reaching the positive end of the tank was the one most influenced by the light? (b) May not this individual have been affected by a slight swirl in the water in being released from the cylinder or in some other manner subjected to mechanical stimulation? (c) Or may it have been affected differently from its fellows, due to some other condition external to itself? (d) Or may it have been influenced by some internal factor or factors and consequently its reaction determined by some "physiological state?" (e) Or may its reaction-time not have been influenced by its general vigor or by its ability as a swimmer? $(f)$ Was the method of handling such as in any manner to unfavorably affect the animals and thus render their activities untrustworthy?

2 . If the individual selected was really the most positively phototactic at the time of the selection, was it also the most positively phototactic an hour or a day later?

3. Was the selection method used calculated to produce a more vigorous race as compared with a less vigorous race?

4. Assuming real and lasting differences in light-reaction between sibs, are these differences heritable anyway?

If one accepted these possible criticisms in their fullest implication it would at once be seen that the results here set forth were impossible of attainment, and the result with Line 757 is perhaps sufficient answer to these questions. The writer does not believe that these possible criticisms are at all damaging to or can be rightfully applied to these experiments; however, they will be discussed individually. (1) and (a) under it will be discussed after its subsidiary questions, $(b)$ to $(f)$, have been considered.

(b) Observations directed upon the effect of mechanical stimulation show that a daphnid when mechanically stimulated usually moves promptly and rapidly; frequently the movement is from the source of mechanical stimulation if that is directive; but if nondirective, the movement is equally prompt and vigorous, though usually not different in direction from that in which the animal was 
previously oriented. In either case the effect is ordinarily very temporary.

In the vast majority of cases, in making the selections, when the cylinder was lifted to release the animals the daphnids at first failed to move at all or moved very slowly and only later began swimming or increased the rate of movement. In spite of all precautions, doubtless some individuals were mechanically stimulated and thus influenced in their reactions; occasionally such was obviously the case. But while such stimulation might influence the rate of movement and occasionally the direction of movement, these effects were temporary and the occurrences of such influences were to all appearances infrequent, so that it is believed the aggregate effect of such influences upon the selections is of little or no significance.

(c) Unquestionably it is true that even when every precaution is taken to secure uniformity of conditions and to eliminate all extraneous light, to eliminate disturbances of the direction of the incident rays of light, to prevent mechanical or other accessory stimulation, and to provide uniformity in handling the animals, etc., perfect conditions are not attainable. Imperfect experimental control of environmental conditions is obvious enough and is referred to elsewhere in this paper (see pages 15, 17-20, and 128-149). But there are no grounds for assuming that these imperjectly controlled environmental conditions were differential or in any appreciable way affected the selections. To assume that in any considerable number of the selections differential stimulation occurred would, we believe, go beyond the facts and be quite unwarranted.

(d) It is obvious that conditions internal to the animals themselves are not subject to complete control. The writer does not doubt that "physiological states" were occasionally a factor, and sometimes a determining factor, in individual selections, but he does not believe that internal conditions were frequently a determining factor. In cases of repeated tests of the reaction-times of a number of individual daphnids, sometimes several hours or even 2 or 3 days apart, the later results usually agreed with the earlier results-i. e., the animals which at the first test were most responsive to the light on subsequent tests were the most responsive or among the most responsive individuals. Hence there is excellent reason for believing that the individuals selected were actually the most responsive and the least responsive individuals of their respective broods. But assuming that temporary physiological states did sometimes influence the selections (as must occasionally have been the case), it would merely operate to render the selections less effective, and unless the internal temporary physiological factors were factors in a prevailing number of the selections, they could not neutralize the selections.

(e) The individuals selected in the plus strains may have been merely the best swimmers, regardless of general vigor, or they may 
have been the most vigorous individuals of their respective broods; but on the whole there seems no good reason for believing this to have been the case. If the differences were merely differences in quickness of movement or swimming ability, it would be quite as interesting to develop "hare" and "tortoise" strains of Cladocera as to develop strains more reactive and less reactive to light; and the result would have the same fundamental bearing on the problem of selection within the pure line. That the reaction-times of the vast majority of individuals were not influenced by differences in vigor is attested by the fact that there is no consistent relation between vigor (as measured by the mean reproductive index) and mean reaction-time. This point is discussed more fully in connection with the detailed analysis of the data for the various lines.

$(f)$ The strains subjected to selection did not show greater mortality nor less vigorous growth and reproductive ability than those lines not used in the selection experiments. The only difference in conditions through which those selected (as compared with those strains not subjected to selection) passed previous to being placed in the experimental tank was being placed for a time in a relatively small amount of the culture-water. There is no reason to think that this profoundly affected their light-reactions, or if it had, that the effect would not have been a horizontal rather than a differential one.

(1) and (1a) On numerous occasions the individuals of a brood were caused to react in the experimental tank a number of times. Of course, on second and subsequent trials only a single individual could be handled at one time in the tank because of the danger of mistaking the identity of the individuals.

Of 10 such experiments, conducted within a few days and including all such experiments made within those days, there was complete agreement in reaction order in 6 experiments; in 3 there was fair agreement, and in 1 there was very poor agreement in reaction order. Even in the last-mentioned case, however, the individuals which reacted more quickly during the first test in general reacted more quickly on the average of all the trials, but the reaction order was greatly ehanged. The objection that the selections in general may have been made on the basis of vigor of individuals has been, we think, effectively discounted. In view of this fact, it is believed that such consistent results as those just indicated show conclusively that neither physiological states nor any other factor operated to obviate or hamper the selection on the basis of fundamental individual differences in reactiveness to light. It is believed that in the vast majority of eases the two selected in the plus strains were more reactive to the illumination to which they were subjected than their fellows, and that those selected in the minus strain were less positive than their fellows. 
2. This point bears on the question of the occurrence of "physiological states" and their relative frequency. The discussion of (1) and $(1 a)$ bears directly on this point.

3. To the possible objection that the method of selection was suited to the production of more vigorous strains in the plus and less vigorous strains in the minus strains, the answer is that such a result did occur to some extent in two of the lines, but it was not a cumulative result and the differences in reproductive vigor were not greater at the close than during the early part of the experiment. These cases are discussed in detail in the analysis of the data for the various lines. But, as is pointed out later, in those cases in which reduced reproductive vigor did occur it was not causally associated with differences in reaction-time.

4. This question, as applied to the selection problem, is a "leading" question. Its answer depends upon whether the differences are germinal or purely somatic. In the vast majority of cases such reaction differences as are encountered in these selection experiments are probably purely somatic, and the effect of selecting such variants is of course nil. Whether some of these reaction differences are due to germinal modifications will be taken up in connection with the experimental data considered in this publication. 


\section{NATURE OF SWIMMING MOVEMENTS OF CLADOCERA SPECIES USED IN SELECTION.}

Daphnia pulex is rather rotund in form and is only slightly heavier than water. It swims by vigorous strokes with perceptible intervals between, thus producing a very jerky movement. It is pelagic in its habits, and ordinarily its swimming strokes are repeated just frequently enough to maintain its level in the water. When locomotion occurs the animal orients itself differently, i. e., instead of its antero-dorsal axis being approximately vertical, it changes to approach a horizontal position with dorsal side uppermost; its swimming movements are more rapidly repeated and the animal's course may be fairly straight. The jerky character of movement is still quite in evidence. This species frequently attaches to the surface film of the water, but almost never to the sides of the container. A vigorous individual rarely or never rests upon the bottom.

$D$. longispina is very similar to $D$. pulex in its habits and movements, but is more slender and somewhat less active; it is not quite so heavy; its axis does not so nearly assume a vertical position in its "place-maintaining" movements; and in its locomotion its movements are somewhat less jerky, due to its relatively smaller antennæ and less vigorous strokes. Like $D$. pulex, it is distinctly pelagic and does not rest upon the bottom. It does not ordinarily attach to the surface film and never to the sides of a container.

Simocephalus exspinosus is a rotund, rather bulky species, much heavier than the two species of Daphnia. It settles rather rapidly through the water, unless kept up by continued swimming movements. It lies upon and moves about over the bottom much of the time, frequently holds fast to the side of the container, and often attaches to and moves about at the surface film. It usually swims with ventral side uppermost. Its swimming movements are less jerky than in either species of Daphnia, due to its relatively smaller swimming antennæ and more rapid antennal movements, though the jerky character is somewhat evident. In nature $S$. exspinosus spends most of its time upon the bottom and upon submerged aquatic vegetation.

\section{BEHAVIOR OF YOUNG OF DIFFERENT SPECIES WHEN RELEASED IN THE EXPERIMENTAL TANK.}

In the experimental tank the vast majority of individuals of $D$. pulex upon their release swam a few strokes without orientation, then oriented with reference to the light and swam toward the source of light. This orientation was not perfect in many cases, so that the animal sometimes swam somewhat diagonally. But even when the direction of movement was somewhat diagonal, the course was usually fairly straight. This diagonal course occasionally led to the side of the tank. In such cases the animal usually followed along 
the side of the tank in the direction of its former orientation, though sometimes it took a diagonal course away from the side of the tank, but in the general direction (as regards light) in which it was formerly oriented. The individuals which were slow in reacting either moved very slowly, scarcely more than executing "place-maintaining movements," or they wandered about independently of the directive light stimulation for a time and later attained and maintained orien. tation with reference to the light. Some individuals wandered about so long or swam so little that they did not reach either end of the tank in the 15 minutes of the experiment. These were the "overtime" individuals which were arbitrarily assigned a reaction-time of 900 seconds. D. pulex seldom attached to the surface film or to the sides of the tank. Negatively reacting individuals were not especially common with $D$. pulex.

The statements regarding the behavior of $D$. pulex in the experimental tank apply to $D$. longispina; this species sometimes became caught in the surface film and was unable to free itself. Such individuals were discarded and excluded from the record.

$S$. exspinosus, on being released within the experimental tank, settled to the bottom at once or swam a few strokes without orientation and then settled to the bottom. Occasionally some individuals just after their release swam upward and attached to the surface film. In many broods, some individuals, after settling to the bottom or rising to the surface, made no further movements during the 15 minutes of the test, while with some broods there was no further movement on the part of any individual. The majority of individuals, however, began moving again within a few seconds, or at most within 2 or 3 minutes, assumed their orientation, and swam toward the light. Most individuals, after orienting, paused for a time, settled to the bottom, and afterward continued their movement toward the light; others, after the second pause, did not move again. With $S$. exspinosus there was less random movement after the first pause than with the two species of Daphnia. Occasionally individuals, in their movement toward the light, swam near the surface, and when they paused attached to the surface film. Such individuals frequently did not move again. As with Daphnia, the orientation often was not perfect and some individuals reached the sides of the tank, frequently attaching there, and making no further movements; but more generally they followed along the side of the tank with the same general orientation as before. Orientation in a negative way was uncommon with this species.

The frequency of occurrence of large numbers of non-reactive individuals of $S$. exspinosus was a distinct difficulty to satisfactory experimental conditions. Because of this apparent difficulty, some of the earlier lines of $S$. exspinosus with which selection was attempted 
were discarded as apparently unprofitable material for a selection experiment on the basis of reactiveness to light. The lines of $S$. exspinosus which were retained did not contain fewer non-reactive individuals during their early history, but the experiments were continued, and the results justify the conclusion that there was after all a sufficient basis for an experiment in selection.

\section{RELATION BETWEEN ENVIRONMENTAL CONDITIONS AND REPRODUCTIVE AGE.}

Reproductive age is very closely related to environmental conditions, principally to temperature. It is a matter of common observation in the rearing of this material that the reproductive age is greatly affected by temperature and food conditions. During a local period of high temperature and warm nights in summer, a generation may be obtained in 6 to 7 days in S. exspinosus and in 5 to 6 or 7 days in Daphnia and even in 1 or 2 days in Moina, while during a period of continued cool days and nights in fall or spring, when the laboratory is not provided with heat, the reproductive age stretches out to 11 to 14 days for Simocephalus and Daphnia and 8 to 12 days for Moina.

Curves were made for some of the lines, showing the mean reproductive ages for different two-month periods. At times they show remarkably close agreement in mean reproductive ages, not only between the two strains of the same line but also between the different lines of the same species and to a considerable degree between $D$. pulex and S. exspinosus. Figure 1в (for Line 695) and Figure 17в (for Line 757) show two of these curves.

\section{STATISTICAL TREATMENT OF DATA.}

Irregularities in phototropic response are common. They are noted in almost every paper dealing with the light-reactions of animals. Dependable results are generally obtained only by securing sufficient data to obtain averages from relatively large numbers.

Like most other material, the Cladocera discussed in this paper showed considerable irregularities in light-reactions, and comparisons of the two selected strains of the same line are made by considering the data by longer periods, so as to avoid the extreme effect of local conditions and fluctuations in the behavior of individual broods.

In the study of a character so complicated as a behavior characteristic it is essential to deal with relatively large numbers, and the safest way to deal with large series of data is by statistical treatment. Much time has been given to the statistical analysis of this data, although the treatment has been carried only so far as seemed 
necessary in order to bring out the real significance of the material, ${ }^{1}$ and has been confined to the determination of standard deviations, probable errors, and a few correlations.

Probable errors have been used in seeking to determine the significance of the reaction-time differences between the selected strains of the various lines. Many more probable errors have been determined (and included in the tables for the benefit of the reader) than have been referred to in the text discussions. On the other hand, probable errors have not been determined for many differences which were obviously too small to have statistical significance. ${ }^{2}$

For the benefit of anyone wishing to work over a portion of the data statistically, the sums of the individual reaction-times and the sums of the squares of the individual reaction-times are given in the tables which present the data for Lines 695 and 757 by broods. Hence, most of the statistical treatment for these two lines is capable of verification from the data presented in this paper. Likewise the data are available for any further statistical treatment.

The standard deviations of the reaction-time means are'large, whether the data is considered by shorter periods or by year periods. This is largely due to the over-time individuals, the data for which afforded considerable difficulty in statistical treatment. Other plans of handling the data for these individuals (other than assuming 900 seconds as their reaction-time) were considered, but they seemed to provide no better method of utilizing this very significant part of the data.

\footnotetext{
${ }^{1}$ Such statistical treatment as has been accorded the data of this paper has been greatly facilitated by suggestions from Dr. J. Arthur Harris, of the Station for Experimental Evolution. However, any errors or insufficient treatment must be ascribed to the writer, who has conducted the statistical analysis.

${ }^{2}$ It is recognized, however, that the value of the probable error is not fully utilized when one fails to determine probable errors for all the differences in a series of data-for, obviously, a difference which is twice its probable error deserves more consideration than one which is only a fraction of its probable error, though a difference less than $21 / 2$ times its probable error is considered of doubtful statistical validity. Nevertheless, to conserve the computer's time, it was felt advisable to omit the determination of probable errors for many of the differences which did not promise marked statistical value.
} 


\section{ANALYSIS OF DATA.}

LINE 695.

\section{Presentation of Data.}

The data for Line 695 may be considered first. Line 695 is one of the original lines taken into the laboratory, the stock having been obtained from the spring-fed pond in the woods (Pond II), November 17, 1911. The selection was begun March 26, 1912. The stock had then descended 8 generations in the laboratory. By that time methods of rearing and handling the material had been worked out and the stock was well established.

The manner of handling the young in making the selections has already been discussed. The selection data complete, summarized by broods, are given in the tables for the 695 plus and the 695 minus strains. Tables 3 and 4 contain in successive vertical columns, beginning at the left, the designation of the generation; the date of selection from within the brood; the hour of the day at which the experiment was conducted; the age of the young, whether a "new" brood or a brood released a day earlier (Sunday's broods and rarely others were tested when a day old); the number of individuals in the brood; the temperature of the water in the experimental tank at the time of the experiment; the number of individuals which went to the negative end of the tank; the number of individuals which failed to respond to the extent of reaching either end of the tank within the period allotted ( 15 minutes); the minimum reaction-time for an individual of each brood; the maximum reaction-time; the sum of the individual reaction-times for the brood; the mean reactiontime for the brood; and finally, the sum of the squares of the individual reaction-times (for computation purposes). ${ }^{1}$

Consultation of tables 3 and 4 shows that there are wide differences in reactiveness of the various broods. These, in part at least, are due to the factors discussed on pages $17-20$ and 128-149 of this paper. It is unfortunate, though not surprising, that these reaction differences are so large, but when all of the factors of the case are taken into account, it is believed that they are not unduly disturbing to the course of the experiment.

Because of the relatively wide differences in reaction-time between different broods and the small numbers in many of the broods,

\footnotetext{
${ }^{1}$ For the benefit of anyone wishing to go over the author's analysis or make further analysis, it was desired to present the complete data for all the lines discussed in this paper. But (in view of the present great cost of printing so many pages of tables) data are presented practically complete for Lines 695 and 757 only. It is quite impracticable to publish the individual reactiontimes for all the individuals tested in making the selections, even for Lines 695 and 757 . The sums of the squares of these reaction-times aro given. This renders available all the data necessary for a critical analysis of the original duta and should satisfy the most exacting reader, so far as Lines 695 and 757 are concerned. The detailed data for all the lines have been typed in tabular $\mathrm{m}$, such as is used for the data for lines 695 and 757 , and are stored in duplicate at the Station

Experimental Evolution, where they may be freely consulted by anyone interested.
} 
TABLE 3.-Summary of selection data by broods for Line 695 plus.

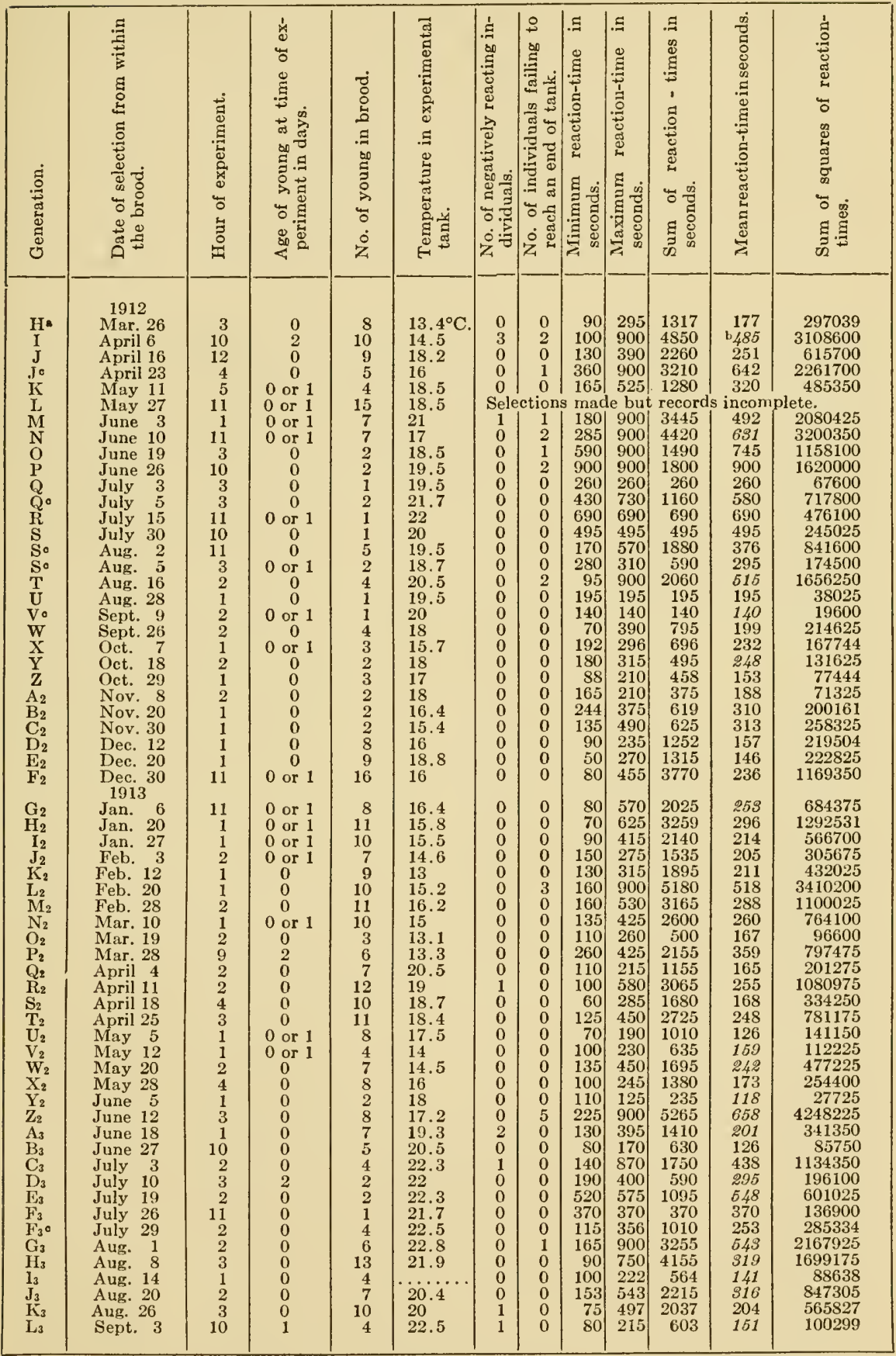

a This is the original brood from which selections were made for the beginning of both the plus and minus strains.

b Mean reaction-times in italics are those for which there is a corresponding mean for a brood tested on the same day in the minus strain.

- Selection was repeated from the later brood because of the loss of the earlier brood. 
TABLE 3.-Summary of selection data by broods for Line 695 plus-Continued.

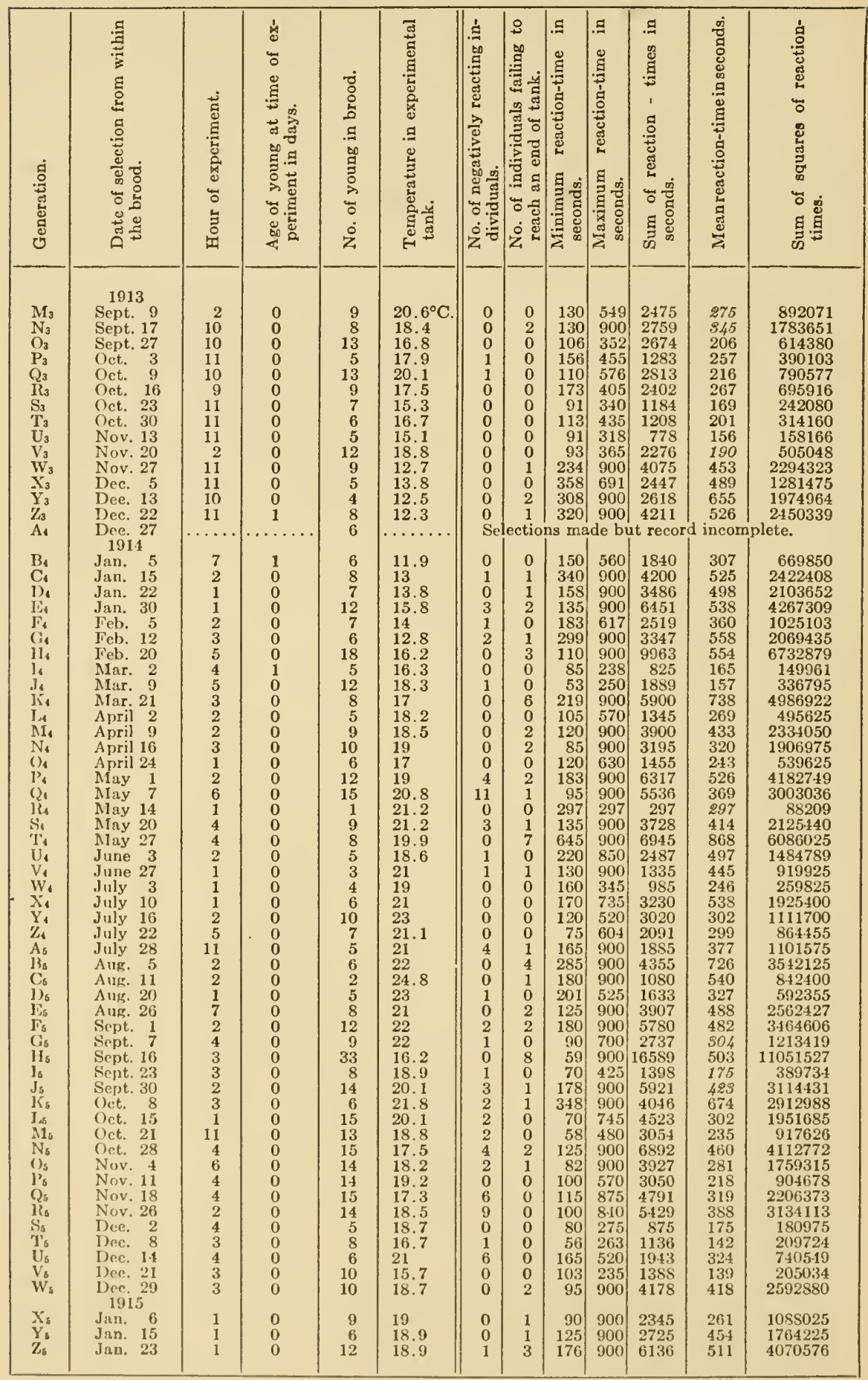


TABLE 3.-Summary of selection data by broods for Line 695 plus-Continued.

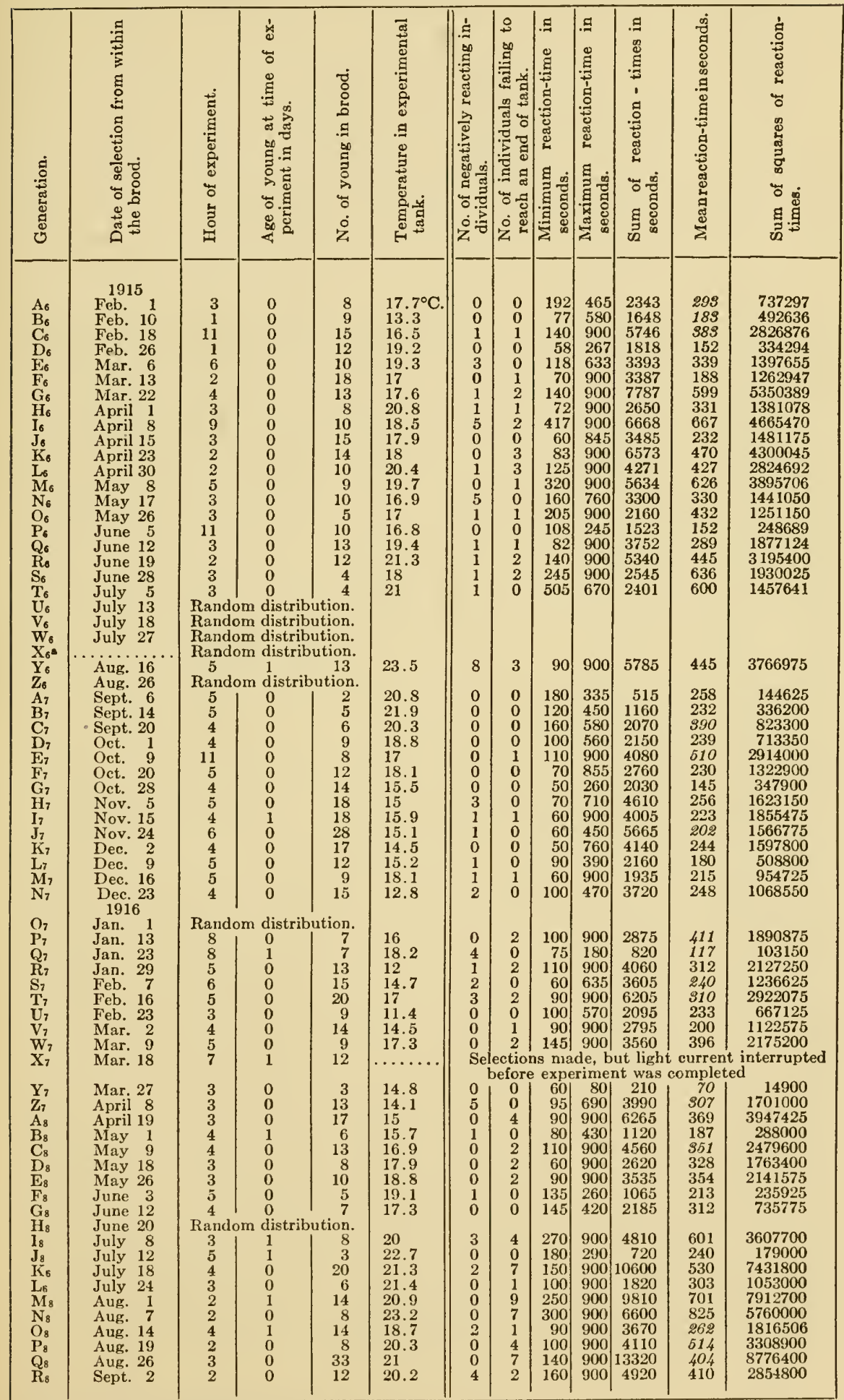

- All of the $695+$ strain was lost except a substrain of $695+$ which had been kept in a dark closet for 13 generations. Renewed from $695 \mathrm{X}_{6}+$ dark. 
TABLE 4.-Summary of selection data by broods for Line 695 minus.

\begin{tabular}{|c|c|c|c|c|c|c|c|c|c|c|c|c|}
\hline 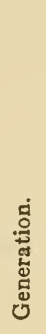 & 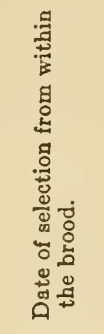 & 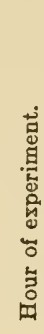 & 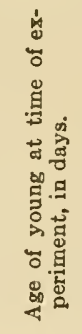 & 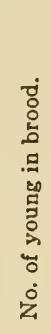 & 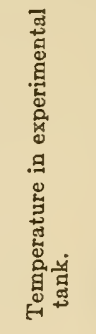 & 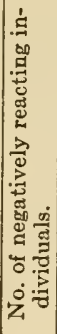 & 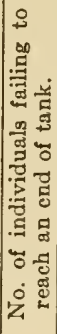 & 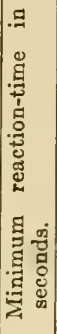 & 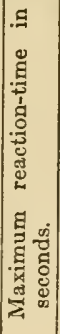 & 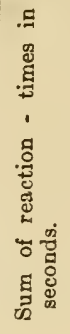 & 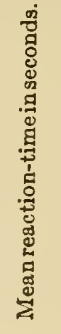 & 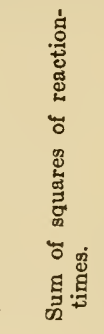 \\
\hline & 1912 & & & & & & & & & & & \\
\hline I & April 6 & 10 & 2 & 10 & $14.5^{\circ} \mathrm{C}$ & 2 & 2 & 200 & 900 & 5385 & 53.9 & 3491975 \\
\hline J & April 17 & 11 & 0 & 3 & 16.6 & 0 & 1 & 165 & 900 & 1537 & 512 & 1060009 \\
\hline I & $\begin{array}{l}\text { May } 6 \\
\text { May } 15\end{array}$ & 11 & 0 or 1 & 6 & 16.3 & 0 & 4 & 215 & 900 & 4250 & 708 & 3475450 \\
\hline I a & $\begin{array}{l}\text { May } 15 \\
\text { May } 20\end{array}$ & 5 & 0 & 6 & $?$ & 0 & 5 & 590 & \begin{tabular}{|l|}
900 \\
\end{tabular} & 5090 & 848 & 4398100 \\
\hline $\mathbf{M}$ & $\begin{array}{l}\text { May } 20 \\
\text { May 25 }\end{array}$ & 3 & 0 & $\frac{1}{5}$ & 17 & 0 & 0 & 230 & 230 & & 230 & 52900 \\
\hline N & June 1 & $\begin{array}{r}4 \\
10\end{array}$ & $\begin{array}{l}0 \\
0\end{array}$ & $\begin{array}{r}5 \\
12\end{array}$ & $\begin{array}{l}19 \\
18.5\end{array}$ & $\begin{array}{l}0 \\
0\end{array}$ & $\begin{array}{l}0 \\
1\end{array}$ & $\begin{array}{r}185 \\
80\end{array}$ & \begin{tabular}{|l|}
645 \\
900
\end{tabular} & $\begin{array}{l}1485 \\
2815\end{array}$ & $\begin{array}{l}297 \\
235\end{array}$ & $\begin{array}{r}594875 \\
1243425\end{array}$ \\
\hline 0 & June 10 & 11 & 0 or 1 & 5 & 17 & 0 & $\begin{array}{l}1 \\
3\end{array}$ & 520 & 900 & 4110 & 822 & 3492500 \\
\hline P & June 18 & 1 & 0 & 4 & 19 & 0 & 0 & 180 & 330 & 935 & 234 & 231625 \\
\hline Q & July 1 & 11 & 0 or 1 & 3 & 18 & 0 & 0 & 320 & 790 & 1495 & 498 & 874725 \\
\hline Il & July 8 & 10 & 0 or 1 & 2 & 22 & 0 & 1 & 290 & 900 & 1190 & 595 & 894100 \\
\hline $\mathrm{R}$. & July 9 & 11 & 0 & 2 & 22 & 0 & 0 & 230 & 345 & 595 & 288 & 171925 \\
\hline $\mathrm{S}$ & July 17 & 9 & 0 & 2 & 22 & 0 & 1 & 450 & 900 & 1350 & 675 & 1012500 \\
\hline Sa & Aug. 1 & 3 & 0 & 4 & 21 & 1 & 2 & 600 & 900 & 3040 & 760 & 2389600 \\
\hline $\mathrm{T}$ & Aug. 16 & 2 & 0 & 1 & 20.5 & 0 & 0 & 235 & 235 & 235 & 235 & 55225 \\
\hline$\tilde{\mathbf{U}}$ & Sept. 9 & 2 & 0 or 1 & 1 & 20 & 0 & 0 & 285 & 285 & 285 & 285 & 81225 \\
\hline $\mathrm{V}$ & Sept. 16 & 2 & 0 & 1 & 19 & 0 & 0 & 255 & 255 & 255 & 255 & 65025 \\
\hline Va & Scpt. 20 & 5 & 0 & 1 & 19.8 & 0 & 0 & 460 & 460 & 460 & 460 & 211600 \\
\hline W & Oet. 2 & 1 & 0 & 6 & 14.1 & 2 & 0 & 95 & 665 & 1868 & 311 & 796624 \\
\hline $\mathrm{X}$ & Oet. 15 & 2 & 0 & 1 & 19.2 & 0 & 0 & 280 & 280 & 280 & 280 & 78400 \\
\hline $\mathrm{X}$ & Oct. 18 & 3 & 0 & 8 & 18 & 1 & 0 & 70 & 615 & 2657 & 332 & 1150719 \\
\hline$Y$ & Nov. 1 & 1 & 0 & 1 & 18 & 0 & 0 & 174 & 174 & 174 & 174 & 30276 \\
\hline $\mathrm{Z}$ & Nov, 16 & 1 & 0 & 2 & 15 & 0 & 0 & 235 & 445 & 680 & 340 & 253250 \\
\hline $\mathrm{A}_{2}$ & Nov, 25 & 2 & 0 or 1 & 4 & 17 & 0 & 0 & 310 & 595 & 1945 & 486 & 991725 \\
\hline $\mathrm{B}_{2}$ & Dec. 7 & 3 & 0 & 5 & 16 & 0 & 0 & 170 & 230 & 980 & 196 & 194350 \\
\hline $\mathrm{C}_{3}$ & Dec. 17 & 2 & 0 & 12 & 19 & 0 & 0 & 105 & 605 & 4372 & 364 & 1987924 \\
\hline $\mathrm{D}_{2}$ & ${ }_{1913}{ }^{26}$ & 1 & 0 & 11 & 14 & 0 & 0 & 175 & 500 & 3058 & 278 & 790954 \\
\hline$E_{3}$ & Jan. 6 & 11 & 0 or 1 & 14 & 16.4 & 0 & 2 & 75 & 900 & 4967 & 961 & 2819819 \\
\hline$F_{3}$ & Jan. 13 & 1 & 0 or 1 & 4 & 14.4 & 0 & 0 & 90 & 190 & 555 & 139 & 84825 \\
\hline $\mathrm{G}_{2}$ & Jan. 21 & 2 & 0 & 8 & 14.4 & 0 & 0 & 125 & 280 & 1625 & 203 & 356475 \\
\hline $\mathrm{H}_{3}$ & Jan. 28 & 3 & 0 & 8 & 13.4 & 0 & 0 & 95 & 365 & 1935 & 242 & 540675 \\
\hline $\mathrm{I}_{2}$ & Feb. 6 & 2 & 0 & 9 & 13 & 0 & 0 & 100 & 355 & 2075 . & 231 & 553475 \\
\hline $\mathrm{J}_{2}$ & Feb. 17 & 1 & 0 or 1 & 9 & 13.4 & 0 & 0 & 140 & 510 & $2970^{\circ}$ & 330 & 1066175 \\
\hline $\mathrm{K}$, & Feb. 24 & 11 & 0 or 1 & 7 & 12.5 & 0 & 0 & 250 & 450 & 2470 & 353 & 908750 \\
\hline $\mathrm{I}_{3}$ & Mar. 3 & 11 & 0 or 1 & 8 & 11.8 & 1 & 0 & 110 & 340 & 1675 & 209 & 416125 \\
\hline$M_{3}$ & Mar. 20 & $i$ & 0 & 1 & 17 & 0 & 0 & 315 & 315 & 315 & 315 & 99225 \\
\hline $\mathrm{N}_{3}$ & April 7 & 4 & 0 or 1 & 4 & 14.8 & 0 & 0 & 100 & 200 & 610 & 153 & 98850 \\
\hline $\mathrm{O}_{2}$ & April 16 & 3 & 0 & 11 & 17.5 & 0 & 0 & 110 & 505 & 2600 & 236 & 777078 \\
\hline$P_{3}$ & April 24 & 2 & 0 & 14 & 17.5 & 3 & 0 & 80 & 395 & 3145 & 225 & 814325 \\
\hline $\mathbf{Q}_{2}$ & May 2 & 3 & 0 or 1 & 6 & 15.8 & 0 & 0 & 95 & 250 & 975 & 163 & 173975 \\
\hline$l_{3}$ & May 12 & 1 & 0 or 1 & 7 & 14 & 0 & 0 & 210 & 460 & 2140 & 306 & 699950 \\
\hline $\mathrm{S}_{2}$ & May 20 & 2 & 0 & 5 & 14.5 & 0 & 0 & 330 & 660 & 2155 & 481 & 1002625 \\
\hline$T_{3}$ & May 29 & 3 & 0 & 6 & 16.5 & 0 & 0 & 70 & 135 & 640 & 107 & 71850 \\
\hline $\mathrm{U}_{3}$ & June 5 & 1 & 0 & 6 & 18 & 0 & 0 & 130 & 250 & 1105 & 184 & 212525 \\
\hline$V_{2}$ & June 12 & 4 & 0 & 9 & 17.2 & 0 & 1 & 95 & 900 & 2795 & 311 & 1364175 \\
\hline W, & June 18 & 2 & 0 & 5 & 19.3 & 0 & 0 & 130 & 610 & 1625 & 325 & 702425 \\
\hline $\mathrm{X}_{2}$ & June 24 & 2 & 0 & 6 & 20.5 & 1 & 1 & 207 & 900 & 3067 & 511 & 1971599 \\
\hline$Y_{3}$ & July 1 & 2 & 0 & 1 & 21.7 & 0 & 0 & 138 & 138 & 138 & 138 & 19044 \\
\hline$Z_{3}$ & July 10 & 3 & 0 & 2 & 22 & 0 & 0 & 290 & 800 & 1090 & 545 & 724100 \\
\hline$A_{3}$ & July 19 & 2 & 0 & 4 & 22.3 & 1 & 1 & 125 & 900 & 1635 & 409 & 1011675 \\
\hline $\mathrm{B}_{3}$ & July 25 & $\overline{5}$ & 0 & 5 & 21.8 & 0 & 1 & 165 & 900 & 1945 & 389 & 1101375 \\
\hline $\mathrm{C}_{3}$ & Aug. 1 & 2 & 0 & 5 & 22.8 & 0 & 2 & 430 & 900 & 3280 & 656 & 2356950 \\
\hline 1) & Aug. 8 & 4 & 0 & 10 & 21.9 & 0 & 0 & 150 & 345 & 2180 & 218 & 516350 \\
\hline $\mathrm{Fiz}$ & Aug. 14 & 2 & 0 & 11 & & 0 & 0 & 80 & 635 & 2630 & 239 & 889150 \\
\hline $1_{2}$ & Aug. 20 & 3 & 0 & 2 & 20.4 & 0 & 1 & 850 & 900 & 1750 & 875 & 1532500 \\
\hline $\mathrm{G}_{3}$ & Aug. 28 & 4 & 0 or 1 & 11 & 21 & 0 & 0 & 100 & 320 & 2083 & 189 & 438627 \\
\hline $11_{3}$ & Sept. 3 & 10 & 1 & 9 & 22.5 & 4 & 0 & 67 & 458 & 1466 & 163 & 360146 \\
\hline$I_{2}$ & Sept. 9 & 2 & 0 & 13 & 20.6 & 0 & 1 & 122 & 900 & 5102 & 393 & 2701034 \\
\hline $\mathrm{J}$ & Sept. 17 & 10 & 0 & 8 & 18.4 & 0 & 0 & 146 & 460 & 1982 & 248 & 564172 \\
\hline$K_{3}$ & Sept. 22 & 11 & 0 & 10 & 20 & 0 & 1 & 113 & 900 & 3011 & 301 & 1414841 \\
\hline 14 & Scpt. 29 & 10 & 1 & 6 & 16.5 & 0 & 0 & 113 & 640 & 1595 & 266 & 629195 \\
\hline $\mathrm{M}_{3}$ & Oct. 13 & 4 & 0 & 9 & 16.6 & 1 & 0 & 123 & 620 & 2565 & 285 & 961813 \\
\hline $\mathrm{N}_{2}$ & ()et. 20 & 11 & 0 & 6 & 17.8 & 0 & 0 & 110 & 244 & 1092 & 182 & 212072 \\
\hline $\mathrm{O}_{2}$ & Oct. 28 & 11 & 0 & 8 & 19.3 & 0 & 0 & 9.1 & 370 & 1281 & 161 & 261488 \\
\hline $\mathbf{P}_{2}$ & Nov. 14 & 11 & 0 & 7 & 16 & 3 & 0 & 74 & 440 & 1411 & 202 & 363415 \\
\hline$Q_{2}$ & Nov. 20 & 11 & 0 & 7 & 16.9 & 0 & 0 & 122 & 510 & 2069 & 296 & 726711 \\
\hline
\end{tabular}

- Selection was repeated from a later brood because of the losa of the etrrlier brood. 
TABLE 4.-Summary of selection data by broods for Line 695 minus-Continued.

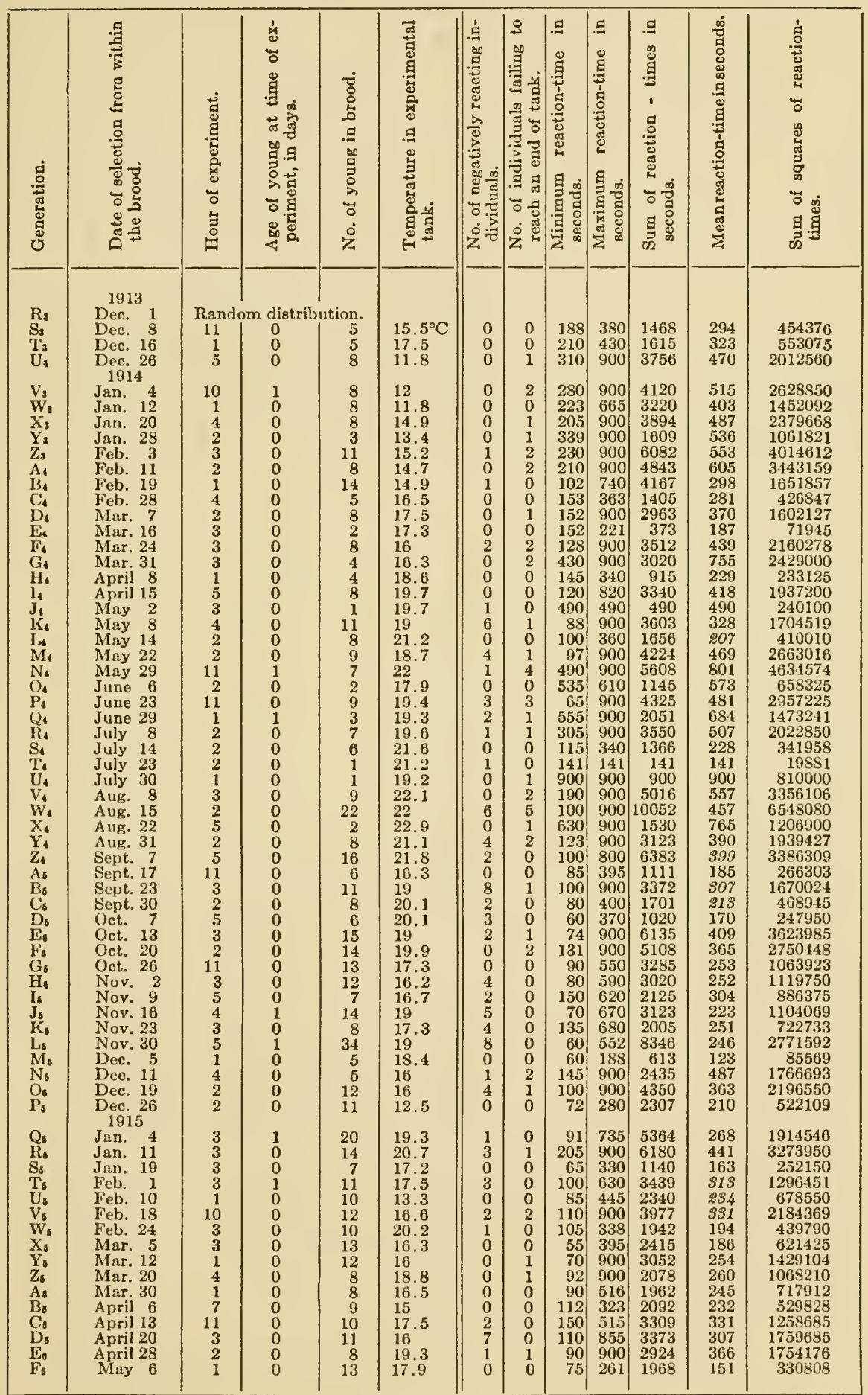


TABLE 4.-Summary of selection data by broods for Line 695 minus-Continued.

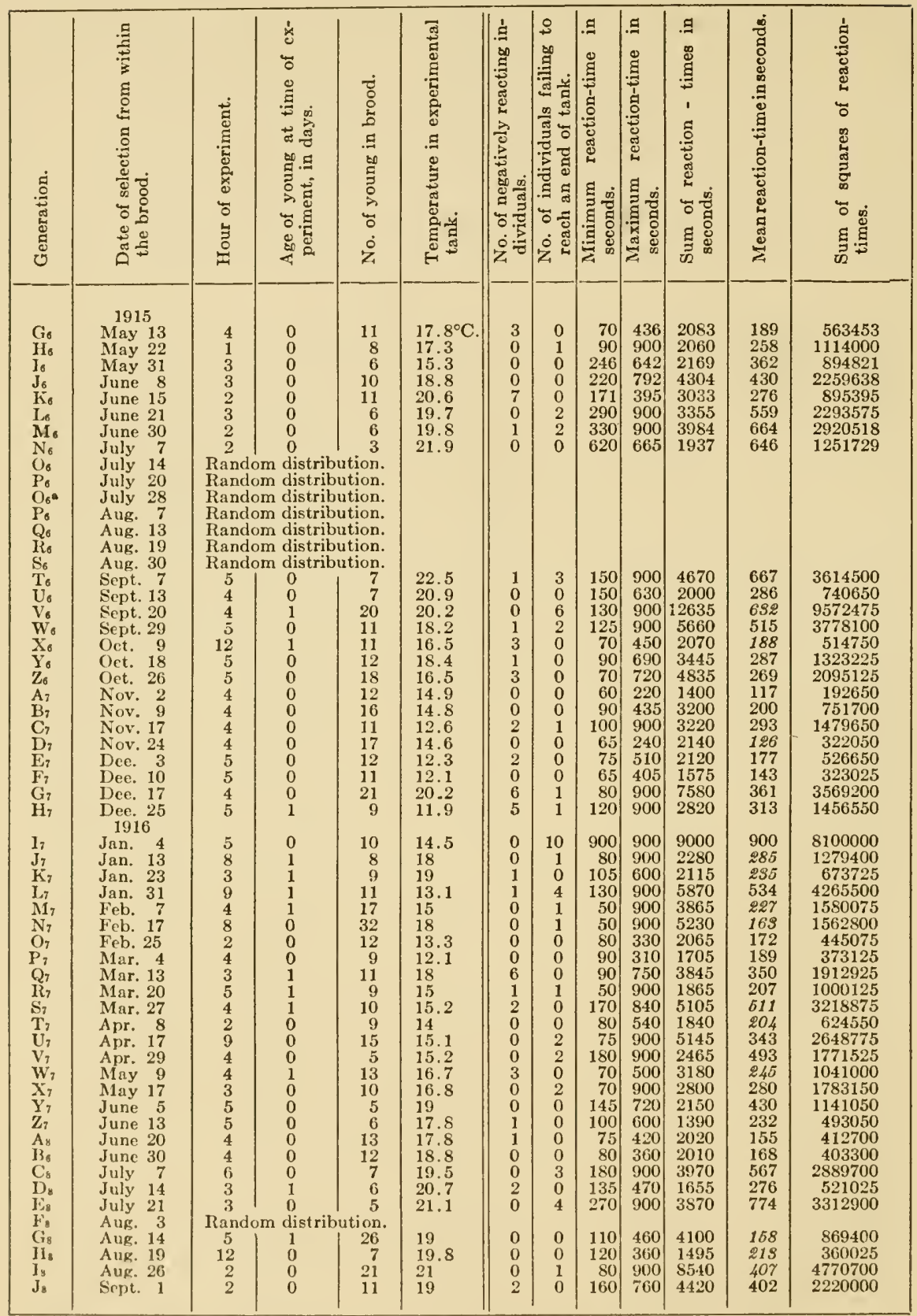

- Strain lost July 22 and renewed from substrain of $695-\left(695 \mathrm{M}_{6}-\right)$ which had been kept in a dark closet for 37 generations. 
a better treatment of the data is secured by considering it by unit groups larger than a single brood. Convenient units of comparison are month and two-month periods, and summaries of the data by such periods will be referred to rather than the data by broods.

Tables 5 and 6 give, in successive columns, the two-month periods; the generations of descent during the periods; the number of broods used in selection; the total number of young tested; the average number of individuals per brood; the average age of the mothers at the time their first broods were produced; the average number of young per day of the mother's age at the time of production of the first brood-the reproductive index; the total number of individuals moving to the negative end of the tank; the number of individuals failing to reach either end of the tank during the time of the test ( 15 minutes); the average minimum reaction-time for the different broods; the average maximum reaction-time; the sum of the individual reaction-times (for computation purposes); the mean

TABLE 5.-Selection data summarized by two-month periods for Line 695 plus.

\begin{tabular}{|c|c|c|c|c|c|c|c|c|c|c|c|c|c|c|}
\hline Time period. & 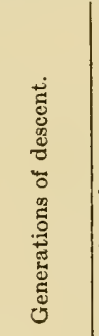 & $\mid \begin{array}{c}\dot{0} \\
0 \\
0 \\
0 \\
0 \\
\\
0 \\
\dot{0} \\
z\end{array}$ & 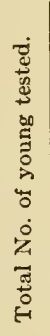 & 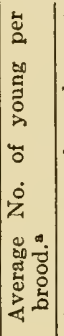 & 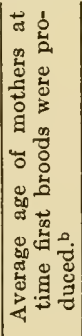 & 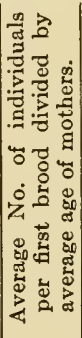 & 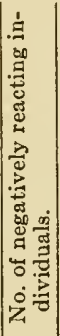 & 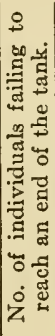 & 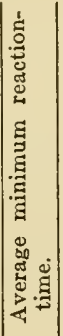 & 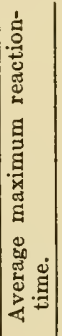 & 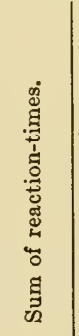 & 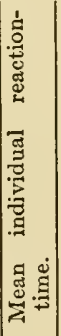 & 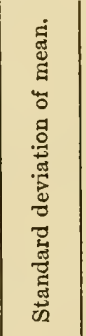 & 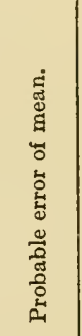 \\
\hline $\begin{array}{ll}\text { Apr.-May } 1912 \ldots \\
\text { June-July } 1912 \ldots\end{array}$ & $\begin{array}{r}9-12 \\
13-19\end{array}$ & $\begin{array}{l}4 \\
8\end{array}$ & $\begin{array}{l}28 \\
23\end{array}$ & $\begin{array}{l}9.5 \\
3.0\end{array}$ & $\begin{array}{r}11.8 \\
8.7\end{array}$ & $\begin{array}{r}0.81 \\
.34\end{array}$ & $\begin{array}{l}3 \\
1\end{array}$ & $\begin{array}{l}3 \\
6\end{array}$ & $\begin{array}{l}189 \\
479\end{array}$ & $\begin{array}{l}679 \\
722\end{array}$ & $\begin{array}{l}11600 \\
13760\end{array}$ & $\begin{array}{l}414 \\
598\end{array}$ & $\left|\begin{array}{l}244.04 \\
240.92\end{array}\right|$ & $\begin{array}{l}31.11 \\
33.88\end{array}$ \\
\hline $\begin{array}{l}\text { Aug.-Sept. 1912 ... } \\
\text { Oct.-Nov. 1912 } \\
\text { Dec.1912-Jan. } 1913 \\
\text { Feb.-Mar. 1913 ... } \\
\text { Apr.-May } 1913 \ldots \\
\text { June-July } 1913 \ldots\end{array}$ & $\begin{array}{l}20-23 \\
24-29 \\
30-35 \\
36-42 \\
43-50 \\
51-58\end{array}$ & $\begin{array}{l}6 \\
6 \\
6 \\
7 \\
8 \\
9\end{array}$ & $\begin{array}{l}17 \\
14 \\
62 \\
56 \\
67 \\
35\end{array}$ & $\mid$\begin{tabular}{r|}
2.0 \\
2.3 \\
10.3 \\
8.0 \\
8.4 \\
3.9
\end{tabular} & $\begin{array}{r}13.7 \\
11.2 \\
9.0 \\
8.3 \\
7.8 \\
7.2\end{array}$ & $\begin{array}{r}.15 \\
.21 \\
1.14 \\
.96 \\
1.08 \\
.54\end{array}$ & $\begin{array}{l}0 \\
0 \\
0 \\
0 \\
1 \\
3\end{array}$ & $\begin{array}{l}2 \\
0 \\
0 \\
3 \\
0 \\
5\end{array}$ & $\begin{array}{r}158 \\
167 \\
77 \\
158 \\
100 \\
209\end{array}$ & $\begin{array}{l}418 \\
316 \\
428 \\
447 \\
331 \\
462\end{array}$ & $\begin{array}{r}5660 \\
3265 \\
13761 \\
16930 \\
13345 \\
12355\end{array}$ & $\begin{array}{l}333 \\
233 \\
222 \\
302 \\
199 \\
353\end{array}$ & $\left|\begin{array}{l}249.77 \\
101.40 \\
\cdots \cdots \\
\cdots \cdots \\
\cdots \cdots\end{array}\right|$ & $\begin{array}{l}40.86 \\
18.28\end{array}$ \\
\hline 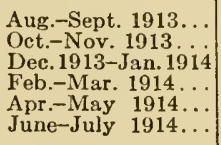 & $\begin{array}{l}59-67 \\
68-75 \\
76-83 \\
84-89 \\
90-98 \\
99-105\end{array}$ & $\begin{array}{l}9 \\
8 \\
7 \\
6 \\
9 \\
7\end{array}$ & $\begin{array}{l}74 \\
66 \\
50 \\
56 \\
75 \\
40\end{array}$ & $\begin{array}{l}7.2 \\
8.4 \\
7.0 \\
9.3 \\
8.2 \\
6.1\end{array}$ & $\begin{array}{l}6.7 \\
7.5 \\
7.9 \\
8.3 \\
7.1 \\
6.3\end{array}$ & $\begin{array}{r}1.07 \\
1.12 \\
.89 \\
1.12 \\
1.15 \\
.97\end{array}$ & $\begin{array}{r}2 \\
2 \\
4 \\
4 \\
18 \\
6\end{array}$ & $\begin{array}{r}3 \\
1 \\
7 \\
10 \\
15 \\
2\end{array}$ & $\begin{array}{l}114 \\
133 \\
253 \\
158 \\
198 \\
149\end{array}$ & $\begin{array}{l}548 \\
474 \\
822 \\
634 \\
766 \\
693\end{array}$ & $\begin{array}{l}20737 \\
16019 \\
25253 \\
24443 \\
32718 \\
15033\end{array}$ & $\begin{array}{l}280 \\
243 \\
505 \\
436 \\
436 \\
376\end{array}$ & $\mid \begin{array}{l}\cdots \cdots \\
\cdots \cdots \\
\cdots \cdots \\
224.64 \\
24\end{array}$ & 23.96 \\
\hline $\begin{array}{l}\text { Aug.-Sept. 1914 ... } \\
\text { Oct.-Nov. 1914 . } \\
\text { Dec.1914-Jan.1915 } \\
\text { Feb.-Mar. 1915 ... } \\
\text { Apr.-May 1915 ... } \\
\text { June-July } 1915 \ldots\end{array}$ & $\begin{array}{l}106-114 \\
115-122 \\
123-130 \\
131-138 \\
139-145 \\
146-153\end{array}$ & $\begin{array}{l}9 \\
8 \\
8 \\
7 \\
8 \\
5\end{array}$ & $\begin{array}{r}97 \\
106 \\
66 \\
85 \\
81 \\
43\end{array}$ & $\mid \begin{array}{r}8.2 \\
12.5 \\
8.4 \\
11.6 \\
10.0 \\
10.5\end{array}$ & $\begin{array}{l}6.6 \\
7.5 \\
7.1 \\
8.3 \\
8.6 \\
7.9\end{array}$ & $\begin{array}{l}1.24 \\
1.67 \\
1.18 \\
1.40 \\
1.16 \\
1.33\end{array}$ & $\begin{array}{r}8 \\
27 \\
8 \\
5 \\
13 \\
4\end{array}$ & $\begin{array}{r}18 \\
4 \\
7 \\
4 \\
11 \\
5\end{array}$ & $\begin{array}{l}152 \\
125 \\
111 \\
114 \\
180 \\
216\end{array}$ & \begin{tabular}{|l|}
783 \\
776 \\
612 \\
664 \\
876 \\
723 \\
\end{tabular} & $\begin{array}{l}43400 \\
35712 \\
20726 \\
26122 \\
34741 \\
15561\end{array}$ & $\begin{array}{l}447 \\
337 \\
314 \\
307 \\
429 \\
362\end{array}$ & \begin{tabular}{c}
$\ldots \ldots$ \\
\hdashline$\ldots \ldots$ \\
\hdashline$\ldots \ldots$ \\
279.77 \\
267.64
\end{tabular} & $\begin{array}{l}20.97 \\
27.5\end{array}$ \\
\hline $\begin{array}{l}\text { Aug.-Sept. } 1915 \ldots \\
\text { Oct.-Nov. } 1915 . \\
\text { Dee.1915-Jan. } 1916 \\
\text { Feb.-Mar. } 1916 \ldots \\
\text { Apr.-May } 1916 \ldots \\
\text { June-July } 1916 \ldots\end{array}$ & $\begin{array}{l}154-160 \\
161-166 \\
167-174 \\
175-181 \\
182-187 \\
188-195\end{array}$ & $\begin{array}{l}4 \\
7 \\
7 \\
6 \\
6 \\
6\end{array}$ & $\begin{array}{r}26 \\
107 \\
80 \\
70 \\
67 \\
49\end{array}$ & $\begin{array}{r}6.6 \\
17.7 \\
12.4 \\
10.3 \\
11.7 \\
9.0\end{array}$ & $\begin{array}{r}9.2 \\
8.4 \\
8.5 \\
7.9 \\
10.4 \\
7.2\end{array}$ & $\begin{array}{l}.72 \\
2.11 \\
1.46 \\
1.30 \\
1.13 \\
1.25\end{array}$ & $\begin{array}{l}8 \\
5 \\
9 \\
5 \\
6 \\
6\end{array}$ & $\begin{array}{r}3 \\
2 \\
5 \\
5 \\
10 \\
12\end{array}$ & $\begin{array}{r}138 \\
74 \\
84 \\
91 \\
88 \\
163\end{array}$ & \begin{tabular}{|l|}
566 \\
662 \\
643 \\
664 \\
787 \\
612
\end{tabular} & $\begin{array}{r}9530 \\
25300 \\
19710 \\
18570 \\
22090 \\
21200\end{array}$ & \begin{tabular}{|l|}
367 \\
236 \\
246 \\
265 \\
330 \\
433
\end{tabular} & $\left\{\begin{array}{l}246.41 \\
206.09 \\
\ldots \ldots \ldots \\
288.31\end{array}\right.$ & $\begin{array}{l}15.54 \\
\ldots \ldots \\
27.78\end{array}$ \\
\hline Aug.-Sept. 1916... & $196-200$ & 6 & 89 & 9.7 & 6.6 & 1.47 & 6 & 30 & 173 & 900 & 42430 & 477 & 338.61 & 24.21 \\
\hline
\end{tabular}

- Including all the data available, some of which is additional to that for the broods tested.

bAll available data is here used, including that for the No. 2 mothers whose broods were not ordinarily tested for use in selection. 
individual reaction-time; the standard deviation of this mean; and its probable error.

For the minus strain, table 6 gives three additional columns: the difference between the means for the plus and the minus strains; the probable error of this difference; and the quotient of this difference divided by the probable error.

These tables are divided into sections, each containing the data for a period of a year, except the data obtained previous to August

TABLE 6.-Selection data summarized by two-month periods for Line 695 minus.

\begin{tabular}{|c|c|c|c|c|c|c|c|c|c|c|c|c|c|c|c|c|c|}
\hline Time period. & 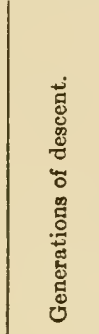 & 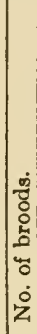 & 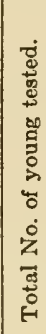 & 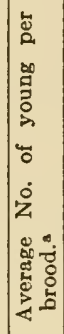 & 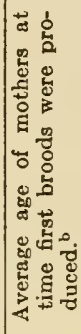 & 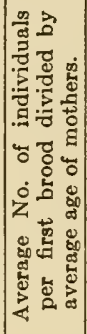 & 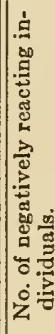 & 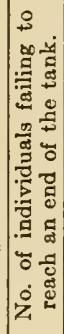 & 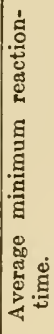 & 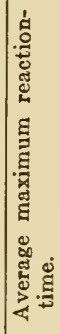 & 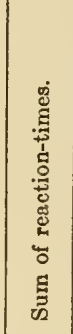 & 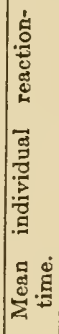 & 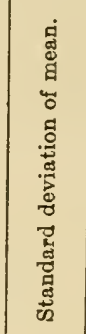 & 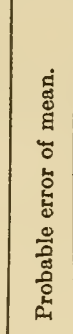 & 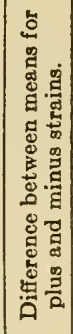 & 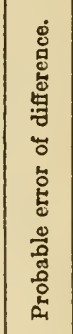 & 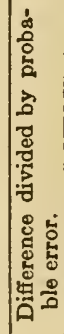 \\
\hline $\begin{array}{l}\text { Apr:-May } 1912 \ldots \\
\text { June-July } 1912 \ldots\end{array}$ & & $\begin{array}{l}6 \\
7\end{array}$ & $\begin{array}{l}31 \\
30\end{array}$ & $\begin{array}{l}5.2 \\
4.7\end{array}$ & $\begin{array}{r}11.8 \\
8.3\end{array}$ & $\begin{array}{r}0.44 \\
.57\end{array}$ & $\begin{array}{l}2 \\
0\end{array}$ & $\begin{array}{r}12 \\
6\end{array}$ & $\begin{array}{l}264 \\
296\end{array}$ & $\begin{array}{l}746 \\
724\end{array}$ & $\begin{array}{l}17977 \\
12470\end{array}$ & $\begin{array}{l}580 \\
416\end{array}$ & $\begin{array}{l}292.29 \\
302.16\end{array}$ & 35.41 & $\begin{array}{l}-166 \\
+182\end{array}$ & $\begin{array}{l}77.13 \\
50.32\end{array}$ & \\
\hline $\begin{array}{l}\text { Aug.-Sept. 1912 ... } \\
\text { Oct.-Nov. 1912 } \\
\text { Dec.1912-Jan. } 1913 \\
\text { Feb.-Mar. 1913 ... } \\
\text { Apr.-May 1913... } \\
\text { June-July 1913... }\end{array}$ & $\begin{array}{l}19-22 \\
23-27 \\
28-34 \\
35-39 \\
40-46 \\
47-54\end{array}$ & $\begin{array}{l}5 \\
6 \\
7 \\
5 \\
7 \\
8\end{array}$ & $\begin{array}{r}8 \\
22 \\
62 \\
34 \\
53 \\
38\end{array}$ & $\begin{array}{l}1.0 \\
2.8 \\
8.9 \\
6.8 \\
7.0 \\
4.2\end{array}$ & $\begin{array}{r}14.1 \\
8.9 \\
9.4 \\
9.4 \\
7.2\end{array}$ & $\begin{array}{r}.20 \\
1.00 \\
.72 \\
.74 \\
.58\end{array}$ & $\begin{array}{l}1 \\
3 \\
0 \\
1 \\
3 \\
2\end{array}$ & $\begin{array}{l}2 \\
0 \\
2 \\
0 \\
0 \\
4\end{array}$ & $\begin{array}{l}367 \\
194 \\
119 \\
183 \\
142 \\
160\end{array}$ & $\begin{array}{l}427 \\
462 \\
439 \\
394 \\
372 \\
675\end{array}$ & $\begin{array}{r}4275 \\
7604 \\
17492 \\
9510 \\
12265 \\
13400\end{array}$ & $\begin{array}{l}534 \\
346 \\
282 \\
380 \\
231 \\
353\end{array}$ & $\begin{array}{l}254.67 \\
174.94 \\
\cdots \cdots \cdots \\
\cdots \cdots \\
\cdots \cdots \cdots \\
\cdots \cdots\end{array}$ & $\mid \begin{array}{l}60.73 \\
25.16 \\
\cdots \\
\cdots \cdots \\
\cdots \cdots \\
\cdots \cdots\end{array}$ & $\begin{array}{l}-201 \\
-113 \\
-60 \\
+22 \\
\pm 32 \\
\pm 000\end{array}$ & $\begin{array}{l}73.20 \\
31.09 \\
\cdots \cdots \\
\cdots \cdots \\
\cdots \cdots\end{array}$ & \\
\hline $\begin{array}{l}3-J a n .1914 \\
\text { ar. } 1914 \ldots \\
\text { ay } 1914 \ldots \\
\text { ly } 1914 \ldots\end{array}$ & $\begin{array}{l}55-64 \\
65-70 \\
71-77 \\
78-85 \\
86-92 \\
93-99\end{array}$ & $\begin{array}{r}10 \\
5 \\
7 \\
8 \\
7 \\
7\end{array}$ & $\begin{array}{l}85 \\
37 \\
45 \\
60 \\
48 \\
29\end{array}$ & $\begin{array}{l}8.5 \\
5.5 \\
6.4 \\
7.5 \\
7.1 \\
4.1\end{array}$ & $\begin{array}{l}6.4 \\
8.0 \\
9.2 \\
7.9 \\
7.0 \\
9.8\end{array}$ & $\begin{array}{r}1.33 \\
.69 \\
.70 \\
.95 \\
1.01 \\
.42\end{array}$ & $\begin{array}{r}4 \\
4 \\
0 \\
4 \\
12 \\
7\end{array}$ & $\begin{array}{l}5 \\
0 \\
5 \\
9 \\
6 \\
6\end{array}$ & $\begin{array}{l}217 \\
105 \\
151 \\
195 \\
219 \\
374\end{array}$ & $\begin{array}{l}646 \\
437 \\
725 \\
728 \\
673 \\
670\end{array}$ & $\begin{array}{r}25079 \\
8421 \\
19682 \\
26365 \\
19836 \\
13478\end{array}$ & $\begin{array}{l}295 \\
228 \\
437 \\
439 \\
413 \\
465\end{array}$ & $\mid \begin{array}{l}\cdots \cdots \\
\cdots \cdots \\
\cdots \cdots \\
170.94\end{array}$ & $\begin{array}{l}\ldots \\
\cdots \\
\cdots \\
\cdots \\
21.41\end{array}$ & $\begin{array}{rr}- & 15 \\
+ & 15 \\
+ & 68 \\
- & 3 \\
+ & 23 \\
- & 89\end{array}$ & $\begin{array}{l}\ldots \ldots \\
\ldots \ldots \\
\cdots \cdots \\
32.13 \\
32\end{array}$ & \\
\hline $\begin{array}{l}\text { Aug.-Sept. 1914... } \\
\text { Oct.-Nov. 1914 } \\
\text { Dec.1914-Jan.1915 } \\
\text { Feb.-Mar. 1915 ... } \\
\text { Apr.-May 1915 .. } \\
\text { June-July 1915... }\end{array}$ & $\begin{array}{l}100-107 \\
108-116 \\
117-124 \\
125-131 \\
132-139 \\
140-145\end{array}$ & $\begin{array}{l}8 \\
9 \\
7 \\
8 \\
8 \\
5\end{array}$ & $\begin{array}{r}82 \\
123 \\
74 \\
84 \\
76 \\
36\end{array}$ & \begin{tabular}{|r|}
9.6 \\
12.4 \\
8.7 \\
11.0 \\
9.9 \\
8.7
\end{tabular} & $\begin{array}{l}7.2 \\
7.0 \\
8.1 \\
8.1 \\
7.6 \\
7.6\end{array}$ & $\begin{array}{l}1.33 \\
1.77 \\
1.07 \\
1.36 \\
1.30 \\
1.14\end{array}$ & $\begin{array}{r}22 \\
28 \\
9 \\
6 \\
13 \\
8\end{array}$ & $\begin{array}{r}11 \\
3 \\
4 \\
4 \\
2 \\
4\end{array}$ & $\begin{array}{r}176 \\
94 \\
105 \\
88 \\
118 \\
326\end{array}$ & $\begin{array}{l}762 \\
648 \\
605 \\
628 \\
604 \\
730\end{array}$ & $\begin{array}{l}32288 \\
34167 \\
22389 \\
21205 \\
19978 \\
16613\end{array}$ & $\begin{array}{l}394 \\
278 \\
303 \\
252 \\
263 \\
461\end{array}$ & $\mid \begin{array}{l}\cdots \ldots \\
\cdots \cdots \\
197.23 \\
233.14\end{array}$ & $\begin{array}{l}15.26 \\
26.21\end{array}$ & $\begin{array}{l}+53 \\
+59 \\
+\quad 11 \\
+55 \\
+166 \\
-\quad 99\end{array}$ & $\mid \begin{array}{l}\cdots \ldots \\
\cdots \cdots \\
\cdots \cdots \\
25.93 \\
38.01\end{array}$ & {$\left[\begin{array}{l}6.40 \\
2.60\end{array}\right.$} \\
\hline $\begin{array}{l}\text { Aug.-Sept. } 1915 \ldots \\
\text { Oct.-Nov. } 1915 . . \\
\text { Dec. 1915-Jan. } 1916 \\
\text { Feb.-Mar. } 1916 \ldots \\
\text { Apr.-May } 1916 \ldots \\
\text { June-July } 1916 \ldots\end{array}$ & $\begin{array}{l}146-153 \\
154-160 \\
161-168 \\
169-175 \\
176-181 \\
182-188\end{array}$ & $\begin{array}{l}4 \\
7 \\
8 \\
7 \\
5 \\
7\end{array}$ & $\begin{array}{r}45 \\
97 \\
91 \\
100 \\
52 \\
54\end{array}$ & $\begin{array}{r}8.8 \\
14.1 \\
12.1 \\
11.3 \\
11.0 \\
6.5\end{array}$ & $\begin{array}{r}8.4 \\
8.0 \\
8.4 \\
7.6 \\
11.6 \\
8.6\end{array}$ & $\begin{array}{r}1.05 \\
1.76 \\
1.44 \\
1.49 \\
.95 \\
.76\end{array}$ & $\begin{array}{r}2 \\
9 \\
15 \\
9 \\
3 \\
4\end{array}$ & $\begin{array}{r}11 \\
1 \\
17 \\
3 \\
6 \\
7\end{array}$ & $\begin{array}{r}139 \\
78 \\
194 \\
83 \\
95 \\
141\end{array}$ & \begin{tabular}{|l|}
833 \\
522 \\
752 \\
704 \\
748 \\
.624 \\
\end{tabular} & $\begin{array}{l}24965 \\
20310 \\
33360 \\
23680 \\
15430 \\
17065\end{array}$ & \begin{tabular}{l|}
555 \\
209 \\
367 \\
237 \\
297 \\
316
\end{tabular} & $\left|\begin{array}{l}292.86 \\
295.95 \\
\ldots \ldots . \\
264.62\end{array}\right|$ & $\begin{array}{l}29.45 \\
20.93 \\
\cdots \ldots \\
24.29\end{array}$ & $\begin{array}{r}-188 \\
+\quad 27 \\
-121 \\
+\quad 28 \\
+\quad 33 \\
+117\end{array}$ & $\begin{array}{l}43.93 \\
26.06 \\
\cdots \cdots \\
36.90\end{array}$ & $\ddot{3} .17$ \\
\hline Aug.-Sept. 1916. & $189-195$ & 4 & 65 & 8.8 & 7.3 & 1.21 & 2 & 1 & 118 & 620 & 18555 & 285 & 212.15 & 17.75 & +192 & 30.02 & \\
\hline
\end{tabular}

- Including all the data available, some of which is additional to that for the broods tested.

All available dats is here used, including that for No. 2 mothers whose broods were not ordinarily tested for use in selection

\section{1, 1912, and subsequent to July 31, 1916. The data obtained previ-} ous to August 1, 1912, deserve less serious consideration than may be given the data obtained later, since previous to that time improved methods of handling the material and additional experimental precautions were occasionally being devised and utilized. From August 1, 1912, the methods of handling the Cladocera material were pretty well standardized and there seems every reason to believe that the data are such as would be obtained by repetition of the experiments. 
The mean reaction-times obtained in the tabulation by twomonth periods (tables 5 and 6 ) are used in the plotting of curves (figure 2c), showing graphically the courses of the selection experiment with Line 695 .

Table 7 gives in abbreviated form selection summaries of the data for 695 plus and 695 minus by the larger periods (mostly yearperiods) into which it was divided in tables 5 and 6 ; it also includes summaries and results of the "test series" and summaries for selection data for three-month periods during which the test series were conducted. In table 7 , in the vertical column to the left, are indicated

TABLE 7.-Selection summary for Line 695.

\begin{tabular}{|c|c|c|c|c|c|c|c|c|c|c|c|c|c|c|c|}
\hline Time period. & Strain. & 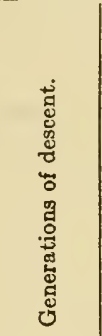 & 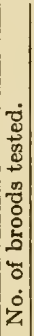 & 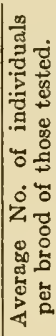 & 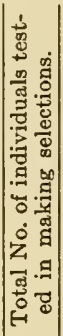 & 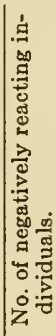 & 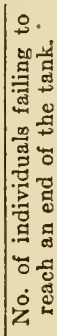 & 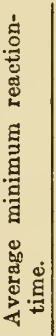 & 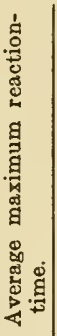 & 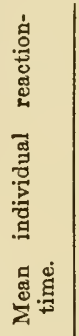 & 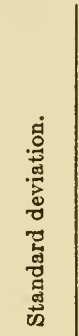 & 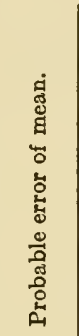 & 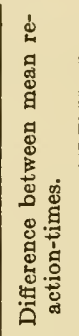 & 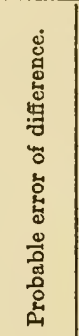 & 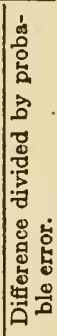 \\
\hline & & -19 & 13 & 4.0 & 51 & 4 & 9 & 302 & 708 & 497.3 & 259.2 & 24.49 & & & \\
\hline A] & & $8-19$ & $\begin{array}{l}13 \\
18 \\
.\end{array}$ & 4.7 & $\begin{array}{l}51 \\
61\end{array} \mid$ & ${ }_{2}^{4}$ & 18 & . & 734 & 499.1 & 308. & $\begin{array}{l}26.69 \\
26.62\end{array}$ & 1.8 & 36.17 & $\ddot{0} \cdot \ddot{0}$ \\
\hline Aug & Plu & $20-58$ & 42 & 6.0 & 251 & 4 & 10 & 148 & 403 & 260.2 & 182.5 & 7.77 & & & \\
\hline & & $19-54$ & 38 & 5.7 & 217 & 10 & 8 & 185 & 472 & 297.5 & 187.7 & 8.59 & -37.9 & 11.59 & 3.2 \\
\hline Aug 1,1 & & -105 & 46 & 7.8 & 361 & 36 & 38 & 166 & 653 & 371.8 & 253.3 & 8.99 & +0.5 & 13.10 & 0.04 \\
\hline & & $\begin{array}{r}-99 \\
61\end{array}$ & 44 & 22.0 & $\begin{array}{l}304 \\
529\end{array} \mid$ & $\begin{array}{l}31 \\
44\end{array}$ & $\begin{array}{r}81 \\
133\end{array}$ & | 181 & $\left|\begin{array}{l}658 \\
769\end{array}\right|$ & $\begin{array}{l}37.3 \\
522.2\end{array}$ & $\begin{array}{r}246.5 \\
284.4\end{array} \mid$ & $\begin{array}{l}9.64 \\
8.34\end{array}$ & $+3 i .7$ & 12.14 & 2.61 \\
\hline & & $\begin{array}{l}01 \\
57\end{array}$ & 24 & & 467 & 28 & 103 & 171 & 837 & 490.5 & 282.5 & 8.82 & & & \\
\hline $1913-$ & & $55-67$ & 10 & 7.2 & 72 & 2 & 4 & 169 & 536 & 296 & & & 122 & & \\
\hline & & $\begin{array}{r}-64 \\
95\end{array}$ & {$\left[\begin{array}{c}12 \\
51\end{array} \mid\right.$} & $\begin{array}{r}7.5 \\
24.3\end{array}$ & $\left|\begin{array}{r}90 \\
1083\end{array}\right|$ & $\begin{array}{l}1 \\
89\end{array}$ & 290 & $\begin{array}{l}206 \\
114\end{array}$ & $\begin{array}{l}657 \\
863\end{array} \mid$ & $\begin{array}{l}294 \\
501\end{array}$ & 311.4 & 6.36 & & & $\cdots$ \\
\hline & & 89 & $\left.\mid \begin{array}{l}1 \\
51\end{array}\right]$ & & 1088 & 76 & 408 & 158 & 852 & 662.8 & 302.2 & 6.19 & -61.8 & 8.88 & 6.96 \\
\hline Apr. $1,1914-$ & & $90-100$ & 11 & 7.5 & 83 & 20 & 16 & 194 & 786 & 440 & & & & & \\
\hline & & $\begin{array}{l}0-90 \\
6-153 \\
6-153\end{array}$ & $\begin{array}{l}100 \\
45\end{array}$ & 10.7 & \begin{tabular}{r|}
628 \\
478
\end{tabular} & 65 & $\begin{array}{l}10 \\
49\end{array}$ & 146 & 743 & 368.7 & 225.4 & 6.97 & +60.0 & 10.68 & 5.62 \\
\hline & & 0 & & 10. & & & 28 & 140 & 659 & 308.7 & 262.3 & & & & \\
\hline & & & & 24.3 & 961 & 122 & 67 & 108 & 900 & 350.1 & 222.9 & 4.8 & & & \\
\hline & & & & & 974 & 110 & 67 & 189 & 791 & 351.2 & 216.2 & & -1.1 & & 0.1 \\
\hline & & 9-149 & 12 & & 120 & 16 & 16 & 168 & 829 & 399.2 & 279.4 & & +81.3 & 22.56 & \\
\hline & & $2-143$ & 12 & 9.1 & 109 & 21 & $\begin{array}{r}6 \\
20\end{array}$ & 168 & $\begin{array}{l}652 \\
747 \\
747\end{array}$ & 317.9 & 225.8 & \begin{tabular}{|l}
14.69 \\
10.43
\end{tabular} & $1+5 i$ & 140 & $\ddot{3}$ \\
\hline $\begin{array}{l}\text { Test } \\
\text { Jun }\end{array}$ & & & & & 246 & $\begin{array}{l}43 \\
26\end{array}$ & 16 & $\begin{array}{l}128 \\
117\end{array}$ & $\left|\begin{array}{l}747 \\
755\end{array}\right|$ & $\begin{array}{l}369 \\
317.9\end{array}$ & $\begin{array}{l}244.3 \\
220.1\end{array}$ & $\begin{array}{r}10.43 \\
9.46\end{array}$ & & & \\
\hline $\mathrm{Ma}$ & & $143-153$ & {$\left[\begin{array}{r}0 \\
8\end{array}\right.$} & 8.4 & $\begin{array}{r}240 \\
67\end{array}$ & 10 & 7 & 221 & 772 & 397.9 & 264.5 & 21.80 & +61.5 & 28.63 & 2.14 \\
\hline & & $\begin{array}{l}136-147 \\
154-195\end{array}$ & $\left|\begin{array}{r}8 \\
36\end{array}\right|$ & & $\begin{array}{r}74 \\
399 \\
\end{array}$ & $\begin{array}{l}11 \\
31\end{array}$ & $\begin{array}{r}5 \\
34\end{array}$ & $\begin{array}{l}235 \\
103\end{array}$ & $\mid \begin{array}{l}655 \\
635\end{array}$ & $\begin{array}{l}396.4 \\
291.5\end{array}$ & $\begin{array}{r}236.8 \\
242.5\end{array}$ & $\begin{array}{r}18.57 \\
8.19\end{array} \mid$ & & & \\
\hline $\mathrm{Ju}$ & & $8-187$ & 38 & & 439 & 42 & $\begin{array}{l}34 \\
45\end{array}$ & 124 & $\begin{array}{l}080 \\
685 \\
\end{array}$ & 307.1 & 262.8 & \begin{tabular}{|l}
0.19 \\
8.46
\end{tabular} & -15.6 & 11.77 & $i \ddot{s i s}$ \\
\hline & & 196-203 & & 12.5 & 102 & 6 & 30 & 156 & 732 & 436.3 & 338.6 & 24.21 & +150.8 & 30.2 & 5.0 \\
\hline Sept. 2,1916 & Minus. & $188-192$ & & & & 2 & & 118 & 620 & 285.5 & 212.1 & 17.74 & & & \\
\hline
\end{tabular}

the periods covered by the various portions of the summary; successive columns to the right of this indicate the strain (whether plus or minus); the generations of descent during the period under consideration; the number of broods used in selection and in obtaining the data; the average number of individuals per brood of those tested; the total number of individuals tested in making selections; the number of individuals moving to the negative end of the tank; the number failing to respond to the extent of reaching either end of the tank; the average minimum reaction-time; the average maximum reaction-time; the mean individual reaction-time; standard deviation 
of this mean; its probable error; the difference between the mean for the plus strain and that for the minus strain; the statistical probable error of this difference; and the quotient of this difference divided by its statistical probable error. For each period considered in this table the corresponding data for the plus and minus strains are given in successive horizontal columns, the plus first and the minus in italics immediately below it. Thus the items for making the significant comparisons between the plus and minus strains are found together.

Table 8 gives a summary of the data for the "same-day" broods, i. e., those broods of the mothers of the corresponding plus and minus strains which reproduced on the same days and the young of which, consequently, were tested under identical conditions. The arrangement of the data is similar to that for table 7 .

TABLE 8.-Same-day broods. Summary of data for Line 695.

\begin{tabular}{|c|c|c|c|c|c|c|c|c|c|c|c|c|c|c|}
\hline Time period. & Strain. & 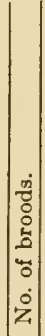 & 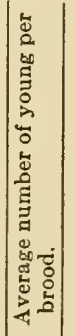 & 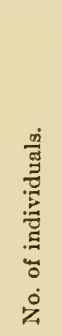 & 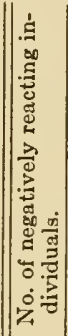 & 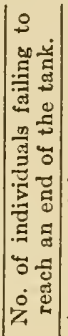 & 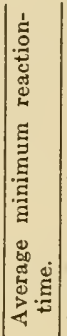 & 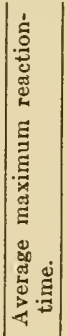 & 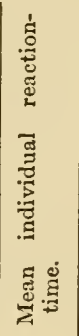 & 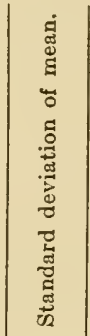 & 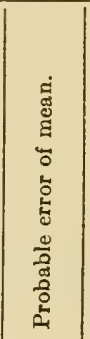 & 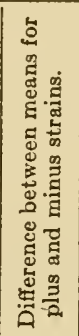 & 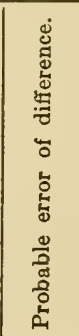 & 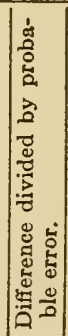 \\
\hline $\begin{array}{rr}\text { Apr. } & 6,1912- \\
\text { July } & 31,1912 \\
\text { Aug. } 1,1912- \\
\text { July } & 31,1913 \\
\text { Aug. } 1,1913- \\
\text { July } & 31,1914 \\
\text { Aug. } 1,194- \\
\text { July } 31,1915 \\
\text { Aug. 1, 1915- } \\
\text { July } 31,1916 \\
\text { Aug. 1, 1916- } \\
\text { Sept. 2, } 1916\end{array}$ & $\begin{array}{l}\left\{\begin{array}{l}\text { Plus..... } \\
\text { Minus... }\end{array}\right. \\
\text { Plus.... } \\
\text { Minus... } \\
\text { Plus..... } \\
\text { Minus... } \\
\text { Plus..... } \\
\text { Minus... } \\
\text { Plus.... } \\
\text { Minus... } \\
\text { Plus.... } \\
\text { Minus... }\end{array}$ & $\begin{array}{r}2 \\
2 \\
11 \\
11 \\
9 \\
9 \\
6 \\
6 \\
10 \\
10 \\
3 \\
3\end{array}$ & \begin{tabular}{|r|}
8.5 \\
7.5 \\
4.3 \\
5.6 \\
7.1 \\
8.1 \\
10.5 \\
11.3 \\
12.0 \\
14.6 \\
18.3 \\
18.0
\end{tabular} & $\begin{array}{r}17 \\
15 \\
47 \\
62 \\
64 \\
73 \\
63 \\
68 \\
120 \\
146 \\
55 \\
54\end{array}$ & $\begin{array}{r}3 \\
2 \\
2 \\
2 \\
1 \\
1 \\
4 \\
6 \\
17 \\
15 \\
9 \\
2 \\
0\end{array}$ & $\begin{array}{r}4 \\
5 \\
7 \\
4 \\
3 \\
4 \\
2 \\
3 \\
9 \\
9 \\
12 \\
1\end{array}$ & $\begin{array}{r}193 \\
360 \\
173 \\
180 \\
138 \\
230 \\
125 \\
96 \\
92 \\
87 \\
110 \\
108\end{array}$ & $\begin{array}{l}900 \\
900 \\
\mathbf{4 5 5} \\
601 \\
527 \\
608 \\
662 \\
679 \\
622 \\
677 \\
900 \\
578\end{array}$ & $\begin{array}{l}545.3 \\
633.0 \\
332.9 \\
333.7 \\
290.6 \\
302.9 \\
314.2 \\
31.9 \\
284.0 \\
277.1 \\
383.6 \\
261.8\end{array}$ & $\begin{array}{l}223.11 \\
250.74 \\
324.97 \\
206.39\end{array}$ & $\begin{array}{r}13.74 \\
14.00 \\
29.56 \\
18.94\end{array}$ & $\begin{array}{lr}- & 88 \\
- & 1 \\
\cdots & 12 \\
+ & 2\end{array}$ & $\begin{array}{l}19.61 \\
35.10\end{array}$ & $\begin{array}{l}0.35 \\
3.47\end{array}$ \\
\hline
\end{tabular}

Figure $2 \mathrm{c}$ shows in diagrammatic form the mean reaction-times of the plus and minus strains of Line 695 by two-month periods. The distances from the axis of ordinates represent two-month periods of the selection data. The ordinates indicate the average reactiontimes in seconds for the two-month periods. The solid line represents the course of the averages for the plus strain, the broken line for the minus strain. The roman numerals indicate the times at which the test series were conducted, and the plus and minus signs within the diagram indicate the positions of the means for these test series.

\section{Analysis of Data for Effect of Selection.}

On the whole, there is a marked coincidence of the fluctuations of the two strains, the means for the plus and minus strains in a general way following the same upward and downward trends. This 
is obviously due to environmental factors. The data for the first 4 months previous to August 1, 1912, may be passed over with slight consideration, for (as stated above) the methods of handling the material were not sufficiently standardized at first. These first 2 two-month ${ }^{1}$ periods show rather widely different averages (see tables 6 and 7 and figure 2c), but from this time on less violent fluctuations in average reaction-times are encountered, except for very wide fluctuations in the average of the minus strain during the latter half of 1915, and an unusual upshoot in the plus strain during the last 4 months of the experiment. ${ }^{2}$

For the year, August 1, 1912-July 31, 1913, the mean reactiontime for the plus strain was 260.2 seconds (251 individual reactiontime records; see table 7) and for the minus strain 297.5 seconds (217 individual reaction-time records). The minus-strain mean was -37.3 seconds greater than that for the plus strain. The difference was 3.2 times the statistical probable error (table 7). This large difference is due, of course, to the difference obtaining for the first 6 months of this year-period. This six-month period is discussed later. In the latter half of the year there was not a consistency in reaction-time differences, though on the average the plus was slightly the more reactive. The "same-day" broods for the year-period have a mean reaction-time for the minus strain only 0.8 second greater than for the plus strain (table 8).

For the year, August 1913-July 1914, the curves show that the two strains differ little in mean reaction-time (plus mean 371.8 seconds with 361 individual reaction-times; minus mean 371.3 seconds with 304 individual reaction-times; see table 7) and in relative vigor (see figure $2 \mathrm{~B}$ ). For the entire year the mean reaction-times differ by only +0.5 second and the same-day broods by only -12.3 seconds (table 8). Two test series were conducted during this period. One in August 1913 consisted of 529 individuals in the plus strain and 467 individuals in the minus strain. The mean reactiontimes were 522.2 seconds and 490.5 seconds for the plus and minus strains respectively, a difference of +31.7 seconds \pm 12.14 seconds. This difference is 2.61 times the probable error. The second test series, May 1914, consisted of 1,083 and 1,088 individuals and the means were 501 and 562.8 seconds. The difference in seconds was $-61.8 \pm 8.88$, a difference 6.96 times the probable error. The results of these two test series are contradictory and judgment will be reserved until the later data are considered.

${ }^{1}$ The summaries of the data for the earlier portion of the experiments were made to include the first 4 months. Summaries thereafter were made covering year periods. Summaries for the lines later subjected to selection were made to conform to the summary periods already utilized for the older lines.

${ }^{2}$ Actually this is only a trifle more than 3 months, as the selection was discontinued September $2,1916$. 
The year, August 1914-July 1915, gives as an average for the plus strain 368.7 seconds (478 individual records), 60 seconds greater than that for the minus strain (475 individual records), a difference 5.62 times the statistical probable error. For the first 10 months the plus strain consistently showed a higher reaction-time. For the 6 same-day broods the plus strain had a higher reaction-time by 2.3 seconds. A test series (May 1915, table 7) showed a higher reactiontime for the minus strain, but the difference was only $-1.1 \pm 6.73$. Another test series (June 1915) gave a higher reaction-time by $51.1 \pm 14.08$ seconds for the plus strain. This difference was 3.63 times the probable error.

During the remainder of the experiment with Line 695 (August 1915-September 1916), the minus strain fluctuated rather widely in mean reaction-time (figure 2c). For the year ending July 31, 1916 (399 and 439 individual reaction-time records), the minus strain had the higher reaction-time by $15.6 \pm 11.77$ seconds. The same-day broods gave a difference of $-6.9 \pm 19.61$ seconds. The remaining short period of the experiment, a trifle more than a month, shows a considerably higher reaction-time (higher by 150.8 seconds) for the plus strain.

If the experiment with Line 695 had been discontinued in January 1913, one might have felt inclined to ascribe a possible effect of selection to the strains of this line (see figure 2c). But it is extremely improbable that such an effect really should be thus ascribed for that period and that the selective effect once obtained was later lost in some manner. If one were to interpret this as an effect of selection acquired through a mutation or acquired in some other manner, it seems quite difficult to account for its loss. The selections were not relaxed and there was no period of high mortality among the stock to account for the loss of a selective difference. In two portions of the experiment the plus strain consistently had a higher reaction-time for 8 months or more at a time. Considering the curves as a whole, there are three periods in which one or the other strain had a higher reaction-time for as long as 6 months at a time. In two of these periods the plus strain had the higher reaction-time and in one of the minus had the higher reaction-time A further examination of these data will be made in order to seek the explanation.

Relation Between Reproductive Vigor and Reactiveness to Light.

It would seem plausible to suppose that relatively slight differences in the general vigor of the two strains might be a factor in determining the reaction-time, particularly in such periods as those just referred to.

The rate of descent of a strain may be considered one measure of its general vigor. Figure $2 \Lambda$ presents the relative rates of descent of the two strains of Line 695; the base-line represents equality of 
descent, i. e., if mothers of the same generation of descent in the two strains produce their young on the same day the circle will fall upon the base-line with the figure 0 adjoining. If young from the same generation of descent appeared 13 days later in the plus than in the minus strain, the solid circle will fall on the base-line with a figure 13 placed above the line, while if the minus strain (as in the case of the seventh entry in this diagram) were 4 generations and a day behind the plus strain in producing young of a given generation, this is indicated by the open circle being placed 4 units below the base-line, with a figure 1 adjoining.

By comparing the relative amounts of descent of the two strains from the end of one two-month period to the end of the following two-month period, one can determine whether the plus or the minus strain had during that interval descended the more rapidly, i. e., which strain was presumably the more vigorous of the two during that limited period. For example, from the end of May 1912 (first entry in this diagram) to the end of July 1912 (second two-month period and second entry in the diagram), the minus strain from having been 1 generation and 2 days in advance of the plus strain had become 13 days ahead of the plus strain in its time of producing young of the same generation of descent. During the following twomonth period (the third) the minus strain became just 1 generation (third entry in the diagram) behind the plus strain. Still one period later (the fourth) it was 1 generation and 7 days in arrears of the plus strain.

Comparing rate of descent with mean reaction-time, the minus strain during the second two-month period descended the less rapidly, but was the more reactive of the two strains. During the third period the minus strain descended the less of the two strains and was the less reactive. During the fourth period the minus strain again descended the less rapidly and was the less reactive. While the difference in reaction-time is frequently in the direction expected if influenced or determined by the relative rates of descent of the two strains, such is not true more often than the reverse is true. For the 27 two-month periods of selection with Line 695, the more rapidly descending of the two strains had the lower reaction-time in 10 cases, the higher reaction-time in 13 cases; for 3 two-month periods their rates of descent were identical; and for 1 period their mean reaction-times were identical. That is, the more vigorous strain, judged by its rate of descent, was the less reactive during 13 of the two-month periods, and in fewer cases (10) the more vigorous strain was the more reactive one. Hence, judged by this measure alone, the more vigorous strain was the more reactive strain less often than it was the less reactive strain.

In a further endeavor to learn if relative vigor is a factor in influencing reaction-times, all of our data for Line 695 which seemed 
to bear on the general vigor of the stock were tabulated. In considering this point three criteria of the general vigor of the material were used, the age of the mother at the time her first brood was produced, the number of young in her first brood, and the interval between the first and second broods. From a general knowledge of the material and use in other connections of these measures of the vigor of the material, the writer can state that these are satisfactory criteria. Figure 1A shows graphically the average number of young in the first brood for Line 695 by the two-month periods of the experiment. Figure $1 \mathrm{~B}$ shows the average age of mother for the same periods.

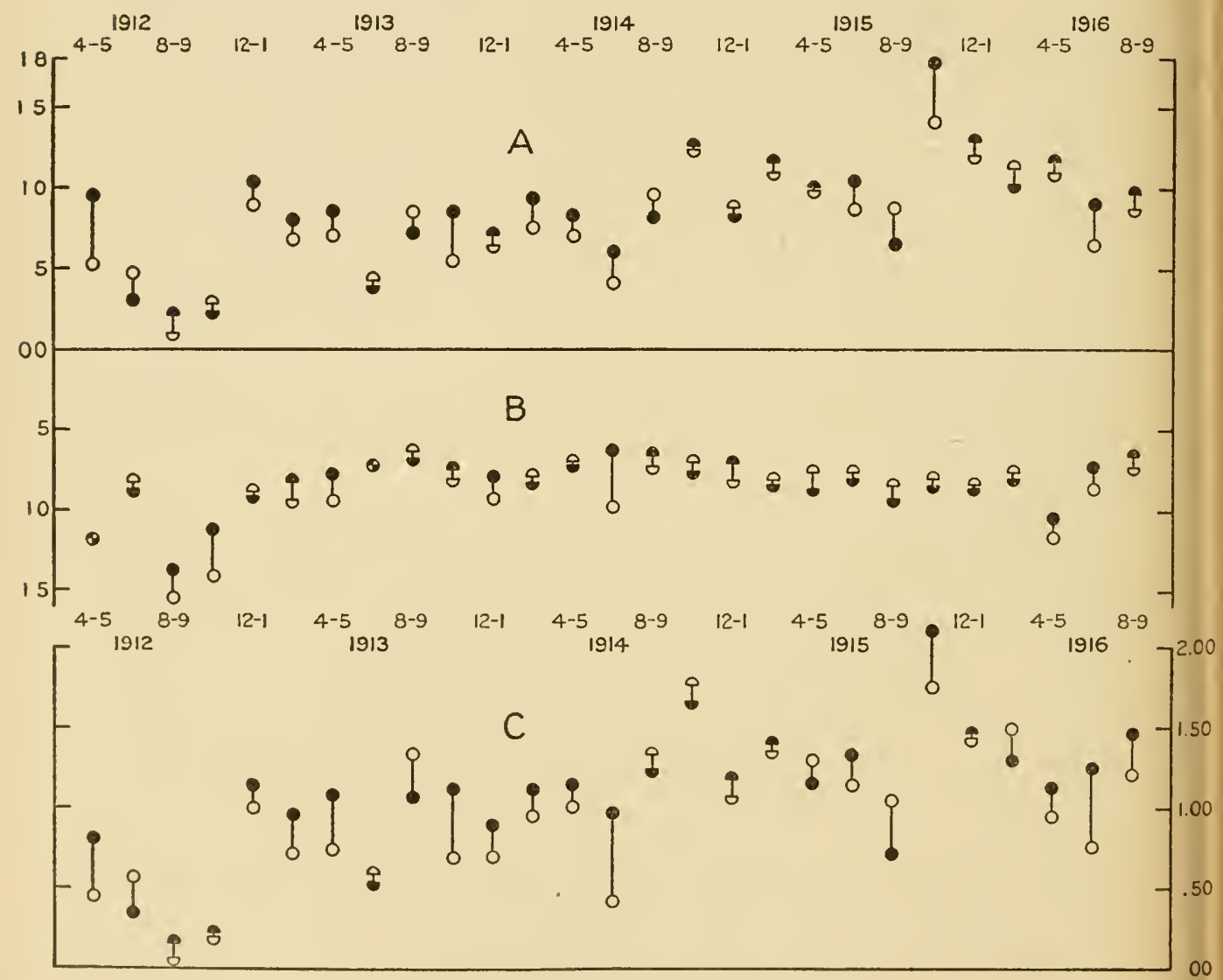

FigURE 1.-Line 695. Reproductive vigor.

A. Average number in the first brood by two-month periods. The vertical scaling above the base-line indicates the number of young; the horizontal sealing, the two-month periods of the experiment. Solid eireles show positions for the plus strain; open circles for the minus strain.

B. Average age of mothers at time first brood was produced. Vertical scaling below the base-line indicates the number of days.

C. Actual values of reproductive indices (average number of young in first brood divided by average age of mother at time first brood was produced). Vertical scaling indicates the numerical values of the reproductive index. Each numerical value of the reproductive index (in $\mathrm{C}$ ) is obtained by dividing the corresponding numerical value in $\mathrm{A}$ by the corresponding numerical value in $\mathrm{B}$. 

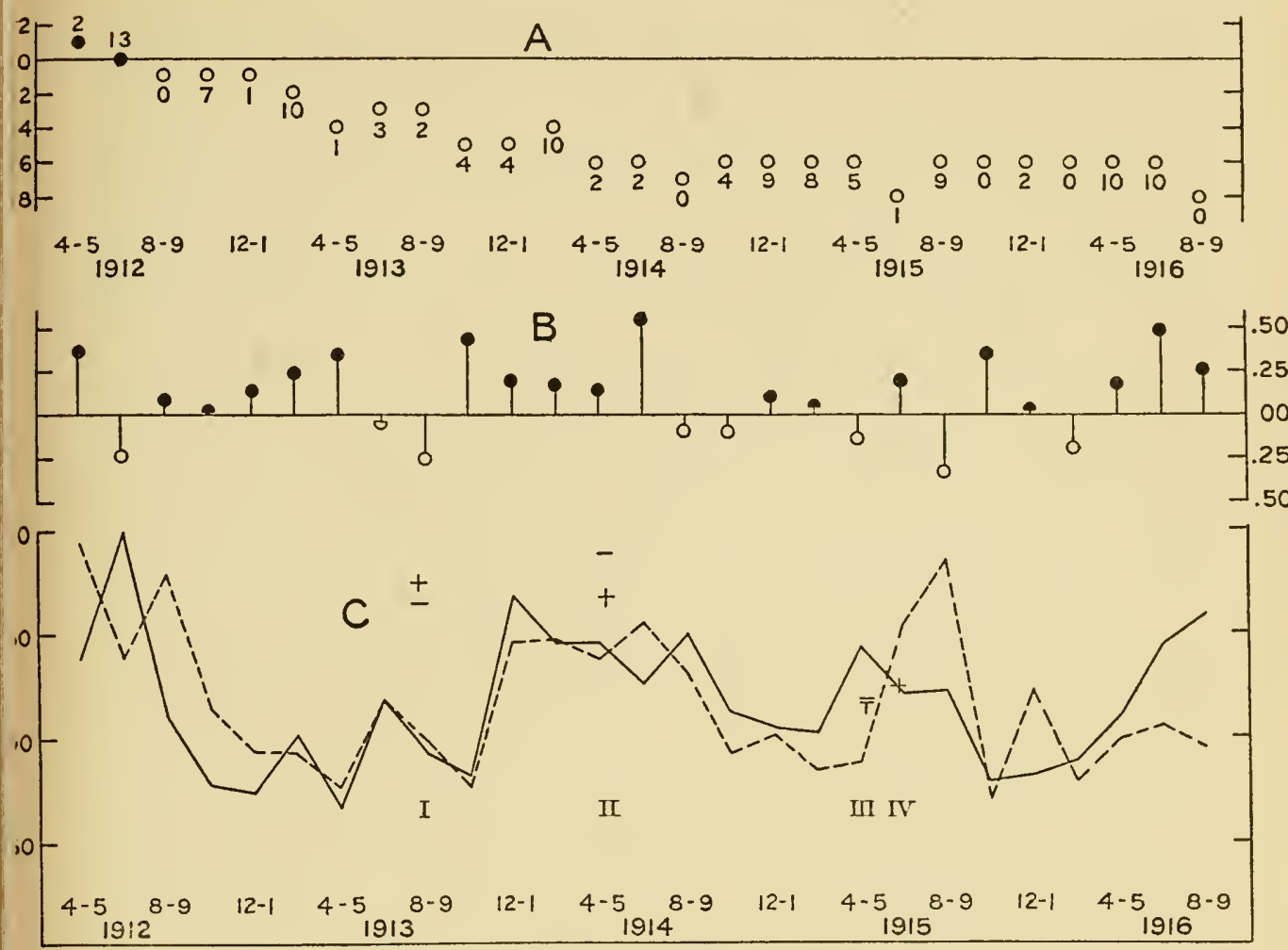

Figure 2.-Line 695.

A. Relative rates of descent of the two strains. The base-line represents an equality of descent, i. e., if both strains produced young of the same generation of descent on the same day the circle would fall on the base-line with a figure " 0 " placed adjacent. Positions above the base-line (solid circles) indicate that the minus strain in a particular generation was lagging by as many generations as the point falls in units below the base-line and by as many additional days as are indicated by the adjacent numeral. The horizontal scaling indicates the two-month periods of the experiment.

B. Reproductive indices plotted to show which strain is superior in vigor (and by how much it is superior) in the different two-month periods in experiment. Solid circles indicate that the plus strain is superior by the amount indicated by the distance the solid circle lies above the baseline; conversely, open circles below the base-line indicate the amount of superiority of the minus strain. The horizontal scale indicates, as always, the two-month periods of the experiment.

C. Reaction-time curves. The plus strain in solid, the minus strain in broken line. The vertical scale indicates seconds of reaction-time, the horizontal scale two-month periods of the experiment. The points in the curves represent mean individual reaction-times by two-month periods. The roman numerals indicate times at which "test series" were conducted, and the plus and minus signs the positions for the test series means for the two strains.

It seemed desirable to combine these measures so as to write the result in a single quantitative term. This was in part accomplished by dividing the mean number of young in the first brood by the mean age of the mothers at the time the first broods were produced. This gives the average number of young per day of the mother's age and may be called the reproductive index. ${ }^{2}$ This reproductive index is

${ }^{1}$ Unfortunately this did not include data for the interval between the first and second broods. This, however, was the least important of the three available measures of vigor, and the data for it was less extensive than for the other two measures. 
given in the seventh vertical column of the tables of data summarized by two-month periods (tables 5 and 6 ).

The reproductive indices for the two strains are plotted in figure 1c, in which the actual values are represented by the amount of elevation above the base-line of the solid and open circles. The solid circles represent the reproductive indices for the plus strain, the open circles for the minus strain. The distance between the solid circle and the open circle for any period represents the difference in reproductive index, the solid circle or the open circle being elevated the more above the base-line as the plus or the minus strain has the larger reproductive index. In figure $2 \mathrm{~B}$ the differences between the reproductive indices for the plus and minus strains are shown, a plus advantage being shown and its amount indicated by the elevation of the solid circle above the base-line and a minus superiority by the amount of the depression of the open circle below the base-line.

Throughout the first of the three periods of the curve for Line 695 , during which there was a consistent difference between the mean reaction-times of the two strains for as great a period as 6 months (August 1912-January 1913), the plus strain had the lower reaction-time and was slightly, though only very slightly, the more vigorous. But during the succeeding four months (February-May 1913; see figures $2 \mathrm{~B}$ and $2 \mathrm{C}$ ) the plus strain had a considerably greater advantage over the minus strain in vigor and yet the mean reaction-times of the two strains were very near together. The fairly wide and rather consistent difference between the mean reaction-times of the plus and minus strains for 6 months during 191213 is not accounted for on this basis.

For the ten-month period (August-September 1914 to AprilMay 1915) during which time the plus strain continuously had a higher reaction-time than the minus strain, the plus strain was slightly the less vigorous of the two during 6 of the 10 months; but during the other 4 months the reverse was true, and for the 10 months as a whole the reproductive vigor of the two strains was practically the same. For the seven-month period at the close of the experiment, during which the plus strain had a considerably higher reaction-time (was less reactive) than the minus strain, the plus strain, judged by the measures applied to it, was actually considerably the more vigorous of the two strains.

Hence, of the three periods of the curve during which the two strains differed consistently in reaction-time for as much as 6 months at a time, only one of these differences, that for the second period, and only a portion of it, could be accounted for on the basis of the more vigorous strain having been the more reactive.

Comparing by two-month periods for the entire duration of the experiment, one finds that the strain of Line 695 which (on the basis of its reproductive index) was the more vigorous had the lower re- 
action-time during 14 of these periods, while in 12 two-month periods the more vigorous strain had the higher reaction-time. For one period the average reaction-times were equal. Compared by periods of a single month, the strain having the greater vigor had a lower reaction-time in 23 cases and a higher reaction-time in 26 cases. For one month the vigor of the two strains measured the same, for one month the reaction-time was the same, and for three months the data were incomplete and a comparison could not be made.

Hence in the selection experiment with Line 695 no relation is discovered between fluctuations in general vigor and mean reaction-time, either when the data are examined month by month or by longer periods during which there was a constant difference in reaction-time. Whether the measure of vigor is taken as the rate of descent or as the reproductive index, any reaction-time differences which one might have expected to find explicable on the basis of differences in vigor between the two strains quite fail to appear so.

The test series may again be referred to. Three of the four of these gave differences in mean reaction-time which are statistically significant; 1 for one the difference was practically nil. Of the three differences of statistical significance, two were differences in which, in opposition to selection, the plus strain had the higher reactiontime and only one of the differences was in the direction of selection. Hence their net effect is to indicate a lack of effect of selection.

Examined as a whole and on the points considered in detail, it is obvious that with Line 695 there was no effect of selection. This is by no means surprising, for if an effect of selection is obtainable with a given material it is not to be expected that such effect will necessarily be secured every time it is attempted. Selection cannot be effective unless germinal variation occurs which affects the character used as a basis for selection; and there seems no logical reason for supposing that germinal variation occurs in all, or to the same extent, or at the same time, in all material which is otherwise apparently entirely similar.

It would be superfluous to make such an extended analysis of the data for each of the lines as has been attempted for Line 695 . Tables of data and diagrams similar to those for Line 695 are given for all the lines (though some of these lines have their data presented somewhat less fully), but it has not seemed necessary to make the treatment nearly so complete. The tabulated summaries and the curves plotting reaction-times and the reproductive indices render the interpretation rather obvious after the full treatment accorded Line 695. Of the other lines, the data for Line 757 alone are examined rather extensively because of the interesting result within that line.

1 The times at which these test series were conducted are indicated by the roman numerals on figure $2 \mathrm{c}$. 


\section{LINE 689.}

Line 689 was obtained from the surface-water pond in an open field (Pond I) and reared in the laboratory for 8 generations before being subjected to selection. Selection was continued 16 months, 44 generations in the plus strain and 42 generations in the minus strain, when the experiment was terminated by the accidental loss of the plus strain.

The data are presented after the plan followed with the data for Line 695 in tables $9,10,11$, and 12 , and in figure $3, \mathrm{~A}, \mathrm{~B}$, and $\mathrm{C}$.

For the first 4 months of selection the mean reaction-time for the plus strain was 498.4 seconds and for the minus strains 464.2 seconds. The difference was $+34.2 \pm 41.4$ seconds (table 11). For the year (nearly), from August 1, 1912, to the close of the ex-

TABLE 9.-Selection data summarized by two-month periods for Line 689 plus.

\begin{tabular}{|c|c|c|c|c|c|c|c|c|c|c|c|c|c|c|}
\hline Time period. & 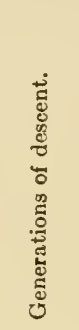 & 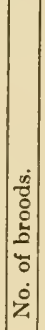 & 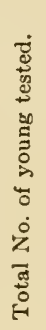 & 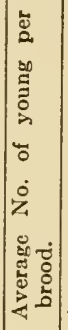 & 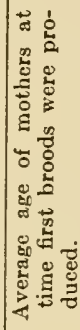 & 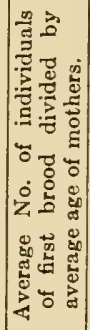 & 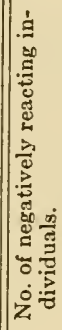 & 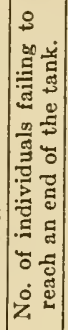 & 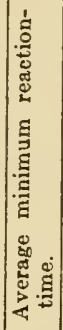 & 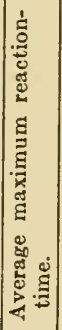 & 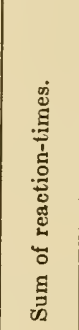 & 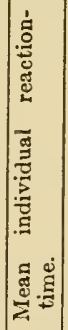 & 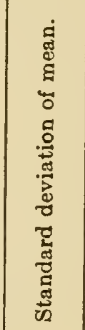 & 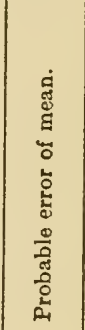 \\
\hline $\begin{array}{l}\text { Apr.-May } 1912 \ldots \\
\text { June-July } 1912 \ldots \\
\text { Aug.-Sept. } 1912 \ldots \\
\text { Oct.-Nov. } 1912 \ldots \\
\text { Dec. 1912-Jan. } 1913 \\
\text { Feb.-Mar. } 1913 \ldots \\
\text { Apr.-May 1913... } \\
\text { June-July } 1913 \ldots \ldots\end{array}$ & $\begin{array}{l}10-14 \\
15-19 \\
20-23 \\
24-26 \\
27-33 \\
3-40 \\
41-47 \\
48-52\end{array}$ & $\begin{array}{l}5 \\
5 \\
6 \\
3 \\
7 \\
8 \\
7 \\
5\end{array}$ & $\begin{array}{l}28 \\
26 \\
15 \\
13 \\
60 \\
69 \\
60 \\
42\end{array}$ & $\begin{array}{l}5.3 \\
5.2 \\
2.3 \\
5.5 \\
5.6 \\
8.3 \\
7.8 \\
7.2\end{array}$ & $\begin{array}{r}11.1 \\
9.0 \\
17.8 \\
18.7 \\
9.0 \\
8.3 \\
7.9 \\
8.2\end{array}$ & $\begin{array}{r}0.48 \\
.58 \\
.13 \\
.29 \\
.96 \\
1.00 \\
.99 \\
.88\end{array}$ & $\begin{array}{l}3 \\
1 \\
0 \\
1 \\
0 \\
1 \\
2 \\
3\end{array}$ & $\begin{array}{l}7 \\
5 \\
3 \\
1 \\
4 \\
3 \\
0 \\
1\end{array}$ & $\begin{array}{l}244 \\
297 \\
315 \\
226 \\
112 \\
144 \\
117 \\
187\end{array}$ & $\mid \begin{array}{l}557 \\
664 \\
464 \\
566 \\
531 \\
476 \\
436 \\
688\end{array}$ & $\begin{array}{r}14090 \\
12825 \\
5007 \\
4302 \\
19043 \\
20838 \\
13468 \\
13775\end{array}$ & $\begin{array}{l}503 \\
493 \\
334 \\
331 \\
317 \\
302 \\
224 \\
328\end{array}$ & $\mid \begin{array}{c}\cdots \cdots \\
291.14 \\
190.45 \\
\cdots \cdots \\
\cdots \cdots \\
221.12\end{array}$ & $\begin{array}{l}50.70 \\
35.63\end{array}$ \\
\hline
\end{tabular}

TABLE 10.-Selection data summarized by two-month periods for line 689 minus.

\begin{tabular}{|c|c|c|c|c|c|c|c|c|c|c|c|c|c|c|c|c|c|}
\hline Time & 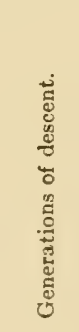 & 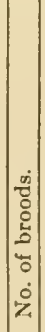 & 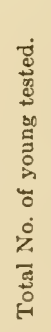 & 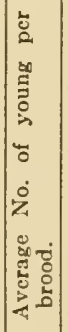 & 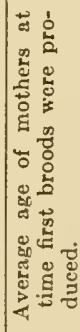 & 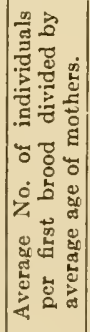 & 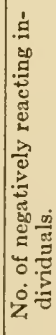 & 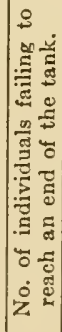 & 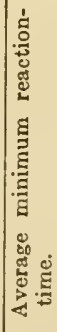 & 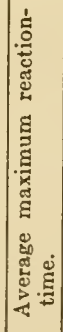 & 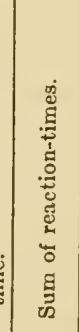 & 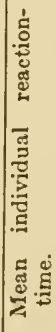 & 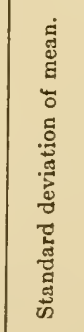 & 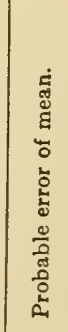 & 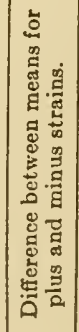 & 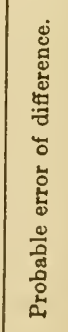 & 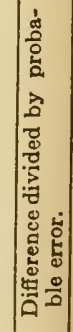 \\
\hline & & $\begin{array}{l}4 \\
5\end{array}$ & $\begin{array}{r}9 \\
20\end{array}$ & $\begin{array}{l}2.3 \\
7.3\end{array}$ & $\begin{array}{r}13.3 \\
9.0\end{array}$ & .17 & $\begin{array}{l}1 \\
0\end{array}$ & $\frac{2}{3}$ & $\begin{array}{l}246 \\
439\end{array}$ & $\begin{array}{l}556 \\
728\end{array}$ & \begin{tabular}{|l|l|}
4018 \\
9415
\end{tabular} & $\begin{array}{l}450 \\
471\end{array}$ & & & $\begin{array}{r}+53 \\
+\quad 22\end{array}$ & & \\
\hline 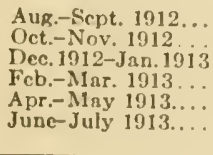 & & \begin{tabular}{l|l}
2 \\
6 \\
7 \\
6 \\
8 \\
6
\end{tabular} & $\begin{array}{r}8 \\
14 \\
51 \\
31 \\
84 \\
35\end{array}$ & $\begin{array}{l}4.0 \\
1.3 \\
7.3 \\
5.2 \\
9.1 \\
5.8\end{array}$ & $\begin{array}{r}21.5 \\
14.6 \\
8.8 \\
9.2 \\
8.0 \\
7.5\end{array}$ & $\begin{array}{r}.19 \\
.09 \\
.83 \\
.57 \\
1.14 \\
.77\end{array}$ & $\begin{array}{l}0 \\
0 \\
2 \\
0 \\
1 \\
2\end{array}$ & $\begin{array}{l}0 \\
0 \\
2 \\
0 \\
0 \\
0\end{array}$ & $\begin{array}{l}138 \\
155 \\
114 \\
173 \\
113 \\
138\end{array}$ & $\begin{array}{l}268 \\
306 \\
353 \\
321 \\
492 \\
468\end{array}$ & $\begin{array}{r}1624 \\
3335 \\
13135 \\
8175 \\
21850 \\
8722\end{array}$ & $\begin{array}{l}203 \\
241 \\
258 \\
26 ! \\
260 \\
249\end{array}$ & $\begin{array}{l}106.46 \\
148.60 \\
\cdots \ldots \\
\cdots \ldots \\
130.89\end{array}$ & $\begin{array}{l}25.39 \\
26.79 \\
\cdots \cdots \\
\cdots \cdots \\
14.92\end{array}$ & $\begin{array}{r}+131 \\
+\quad 90 \\
+59 \\
+38 \\
+\quad 36 \\
+\quad 79\end{array}$ & & \\
\hline
\end{tabular}


TABLE 11.-Selection summary for Line 689.

\begin{tabular}{|c|c|c|c|c|c|c|c|c|c|c|c|c|c|c|c|}
\hline Time period. & Strain. & 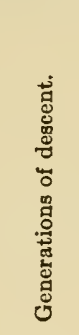 & 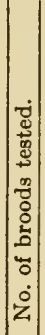 & 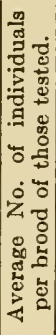 & 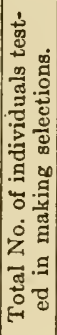 & 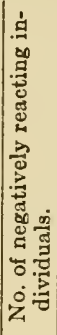 & 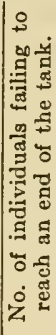 & 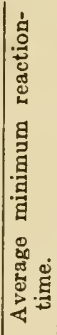 & 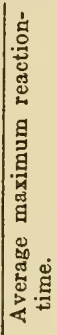 & 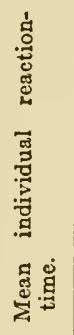 & 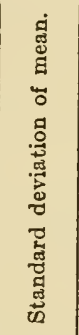 & 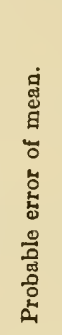 & 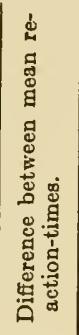 & 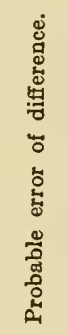 & 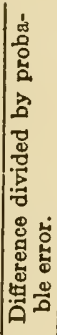 \\
\hline \multirow{4}{*}{$\begin{array}{r}\text { Apr.-July } 31 . \\
\text { 1912........ } \\
\text { Aug. 1, 1912- } \\
\text { July } 16,1913\end{array}$} & $\{$ Plus. & $9-19$ & 10 & 5.4 & 54 & 4 & 12 & 271 & 611 & 498.4 & 260.7 & 23.9 & +34.2 & 41.4 & 0.83 \\
\hline & Minus. & $9-17$ & 9 & 3.2 & 29 & 1 & 5 & 353 & 665 & 464.2 & 269.4 & 38.7 & & & \\
\hline & Plus.. & $20-52$ & 36 & 7.2 & 259 & 7 & 12 & 174 & 514 & 295.1 & 194.8 & 8.2 & +40.0 & 10.5 & 3.71 \\
\hline & Minus. & $18-50$ & 35 & 6.4 & 228 & 5 & 2 & 186 & 392 & 255.1 & 145.2 & 6.6 & & & \\
\hline
\end{tabular}

TABLE 12.-Same-day broods. Summary of data for Line 689.

\begin{tabular}{|c|c|c|c|c|c|c|c|c|c|c|}
\hline Time period. & Strain. & 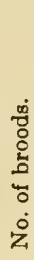 & 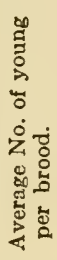 & 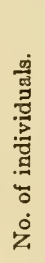 & 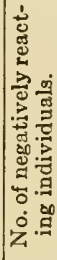 & 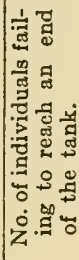 & 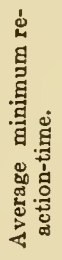 & 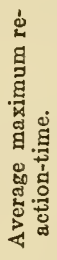 & 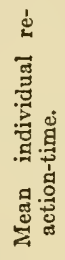 & 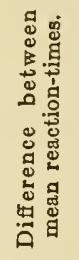 \\
\hline \multirow{4}{*}{$\begin{array}{r}\text { Apr. } 9,1912-\text { July } 31, \\
1912 \ldots \ldots \ldots \ldots \ldots \ldots \\
\text { Aug. } 1,1912-J u l y 31, \\
1913 \ldots \ldots \ldots \ldots \ldots \ldots\end{array}$} & $\{$ Plus.. & 1 & 5.0 & 5 & 0 & 3 & 315 & 900 & 712 & \multirow[t]{2}{*}{+163} \\
\hline & Minus & 1 & 4.0 & 4 & 0 & 0 & 440 & 690 & 549 & \\
\hline & fPlus. . & 10 & 8.9 & 89 & 4 & 2 & 125 & 464 & 295 & +3 \\
\hline & Minus & 10 & 7.2 & 72 & 1 & 2 & 131 & 467 & 292 & \\
\hline
\end{tabular}

periment with this line in July 1913, the mean for the plus strain was 295.1 seconds and for the minus 255.1 seconds. The difference was $+40.0 \pm 10.5$ seconds, 3.71 times its probable error. There was only one same-day brood ${ }^{1}$ for the four-month period, but there were ten same-day broods during the later year-period. For these same-day broods likewise the reaction-time for the minus strain was lower than for the plus strain, but the difference was only 3 seconds (table 12).

It is an interesting fact that in this line, in opposition to selection, the minus strain persistently (except for 1 two-month period, see table 10) maintained a lower reaction-time than the plus strain. This difference, while not large for the greater part, is so general that it can scarcely seem to be merely coincidental. The same-day broods (table 12) show the minus broods with a smaller reactiontime, but for the only significant group of these the difference is so slight ( 3 seconds) as scarcely to be suggestive.

\footnotetext{
${ }^{1}$ For this pair of very small broods the mean of the plus strain was 163 seconds greater than that for the minus strain.
} 
There were more over-time individuals in the plus strain, 24 as compared with 7 in the minus strain. The average minimum and maximum reaction-times likewise indicate greater reactiveness in the minus strain for the last 12 of the total 16 months of the experiment. The average minimum reaction-time for all the broods tested in the plus strain for this last year was 174 seconds (table 11), while the corresponding average for the minus strain was 136 seconds, indicating that the most reactive individuals in the minus strain had a lower reaction-time by 38 seconds than the corresponding individuals in the plus strain. A corresponding comparison for the maximum reaction-times for the two strains gives 514 seconds as the average maximum for the plus and 392 seconds as the average for the minus strain, the difference (122 seconds) indicating that the individuals with the highest reaction-times in the plus strain were 31 per cent slower in reacting than the corresponding individuals in the minus strains. These portions of data tend to confirm a greater reactiveness for the minus strain than for the plus strain.

Comparison of the curves for the two strains of Line 689 may be made with the combined mean reaction-time curves for all the plus and for all the minus strains of those Daphnia pulex lines between the two strains of which there were no consistent differences in reactiveness-Lines 691，695, 713,714 , and 751 (see figure $3 \mathrm{c}$ ). Inspection of these curves shows
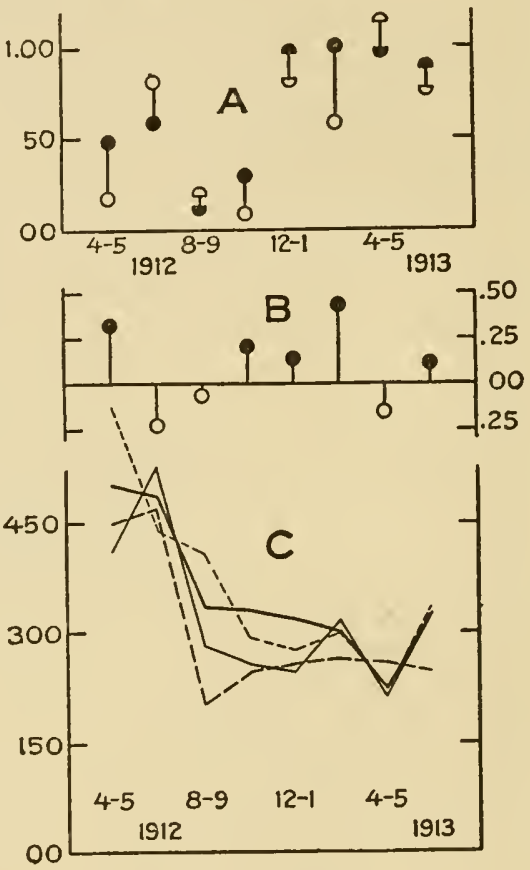

Figure 3.-Line 689.

A. Reproductive indices, actual values.

B. Reproductive indices, superiority.

C. Reaction-time curves with superimposed curves (in faint lines) representing the combined reaction-time means for the plus and minus strains of all Daphnia pulex lines in which significant reaction-time differences did not arise-Lines $691,695,713,714$, and 751 .

that for 3 two-month periods (August 1912-January 1913) the plus strain of Line 689 was abnormally high, while the minus strain of Line 689 was abnormally low in reaction-time, and that aside from these 3 two-month periods the two strains of Line 689 did not differ so greatly in their reactiveness. It would seem possible that the pronounced divergence in reactiveness between the two strains of this line for the period indicated may have been due to the coincidence of unusual reactiveness of the minus strain and slight reactiveness of the plus strain brought about by differential 
environmental factors (see page 140). However, in 4 of the 5 other two-month periods of the experiment, the minus strain was the more reactive (the combined mean was 42 seconds greater for the plus strain), and it is possible that there really existed a genetic difference between the two strains of this line.

Perhaps the most that can be said regarding Line 689 is that the persistently lower reaction-time in the minus strain is suggestive of a genetic difference in the reverse of selection. It is much to be regretted that this line could not have been continued longer or that large test series were not conducted in order to secure better evidence concerning the real persistence of this apparent difference in reactiontime.

With regard to any relation between mean reproductive vigor and mean reaction-time in Line 689 , it may be said that no relation is discoverable. On the whole, the plus strain was somewhat the more vigorous (see figure $3, \mathrm{~A}$ and $\mathrm{B}$ ) while the minus strain was the more reactive. Further, there is an entire lack of coincidence of lowered reaction-time means with higher reproductive indices.

The influence of general environmental factors is seen in the somewhat coincident up-and-down movements of the curves for the two strains.

\section{LINE 691.}

The data for Line 691 are presented in tables 13 and 14 and in figure 4. This is one of the original lines of $D$. pulex. Selection was begun in the seventh generation and continued for 87 and 89 generations in the two strains. The experiment was terminated by the loss of the plus strain after 27 months of selection.

For the first 4 months of the experiment the mean reactiontimes for the plus and minus strains (only 40 and 35 individuals respectively) were 480.9 and 434.9 seconds (table 13). The plus

TABLE 13.-Selection summary for Line 691.

\begin{tabular}{|c|c|c|c|c|c|c|c|c|c|c|c|c|c|c|c|}
\hline Time period. & Strain. & 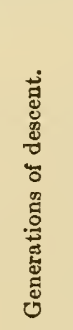 & 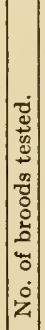 & 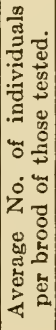 & 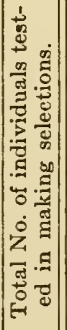 & 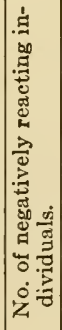 & 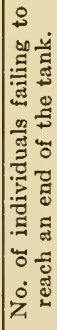 & 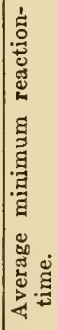 & 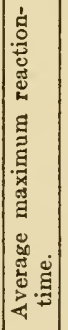 & 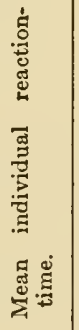 & 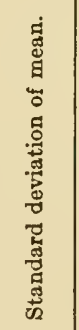 & 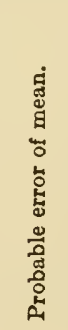 & 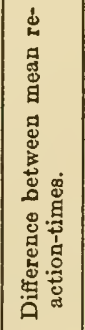 & 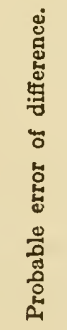 & 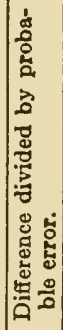 \\
\hline $\begin{array}{c}\text { Apr. 12, 1912- } \\
\text { July 31, 1912 } \\
\text { Aug. 1, 1912- } \\
\text { July 31, 1913 } \\
\text { Aug. 1, 1913- } \\
\text { June 12, 1914 }\end{array}$ & $\left\{\begin{array}{l}\text { Plus..... } \\
\text { Minus ... } \\
\text { Plus.... } \\
\text { Minus .. } \\
\text { Plus.... } \\
\text { Minus .. }\end{array}\right.$ & $\begin{array}{l}10-19 \\
11-18 \\
20-55 \\
19-57 \\
56-93 \\
58-95\end{array}$ & $\begin{array}{r}11 \\
7 \\
38 \\
40 \\
39 \\
39\end{array}$ & $\begin{array}{l}3.7 \\
5.0 \\
5.9 \\
6.4 \\
7.3 \\
7.0\end{array}$ & \begin{tabular}{|r|}
40 \\
35 \\
225 \\
257 \\
285 \\
273
\end{tabular} & $\begin{array}{r}1 \\
1 \\
8 \\
20 \\
25 \\
22\end{array}$ & $\begin{array}{r}10 \\
9 \\
6 \\
19 \\
37 \\
38\end{array}$ & $\begin{array}{l}347 \\
169 \\
142 \\
140 \\
171 \\
228\end{array}$ & \begin{tabular}{|l|}
743 \\
577 \\
373 \\
459 \\
680 \\
731
\end{tabular} & $\begin{array}{r}480.9 \\
44.9 \\
248.8 \\
296.6 \\
391.0 \\
416.2\end{array}$ & $\begin{array}{l}299.0 \\
300.5 \\
164.5 \\
220.6 \\
265.8 \\
268.2\end{array}$ & $\begin{array}{r}31.9 \\
34.9 \\
7.4 \\
9.3 \\
10.6 \\
10.9\end{array}$ & $\begin{array}{l}+46.0 \\
\cdots \ldots . \\
-47.8 \\
-25.2\end{array}$ & 15.2 & 1.66 \\
\hline
\end{tabular}


TABLE 14.-Same-day broods. Summary of data for Line 691.

\begin{tabular}{|c|c|c|c|c|c|c|c|c|c|c|c|c|c|c|}
\hline Time period. & Strain. & 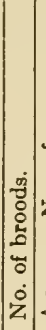 & 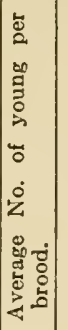 & 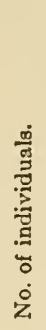 & 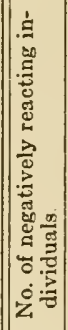 & 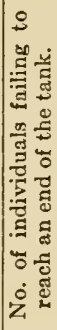 & 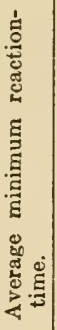 & 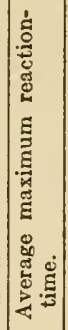 & 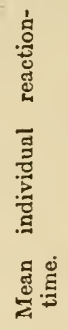 & 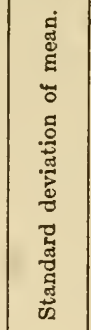 & 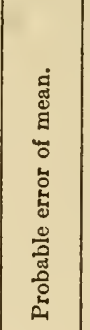 & 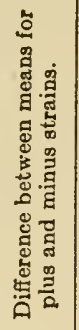 & 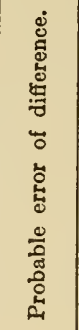 & 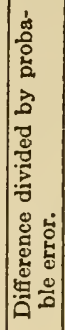 \\
\hline $\begin{array}{c}\text { Apr. } 8,1912- \\
\text { July } 31,1912 \\
\text { Aug. } 1,1912- \\
\text { July } 31,1913 \\
\text { Aug. } 1,1913- \\
\text { June } 9,1914\end{array}$ & $\begin{array}{l}\text { Plus..... } \\
\text { Minus.. } \\
\text { Plus.... } \\
\text { Minus... } \\
\text { Plus.... } \\
\text { Minus.. }\end{array}$ & $\begin{array}{l}2 \\
2 \\
8 \\
8 \\
6 \\
6\end{array}$ & \begin{tabular}{|l|}
3.5 \\
4.0 \\
3.5 \\
5.5 \\
6.7 \\
7.8
\end{tabular} & $\begin{array}{r}7 \\
8 \\
28 \\
42 \\
40 \\
47\end{array}$ & $\begin{array}{l}0 \\
0 \\
1 \\
6 \\
6 \\
7\end{array}$ & $\begin{array}{l}3 \\
1 \\
1 \\
6 \\
7 \\
5\end{array}$ & $\begin{array}{l}285 \\
125 \\
162 \\
166 \\
168 \\
102\end{array}$ & $\begin{array}{l}900 \\
555 \\
260 \\
481 \\
781 \\
813\end{array}$ & $\begin{array}{l}634 \\
303 \\
192 \\
348 \\
413 \\
370\end{array}$ & $\begin{array}{r}98.69 \\
272.26\end{array}$ & $\begin{array}{l}12.58 \\
28.34\end{array}$ & $\begin{array}{r}-156 \\
+43\end{array}$ & 31.00 & 5.08 \\
\hline
\end{tabular}

mean was larger by $46 \pm 46.8$ seconds. ${ }^{1}$ For the year, August $1912-$ July 1913 , the two means were 248.8 and 296.6 seconds (225 and 257 individuals). The difference, $-47.8 \pm 11.9$ seconds, was 4.02 times the probable error. The same-day broods for this year-period, of which there were 8 , gave a mean of 192 seconds for the plus and of 348 seconds for the minus strain and a difference of $-156 \pm 31.00$ seconds-5.03 times the probable error (table 14). In spite of the irregular course of the curves, the data for this year might seem to indicate a possible (though slight) effect of selection, except for the fact that the further history of the line does not bear out this interpretation.

For the following year (nearly), which concludes the data for this line, the mean for the plus strain was 391.0 seconds (285 individuals); for the minus strain 416.2 seconds ( 273 individuals). The difference was $-25.2 \pm 15.2$ seconds (table 13 ) and is not of statistical significance. There were 6 same-day broods for this period, for which the plus mean was 413 seconds and the minus mean 370 seconds (table 14). This difference ( +43 seconds), while not of statistical significance, is in the reverse of an effect of selection. No test series were obtained for Line 691.

Figure 4 shows the curves of the mean reaction-times for the two strains for Line 691 by two-month periods. The curves are quite irregular and indicate considerable fluctuation in mean reaction-times, particularly for the minus strain, which, except for its wide fluctuations, was persistently the less reactive of the two strains after the first 4 months of selection. The curves for the two strains follow each other in a general way, but are so irregular that they cross 8 times. The rather persistently (though only slightly) higher reaction-time of the minus strain is suggestive of a possible slight

${ }^{1}$ There were only 2 same-day hroods, involving totals of only 7 individuals in the plus and 8 individuals in the minus strain. The means were 634 and 303 seconds, the difference being +331 seconds. These broods came in July, when the plus strain was relatively slightly reactive 
effect of selection within this line. However, the actually smaller difference in mean reaction-times during the last year as compared with the preceding year does not lend support to this supposition, and the same-day-brood data for the last longer period are in opposition to an effect of selection, so that a result of selection within Line 691 must be considered very questionable.

Obtaining the data for reproductive vigor (from the daily laboratory notes) is laborious and was not done for Line 691 and a number of the other lines in which there was obviously no effect of selection or in which the results were inconclusive.

The parallel effect of broad environmental influences upon the reaction-time means for the two strains is shown in the curves (figure 4) for the two strains, they in a general way following the same course.

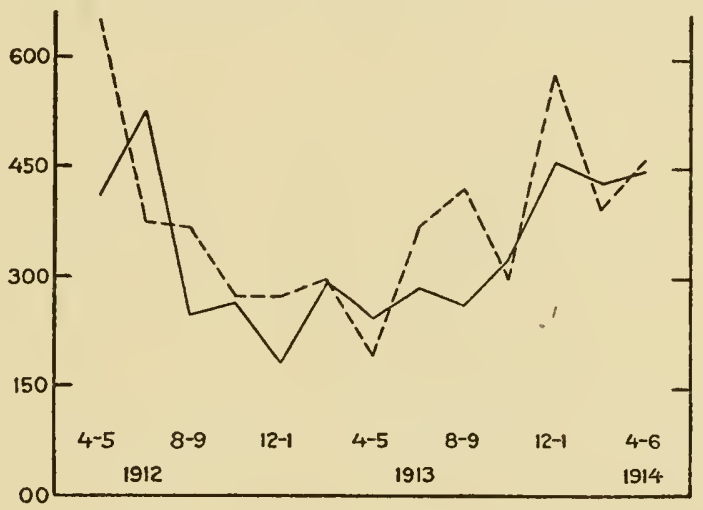

FIGURE 4.-Line 691. Reaction-time curves.

LINE 711.

Tables $15,16,17$, and 18 and figure 5 present the data for Line 711.

TABLE 15.-Selection data summarized by two-month periods for Line 711 plus.

\begin{tabular}{|c|c|c|c|c|c|c|c|c|c|c|c|}
\hline Time period. & 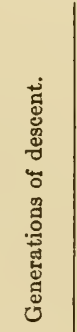 & 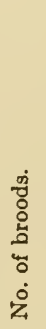 & 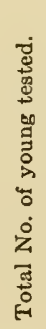 & 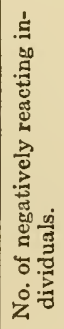 & 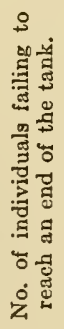 & 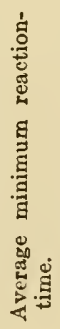 & 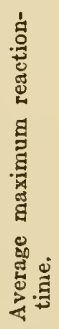 & 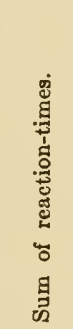 & 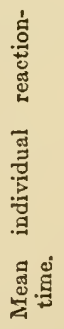 & 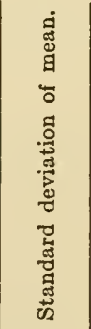 & 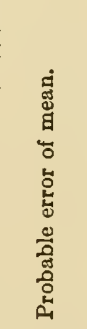 \\
\hline 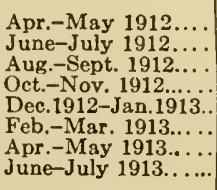 & $\begin{array}{r}7-12 \\
13-17 \\
18-19 \\
20-23 \\
24-31 \\
32-36 \\
37-43 \\
44-50\end{array}$ & $\begin{array}{l}6 \\
6 \\
2 \\
4 \\
8 \\
5 \\
7 \\
7 \\
7\end{array}$ & $\begin{array}{r}30 \\
22 \\
6 \\
14 \\
83 \\
34 \\
62 \\
36\end{array}$ & $\begin{array}{l}3 \\
0 \\
0 \\
2 \\
1 \\
0 \\
1 \\
1\end{array}$ & $\begin{array}{r}8 \\
10 \\
0 \\
0 \\
4 \\
0 \\
0 \\
0\end{array}$ & $\begin{array}{l}299 \\
345 \\
144 \\
124 \\
114 \\
141 \\
119 \\
148\end{array}$ & $\begin{array}{l}783 \\
668 \\
220 \\
449 \\
506 \\
397 \\
349 \\
343\end{array}$ & $\begin{array}{r}13605 \\
11805 \\
1043 \\
3662 \\
22875 \\
9225 \\
13095 \\
6792\end{array}$ & $\begin{array}{l}454 \\
537 \\
174 \\
262 \\
276 \\
271 \\
211 \\
189\end{array}$ & $\begin{array}{r}308.91 \\
\ldots .71 .77 \\
\ldots \ldots \\
\ldots \ldots \\
\cdots \cdots \\
\cdots \\
96.7 \dot{5}\end{array}$ & $\begin{array}{l}38.040 \\
\ldots .5 \\
11.5 \\
\ldots \ldots \ldots \\
\cdots \cdots \cdots \\
\cdots \\
10 . \dot{8} \dot{8}\end{array}$ \\
\hline
\end{tabular}


TABLE 16.- Selection data summarized by two-month periods for Line 711 minus.

\begin{tabular}{|c|c|c|c|c|c|c|c|c|c|c|c|c|c|}
\hline Time period. & 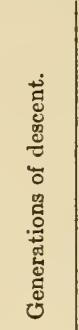 & 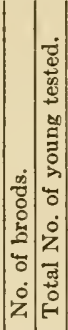 & 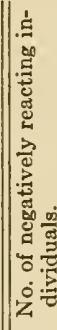 & 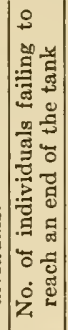 & 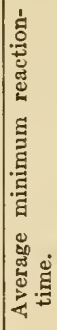 & 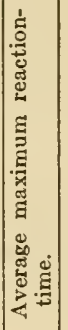 & 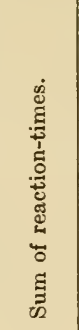 & 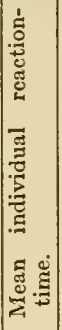 & 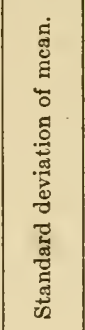 & 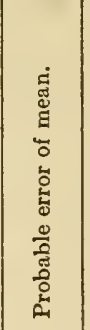 & 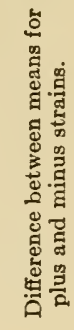 & 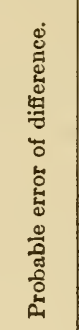 & 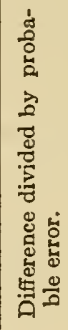 \\
\hline $\begin{array}{ll}\text { Apr.-May } & 1912 \ldots \\
\text { June-July } & 1912 \ldots\end{array}$ & $\begin{array}{r}7-12 \\
13-18\end{array}$ & \begin{tabular}{|l|l|l|l|}
6 & 25 \\
6 & 24 \\
\end{tabular} & $\begin{array}{l}1 \\
1\end{array}$ & $\begin{array}{r}14 \\
8\end{array}$ & $\begin{array}{l}458 \\
308\end{array}$ & $\begin{array}{l}900 \\
643\end{array}$ & $\begin{array}{l}17440 \\
11381\end{array}$ & \begin{tabular}{|l|}
6998 \\
474 \\
\end{tabular} & $\begin{array}{l}265.71 \\
\cdots \ldots .\end{array}$ & 35.84 & $\begin{array}{r}-244 \\
+63\end{array}$ & 52.27 & 4.66 \\
\hline $\begin{array}{l}\text { Aug.-Sept. } 1912 \ldots \\
\text { Oct.-Nov, } 1912 \ldots \\
\text { Dec.1912-Jan.1913 } \\
\text { Feb.-Mar. } 1913 \ldots \\
\text { Apr.-May } 1913 \ldots \\
\text { June-July } 1913 \ldots\end{array}$ & $\begin{array}{l}18-19 \\
20-25 \\
26-31 \\
32-38 \\
39-45 \\
46-51\end{array}$ & \begin{tabular}{|l|l|}
3 & 5 \\
7 & 17 \\
6 & 41 \\
7 & 43 \\
7 & 40 \\
6 & 44
\end{tabular} & $\begin{array}{r}2 \\
3 \\
1 \\
2 \\
1 \\
10\end{array}$ & $\begin{array}{l}0 \\
0 \\
2 \\
0 \\
0 \\
2\end{array}$ & $\begin{array}{l}348 \\
229 \\
113 \\
123 \\
131 \\
132\end{array}$ & $\begin{array}{l}\mathbf{5 7 2} \\
335 \\
380 \\
418 \\
341 \\
573\end{array}$ & $\begin{array}{r}2385 \\
5019 \\
12484 \\
12550 \\
9515 \\
12275\end{array}$ & \begin{tabular}{|l|}
477 \\
295 \\
304 \\
292 \\
238 \\
279
\end{tabular} & \begin{tabular}{l}
171.16 \\
$\cdots \cdots \cdots$ \\
$\cdots \cdots$ \\
\hdashline$\ldots \ldots$ \\
201.87
\end{tabular} & $\because 20.53$ & $\begin{array}{l}-303 \\
-33 \\
-28 \\
-21 \\
-27 \\
-90\end{array}$ & 52.89 & $\begin{array}{c}5.33 \\
\cdots \cdots \\
\cdots,\end{array}$ \\
\hline
\end{tabular}

TABLE 17.-Selection summary for Line 711.

\begin{tabular}{|c|c|c|c|c|c|c|c|c|c|c|c|c|c|c|c|}
\hline Time period. & Strain. & 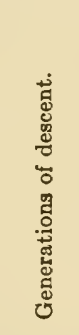 & 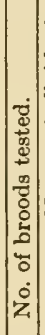 & 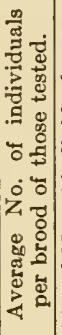 & 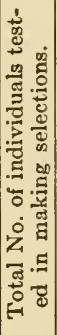 & 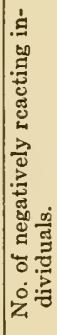 & 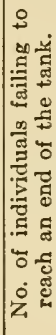 & 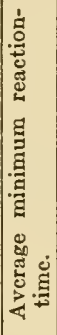 & 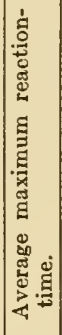 & 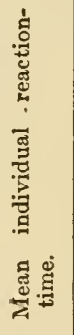 & 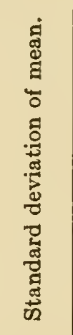 & 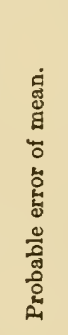 & 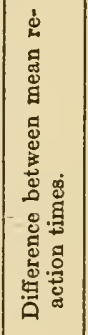 & 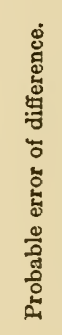 & 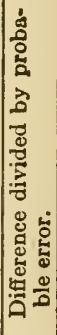 \\
\hline \multirow{4}{*}{$\begin{array}{l}\text { A pr. } 1912- \\
\text { July } 31,1912 \\
\text { Aug. 1, 1912- } \\
\text { July } 31,1913\end{array}$} & $\{$ Plus. & $6-17$ & 12 & 4.3 & 52 & 3 & 18 & 322 & 727 & 488.7 & 327.7 & 30.7 & & & $\cdots$ \\
\hline & Minus. & $6-18$ & 12 & 4.1 & 49 & 2 & 22 & s76 & 760 & 688.2 & $\$ 15.1$ & 80.4 & -99.6 & 48.1 & 2.31 \\
\hline & \{Plus... & $18-50$ & 33 & 7.1 & 235 & 5 & 4 & 129 & 397 & 241.2 & 163.3 & 7.2 & & & \\
\hline & Minus. & $18-61$ & 36 & 5.3 & 190 & 19 & 4 & 164 & 419 & 286.9 & 199.8 & 9.5 & -45.7 & 11.9 & 3.84 \\
\hline
\end{tabular}

TABLE 18.-Same-day broods. Summary of data for Line 711.

\begin{tabular}{|c|c|c|c|c|c|c|c|c|c|c|}
\hline Time period. & Strain. & 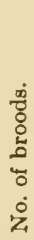 & 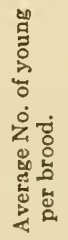 & 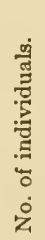 & 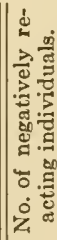 & 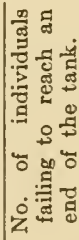 & 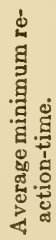 & 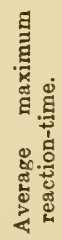 & 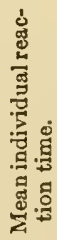 & 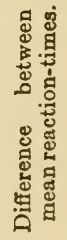 \\
\hline \multirow{2}{*}{$\begin{array}{r}\text { Mar. 26, 1912-July } 31, \\
1912 \ldots \ldots \ldots \ldots \ldots \ldots\end{array}$} & $\{$ Plus.. & 3 & 4.0 & 12 & 0 & 7 & 477 & 900 & 680 & +42 \\
\hline & Minus & $s$ & 3.7 & 11 & 1 & $\sigma$ & $\$ 53$ & 820 & 688 & \\
\hline \multirow{2}{*}{ 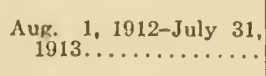 } & f Plus. . & 6 & 8.3 & 50 & 1 & 6 & 128 & 398 & 224 & \\
\hline & (Mlinus & 6 & 5.5 & ss & 6 & 0 & 192 & 948 & 281 & -7 \\
\hline
\end{tabular}


This is one of the original lines of D. pulex obtained from Pond II, the spring-fed pond in the woods, during November 1911. Selection was begun in the sixth laboratory generation and continued for 15 months, for 45 generations in the plus and 46 generations in the minus strains.

For the first 4 months of the experiment with this line the means were, for the plus strain 488.7 seconds (52 individuals) and for the minus strain 588.2 seconds (49 individuals). The difference $(-99.5 \pm 43.1$ seconds) was 2.31 times the probable error (table 17). The mean reaction-time for the plus strain for the first two-month period was 244 seconds less than that for the minus strain, but for

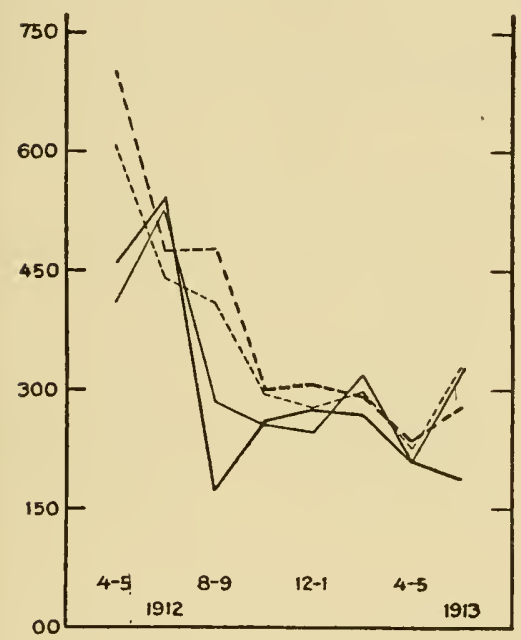

Figure 5.-Line 711.

Reaction-time curves with superimposed curves representing the combined reaction-time means for the plus and minus strains of all Daphnia pulex lines in which significant reaction-time differences did not arise. the second two-month period the minus strain had the lower reactiontime by 63 seconds (tables 15 and 16). There were 3 same-day broods, for which those of the plus strain had a higher mean reaction-time by 42 seconds (table 18). The data for this first 4 months of selection are not as satisfactory as that obtained later and wide fluctuations are less surprising.

For the remaining year (nearly) of the experiment with this line, the mean for the plus strain was 241.2 seconds (235 individuals); that for the minus strain was 286.9 seconds (190 individuals). The same-day broods, of which there were 6 , have means differing by only -7 seconds. Examination of the data (tables 15 and 16) and the curves (figure 5) for this line shows consistent differences in mean reaction-times during this year-period. The wide divergence in mean reaction-times for August-September is a chance result due to there being extremely few tested individuals during this period. But for the following 5 two-month periods the numbers of tested individuals were greater and the rather uniform courses of the curves are suggestive of a difference due to selection.

Comparison of the curves for the means of the two strains of this line with the combined mean reaction-time curves for Lines $691,695,713,714$, and 751 (in which genetic differences presumably did not arise) shows (figure 5) that the plus strain of Line 711 after the first 4 months of the experiment was somewhat more reactive than the other plus strains. The means for the minus strain in general were higher than the combined means for the other minus 
strains. Hence this comparison affords further evidence of an effect of selection in Line 711.

An effect of selection within Line 711 is not certainly established, however, in view of the lack of sufficient confirmation from the sameday-brood data. But these data were not very numerous and it is

TABLE 19.-Selection summary for Line 713.

\begin{tabular}{|c|c|c|c|c|c|c|c|c|c|c|c|c|c|c|c|}
\hline Time period. & Btrain. & 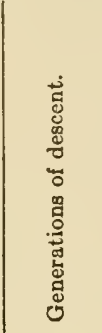 & 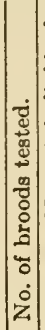 & 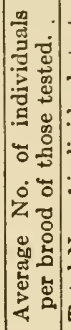 & 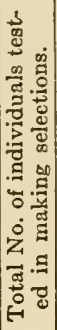 & 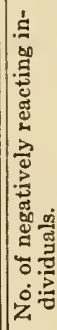 & 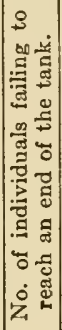 & 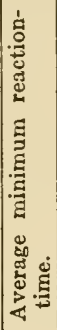 & 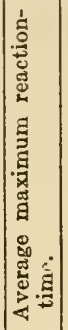 & 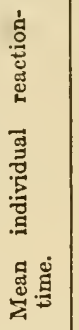 & 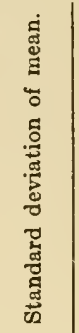 & 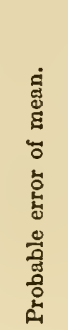 & 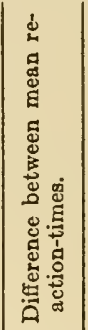 & 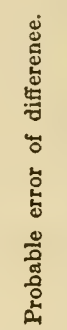 & 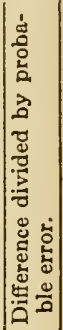 \\
\hline$A p r$ & & & 10 & & 54 & & 15 & 232 & 644 & 476.7 & 314.5 & 28.9 & 17.0 & 37.5 & 45 \\
\hline & & & 12 & & $\begin{array}{l}54 \\
61\end{array}$ & $\begin{array}{l}3 \\
2\end{array}$ & 14 & 286 & $\left|\begin{array}{l}0443 \\
743\end{array}\right|$ & 459.7 & (277.4 & 24.0 & & & 45 \\
\hline & & $19-53$ & 37 & 6.4 & 236 & 3 & 5 & 139 & 401 & 244 & 163.0 & 7.2 & & & \\
\hline $\mathrm{Ju}$ & & & 36 & 5.6 & 203 & 7 & 11 & 193 & 431 & 285.4 & 188.8 & 8.9 & 40.8 & 11.5 & $\ddot{3} . \ddot{\sigma} \dot{\sigma}$ \\
\hline Aug. $1,1913-$ & Plus.... & $\begin{array}{l}54-96 \\
55-93\end{array}$ & 42 & $\left|\begin{array}{l}9.1 \\
8.2\end{array}\right|$ & $\begin{array}{l}383 \\
32 \gamma\end{array}$ & $\begin{array}{l}28 \\
20\end{array}$ & 72 & 202 & $\mid \begin{array}{l}667 \\
792\end{array}$ & 431.3 & 287.7 & 9.9 & +27.0 & 13.9 & 1.94 \\
\hline & & & & $\mid \begin{array}{l}0.2 \\
17.9\end{array}$ & $\begin{array}{l}327 \\
268\end{array}$ & 31 & 12 & 113 & 708 & 265.9 & 217.1 & 8.9 & $\ddot{+i 8.6}$ & ii. 6 & $i . \dot{5} 8$ \\
\hline $1914 \ldots$ & & $i$ & {$\left[\begin{array}{l}10 \\
15\end{array}\right.$} & 18.2 & 273 & 32 & 6 & 120 & 629 & 247.3 & 181.6 & 7.4 & & & \\
\hline & & $76-84$ & 9 & 8.3 & 75 & 4 & 15 & 149 & 758 & 425 & & & 00 & & \\
\hline & & & 10 & 7.1 & 71 & 4 & 9 & & 722 & & & & 32.3 & & \\
\hline & & $97-1$ & 40 & 011.9 & 477 & 43 & 39 & 145 & 633 & 306.0 & 241.3 & 7.5 & -49.6 & $10 i$ & 130 \\
\hline & & $\begin{array}{r}94-1 \\
1\end{array}$ & $\begin{array}{r}46 \\
9 \\
\end{array}$ & 920.0 & $\begin{array}{l}560 \\
180\end{array}$ & $\begin{array}{l}85 \\
31\end{array}$ & $\begin{array}{l}43 \\
19\end{array}$ & $\begin{array}{r}441 \\
91\end{array}$ & $\begin{array}{l}698 \\
778 \\
\end{array}$ & $\begin{array}{l}349.6 \\
342.9\end{array}$ & 247.2 & $\begin{array}{r}6.8 \\
12.4\end{array}$ & & & \\
\hline $1915 \ldots$ & Minus.. & 1. & & & \begin{tabular}{|l|}
1000 \\
178
\end{tabular} \mid & 22 & 17 & 104 & 796 & 384.4 & 261.7 & 13.2 & $-4 i . \dot{5}$ & 18.2 & 28 \\
\hline Test & & & 32 & 239.6 & 1266 & 66 & 161 & 96 & $\left|\begin{array}{l}817 \\
86 \gamma\end{array}\right|$ & $\begin{array}{l}372.7 \\
371 . \gamma\end{array}$ & 265.2 & 5.0 & +1.0 & 6.9 & 14 \\
\hline Feb. & & $120-130$ & & 14 & $\begin{array}{r}2688 \\
157\end{array}$ & $\begin{array}{l}247 \\
19\end{array}$ & $\begin{array}{r}114 \\
17\end{array}$ & 104 & $\mid \begin{array}{l}867 \\
678\end{array}$ & $\begin{array}{l}371.7 \\
335.8\end{array}$ & & & $\ddot{+193}$ & $\ldots$ & . \\
\hline Apr. 30,1915 & Minus. & $119-130$ & 12 & 11. & 138 & 14 & 10 & 102 & 602 & 316.5 & & & & & \\
\hline
\end{tabular}

TABLE 20.-Same-day broods. Summary of data for Line $\tilde{1} 18$.

\begin{tabular}{|c|c|c|c|c|c|c|c|c|c|c|c|c|c|c|}
\hline Time period. & Strain. & 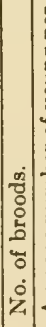 & 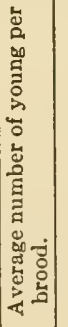 & 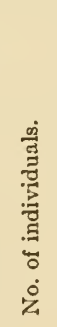 & 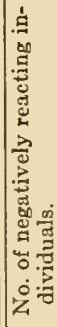 & 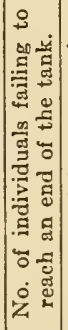 & 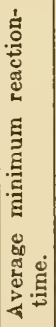 & 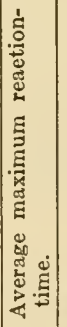 & 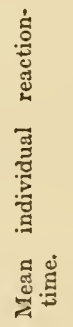 & 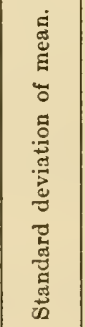 & 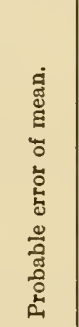 & 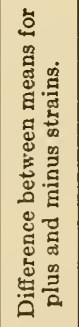 & 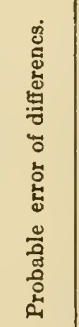 & 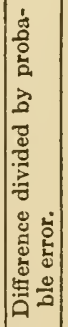 \\
\hline $\begin{array}{l}\text { Apr. } 13,1912- \\
\text { July } 31,1912 \\
\text { Augg 1, } 1912- \\
\text { July } 31,1913 \\
\text { Aug .1, } 1913- \\
\text { July } 31,1914 \\
\text { Aug } 1,1914- \\
\text { July } 7,1915\end{array}$ & $\left\{\begin{array}{l}\text { Plus... } \\
\text { Minus } \\
\text { Plus... } \\
\text { Minus } \\
\text { Plus... } \\
\text { Minus } \\
\text { Plus... } \\
\text { Minus. }\end{array}\right.$ & \begin{tabular}{r|r}
3 & \\
3 & \\
14 & \\
14 & \\
7 \\
7 \\
14 \\
14 & 1 \\
14 &
\end{tabular} & \begin{tabular}{r|}
2.7 \\
3.0 \\
7.1 \\
7.4 \\
8.9 \\
8.4 \\
13.8 \\
13.1
\end{tabular} & $\begin{array}{r}8 \\
9 \\
100 \\
103 \\
62 \\
59 \\
193 \\
184\end{array}$ & $\begin{array}{r}2 \\
0 \\
1 \\
3 \\
5 \\
5 \\
15 \\
29\end{array}$ & $\begin{array}{r}2 \\
1 \\
1 \\
9 \\
24 \\
7 \\
17 \\
12\end{array}$ & $\begin{array}{l}338 \\
325 \\
130 \\
248 \\
343 \\
184 \\
125 \\
146\end{array}$ & $\mid \begin{array}{l}403 \\
660 \\
389 \\
541 \\
829 \\
764 \\
690 \\
686\end{array}$ & $\begin{array}{l}490 \\
437 \\
234 \\
322 \\
620 \\
380 \\
305 \\
393\end{array}$ & $\begin{array}{l}154.42 \\
208.08 \\
290.23 \\
271.48\end{array}$ & $\begin{array}{l}10.42 \\
13.83 \\
24.86 \\
23.84\end{array}$ & $\begin{array}{r}-88 \\
+240 \\
\ldots \ldots\end{array}$ & $\begin{array}{l}17.31 \\
34.44\end{array}$ & $\begin{array}{l}5.08 \\
6.96\end{array}$ \\
\hline
\end{tabular}

difficult to ignore the very consistent differences between the two strains after the first 4 months of the experiment. It is to be regretted that no test series was conducted with this line.

This case is very similar to that for Line 689 , with which there was a similar difference, but in the reverse direction. 
With Line 711, as well as with most of the other lines, the courses of the curves for the two strains illustrate the marked effect of environmental influences upon reaction-time (figure 5).

LINE 713.

The data for Line 713 are shown in tables 19 and 20 and in figure 6 . Scarcely more than a glance at figure 6 is necessary to convince one that with Line 713 there was no effect of selection, though the selection data for the last year period are suggestive of a possible selective effect. Environmental influences were obviously at play in directing the general course of the curves, which follow each other in an interesting way. The curve for the plus strain is quite irregular, while that for the minus strain is surprisingly free from large minor fluctuations.

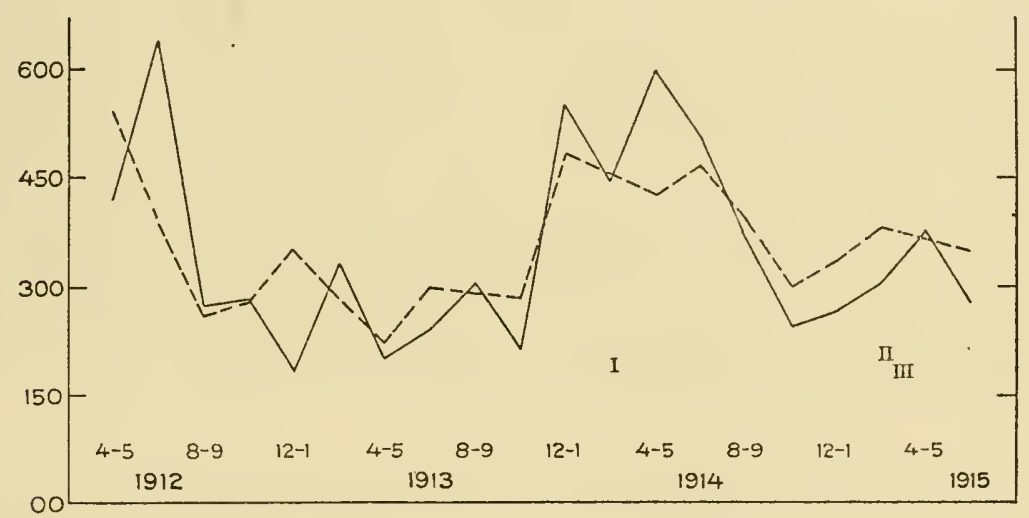

Figure 6.-Line 713. Reaction-time curves.

For the first 4 months the means for the two strains were 476.7 and 459.7 seconds (table 19). The difference is $+17.0 \pm 37.5$ seconds. There were 3 very small same-day broods for each strain, with the average for the plus strain 53 seconds the larger (table 18). The large upshoot in the curve for the plus strain for June-July is from an average obtained from a very small number of individuals.

The data for the year, August 1912-July 1913, show these means for the plus and minus strains: 244.6 and 285.4 seconds. The difference is $-40.8 \pm 11.5$ seconds, 3.55 times the probable error. The 14 same-day broods for this period have as averages 233.7 and 321.9 seconds, the minus-strain average being larger by $88 \pm 17.31$ seconds. The extremely fluctuating course of the curves for this year-period indicates that the differences obtained are not due to an effect of selection.

During the next year, August 1913-July 1914, the plus mean is higher by $27.0 \pm 13.89$ seconds. (The plus mean is 431.3 seconds and the minus mean 404.3 seconds.) The 7 same-day broods averaged 
620 and 380 seconds, the plus mean being $240 \pm 34.44$ seconds the larger. ${ }^{1}$

A small test series (268 and 273 individuals in the two strains) conducted during March 1914, gave 265.9 and 247.3 seconds as the plus and minus mean reaction-times (table 19). The difference $(+18.6 \pm 11.62$ seconds) was 1.58 times the probable error.

For the final year of the experiment with Line 713 (August 1914-July 7,1915 ) the means were 306.0 and 349.6 seconds. The difference was $-43.6 \pm 10.1$ seconds, or 4.32 times the probable error. For the 14 same-day broods the means were 305 and 333 seconds, the difference being only -28 seconds. Two test series were conducted during March of this year. The first consisted of a comparatively small number of individuals (180 and 178). The means were 342.9 and 384.4 seconds. The difference $(-41.5 \pm 18.15$ seconds) is 2.28 times the probable error and is not a significant difference. A much larger and more adequate test series was conducted after that just referred to. The numbers were 1,266 and 1,268 for the plus and minus strains, respectively. The means were 372.7 and 371.7 seconds. The difference was only $+1.0 \pm 6.88$ seconds. This test series was conducted with every care and it is believed may safely be regarded as a crucial test. It brings out clearly enough that, in spite of the small but rather consistent difference in mean reaction-times during the last year of the experiment, there is not an effect of selection in Line 713.

\section{LINE 714.}

Line 714 was one of the original lines of $D$. pulex. Selection was begun in the eighth generation and continued for more than 53 months, 184 generations in the plus strain and 196 generations in the minus strain. The data for Line 714 are given in tables 21 and 22 and in figure 7.

For the first 4 months of the experiment the mean reaction-time for the plus strain was 495.4 and for the minus strain 618.9 seconds (table 21$)$. The difference was rather large $(-123.5 \pm 32.0$ seconds, 3.86 times the probable error). There were only two small sameday broods for this period (table 22), for which the mean for the minus strain was 231 seconds the larger.

For the year-period (August 1, 1912-July 31, 1913) the mean reaction-time for the plus strain was 309.2 seconds and that for the minus strain 278.5 seconds. The difference was $+30.7 \pm 12.4$ seconds (2.48 times the probable error). This difference is in the reverse direction to that for the earlier (four-month) period. The 3 same-day broods had a mean for the plus strain $226 \pm 27.62$ seconds the larger.

${ }^{1}$ Of theso 7 same-day broods, 4 occurred during May, when the plus strain for some unaccounted-for reason was rather non-reaetive for $D$. pulex. 
For the next year-period (August 1, 1913-July 31, 1914) the means were 406.4 and 439.2 seconds. The difference $(-32.8 \pm 14.5$

TABLE 21.-Selection summary for Line 714 .

\begin{tabular}{|c|c|c|c|c|c|c|c|c|c|c|c|c|c|c|c|}
\hline Time period. & Strain. & 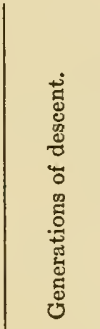 & 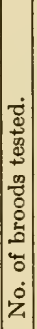 & 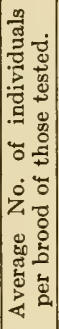 & 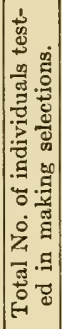 & 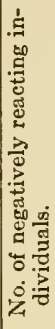 & 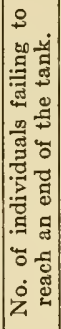 & 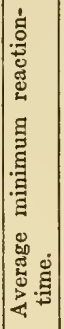 & 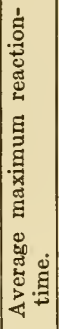 & 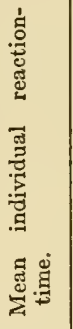 & 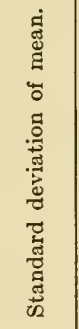 & 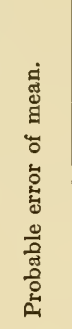 & 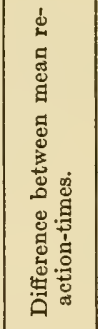 & 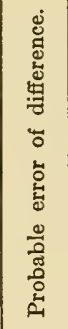 & 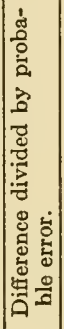 \\
\hline pr. & & & 13 & 4.6 & 55 & 4 & 12 & 257 & 695 & & & & & & \\
\hline $\mathrm{Ju}$ & & & 11 & 6.5 & $\gamma_{1}$ & 1 & 29 & 326 & 717 & 618 & 272.6 & 21.8 & -123.5 & 32.0 & 3.86 \\
\hline Aug. $1,1912-$ & Plus.... & $22-55$ & 36 & 6.1 & 220 & 10 & 9 & 164 & 440 & 309.2 & 209.8 & 9.5 & +30.7 & 12.4 & 2.48 \\
\hline y 31,1 & Min & & .35 & $6 . \hat{5}$ & 229 & 4 & 8 & 153 & 446 & 278.5 & 175.0 & 7.9 & & & \\
\hline 1,1013 & & $56-100$ & 44 & 6.9 & 311 & 31 & 39 & 197 & 658 & 406.4 & 268.4 & 10.3 & & & \\
\hline у 31,191 & $M$ & & 46 & 7.4 & 349 & 30 & 58 & 210 & 702 & 435 & 284 & 10.8 & -32.8 & 14.5 & 2.26 \\
\hline Aug. 1,1 & & $101-144$ & 41 & 9.3 & 383 & 39 & 52 & 169 & 724 & & 268 & 9. & +15.8 & 12.3 & 1.28 \\
\hline July 31,1915 & & $102-147$ & 45 & 10.3 & 465 & 79 & 47 & 170 & 697 & 362 & 259.4 & 8.1 & & & \\
\hline Test series, & Plus & 112 & 16 & 15.6 & 249 & 39 & 8 & 105 & 738 & 344 & 222.9 & 9.5 & +13.0 & 12.9 & 1.01 \\
\hline & & & 16 & 18.1 & 289 & 47 & 18 & 95 & 734 & & 218 & 8.7 & & & \\
\hline $1,1914-$ & $\mathrm{Pl}$ & $105-116$ & 12 & 10.4 & 125 & 17 & 13 & 167 & 739 & & & 15.6 & +95.2 & 18.9 & 5.03 \\
\hline v. 31,1914 & & $107-118$ & 12 & 11.5 & 138 & 25 & 2 & 107 & 609 & & 185 & 10.6 & & & \\
\hline Test & & & & 30.1 & 1055 & 244 & & 108 & 841 & & & & +18.9 & 7.72 & 2.46 \\
\hline Nov. $1914 .$. & & & 35 & 31.1 & 1089 & $27 \bar{\gamma}$ & 80 & 96 & 847 & & 243.5 & 4.98 & & & \\
\hline Oct. $1,1914-$ & Plus & $109-121$ & 13 & 11.2 & 145 & 24 & 9 & 130 & 691 & & & & & & \\
\hline & & $111-123$ & 13 & 11.9 & 155 & 36 & 0 & 97 & 596 & & & & -27.7 & & \\
\hline Test series, & S Plus.... & $\quad 129$ & 36 & 31.2 & 1123 & 242 & 195 & 96 & 804 & & 287 & & +25.3 & 8.0 & 3.16 \\
\hline $\mathrm{Mr}$ & & & 36 & 31.5 & 1133 & 193 & 181 & $9 S$ & 892 & & 275.3 & 5.52 & & $\ldots \ldots$ & \\
\hline Feb. 1,1 & & $125-13$ & 10 & 10.2 & 102 & 6 & 9 & 101 & 711 & & & & & & \\
\hline Apr. 30,19 & $M$ in & $127-138$ & 12 & 13.2 & 159 & 20 & 8 & 110 & 529 & & & & -98.8 & & \\
\hline Aug. 1,191 & & $145-185$ & 37 & 11.5 & 427 & 36 & 41 & 107 & 662 & & 250.6 & 8.2 & & & \\
\hline & & & 39 & 11.1 & 434 & 85 & 35 & 108 & 728 & & 222.1 & 7.2 & -2.4 & 10.9 & \\
\hline Aug. 1,1916- & \{ Plus.... & $186-194$ & 7 & 9.4 & 66 & 3 & 16 & 146 & 762 & & 227.1 & 18.9 & +63.8 & 32.4 & 1.97 \\
\hline Sept.16, 1916 & Minus .. & $196-202$ & 7 & 7.6 & & 3 & 8 & 87 & 562 & 329.7 & 284.4 & 26.4 & & & \\
\hline
\end{tabular}

TABLE 22.-Same-day broods. Summary of data for Line 714.

\begin{tabular}{|c|c|c|c|c|c|c|c|c|c|c|c|c|c|c|}
\hline Time period. & Strain. & $\begin{array}{l}0 \\
8 \\
0 \\
0 \\
\vdots \\
4 \\
0 \\
0 \\
z\end{array}$ & 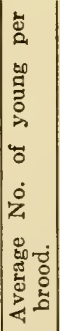 & 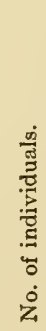 & 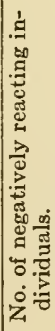 & 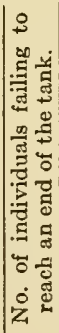 & 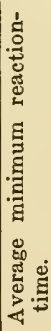 & 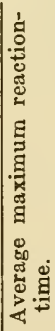 & 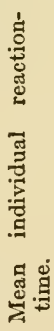 & 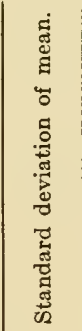 & 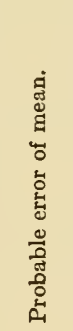 & 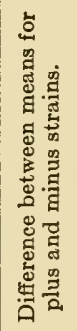 & 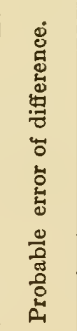 & 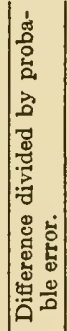 \\
\hline & & 2 & 2.5 & 5 & 0 & 1 & 190 & 528 & 438 & 261.04 & 78. & & & \\
\hline & & 2 & 6.5 & 18 & 1 & $\frac{1}{7}$ & 290 & 790 & 669 & 274.24 & & -231 & $\ddot{9} .98$ & $8 \mid 2.45$ \\
\hline Aug. $1,1912-$ & Plu & $\tilde{3}$ & 6.0 & 18 & 1 & 4 & 340 & 66 & 429 & 289.06 & & +226 & 27.62 & 8.1 \\
\hline July 31,1913 & Minus... & 3 & 2.7 & 8 & 0 & 0 & 135 & 228 & 203 & 91.12 & 21.73 & & $\ldots \ldots$ & \\
\hline Aug. 1,1 & ( Plus.... & 6 & 5.3 & 32 & 3 & 4 & & 60 & & & & & & \\
\hline July 31,1914 & Minus.. & 6 & 5.8 & & 0 & $\overline{6}$ & 289 & 675 & & 269.48 & & -105 & 42.82 & 2.45 \\
\hline Aug. $1,1914-$ & Plus.... & 13 & 9.9 & 129 & 19 & 5 & 117 & 657 & 292 & 203.96 & 12.12 & & & \\
\hline & & 13 & 12.7 & 165 & 29 & 26 & & 700 & & 289.43 & 15.20 & -114 & 19.44 & 5.86 \\
\hline Aug. $1,1915-$ & Plus.... & 5 & 11.6 & 58 & 11 & 5 & 113 & 720 & 342 & $\ldots \ldots$ & $\ldots \ldots$ & & $\cdots \cdots$ & $\cdots$ \\
\hline $\begin{array}{r}\text { July } 31,1 \\
\text { Aug. } 1,19\end{array}$ & & $\begin{array}{l}5 \\
6\end{array}$ & $\begin{array}{l}9.4 \\
8.5\end{array}$ & $\begin{array}{l}47 \\
51\end{array}$ & $\begin{array}{l}6 \\
3\end{array}$ & $\begin{array}{r}3 \\
12\end{array}$ & $\begin{array}{l}111 \\
155\end{array}$ & $\begin{array}{l}722 \\
739\end{array}$ & $\begin{array}{l}3.9 \\
40\end{array}$ & & & & & \\
\hline Sept.16, 1916 & Minus... & 6 & 8.0 & 48 & 3 & & 88 & 627 & 951 & & & & & \\
\hline
\end{tabular}

seconds) is 2.26 times the probable error. There were 6 rather small same-day broods, for which the mean for the minus strain was $105 \pm 42.82$ seconds the larger. Again, as compared with the pre- 
ceding long period, there is a reversal in this longer period of the direction of the difference in the mean reaction-times for the entire data and in that for the same-day broods.

For the next year-period (August 1, 1914-July 31, 1915), the means were 378.1 and 362.3 seconds. The difference, which was $+15.8 \pm 12.3$ seconds, is not statistically significant and is again in the reverse direction from that for the preceding period. During this year-period the same-day-brood data consisted of 13 broods and

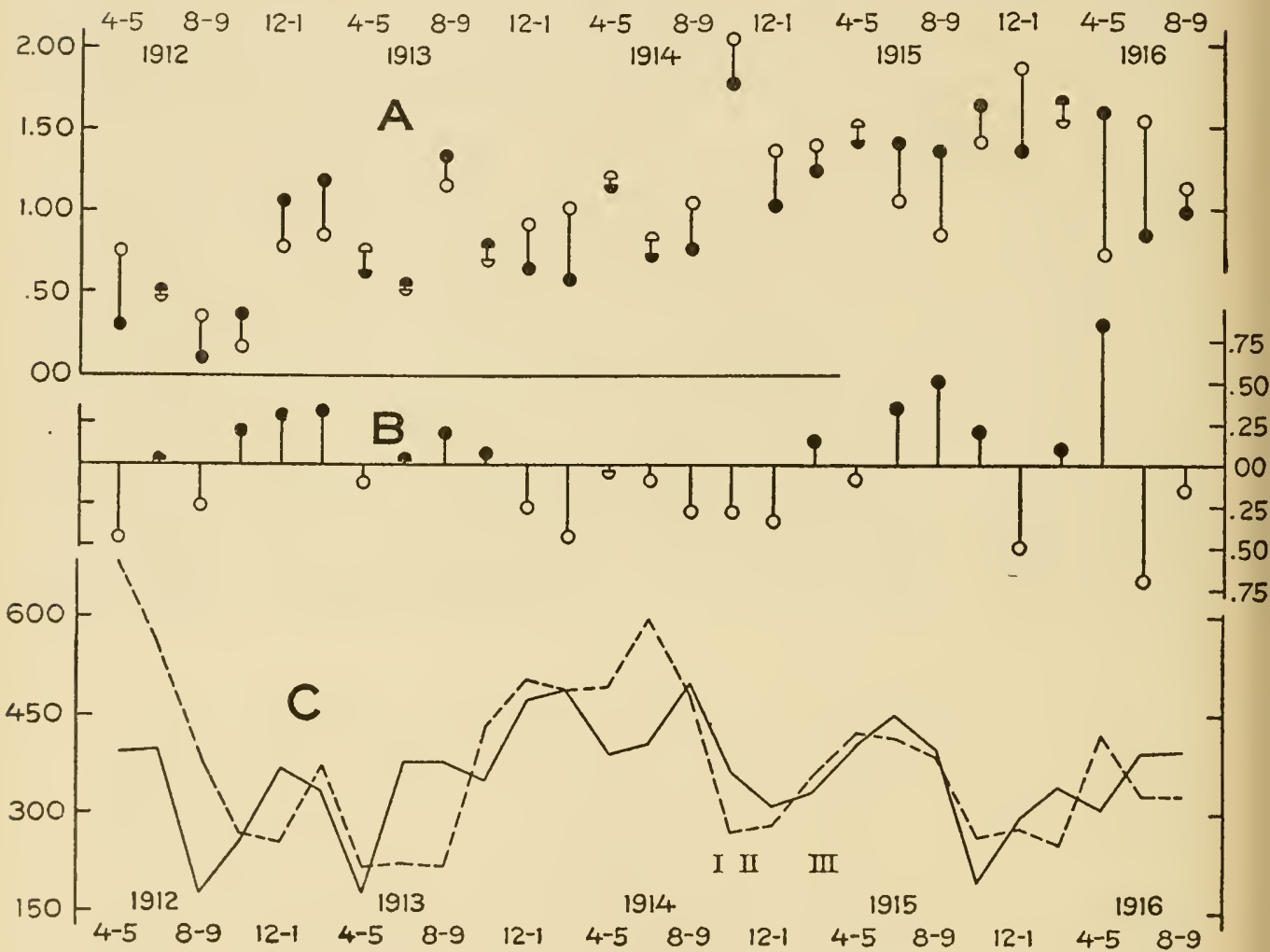

Frgure 7.-Line 714.

A. Reproductive indices, actual values.

B. Reproductive indices, superiority.

C. Reaction-time curves.

the mean for the minus strain was $114 \pm 19.44$ seconds higher than that for the plus strain. This is a difference almost 6 times the statistical probable error. ${ }^{1}$

A test series conducted during October 1914, containing 249 individuals in the plus strain and 289 in the minus strain, gave

I These same-day broods are pretty well seattered through the year period, except that none occurred during the last 4 months. The averages obtained for the same-day broods are more dependable than the averages for the data as a wholo when there are sufficient numbers, and 129 and 165 individuals constitute fairly good numbers. It is unusual that the reaction-time means for the complete data and for the same-day-brood data for the same period should differ so widely as in the present case. 
means of 344.8 seconds for the plus strain and 331.8 seconds for the minus strain. The difference, $+13.0 \pm 12.9$ seconds, is not of statistical significance. A second test series conducted in November 1914 contained 1,055 individuals in the plus strain and 1,089 in the minus strain. The difference in the mean reaction-time was $+18.9 \pm 7.72$ seconds, 2.46 times the probable error. A third test series was conducted during March 1915. The numbers were large, 1,123 and 1,133 individuals in the two strains. The mean reaction-times were 421.9 and 396.6 seconds. The difference was $+25.3 \pm 8.0$ seconds and is 3.16 times the probable error.

It will be seen that there is a rather striking similarity in the differences obtained for the 3 test series and for the entire selection data for this year-period, the differences being $+13.0,+18.9$, and +25.3 for the 3 test series and +15.8 seconds for the selection data as a whole. Such harmonious results seem to indicate that the plus strain of Line 714, during this year-period, was actually less reactive in spite of selection, although the same-day-brood data oppose this conclusion.

For the next year-period of selection with Line 714 (August 1, 1915-July 31,1916$)$ the means were 301.1 and 303.5 seconds. The difference was $-2.4 \pm 10.9$ seconds. There remains a short period of $1 \frac{1}{2}$ months during which selection was continued. There were only 66 individuals in the plus and 53 individuals in the minus strain. The difference $(+63.8 \pm 32.4)$ is not statistically significant.

Considering the data for Line 714 as a whole, it is clear that there is not an effect of selection.

Figure $7 \mathrm{c}$, showing the reaction-time curves for the two strains of Line 714, presents curves with large minor irregularities. It will be noted that throughout the first 6 months of selection with Line 714 there is a considerable divergence, the minus strain having much the higher reaction-time. Such consistencies in reaction-time differences for limited periods also occur in Line 695 for a period of 8 months and in Line 740 for a period of 10 months. It would seem that these are more than mere chance results, but in each of these 3 cases further selection not only did not result in increasing the divergence, but. in all 3 of these cases the divergence disappeared. Assuming for the moment that an effect of selection was present in these cases, it was later lost; but in what manner this loss could have occurred is not clear. Selections were not relaxed, and there seems to be no reason to suppose that a mutation had affected one of the strains in each of these 3 lines.

However suggestive of an effect of selection the early portion of the curves for Line 714 are, it is clear from the remainder of the curves that a selective effect is not present (figure $7 \mathrm{c}$ ). The detailed analysis of the data has already shown this. 
The minus strain of Line 714 was on the whole slightly more vigorous than the plus strain. ${ }^{1}$ The plus strain was superior in vigor during 13 two-month periods; the minus strain more vigorous during 14 two-month periods. The differences in favor of the minus strain were somewhat greater than those in favor of the plus strain.

There is no apparent relation between vigor and reaction-time. Casual inspection of the reaction curves and the reproductive index figure (figure 7) gives this impression, and the following facts bear it out: During 11 periods the temporarily more vigorous strain was the more reactive, during 15 periods the more vigorous strain was the less reactive, and during 1 period the reaction-times were the same. Selecting the 9 periods during which the mean reproductive indices differed by more than 0.30 , it is found that in 5 periods the more vigorous strain is the less reactive, in 3 periods the more vigorous strain is the more reactive, and for 1 period the mean reaction-times were the same. Selecting the 9 two-month periods during which the reaction-time means differed by more than 100 seconds, it is found that in 2 cases these large differences in the mean reaction-time correspond with periods in which the more reactive strain was also the more vigorous, but that in 7 cases the more reactive strain was the less vigorous of the two.

There is an interesting feature of the curves (figure $7 \mathrm{c}$ ) in the marked influence of environment upon the mean reaction-time of the two strains. In spite of considerable irregularities of the curves for the two strains, they follow each other to a remarkable extent. Nothing other than environmental influences would seem to account for such a coincidence.

\section{LINE 719.}

The data for Line 719 will be found in tables 23, 24, 25, and 26 and in figure 8. This is one of the original lines of Daphnia pulex taken into the laboratory in November 1911. Selection was begun (March 28, 1912) in the eighth laboratory generation and continued for 130 and 138 generations, until both strains were lost in June 1915.

Consultation of the curves (figure $\mathrm{Sc}$ ) shows that there is no effect of selection; some interesting features of this data, however, will be brought out by a somewhat detailed analysis.

For the first 4 months the mean reaction-times for the plus and minus strains were 450.1 and 493.1 seconds. The difference is $-43 \pm 31.8$ seconds (table 25 ). For the same-day broods (only 3 ) the corresponding data are 718 and 539 seconds, the difference being $+179 \pm 76.00$ seconds.

'The average reproductive index (obtained by dividing the sum of the reproductive indices by two-month periods by the number of two-month periods) for the plus strain was 1.006 , for the minus strain 1.034 . 
$\mathrm{T}_{\mathrm{ABLE}}$ 23.-Selection data summarized by two-month periods for Line 119 plus.

\begin{tabular}{|c|c|c|c|c|c|c|c|c|c|c|c|c|c|c|}
\hline Time period. & 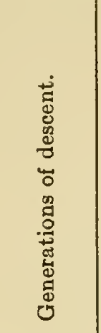 & $\mid \begin{array}{c}0 \\
0 \\
0 \\
0 \\
0 \\
0 \\
0 \\
0 \\
\dot{0} \\
z\end{array}$ & 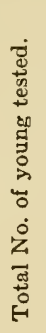 & 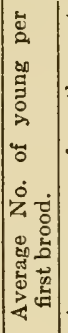 & 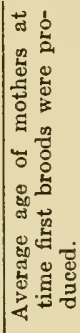 & 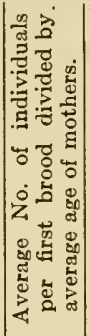 & 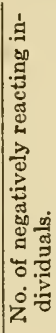 & 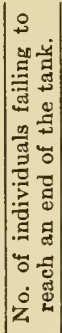 & 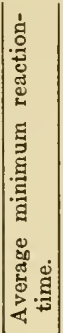 & 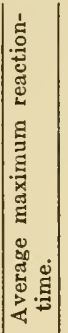 & 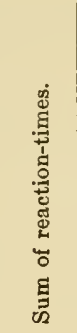 & 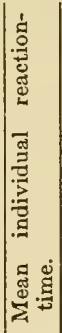 & 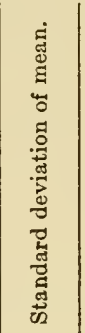 & 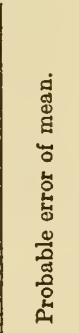 \\
\hline $\begin{array}{l}\text { Apr.-May } 1912 \ldots \\
\text { June-July } 1912 \ldots\end{array}$ & $\begin{array}{r}9-13 \\
14-19\end{array}$ & $\begin{array}{l}8 \\
6\end{array}$ & $\begin{array}{l}27 \\
51\end{array}$ & $\begin{array}{l}6.8 \\
6.8\end{array}$ & $\begin{array}{r}9.6 \\
11.4\end{array}$ & $\begin{array}{r}0.71 \\
.60\end{array}$ & $\begin{array}{l}0 \\
4\end{array}$ & $\begin{array}{r}16 \\
3\end{array}$ & $\begin{array}{l}214 \\
240\end{array}$ & $\begin{array}{l}534 \\
635\end{array}$ & $\begin{array}{l}15738 \\
19370\end{array}$ & $\begin{array}{r}583 \\
380\end{array}$ & & \\
\hline $\begin{array}{l}\text { Aug.-Sept. } 1912 \ldots \\
\text { Oct.-Nov. } 1912 . . \\
\text { Dec.1912-Jau. } 1913 \\
\text { Feb.-Mar. } 1913 \ldots \\
\text { Apr.-May } 1913 \ldots \\
\text { June-July } 1913 \ldots\end{array}$ & $\begin{array}{l}20-21 \\
21-24 \\
25-31 \\
32-38 \\
39-45 \\
46-54\end{array}$ & $\begin{array}{l}2 \\
4 \\
7 \\
7 \\
7 \\
9\end{array}$ & $\begin{array}{r}3 \\
16 \\
67 \\
51 \\
47 \\
57\end{array}$ & \begin{tabular}{r|}
1.5 \\
2.3 \\
10.2 \\
7.3 \\
6.7 \\
6.0
\end{tabular} & $\begin{array}{r}11.5 \\
12.8 \\
9.1 \\
8.5 \\
8.3 \\
7.2\end{array}$ & $\begin{array}{r}.13 \\
.18 \\
1.12 \\
.86 \\
.81 \\
.83\end{array}$ & $\begin{array}{l}0 \\
0 \\
2 \\
1 \\
1 \\
2\end{array}$ & $\begin{array}{r}0 \\
0 \\
6 \\
5 \\
0 \\
12\end{array}$ & \begin{tabular}{l|}
288 \\
220 \\
115 \\
147 \\
111 \\
173
\end{tabular} & $\begin{array}{l}295 \\
448 \\
476 \\
437 \\
316 \\
595\end{array}$ & $\begin{array}{r}825 \\
4138 \\
18737 \\
16685 \\
9910 \\
22603\end{array}$ & $\begin{array}{l}275 \\
259 \\
280 \\
327 \\
21 \\
397\end{array}$ & $\left|\begin{array}{ll}\cdots \cdots \\
224.17\end{array}\right|$ & $\ddot{2 i} i \bar{i}$ \\
\hline $\begin{array}{l}\text { Aug.-Sept. 1913... } \\
\text { Oct.-Nov. 1913. } \\
\text { Dec.1913- Jan.19i4 } \\
\text { Feb.-Mar. 1914... } \\
\text { Apr.-May } 1914 \ldots \\
\text { June-July } 1914 . . .\end{array}$ & $\begin{array}{l}55-62 \\
63-68 \\
69-75 \\
76-81 \\
82-90 \\
91-96\end{array}$ & $\begin{array}{l}8 \\
5 \\
7 \\
6 \\
9\end{array}$ & $\begin{array}{l}86 \\
37 \\
48 \\
32 \\
81 \\
31\end{array}$ & $\begin{array}{l}9.2 \\
6.3 \\
6.2 \\
5.6 \\
8.5 \\
4.6\end{array}$ & $\begin{array}{l}6.3 \\
7.5 \\
8.4 \\
8.8 \\
7.1 \\
7.2\end{array}$ & $\begin{array}{r}1.46 \\
.84 \\
.74 \\
1.64 \\
1.20 \\
.64\end{array}$ & $\begin{array}{r}9 \\
2 \\
1 \\
1 \\
13 \\
13 \\
6\end{array}$ & $\begin{array}{r}7 \\
0 \\
9 \\
3 \\
11 \\
9\end{array}$ & $\begin{array}{l}105 \\
141 \\
319 \\
233 \\
186 \\
326\end{array}$ & $\begin{array}{l}539 \\
394 \\
725 \\
626 \\
801 \\
814\end{array}$ & $\begin{array}{r}31176 \\
9044 \\
22299 \\
14002 \\
34335 \\
18139\end{array}$ & $\begin{array}{l}363 \\
244 \\
465 \\
438 \\
424 \\
585\end{array}$ & $\mid \begin{array}{l}251.87 \\
258.36\end{array}$ & 25 is \\
\hline $\begin{array}{l}\text { Aug.-Sept. } 1914 \ldots \\
\text { Oct.-Nov. } 1914 \ldots \\
\text { Dec.1914-Jan.1915 } \\
\text { Feb.-Mar. } 1915, \ldots \\
\text { Apr.-May-June ;i5 }\end{array}$ & $\begin{array}{r}97-104 \\
105-113 \\
114-121 \\
122-127 \\
128-137\end{array}$ & $\begin{array}{r}8 \\
9 \\
8 \\
5 \\
10\end{array}$ & $\begin{array}{r}73 \\
108 \\
65 \\
59 \\
79\end{array}$ & \begin{tabular}{r|}
9.6 \\
12.2 \\
8.1 \\
12.5 \\
8.4
\end{tabular} & $\begin{array}{l}7.1 \\
7.4 \\
7.9 \\
9.1 \\
8.2\end{array}$ & $\begin{array}{l}1.35 \\
1.65 \\
1.03 \\
1.37 \\
1.02\end{array}$ & $\begin{array}{r}11 \\
24 \\
3 \\
9 \\
6\end{array}$ & $\begin{array}{r}13 \\
2 \\
9 \\
7 \\
18\end{array}$ & \begin{tabular}{r|}
165 \\
87 \\
119 \\
137 \\
315
\end{tabular} & $\begin{array}{l}834 \\
517 \\
698 \\
623 \\
768\end{array}$ & $\begin{array}{l}33103 \\
28021 \\
24354 \\
20971 \\
33398\end{array}$ & \begin{tabular}{|l|}
453 \\
259 \\
375 \\
355 \\
423
\end{tabular} & $\mid \begin{array}{c}\ldots \ldots \\
\cdots \cdots \\
297.34 \\
29 \\
\end{array}$ & $\begin{array}{l}\cdots \ldots \\
22.57\end{array}$ \\
\hline
\end{tabular}

TABLE 24.-Selection data summarized by two-month periods for Line 719 minus.

\begin{tabular}{|c|c|c|c|c|c|c|c|c|c|c|c|c|c|c|c|c|}
\hline Time period. & 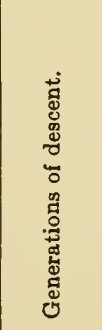 & 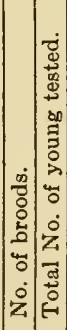 & 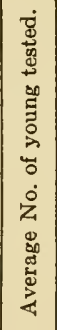 & 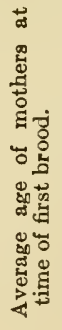 & 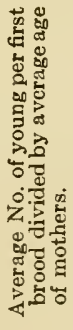 & 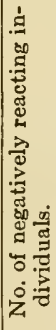 & 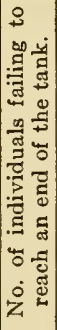 & 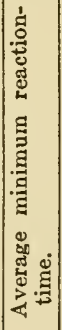 & 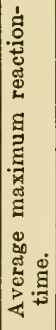 & 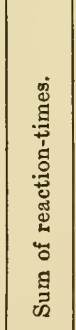 & 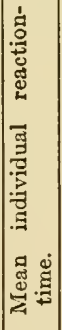 & 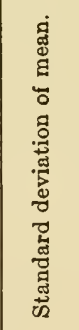 & 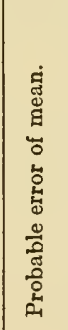 & 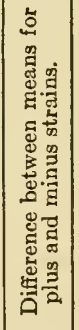 & 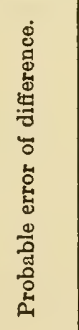 & 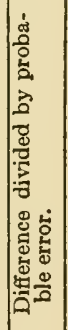 \\
\hline $\begin{array}{l}\text { Apr.-May } 1912 \ldots \\
\text { June-July } 1912 \ldots\end{array}$ & $\begin{array}{r}9-14 \\
15-21\end{array}$ & \begin{tabular}{l|l|}
7 & 37 \\
8 & 39
\end{tabular} & \begin{tabular}{|l|}
6.2 \\
5.6
\end{tabular} & $\begin{array}{l}9.1 \\
8.5\end{array}$ & $\begin{array}{r}0.68 \\
.66\end{array}$ & $\begin{array}{l}0 \\
0\end{array}$ & $\begin{array}{r}14 \\
7\end{array}$ & $\begin{array}{l}292 \\
210\end{array}$ & \begin{tabular}{|l|}
896 \\
719
\end{tabular} & $\left|\begin{array}{l}21155 \\
16320\end{array}\right|$ & $\begin{array}{l}572 \\
418\end{array}$ & & & $\begin{array}{l}+11 \\
-38\end{array}$ & & \\
\hline $\begin{array}{l}\text { Aug.-Sept. } 1912 \ldots \\
\text { Oct.-Nov. } 1912 \ldots \\
\text { Dec. 1912-Jan. } 1913 \\
\text { Feb.-Mar. 1913... } \\
\text { Apr.-May } 1913 \ldots \\
\text { June-July } 1913 \ldots\end{array}$ & $\begin{array}{l}22-24 \\
25-28 \\
29-36 \\
37-42 \\
43-50 \\
51-58\end{array}$ & \begin{tabular}{|r|r|}
3 & 4 \\
6 & 15 \\
8 & 55 \\
6 & 35 \\
8 & 60 \\
10 & 41
\end{tabular} & \begin{tabular}{|l|}
1.3 \\
1.5 \\
6.9 \\
5.8 \\
7.5 \\
4.6
\end{tabular} & $\begin{array}{r}17.5 \\
19.5 \\
8.4 \\
9.0 \\
7.4 \\
7.2\end{array}$ & $\begin{array}{r}.07 \\
.08 \\
.82 \\
.64 \\
1.00 \\
.64\end{array}$ & $\begin{array}{l}0 \\
0 \\
0 \\
0 \\
6 \\
4\end{array}$ & $\begin{array}{l}0 \\
0 \\
0 \\
0 \\
0 \\
1\end{array}$ & \begin{tabular}{r|}
200 \\
184 \\
93 \\
126 \\
124 \\
255
\end{tabular} & \begin{tabular}{|l|}
251 \\
239 \\
333 \\
353 \\
423 \\
492
\end{tabular} & $\begin{array}{r}854 \\
3809 \\
12566 \\
7938 \\
15220 \\
13543\end{array}$ & \begin{tabular}{|l|}
214 \\
254 \\
228 \\
227 \\
254 \\
330
\end{tabular} & $\begin{array}{l}\ldots \ldots \\
\ldots \ldots \\
i 13.26 \\
\ldots \ldots \\
\ldots \ldots\end{array}$ & $\begin{array}{l}12.91 \\
\ldots \ldots\end{array}$ & $\mid \begin{array}{r}+61 \\
+5 \\
+52 \\
+100 \\
-43 \\
+67\end{array}$ & 24 . & $\ddot{4} \ddot{0}$ \\
\hline 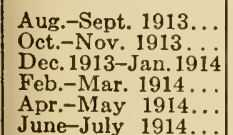 & $\begin{array}{l}59-67 \\
68-74 \\
75-81 \\
82-89 \\
90-97 \\
98-105\end{array}$ & \begin{tabular}{l|l}
9 & 74 \\
7 & 56 \\
7 & 58 \\
7 & 40 \\
8 & 84 \\
8 & 63
\end{tabular} & \begin{tabular}{|l|}
8.2 \\
8.0 \\
8.3 \\
5.7 \\
5.7 \\
7.8
\end{tabular} & $\begin{array}{l}7.0 \\
8.1 \\
8.3 \\
9.0 \\
6.9 \\
7.8\end{array}$ & $\begin{array}{r}1.17 \\
.99 \\
1.00 \\
.63 \\
.83 \\
1.00\end{array}$ & $\begin{array}{r}8 \\
0 \\
4 \\
2 \\
4 \\
10\end{array}$ & $\begin{array}{r}4 \\
3 \\
5 \\
2 \\
22 \\
9\end{array}$ & \begin{tabular}{l|}
101 \\
149 \\
179 \\
255 \\
229 \\
210
\end{tabular} & \begin{tabular}{|l|}
634 \\
403 \\
701 \\
722 \\
837 \\
791
\end{tabular} & $\left|\begin{array}{l}18502 \\
14036 \\
21682 \\
16870 \\
36841 \\
29417\end{array}\right|$ & \begin{tabular}{|l|}
250 \\
251 \\
374 \\
422 \\
439 \\
467
\end{tabular} & $\begin{array}{l}196.73 \\
207.78 \\
\cdots \ldots . . \\
2 \dot{2} 1.18\end{array}$ & 18.40 & $\begin{array}{r}+113 \\
-7 \\
+91 \\
+16 \\
-115 \\
+118\end{array}$ & 23.94 & $\begin{array}{l}2.91 \\
\cdots \\
3.24\end{array}$ \\
\hline $\begin{array}{l}\text { Aug.-Sept. 1914... } \\
\text { Oct.-Nov. 1914... } \\
\text { Dec.1914-Jan. } 1915 \\
\text { Feb.-Mar. 1915. } \\
\text { Apr.,May,Jube,19i5 }\end{array}$ & $\begin{array}{l}106-112 \\
113-120 \\
121-128 \\
129-135 \\
136-145\end{array}$ & \begin{tabular}{l|l|}
7 & 50 \\
8 & 83 \\
8 & 87 \\
7 & 70 \\
9 & 65
\end{tabular} & $\begin{array}{r}6.6 \\
9.5 \\
10.9 \\
9.5 \\
8.1\end{array}$ & $\begin{array}{l}7.3 \\
7.4 \\
7.8 \\
8.5 \\
7.8\end{array}$ & $\begin{array}{l}.90 \\
1.28 \\
1.39 \\
1.12 \\
1.04\end{array}$ & $\begin{array}{r}15 \\
20 \\
9 \\
8 \\
19\end{array}$ & $\begin{array}{l}6 \\
5 \\
5 \\
7 \\
6\end{array}$ & \begin{tabular}{l|}
206 \\
183 \\
168 \\
116 \\
147
\end{tabular} & $\begin{array}{l}769 \\
646 \\
697 \\
639 \\
606\end{array}$ & $\left|\begin{array}{l}20071 \\
22045 \\
31633 \\
26135 \\
22580\end{array}\right|$ & \begin{tabular}{|l|}
401 \\
266 \\
364 \\
373 \\
347
\end{tabular} & & & $\begin{array}{r}+52 \\
-7 \\
+11 \\
-18 \\
+76\end{array}$ & & 2.43 \\
\hline
\end{tabular}


During the year (August 1912-July 1913) the means were 302.5 and 256.3 seconds. The difference $(+46.2 \pm 12.1$ seconds) is 3.81 times the probable error, a difference statistically significant. For the 12 same-day broods the means are 314 and 254 secondsand the difference is $+60 \pm 21.68$ seconds, 2.76 times the probable error.

TABLE 25.-Selection summary for Line 719.

\begin{tabular}{|c|c|c|c|c|c|c|c|c|c|c|c|c|c|c|c|}
\hline Time period. & Strain. & 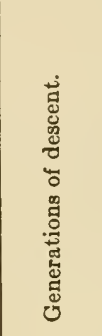 & 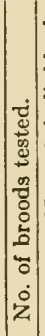 & 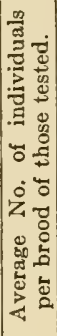 & 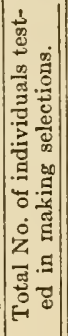 & 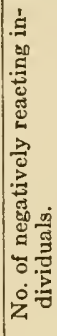 & 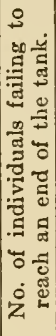 & 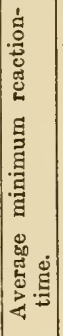 & 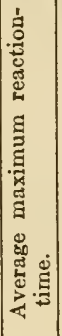 & 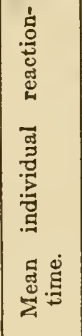 & 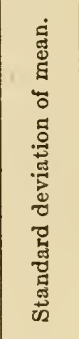 & 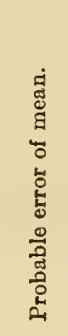 & 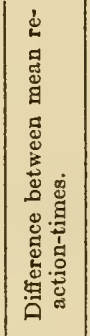 & 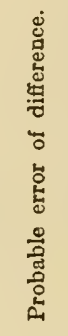 & 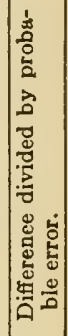 \\
\hline & & $9-19$ & & 5.6 & 78 & 4 & & 225 & 577 & 50.1 & & & & & \\
\hline & & & 15 & 5.1 & 76 & 0 & 21 & 251 & 808 & 493.1 & 308 & & -48 & 91.8 & 1.85 \\
\hline Aug & Ply & $20-54$ & 36 & 6.7 & 241 & 6 & 23 & 156 & 454 & 302 & 232 & 10.1 & +46.2 & 12.1 & 3.81 \\
\hline & & $22-58$ & $\mid 41$ & 5.1 & 210 & 10 & 11 & 164 & $\begin{array}{l}372 \\
664 \\
\end{array}$ & $\begin{array}{l}256.3 \\
4096\end{array}$ & 142.9 & $\begin{array}{l}6.6 \\
0.8\end{array}$ & +33 & 132 & \\
\hline $\begin{array}{l}\text { A ug. } \\
\text { July }\end{array}$ & Plus. & $\begin{array}{l}55-96 \\
59-105\end{array}$ & $\begin{array}{r}41 \\
46\end{array} \mid$ & $\begin{array}{l}7.7 \\
8.2\end{array}$ & $\mid \begin{array}{l}315 \\
375\end{array}$ & $\begin{array}{l}31 \\
28\end{array}$ & $\begin{array}{l}39 \\
45\end{array}$ & $\begin{array}{l}215 \\
185\end{array}$ & $\begin{array}{l}664 \\
685\end{array}$ & $\begin{array}{l}409.6 \\
366.3\end{array}$ & 257.6 & $\begin{array}{l}9.8 \\
8.9\end{array}$ & +43.3 & 13.2 & 3.28 \\
\hline Beries, & & 89 & 23 & 13.9 & 320 & 96 & 82 & 156 & 879 & 520.8 & 289.2 & 10.9 & +57.2 & 14.9 & 3.83 \\
\hline M & & $\begin{array}{r}96 \\
96\end{array}$ & $\left|\begin{array}{c}23 \\
10\end{array}\right|$ & 14.4 & $\left|\begin{array}{r}331 \\
98\end{array}\right|$ & 121 & 60 & $\begin{array}{l}154 \\
294 \\
204\end{array}$ & $\begin{array}{r}808 \\
806\end{array}$ & & 271 & & +192 & & \\
\hline Apr. & $\begin{array}{l}\text { Plus } \\
\text { Min }\end{array}$ & $\begin{array}{l}82-93 \\
90-101\end{array}$ & $\left|\begin{array}{l}12 \\
12\end{array}\right|$ & $\begin{array}{l}8.2 \\
9.0\end{array}$ & $\begin{array}{r}98 \\
108\end{array}$ & $\begin{array}{r}15 \\
5\end{array}$ & 29 & & $\begin{array}{l}826 \\
794\end{array}$ & $\begin{array}{l}453.7 \\
434.5\end{array}$ & & & +19.2 & & \\
\hline & & $97-137$ & 40 & 9.6 & 384 & 53 & 49 & 172 & 693 & 364.2 & 264.9 & 9.1 & +19.2 & 12.5 & 1.53 \\
\hline & & $106-14$ & 39 & 9.1 & 355 & 71 & 29 & 164 & 668 & & & & & & \\
\hline Test se & & 11 & $\begin{array}{l}43 \\
9.9\end{array}$ & 22.8 & $\mid \begin{array}{r}979 \\
1019\end{array}$ & 189 & $\begin{array}{l}46 \\
35\end{array}$ & \begin{tabular}{r|r}
95 \\
103
\end{tabular} & $\mid \begin{array}{l}688 \\
697 \\
\end{array}$ & $\begin{array}{l}310.9 \\
290.6\end{array}$ & $\begin{array}{l}217.2 \\
197.0\end{array}$ & 4.7 & +20.3 & 6.3 & 3.22 \\
\hline & & $105-117$ & $\begin{array}{l}40 \\
13\end{array}$ & 9.9 & 129 & 27 & 3 & 93 & 511 & & & & & & \\
\hline & & & & 117 & 138 & 26 & 6 & 161 & 644 & & & & -27.0 & & \\
\hline
\end{tabular}

TABLE 26.-Same-day broods. Summary of data for Line $\approx 19$.

\begin{tabular}{|c|c|c|c|c|c|c|c|c|c|c|c|c|c|c|}
\hline Time period. & Strain. & 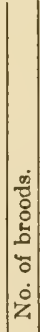 & 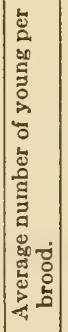 & 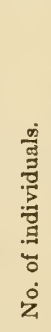 & 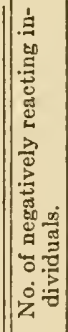 & 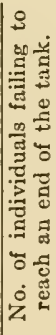 & 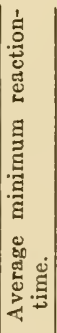 & 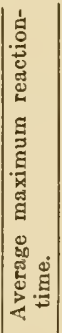 & 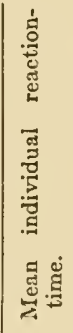 & 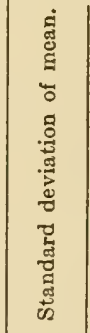 & 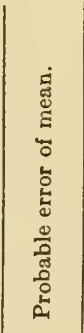 & 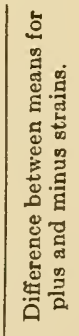 & 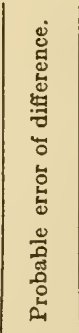 & 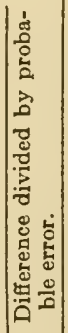 \\
\hline $\begin{array}{l}\text { Apr. 8, 1912- } \\
\text { July 31, 1912 } \\
\text { Aug. 1, 1912- } \\
\text { July 31, 1913 } \\
\text { Aug. 1, 1913- } \\
\text { July 31, 1914 } \\
\text { Aug. 1, 1914- } \\
\text { June 25, 1915 }\end{array}$ & $\begin{array}{l}\text { Plus.. } \\
\text { Minus } \\
\text { Plus. } \\
\text { Minus } \\
\text { Plus.. } \\
\text { Minus } \\
\text { Plus. } \\
\text { Minus }\end{array}$ & $\begin{array}{r}3 \\
S \\
12 \\
12 \\
11 \\
11 \\
10 \\
11\end{array}$ & $\begin{array}{r}3.3 \\
5.7 \\
7.3 \\
6.9 \\
7.9 \\
8.0 \\
11.3 \\
7.8\end{array}$ & $\begin{array}{r}10 \\
17 \\
88 \\
89 \\
87 \\
88 \\
113 \\
78\end{array}$ & $\begin{array}{r}0 \\
0 \\
2 \\
3 \\
8 \\
9 \\
14 \\
12\end{array}$ & $\begin{array}{r}5 \\
6 \\
12 \\
1 \\
4 \\
10 \\
11 \\
7\end{array}$ & $\begin{array}{l}557 \\
228 \\
141 \\
131 \\
174 \\
204 \\
114 \\
252\end{array}$ & $\begin{array}{l}703 \\
892 \\
465 \\
451 \\
624 \\
665 \\
741 \\
731\end{array}$ & $\begin{array}{l}718 \\
589 \\
314 \\
254 \\
340 \\
39 \% \\
351 \\
3 \% 8\end{array}$ & $\begin{array}{l}257.80 \\
320.75 \\
262.11 \\
144.66 \\
207.54 \\
249.62\end{array}$ & \begin{tabular}{|l|}
54.99 \\
52.47 \\
18.85 \\
10.71 \\
15.01 \\
17.95
\end{tabular} & $\begin{array}{l}+179 \\
\cdots 60 \\
+60 \\
\cdots \\
-54 \\
\cdots \\
-27\end{array}$ & $\begin{array}{r}76.00 \\
21.68\end{array}$ & $\mid \begin{array}{l}2.35 \\
2.76\end{array}$ \\
\hline
\end{tabular}

For the following year (August 1913-July 1914) the means are 409.6 and 366.3 scconds. The difference is $+43.3 \pm 13.2$ seconds and is 3.28 times the probable error. Again the plus mean is larger by a margin of statistical value. The 11 same-day broods have 
means (340 and 394 seconds) differing by $-54 \pm 23.39$ seconds, a result out of accord with that for the means for the complete data for this year and with that for the test series now to be considered.

The test series conducted in May 1914 consisted of 23 broods from each strain (320 individuals of the plus and 331 individuals of the minus strain). Of the 23 pairs of broods, 17 broods from the plus strain had the higher reaction-time, while the minus brood had the higher reaction-time in only 6 cases. The reaction-time means for the entire test series were 520.8 and 463.6 seconds. The difference was $+57.2 \pm 14.9$ seconds, a difference 3.83 times the probable error (table 25).

For the final period (11 months) of the experiment with Line 719 , the mean for the plus strain was 364.2 seconds, for the minus strain 345.0 seconds. The difference was $+19.2 \pm 12.5$ seconds, a difference only 1.53 times the probable error. The ten same-day broods gave means of 351 and 378 seconds, and a difference of -27 seconds; again the same-day-brood data is out of accord with the data for the year-period. A test series conducted during November 1914 and consisting of nearly 1,000 individuals from each of the strains gave means of 310.9 and 290.6 seconds and a difference of $+20.3 \pm 6.3$ seconds (table 25 ). This difference, while small, is 3.22 times the statistical probable error.

The course of the curves (figure $8 \mathrm{c}$ ) throughout is rather irregular, particularly for the plus strain, but the marked tendency for the curve for the plus strain to be higher than that for the minus strain is suggestive of a real difference in reactiveness between these two strains, with the minus strain generally, though slightly, the more reactive. In addition to the data for the entire course of the experiment when considered by longer periods, the two test series, and a minor portion of the data for the same-day broods, likewise tend to indicate that the minus strain was the more reactive. But the differences are less pronounced during the last year of the experiment than during the earlier two years. The minus strain was more reactive than the plus strain by only 19 seconds (a difference not of statistical value) during the last year-period. The differences for the earlier two years were 46 and 43 seconds and were 3.81 and 3.28 times their probable errors. However, the large test series conducted during this last year-period indicated that the minus strain was the more reactive by 20.3 seconds (a difference very near that for the last year's selection data) and because of the large number of individuals used in this series and the consequently smaller probable error this difference was 3.22 times the probable error.

The data for Line 719 as a whole and particularly the data of the 2 test series are very suggestive of a genetic difference in opposition to selection between the two strains of Line 719, in spite of the lack of confirmation from most of the same-day-brood data and the 
reduction in amount of this difference during the last year of the experiment.

Additional evidence of a significantly lowered reaction-time for the minus strain of Line 719 is obtained by comparison with the minus strains of the other $D$. pulex lines which showed no evidence of modification in reactiveness during the selection experiments, Lines 691, 695, 713, 714, and 751. A composite curve for the reaction-time mean for the minus strains of these lines compared with
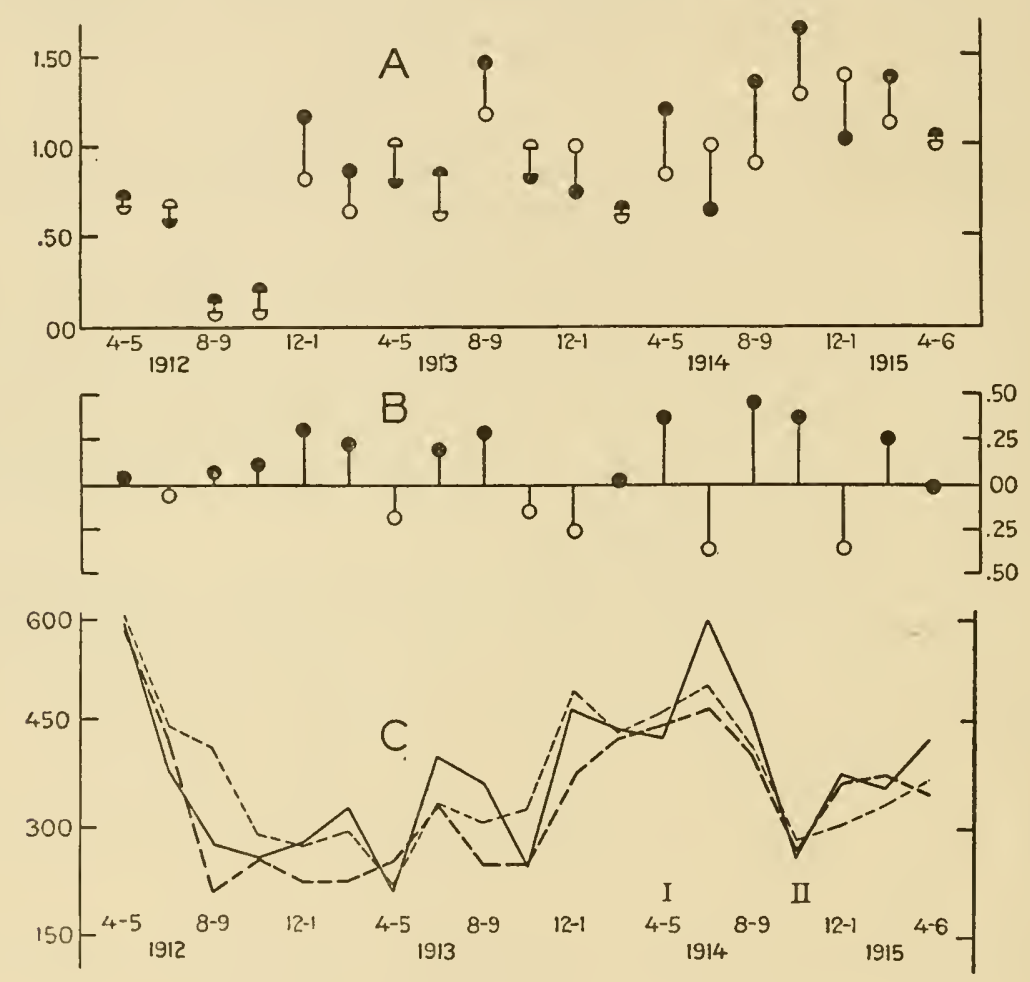

Figure 8.- Line 719.

A. Reproductive indices, actual values.

B. Reproductive indices, superiority.

C. Reaction-time curves with a superimposed curve (in faint broken line) representing the combined reaction-time means for the minus strains of all Daphnia pulex lines in which significant reaction-time differences probably did not arise.

the mean for the minus strain of Line 719 (figure $8 \mathrm{c}$ ) shows that beginning with August 1912 and continuing to January 1914 the mean for the minus strain of Line 719 was lower than that for the combined mean for the other minus strains for the same two-month periods in 8 of 9 two-month periods; 6 of these differences (ranging from 48 to 197 seconds) were of statistical value and one other just escaped statistical significance because of the small numbers of reaction-time records involved. From February 1914 the minus 
strain of Line 719 continued more reactive than the combined means of the other lines for 10 months, but the differences were small and not of statistical value. For the remaining 7 months of the curve the differences were variable and the mean for the plus strain did not differ appreciably from the composite curve of means for the corresponding plus strains.

The evidence seems suggestive of a mutation in the minus strain of Line 719, rendering it the more reactive to light. Since the difference between the mean for the minus strain of Line 719 and the plus strain of the same line, as well as between the Line 719 minus strain and the combined means for the minus strains of the lines, which may fairly serve as checks, later decreased and was apparently practically lost, it seems probable that selection served to reduce or eliminate the effect of this apparent mutation.

This reduction in (or possible elimination of) the reaction-time difference in Line 719 is worthy of consideration as contrasted with Line 757, in which the difference in reaction-time (which in that case is in the direction attempted in selection) became larger and larger in successive year-periods, until, instead of being a difference of 5.5 per cent, as in the last period of selection in Line 719, it was 99 per cent in the last year-period for Line 757.

Line 719 affords a case parallel to that of Line 689, in which the plus strain likewise persistently had a higher reaction-time, contrary to any influence of selection. With Line 689 the period of the experiment was much shorter, but otherwise the results are very similar, except that in Line 719 the difference is not so large or so uniform, is not supported by most of the same-day-brood data, and became much smaller during the latter part of the experiment.

It is to be noted with Line 719 that in reproductive vigor the minus strain was in general inferior to the plus strain. This was markedly true during the first and the last year-periods. The minus strain was slightly superior in vigor during the second year-period. Yet the minus strain was the more reactive throughout all these year-periods and was (absolutely) somewhat less reactive during its year of superior vigor (August 1913-July 1914) than during the other two years.

The curves for the mean reaction-times by two-month periods (figure 8c) indicate an interesting correlation between the means for the two strains, the plus and minus curves, in spite of their fluctuations, following each other remarkably closely. This is again an expression of environmental effect. The small and variable, though fairly pronounced, superiority in reactiveness on the part of the minus strain for most of the period of selection is rendered even more interesting by the fact that the differences persist while the curves sweep up and down under environmental influences. 


\section{LINE 751.}

Line 751 was obtained in October 1912 from the surface-water pond on the upland (Pond I), from which Line 689 came a year earlier. ${ }^{1}$ Selection was begun at once. This is the only line of Daphnia pulex with which selection was not begun during March 1912, after having been in the laboratory from 5 to 8 generations before

TABLE 27.-Selection summary for Line 751.

\begin{tabular}{|c|c|c|c|c|c|c|c|c|c|c|c|c|c|c|c|}
\hline Time period. & Strain. & 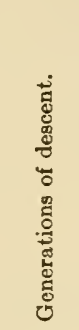 & 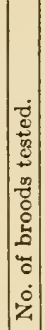 & 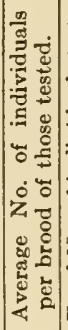 & 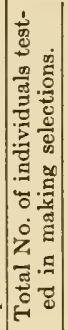 & 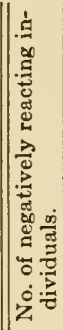 & 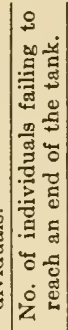 & 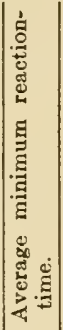 & 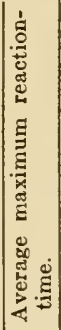 & 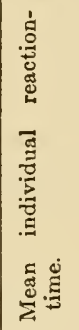 & 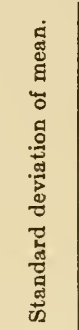 & 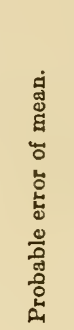 & 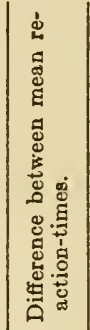 & 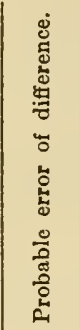 & 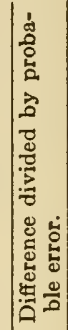 \\
\hline 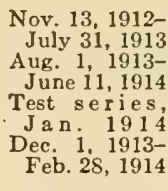 & 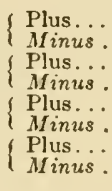 & $\begin{array}{r}1-31 \\
1-91 \\
32-71 \\
32-70 \\
54 \\
59 \\
48-58 \\
47-57\end{array}$ & $\begin{array}{l}32 \\
33 \\
40 \\
40 \\
17 \\
17 \\
11 \\
11\end{array}$ & $\begin{array}{r}8.2 \\
8.1 \\
8.0 \\
8.3 \\
19.3 \\
19.2 \\
8.0 \\
5.8\end{array}$ & $\begin{array}{r}261 \\
267 \\
321 \\
331 \\
328 \\
327 \\
88 \\
64\end{array}$ & $\begin{array}{r}10 \\
15 \\
14 \\
27 \\
19 \\
16 \\
3 \\
1\end{array}$ & $\begin{array}{r}8 \\
5 \\
31 \\
42 \\
41 \\
50 \\
10 \\
10\end{array}$ & $\begin{array}{l}139 \\
140 \\
177 \\
187 \\
140 \\
140 \\
207 \\
250\end{array}$ & $\begin{array}{l}450 \\
459 \\
657 \\
648 \\
752 \\
738 \\
688 \\
664\end{array}$ & $\begin{array}{l}282.2 \\
270.8 \\
375.4 \\
400.7 \\
416.1 \\
439.9 \\
414.0 \\
488.7\end{array}$ & $\begin{array}{l}179.6 \\
164.1 \\
252.7 \\
256.7 \\
260.0 \\
267.7 \\
233.0 \\
252.6\end{array}$ & $\begin{array}{r}7.73 \\
6.78 \\
9.51 \\
9.52 \\
9.7 \\
10.0 \\
16.8 \\
21.9\end{array}$ & 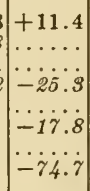 & \begin{tabular}{c}
13.46 \\
13.9 \\
\hdashline $2^{7} .10$
\end{tabular} & $\begin{array}{l}1.88 \\
1.28\end{array}$ \\
\hline
\end{tabular}

TABLE 28.-Same-day broods. Summary of data for Line $\% 51$.

\begin{tabular}{|c|c|c|c|c|c|c|c|c|c|c|c|c|c|c|}
\hline Time period. & Strain. & 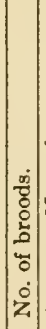 & 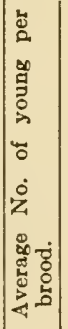 & 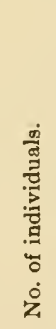 & 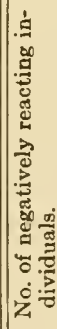 & 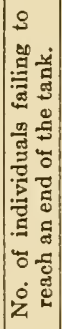 & 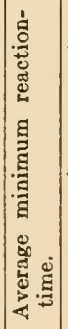 & 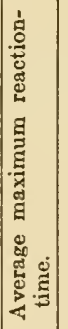 & 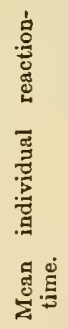 & 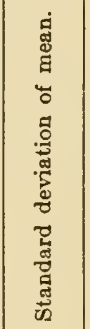 & 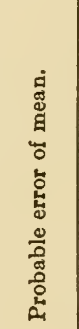 & 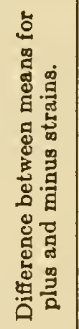 & 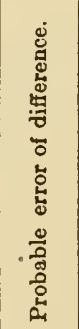 & 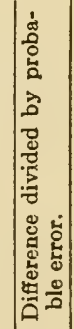 \\
\hline $\begin{array}{r}\text { Nov. } 13,1912- \\
\text { July } 31,1913 \\
\text { Aug. 1, 1913- } \\
\text { June 11, } 1914\end{array}$ & $\left\{\begin{array}{l}\text { Plus...... } \\
\text { Minus... } \\
\text { Plus.... } \\
\text { Minus... }\end{array}\right.$ & $\begin{array}{l}16 \\
16 \\
13 \\
19\end{array}$ & $\begin{array}{l}7.4 \\
8.4 \\
6.8 \\
8.5\end{array}$ & $\begin{array}{r}119 \\
195 \\
88 \\
111\end{array}$ & $\begin{array}{r}8 \\
13 \\
7 \\
14\end{array}$ & $\begin{array}{r}5 \\
2 \\
10 \\
6\end{array}$ & $\begin{array}{l}166 \\
165 \\
165 \\
163\end{array}$ & $\begin{array}{l}489 \\
476 \\
565 \\
676\end{array}$ & $\begin{array}{l}325 \\
288 \\
350 \\
345\end{array}$ & $\begin{array}{l}204.06 \\
1 \approx 0.04\end{array}$ & $\begin{array}{r}12.62 \\
9.87\end{array}$ & $\begin{array}{c}+37 \\
\cdots \cdots+5 \\
\cdots\end{array}$ & 16.02 & 2.30 \\
\hline
\end{tabular}

the beginning of selection. Selection was continued for almost 20 months, when both strains were lost (in the seventy-first and seventieth generations). The data for this line are given in tables 27 and 28 and figure 9.

For the first longer period of selection (9 months) the mean reaction-time for the plus strain was 282.2 seconds, for the minus strain 270.8 seconds. The difference $(+11.4 \pm 10.28)$ was not significant (table 27). There was a large number (16) of same-day

${ }^{1}$ All the lines of D. pulex except 689 and 751 came from Pond II, the spring-fed pond in the woods. 
broods. The mean reaction-time for those of the plus strain was 325 seconds, for the minus strain 288 seconds. The difference $(+37 \pm 16.02$ seconds) is in the same direction as that for the entire data for this period. For the remaining period of selection with this line, $10 \frac{1}{2}$ months, the mean reaction-times were 375.4 seconds and 400.7 seconds for the plus and minus strains, respectively. The difference was $-25.3 \pm 13.46$ seconds, a difference not of statistical significance. There was again a considerable number of same-day broods (13), for which the mean reaction-times were 350 and 345 seconds and the difference +5 seconds.

A test series conducted in January 1914, consisting of 328 individuals in the plus strain and 327 individuals in the minus strain, gave a mean reaction-time of 416.1 seconds for the plus strain and 433.9 seconds for the minus strain. The difference was $-17.8 \pm 13.9$ seconds. This difference like the others is not of statistical value.

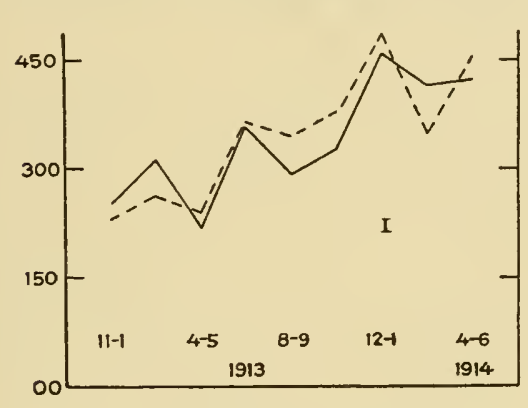

FIGURE 9.-Line 751.

Reaction-time curves.

A curve for the reaction-time means of this line is shown in figure 9 and, like the numerical summaries just considered, shows that there is probably no effect of selection. There is just a possible suggestion of an effect of selection, however, in the last year's data, inasmuch as during this period the plus strain was continuously the more reactive, except for one two-month period. But in view of the great fluctuation in the reaction-time curves for the other lines subjected to selection, this suggestion has little weight.

There is a feature of interest in the curves for this line, as with many other lines, the general close correspondence in the levels of the plus and minus curves in the different two-month periods; on the whole they sweep upward and downward together, an expression of a parallel effect of environment upon the two strains.

It is a matter of interest and some importance to note that the means for the two strains of Line 751 start at approximately the same levels which were held by the other $D$. pulex selection lines (Lines 689, 691, 695, 711, 713, 714, and 719) during the same twomonth period, although the other lines had been subjected to laboratory culture for approximately a year and to selection for 8 months before Line 751 was brought into the laboratory. Comparison of the curves for Line 751 (figure 9) and for the other $D$. pulex lines (figures $2 \mathrm{c}, 3 \mathrm{c}, 4,5,6,7 \mathrm{c}$, and $8 \mathrm{c}$ ) and with the composite curves for all the $D$. pulex plus and minus strains (figure 10D, on which the curves for Line 751 are superimposed), strikingly brings out this fact. This is important as showing that under laboratory conditions strains of 
a given species tend to have approximately the same reaction-time means, regardless of the length of their previous laboratory history.

\section{LINE 762.}

Line 762 was one of the two lineally distinct lines of $D$. longispina subjected to selection. It was obtained October 19, 1912, from Pond I, one of the surface-water ponds on the upland, and was subjected to selection at once. This is a less favorable species for selection on the basis of reactiveness to light than the other species used. While it is moderately reactive, it does not so readily withstand the handling, and individuals sometimes become disabled or become lodged in the surface film of the water.

The summary of the data for Line 762 is found in table 29 and in figure $10 \mathrm{~A}$. The experiment with this line was of relatively short duration (10 months) as compared with the other lines, due to the

TABLE 29.-Selection summary for Line 762.

\begin{tabular}{|c|c|c|c|c|c|c|c|c|c|c|c|c|c|c|c|}
\hline Time period. & Strain. & 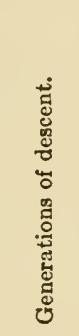 & 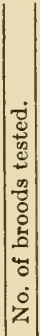 & 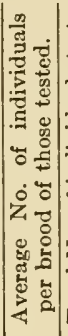 & 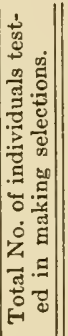 & 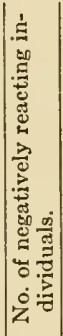 & 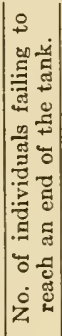 & 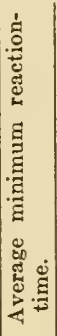 & 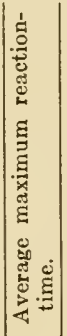 & 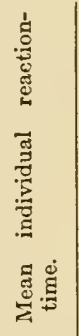 & 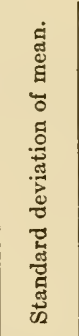 & 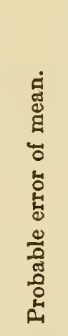 & 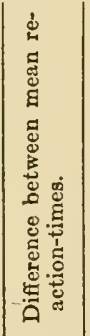 & 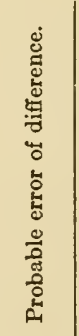 & 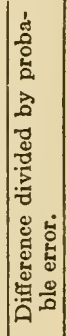 \\
\hline $\begin{array}{c}\text { Nov. } 1912- \\
\text { July } 31,1913 \\
\text { Aug. 1 1913-1913- } \\
\text { Sept. 8, 1913 }\end{array}$ & $\begin{array}{l}\text { Plus.... } \\
\text { Minus.. } \\
\text { Plus... } \\
\text { Minus. }\end{array}$ & $\begin{array}{r}1-30 \\
1-28 \\
31-36 \\
29-35\end{array}$ & $\begin{array}{r}31 \\
31 \\
6 \\
7\end{array} \mid$ & $\begin{array}{r}6.9 \\
6.4 \\
9.8 \\
11.3\end{array}$ & $\begin{array}{r}215 \\
199 \\
59 \\
79\end{array}$ & $\begin{array}{l}1 \\
3 \\
1 \\
8\end{array}$ & $\begin{array}{r}21 \\
20 \\
4 \\
21\end{array}$ & $\begin{array}{l}168 \\
168 \\
111 \\
147\end{array}$ & $\begin{array}{l}573 \\
608 \\
581 \\
900\end{array}$ & $\begin{array}{l}366.2 \\
377.3 \\
269.3 \\
482.3\end{array}$ & $\begin{array}{l}229.2 \\
257.1 \\
224.1 \\
305.5\end{array}$ & $\begin{array}{l}10.5 \\
12.8 \\
19.7 \\
23.2\end{array}$ & $\left|\begin{array}{l}-11 i .1 \\
-213.0\end{array}\right|$ & $\begin{array}{r}16.19 \\
30.42\end{array}$ & $\because \ddot{60}$ \\
\hline
\end{tabular}

accidental loss of the plus strain in September 1913. Shortly after this loss the experiment was resumed by selecting in both directions from the minus strain. The line was henceforth designated Line 766. This was in effect a return selection within the minus strain. ${ }^{1}$

The data for the first nine-month period (November 1912July 1913, table 29) gives reaction-time means of 366.2 and 377.3 seconds. The difference $(-11.1 \pm 16.19$ seconds $)$ is not significant. The 10 same-day broods for this line, comprised mostly of broods produced during June and July, gave the following means: 355 seconds for the plus strain ( 57 individuals) and 349 seconds for the minus strain (54 individuals). The same-day-brood data rather clearly substantiate the conclusion which the curves (figure 10A) suggest, that until that time there was no effect of selection.

For the final portion of the experiment, a little more than a month (until the plus strain was lost), the plus strain was markedly

IIt is unfortunate that return selections were not conducted in other lines, particularly in Line 757. The return selection in Line 762 (which then became Line 766) is not significant as a return selection, because presumably there was not an effect of selection within Line 762 . 
the more reactive, the means being 269 and 482 seconds and the difference $-213 \pm 30.42$ seconds. There is, moreover, an interesting difference noted between every plus brood and every minus brood tested during this period. Without exception the plus broods were considerably more reactive than the minus broods tested at the nearest dates. Such a consistent difference in reactiveness involving every individual brood ${ }^{1}$ is not generally found in the data obtained from these selection experiments, except in portions of the data for Line 757 , in which a pronounced effect of selection was obtained.

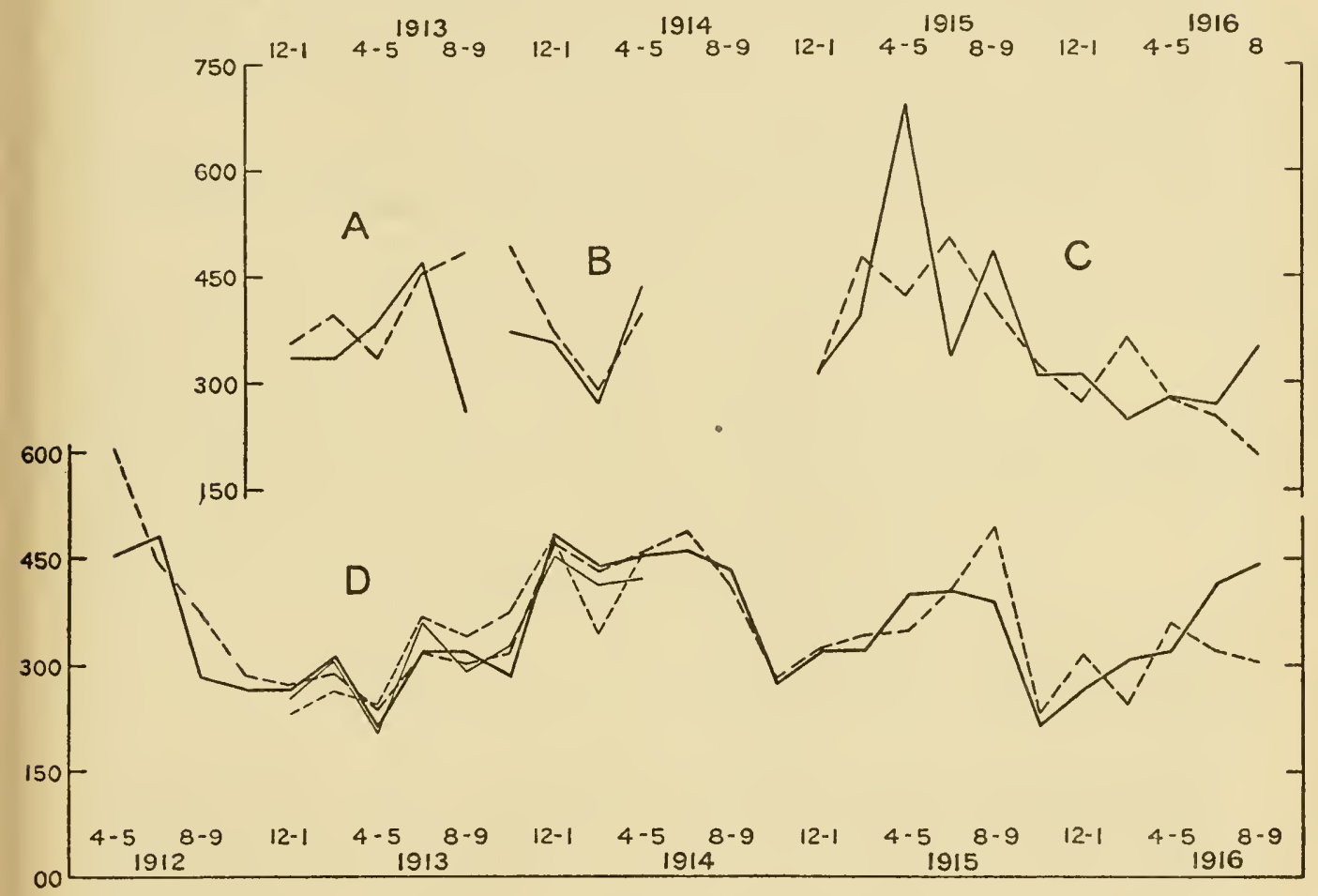

Figure 10.

A, B, C. Reaction-time curves for Daphnia longispina-Lines 762,766 , and 768 , respectively. D. Composite reaction-time curves for all plus and all minus strains of Daphnia pulex with reaction-time curves for Line 751 superimposed.

The divergence in reaction-time means for this last two-month period and particularly the complete and unusual consistency of differences in reaction-time, brood by brood, for this last period suggest an effect of selection. The amount of these data is too small to be more than slightly suggestive, but it seems quite possible that a mutation occurred in the plus strain of Line 762, thus producing

${ }^{1}$ It will be remembered that temporary enviromental conditions are very potent factors in modifying the reaction-time means of individual broods and that consequently rather wide fluctuations occur in all the data. Hence, only in cases in which the reactiveness of the two strains differs greatly do we fail to find the reaction-time means for different broods of the two strains of a line overlapping to a wide degree. 
the great lowering of the plus mean and the marked differences in reactiveness between the two strains not present earlier.

\section{LINE 766.}

As noted above, the two strains of this line were derived from the minus strain of Line 762 . The minus strain was a continuation of the minus strain of Line 762 , the selection having been interrupted for three generations. The plus strain of Line 766 was derived from the minus strain of Line 762 by selecting the most reactive individual from the thirty-ninth generation of the minus strain of that line. The summary of the data is given in table 30 and figure 10B. Selection was continued for only 7 months, when it was interrupted by the loss of the plus strain.

A rather wide difference in mean reaction-times for the first two-month period is not continued during the remainder of the ex-

TABLE 30.-Selection summary for Line 766 .

\begin{tabular}{|c|c|c|c|c|c|c|c|c|c|c|c|c|c|c|c|}
\hline Time period. & Strain. & 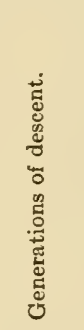 & 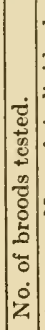 & 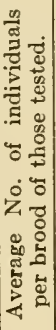 & 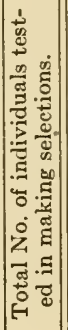 & 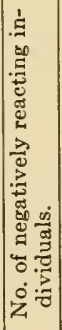 & 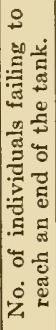 & 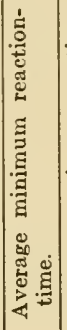 & 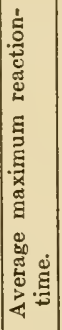 & 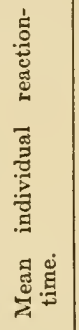 & 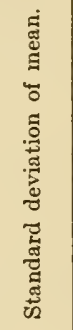 & 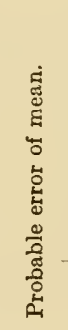 & 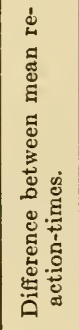 & 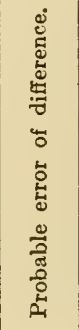 & 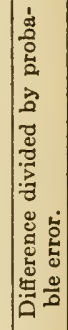 \\
\hline $\begin{array}{c}\text { Oct. } 1,1913-19 \\
\text { Apr. } 1914\end{array}$ & $\begin{array}{l}\text { Plus.... } \\
\text { Minus. }\end{array}$ & $\begin{array}{l}39-61 \\
40-56\end{array}$ & $\begin{array}{l}22 \\
18\end{array}$ & $\begin{array}{l}7.0 \\
6.4\end{array}$ & $\begin{array}{l}154 \\
116\end{array}$ & $\begin{array}{l}1 \\
1\end{array}$ & $\begin{array}{l}10 \\
18\end{array}$ & $\begin{array}{l}182 \\
222\end{array}$ & $\begin{array}{l}622 \\
695 \\
\end{array}$ & $\begin{array}{l}327.0 \\
385.8\end{array}$ & $\begin{array}{l}247.3 \\
268.8\end{array}$ & $\begin{array}{l}13.4 \\
16.8\end{array}$ & -58.8 & 21.54 & 42.72 \\
\hline
\end{tabular}

periment. The mean reaction-times for the two strains for the entire period of the experiment were 327 and 385.8 seconds (table 30 ). While the difference is -58.8 seconds and is 2.72 times the probable error, it is largely due to the difference in mean-reaction time obtaining for the first two months. There were two same-day broods containing totals of only 11 and 9 individuals in the plus and minus strains, respectively. The averages were 222 and 250 seconds and the difference was -28 seconds, a difference which, with so few individuals, is not significant. There is no effect of selection.

The effect of environmental influences upon reaction-time is indicated by the generally coincident up-and-down courses of the curves of the two strains of Line 762 and Line 766 (see figure 10, $\mathrm{A}$ and $\mathrm{B})$.

\section{LiNe 768.}

Line 768 was the second of the two genetically distinct lines of D. longispina. It was taken into the laboratory from Pond IV in November 1913, but selection was not begun until December 1914 
in the fifty-fourth laboratory generation. Selections were continued for 21 months, 75 and 74 generations in the plus and minus strains, respectively. The data will be found in tables 31 and 32 and in figure $10 \mathrm{c}$.

The data for the first longer period (December 1914-July 1915) consists of 29 and 28 broods from the two strains, there being 238 and 239 individuals. The mean reaction-times were 426 and 443 seconds. The difference is $-17 \pm 19.5$ seconds (table 31 ). There

TABLE 31.-Selection summary for Line 768.

\begin{tabular}{|c|c|c|c|c|c|c|c|c|c|c|c|c|c|c|c|}
\hline Time period. & Strain. & 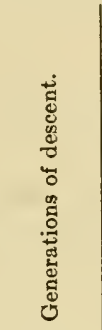 & 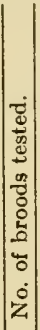 & 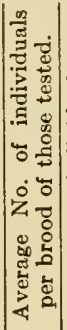 & 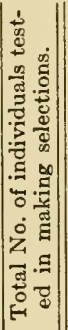 & 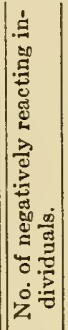 & 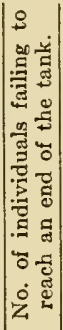 & 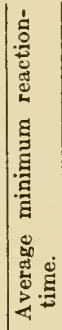 & 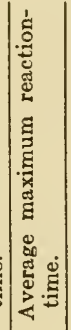 & 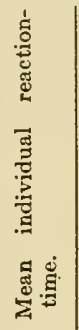 & 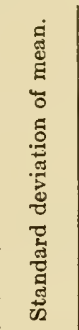 & 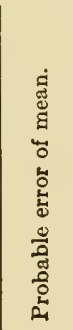 & 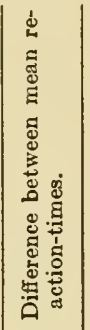 & 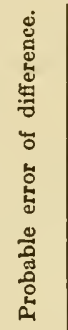 & 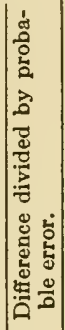 \\
\hline $\begin{array}{l}\text { Dec. 21, 1914- } \\
\text { July 31, 1915- } \\
\text { Aug. 1, 1915- } \\
\text { July } 31,1916 \\
\text { Aug. } 1,1916- \\
\text { Aug. } 22,1916\end{array}$ & $\begin{array}{l}\text { Plus.... } \\
\text { Minus . } \\
\text { Plus.... } \\
\text { Minus . } \\
\text { Plus... } \\
\text { Minus . }\end{array}$ & $\begin{array}{c}54-83 \\
64-82 \\
84-125 \\
89-124 \\
126-128 \\
125-127\end{array}$ & $\begin{array}{r}29 \\
28 \\
39 \\
38 \\
3 \\
3\end{array}$ & $\begin{array}{l}8.2 \\
8.5 \\
9.7 \\
7.7 \\
9.7 \\
7.3\end{array}$ & \begin{tabular}{|r|}
238 \\
239 \\
376 \\
294 \\
29 \\
22
\end{tabular} & $\begin{array}{l}8 \\
7 \\
7 \\
6 \\
0 \\
0\end{array}$ & $\begin{array}{r}58 \\
51 \\
31 \\
24 \\
3 \\
1\end{array}$ & $\begin{array}{r}211 \\
181 \\
111 \\
144 \\
143 \\
65\end{array}$ & $\begin{array}{l}730 \\
772 \\
657 \\
647 \\
845 \\
507\end{array}$ & $\begin{array}{l}426.0 \\
443.0 \\
315.7 \\
328.0 \\
350.0 \\
198.4\end{array}$ & $\begin{array}{l}331.2 \\
299.7 \\
242.1 \\
230.8 \\
268.5 \\
186.1\end{array}$ & \begin{tabular}{|r|}
14.5 \\
13.1 \\
8.4 \\
9.1 \\
33.6 \\
26.8
\end{tabular} & $\begin{array}{l}-17.0 \\
\because 72 . \\
+151.6\end{array}$ & $\begin{array}{l}12.4 \\
43.0\end{array}$ & 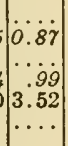 \\
\hline
\end{tabular}

TABLE 32.-Same-day broods. Summary of data for Line 768.

\begin{tabular}{|c|c|c|c|c|c|c|c|c|c|c|}
\hline Time period. & Strain. & $\begin{array}{l}\dot{0} \\
\dot{0} \\
\dot{0} \\
\dot{0} \\
\dot{0} \\
\dot{z}\end{array}$ & 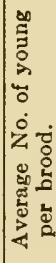 & 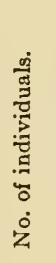 & 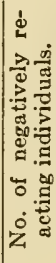 & 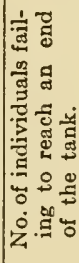 & 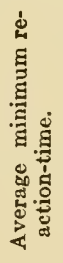 & 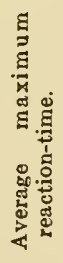 & 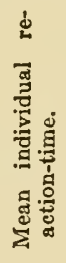 & 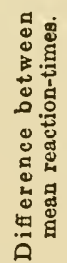 \\
\hline \multirow{2}{*}{$\begin{array}{r}\text { Dec. } 21,1914-J u l y ~ 31 \\
1915 \ldots \ldots \ldots \ldots \ldots \ldots\end{array}$} & \{ Plus... & 17 & 10.6 & 180 & 2 & 52 & 212 & 808 & 454 & +16 \\
\hline & Minus. & 17 & 9.9 & 169 & 6 & 37 & 112 & 827 & 488 & \\
\hline \multirow{2}{*}{ 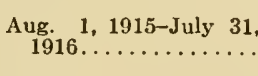 } & (Plus.... & 4 & 12.5 & 50 & 1 & 3 & 106 & 603 & 374 & +38 \\
\hline & Minus. & 4 & 9.8 & 39 & 0 & 2 & 118 & 615 & 336 & \\
\hline
\end{tabular}

were a large number (17) of same-day broods for this period, for which the mean reaction-times were 454 and 438 seconds. The difference is +16 seconds (table 32 ).

For the year-period (August 1915-July 1916) there were 39 and 38 broods consisting of 376 and 294 individuals in the two strains. The mean reaction-times were 315.7 and 328 seconds. The difference is $-12.3 \pm 12.4$ seconds. There were only 4 same-day broods, for which the mean reaction-times were 374 and 336 seconds. The difference is +38 seconds. 
This experiment was continued during the most of another month, but the data consists of the records for only 3 broods from each strain. The means are 350 and 198.4 seconds. The difference ( +151.6 seconds), while large, is based upon entirely too few individual reaction-times to be assigned significance. It is obvious that with Line 768 there was no effect of selection.

The reproductive indices for this line have not been worked out, but the plus strain was apparently somewhat the more vigorous. That this difference in vigor has not influenced reaction-time, to any considerable extent at any rate, is evident from the fact that the same-day broods of the plus strain were on the whole less reactive than those of the minus strain.

There is again, as with many other lines, an obvious effect of environmental conditions upon reaction-time. In spite of rather wide local fluctuations, the means for the two strains, on the whole, follow each other rather closely, as is shown in figure 10c.

Reference to figure 10 (in which are given, separately, the reaction-time curves for the three selection lines of $D$. longispina and composite curves for the reaction-times of all the $D$. pulex selection lines) shows that there is a striking, though somewhat rough, parallelism between the reaction-time curves for the $D$. longispina and the $D$. pulex lines. This is an expression of similar influences of the same environmental factors upon the reactiveness to light of the two species. 


\section{GENERAL INTRODUCTION FOR SIMOCEP̊HALUS EXSPINOSUS LINES.}

S. exspinosus in some regards seemed an unfavorable species for selection on the basis of its reaction to light. During the tests individuals frequently attached to the surface film or to the sides of the experimental tank and rested there during the remainder of the test (see also page 25). Further, and to an even greater degree, the $S$. exspinosus young were unsatisfactory in that they so generally settled to the bottom of the tank and appeared non-reactive to light. In most broods there were several individuals which failed to reach either end of the tank during the 15 minutes of the experiment, while in some broods (particularly during the earlier course of the experiments) there was no response on the part of any individual of the brood. The reactiveness to light during the early course of the experiments was so slight that in many cases there were really no grounds for making a selection and there seemed little hope of a sufficient reactiveness to light to afford a basis for conducting an experiment in selection on this character.

Several of the earlier $S$. exspinosus lines were discarded as unprofitable after a few generations of selection. Lines 740 and 757 , while not promising at the start, were continued and subjected to selection for a time to see if it then seemed advisable to continue the selections. Even comparatively slightly reactive material might conceivably afford a basis for selection if there were enough reactive individuals to make a selection possible in a considerable percentage of cases. In addition to broods (particularly the earlier broods of these two lines) which showed absolutely no reaction to the light, there were other broods in which the only selection possible (in the plus strain) was from among individuals which had moved very slightly toward the light. In the minus strains the only choice in a vast majority of cases was an individual which showed no reaction to light. There were numbers of these in nearly every brood. Negatively reacting individuals were so rare with this species that it was seldom possible to make selections in the minus strains on the ground of a negative reaction to light'. But after a few generations it was considered that the reactiveness of the strains of Lines 740 and 757 seemed sufficient to justify the continuation of these lines in the hope that there was sufficient reactiveness to test out the possibility of selection. The results justify the conclusion then reached, that after all there was sufficient basis for an experiment in selection.

It is worthy of emphasis that the selections in the minus strains of lines of Simocephalus were rarely on the ground of a negative

${ }^{1}$ However, as noted elsewhere (page 16), it is questionable if there is any real significance to be assigned to the negative reactions of the few individuals which went to the negative end of the experimental tank. 
reaction to light; that the only selection possible in very many cases was from among individuals showing no reaction; and that in the remaining cases the selections in the minus strains were postively reacting individuals with the highest reaction-times.

Lines 740 and 757 were subjected to selection from August and November 1912 to May 1917. Lines 794, 795, and 796 were used in selection from December 1914 to May 1917. All these lines of $S$. expinosus, except Line 757 , originated from mothers obtained from Pond IV, the larger surface-water pond on the hill, a mile from the laboratory of the Station for Experimental Evolution.

TABLE 33.-Selection summary for Line 794.

\begin{tabular}{|c|c|c|c|c|c|c|c|c|c|c|c|c|c|c|c|}
\hline Time period. & Strain. & 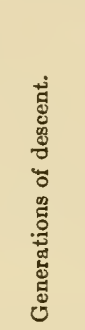 & 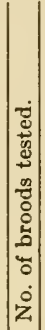 & 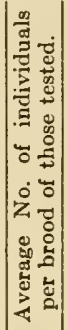 & 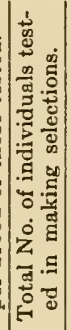 & 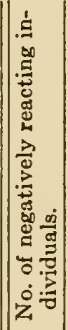 & 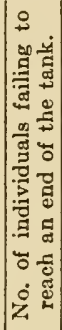 & 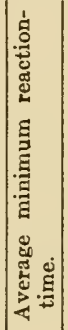 & 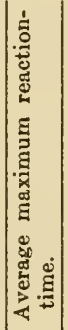 & 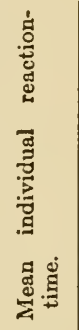 & 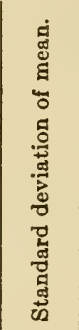 & 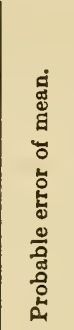 & 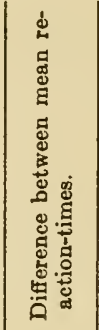 & 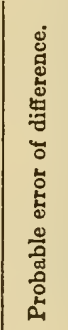 & 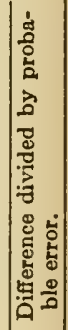 \\
\hline $\begin{array}{l}\text { Dec. } 23,1914- \\
\text { July } 31,1915 \\
\text { Aug. } 1,1915- \\
\text { July } 31,1916 \\
\text { Test seri e } 8, \\
\text { July } 1916 \text {, } \\
\text { June } 1,1916- \\
\text { Aug. } 31,1916 \\
\text { Aug. } 1,1916- \\
\text { May } 1,1917\end{array}$ & 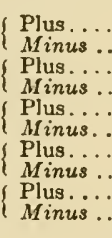 & $\begin{array}{r}1-27 \\
1-26 \\
28-63 \\
27-61 \\
62 \\
61 \\
59-67 \\
59-64 \\
64-91 \\
62-90\end{array}$ & $\begin{array}{r}27 \\
26 \\
33 \\
32 \\
36 \\
36 \\
7 \\
6 \\
24 \\
29\end{array}$ & $\begin{array}{r}13.3 \\
11.5 \\
15.0 \\
14.7 \\
27.5 \\
26.8 \\
15.6 \\
9.7 \\
15.1 \\
12.9\end{array}$ & \begin{tabular}{|r|}
358 \\
288 \\
495 \\
471 \\
989 \\
965 \\
109 \\
58 \\
363 \\
297
\end{tabular} & $\begin{array}{r}13 \\
8 \\
10 \\
24 \\
7 \\
8 \\
2 \\
1 \\
0 \\
0\end{array}$ & $\begin{array}{r}115 \\
65 \\
171 \\
241 \\
239 \\
254 \\
16 \\
14 \\
64 \\
49\end{array}$ & $\begin{array}{c}218 \\
239 \\
195 \\
316 \\
102 \\
98 \\
104 \\
98 \\
163 \\
182\end{array}$ & $\begin{array}{l}829 \\
738 \\
804 \\
843 \\
647 \\
654 \\
720 \\
592 \\
625 \\
639\end{array}$ & $\begin{array}{l}529.4 \\
451.8 \\
483.8 \\
589.1 \\
395.9 \\
395.2 \\
314.4 \\
409.5 \\
309.9 \\
979.8\end{array}$ & \begin{tabular}{|l}
301.0 \\
284.4 \\
325.2 \\
354.3 \\
309.4 \\
324.9 \\
266.4 \\
329.5 \\
290.4 \\
289.9
\end{tabular} & $\begin{array}{r}10.7 \\
11.8 \\
9.9 \\
10.4 \\
6.6 \\
7.1 \\
17.2 \\
29.8 \\
10.3 \\
11.3\end{array}$ & $\begin{array}{l}-9 \dot{5} . i \\
-6 \dot{s} .9\end{array}$ & $\begin{array}{r}14.3 \\
9.7 \\
2 \ldots\end{array}$ & 7.86 \\
\hline
\end{tabular}

TABLE 34.-Same-day broods. Summary of data for Line 794.

\begin{tabular}{|c|c|c|c|c|c|c|c|c|c|c|c|c|c|}
\hline Time period. & Strain. & 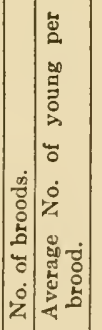 & 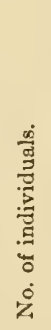 & 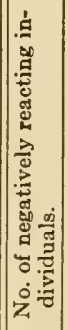 & 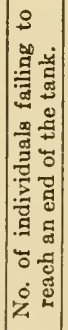 & 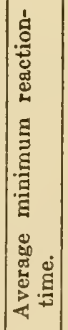 & 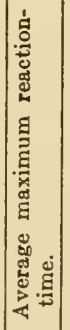 & 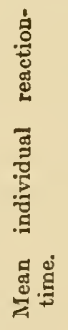 & 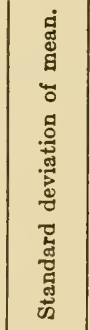 & 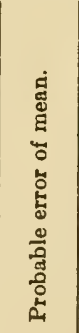 & 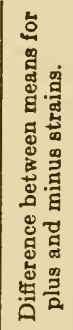 & 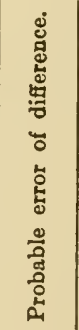 & 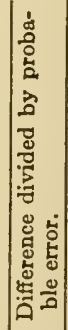 \\
\hline $\begin{array}{r}\text { Dee. } 23,1914- \\
\text { July } 31,1915 \\
\text { Aug. } 1,1915- \\
\text { July } 31,1916 \\
\text { Aug. } 1,1916- \\
\text { M1ay } 1,1917\end{array}$ & $\begin{array}{l}\text { Plus... } \\
\text { Minus. } \\
\text { Plus... } \\
\text { Minus. } \\
\text { Plus... } \\
\text { Minus. }\end{array}$ & \begin{tabular}{l|l|l|}
7 & 13.1 \\
7 & 11.6 \\
5 & 16.2 \\
5 & 18.8 \\
2 & 12.0 \\
2 & 13.0
\end{tabular} & $\begin{array}{l}92 \\
81 \\
81 \\
69 \\
24 \\
26\end{array}$ & $\begin{array}{l}1 \\
2 \\
0 \\
4 \\
0 \\
0\end{array}$ & $\begin{array}{r}22 \\
8 \\
28 \\
23 \\
4 \\
4\end{array}$ & $\begin{array}{l}155 \\
173 \\
259 \\
286 \\
105 \\
315\end{array}$ & $\begin{array}{l}876 \\
681 \\
900 \\
900 \\
645 \\
645\end{array}$ & $\begin{array}{l}475 \\
3.59 \\
463 \\
490 \\
323 \\
457\end{array}$ & $\begin{array}{r}270.21 \\
248.69\end{array} \mid$ & $\begin{array}{l}37.20 \\
32.90\end{array}$ & $\begin{array}{l}+116 \\
\ldots \ldots \\
\cdots 27 \\
-134 \\
-134\end{array}$ & 49.66 & 209 \\
\hline
\end{tabular}

Line 794.

The selection data for Line 794 are given in tables 33 and 34 and figure 11.

This line and Lines 795 and 796 originated from three mothers collected December 11, 1914. Selection was begun with the first 
broods of young produced in the laboratory and continued for 29 months, 91 generations in the plus strain and 90 generations in the minus strain.

For the first longer period (December 1914-July 1915) of the experiment the means for the plus and minus strains (358 and 288 individuals) were, respectively, 529.4 and 451.8 seconds (table 33 ). The difference $(+77.6 \pm 15.6$ seconds) was 4.97 times the probable error. For the first single month of selection (December 1914) the plus strain was more reactive by 40 seconds and again in June 1915 the plus strain was the more reactive strain, this time by a large margin, 274 seconds; but for the other 6 months of the first longer period the minus was more reactive by differences ranging from 88 to 219 seconds. For the same-day broods (table 34) the means were 475 and 359 seconds, the plus strain having a higher mean by $116 \pm 25.78$ seconds. Of the 7 same-day broods for this period, 5 occurred in succession in January and February 1915, almost immediately after the beginning of the experiment. The differences were $+175,+207,+193,+140$, and +152 seconds. Data for a pair of same-day broods occurring just before these five are incomplete, but the minus brood was the more reactive by at least 196 seconds, while the pair of broods just preceding those last mentioned were likewise same-day broods with the plus the more reactive by a small margin (27 seconds). Thus there were in effect 7 successive same-day broods, in all of which the minus brood was considerably the more reactive. These differences are so large and so persistent as to indicate for this early and limited period (January-February 1915) a real difference in reaction-time, with the minus strain the more reactive. In the last 2 months of this longer period (to August 1915) the minus strain had much the larger reaction-time, and this difference was greatly increased in the next two-month period and continued very large for another two-month period. ${ }^{1}$

The second longer period (the year August 1915-July 1916) gave averages of 483.8 and 589.1 seconds. The difference was $-105.3 \pm 14.3$ seconds, or 7.36 times the probable error. For the same period the 5 same-day broods had a difference of -27 seconds. This year's data, taken as a whole, might at first thought be considered suggestive of an effect of selection; but the great irregularities of the curves, the small difference between same-day-brood means, and the large differences in the opposite direction for the preceding year do not favor such an interpretation. A test series conducted during July 1916, consisting of nearly 1,000 individuals of each strain, gave means differing by only $+0.7 \pm 9.7$ seconds. This test

\footnotetext{
1 The very great divergence in the two reaction-time curves, the minus strain being the less reactive of the two, for the six-month period June to November 1915 is no more easily accounted for than the earlier six-month period, during which the plus strain was markedly the less reactive.
} 
series shows effectively that there was up to July 1916 no certain basis for assuming an effect of selection within this line.

During the last longer period (August 1916-May 1917) of selection with Line 794 the means were 309.9 and 373.8 seconds. The difference $(-63.9 \pm 15.3$ seconds) was 4.18 times its probable error. The 2 same-day broods gave means differing by $-134 \pm 49.66$ seconds. As for the preceding year, the means are suggestive of an effect of selection, but the irregular course of the curves (figure 11c), together with the result of the test series conducted in July 1916 (table 33) and the much higher reaction-time for the plus strain during 6 months of the experiment, make this interpretation questionable. It is noteworthy, however, that in spite of considerable irregularities in the curves, the curve for the minus strain is appreciably lower than that for the plus strain in only one of the 9 twomonth periods after the first 12 months of the experiment. After this early period all the data except the test-series data indicate that the minus strain was on the whole the less reactive throughout the experiment.

Since the mothers from which the two strains of Line 794 originated were sisters from the same brood, it is hard to understand to what the difference in reactiveness (the minus strain being markedly the more reactive) during the period of the experiment (JuneNovember 1915) can have been due. It is possible to think of it as a mutation in the minus strain, the effect of which was later eliminated by selection or by a second mutation in the same strain in the direction of less reactiveness to light; but these are mere surmises for which there is no real evidence and the differences themselves are not pronounced and certain enough to be considered as of great significance. It is probable, however, that the rather wide differences in reactiveness in the minus strain of this line at different periods of the experiment are due to non-genetic factors, such as produced similar effects in Lines 695 and 740 (see figures 2c and 15) and elsewhere. Nevertheless, the data leave room for the suggestion that selection was possibly responsible for the elimination of the greater reactiveness on the part of the minus strain, however it may have occurred, and a development of a relatively greater reactiveness on the part of the plus strain.

Figure $11 \mathrm{~A}$ indicates graphically the general reproductive levels for the two strains during the different two-month periods. There is no obvious relation between reproductive vigor and mean reactiontime unless the gencrally lower reproductive vigor of the minus strain be assumed to account for the generally higher reaction-time of the minus as compared with the plus strain; but with Line 795 (see figure $12 \mathrm{~B}$ ) the plus strain in general showed an even greater superiority in vigor, yet it was much less reactive than the minus 
strain of the same line. Examined in detail, the data for reproductive vigor and reaction-time do not appear to be related. ${ }^{1}$
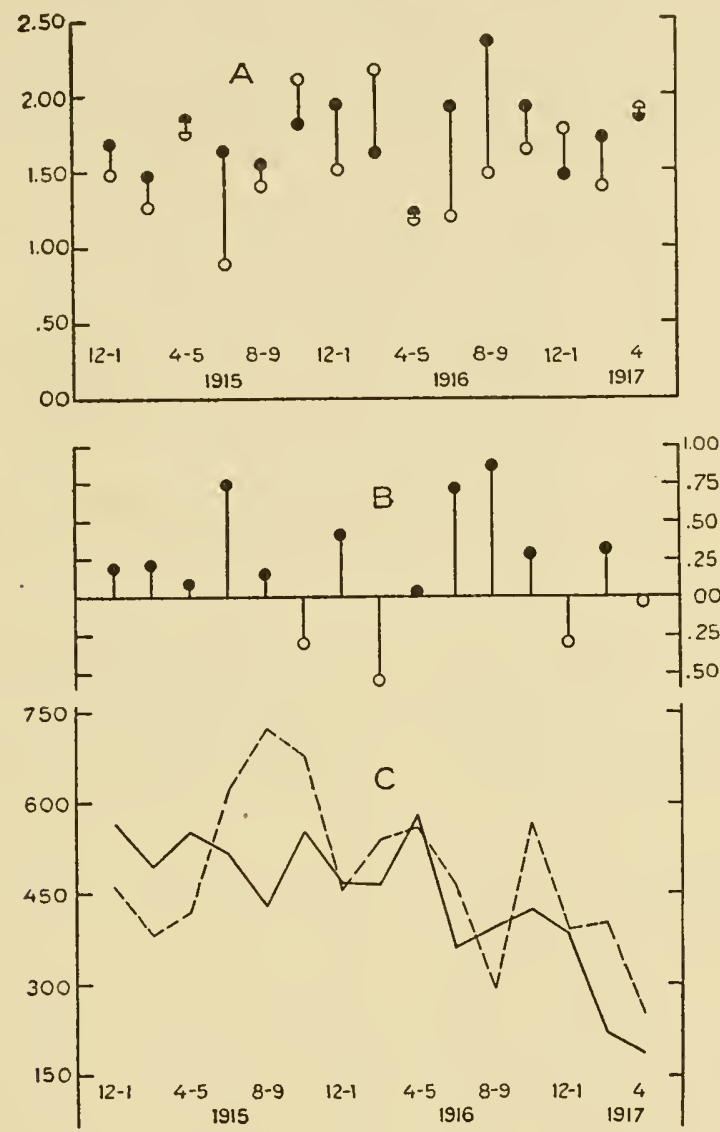

Figure 11.-Line 794.

A. Reproductive indices, actual values.

B. Reproductive indices, superiority.

C. Reaction-time curves.

\section{LiNe 795.}

Line 795 is a sister line of Lines 794 and 796 and was subjected to selection for a like period covering 94 generations for the plus and 95 generations for the minus strain. The data will be found in tables 35 and 36 and in figure 12 .

${ }^{1}$ For example, during the first 6 months the plus strain of Line 794 was persistently the more vigorous and generally the less reactive. The 7 high points in figure $11 \mathrm{~A}$ showing high reproductive indices (above 1.75) for the plus strain correspond 4 times with periods of greater reactiveness in the same strain, and 3 times with periods of less reactiveness; 5 similar high points of reproductive indices for the minus strain correspond with 1 period of relatively greater reactiveness in the minus strain and with 4 points of lesser reactiveness. The two-month periods of relatively low reproductive indices for the two strains likewise fail to correspond with periods of lesser reactiveness to light. 
Casual examination seems to reveal at once the fact that there is no effect of selection, and this is probably correct, but on careful analysis it is not altogether certain that an effect of selection is entirely lacking. The plus strain is generally the less reactive, but the curve for the minus strain is extremely fluctuating.

For the first longer period ( 8 months) the mean for the plus strain was 703.3 seconds, for the minus strain 571.4 seconds (table

TABLE 35.-Selection summary for Line 795.

\begin{tabular}{|c|c|c|c|c|c|c|c|c|c|c|c|c|c|c|c|}
\hline Time period. & Strain. & 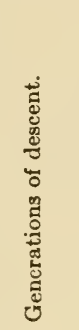 & 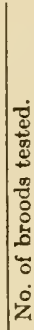 & 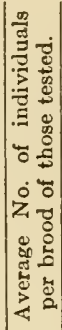 & 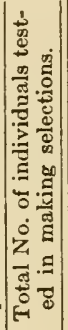 & 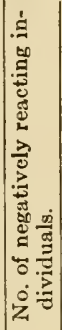 & 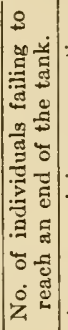 & 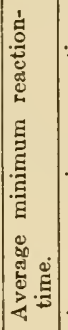 & 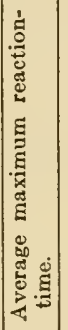 & 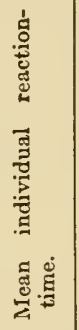 & 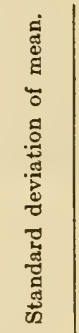 & 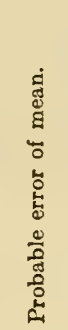 & 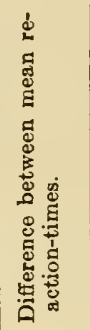 & 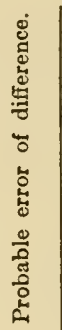 & 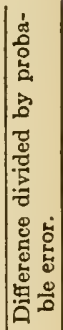 \\
\hline Dec. $24,1914-$ & & $1-27$ & 27 & 10.8 & 292 & 14 & & & & 703.3 & 254.4 & 10.0 & +131.9 & 15.7 & 8.40 \\
\hline ly 31,1915 & & $1-2 \gamma$ & & & .280 & 4 & 103 & 317 & 875 & 571.4 & 299.1 & 12.1 & 1200.0 & & \\
\hline $\begin{array}{c}\text { Aug. 1, } 1915- \\
\text { July } 31,1916\end{array}$ & $\begin{array}{l}\text { Plus... } \\
\text { Minus. }\end{array}$ & $\begin{array}{l}28-65 \\
28-64\end{array}$ & $\begin{array}{l}37 \\
35\end{array}$ & 15.7 & $\left|\begin{array}{l}580 \\
3 \sim 6\end{array}\right|$ & $\begin{array}{l}18 \\
10\end{array}$ & $\begin{array}{l}301 \\
118\end{array}$ & $\begin{array}{l}325 \\
334\end{array}$ & $\mid \begin{array}{l}842 \\
798\end{array}$ & $\begin{array}{l}6250.0 \\
530.7\end{array}$ & 323.1 & $\begin{array}{r}8.6 \\
11.2\end{array}$ & +94.3 & 14. & 6.64 \\
\hline Test series, & & 60 & & 63.5 & 1397 & 12 & 733 & 230 & 880 & 615.4 & 330.9 & 6.0 & +23.8 & 8.9 & 2.67 \\
\hline June 1916 . & Minus & 60 & 22 & 60.8 & 1338 & 21 & 683 & 188 & 883 & 591.6 & 356.1 & 6.6 & & & \\
\hline$\underset{\text { July }}{\text { May }} 1,1916-1916-$ & $\begin{array}{l}\text { Plus.. } \\
\text { Minus }\end{array}$ & $\begin{array}{l}57-65 \\
56-64\end{array}$ & & $\begin{array}{l}16.1 \\
10.8\end{array}$ & $\begin{array}{r}129 \\
82\end{array}$ & ${ }_{0}^{7}$ & $\begin{array}{l}60 \\
29\end{array}$ & $\left|\begin{array}{l}181 \\
257\end{array}\right|$ & $\mid \begin{array}{l}750 \\
776\end{array}$ & $\begin{array}{l}594.7 \\
448.1\end{array}$ & $\begin{array}{l}316.7 \\
341.7\end{array}$ & $\begin{array}{l}18.8 \\
25.5\end{array}$ & +146.6 & 31.6 & 4.63 \\
\hline Aug. 1, $1916-$ & Plus & $66-94$ & 24 & 14.8 & 356 & 0 & 115 & 133 & 815 & 457.2 & 326.4 & 11.7 & & & \\
\hline May 1,1917 & Minu & $65-96$ & & & 287 & 4 & & 264 & 735 & 502.0 & 330.1 & 13.1 & -44.8 & 17.6 & 2.55 \\
\hline
\end{tabular}

TABle 36.-Same-day broods. Summary of data for Line 795.

\begin{tabular}{|c|c|c|c|c|c|c|c|c|c|c|c|c|c|c|}
\hline Time period. & Strain. & 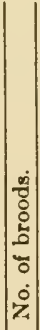 & 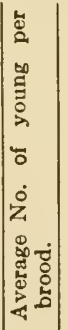 & 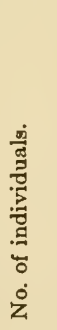 & 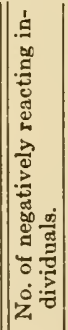 & 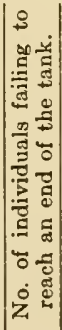 & 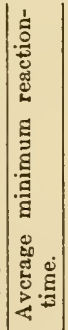 & 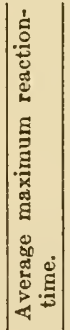 & 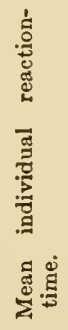 & 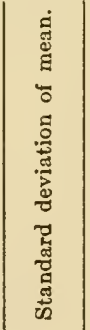 & 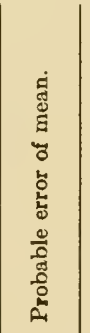 & 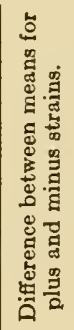 & 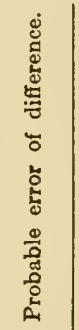 & 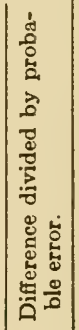 \\
\hline $\begin{array}{l}\text { Dec. 24, 1914- } \\
\text { July 31, 1915 } \\
\text { Aug. } 1,1915 \\
\text { July } 31,1916 \\
\text { Aug. } 1,1916- \\
\text { May } 1,1917\end{array}$ & $\begin{array}{l}\text { Plus... } \\
\text { Minus } \\
\text { Plus... } \\
\text { Mfinus } \\
\text { Plus... } \\
\text { Minus }\end{array}$ & $\begin{array}{r}12 \\
12 \\
12 \\
12 \\
5 \\
5\end{array}$ & $\begin{array}{l}11.6 \\
10.7 \\
13.5 \\
10.2 \\
12.6 \\
14.6\end{array}$ & $\begin{array}{r}139 \\
128 \\
162 \\
123 \\
63 \\
73\end{array}$ & $\begin{array}{l}8 \\
3 \\
3 \\
4 \\
0 \\
2\end{array}$ & $\begin{array}{l}70 \\
57 \\
88 \\
45 \\
9 \\
30\end{array}$ & \begin{tabular}{l|}
363 \\
354 \\
334 \\
278 \\
117 \\
458
\end{tabular} & $\begin{array}{l}900 \\
878 \\
725 \\
818 \\
714 \\
900\end{array}$ & $\begin{array}{l}661 \\
698 \\
617 \\
479 \\
307 \\
671\end{array}$ & $\begin{array}{l}277.77 \\
29.9 .17 \\
323.84 \\
3.37 .18 \\
263.21 \\
313.97\end{array}$ & $\begin{array}{l}15.89 \\
17.84 \\
17.16 \\
20.51 \\
22.37 \\
24.78\end{array}$ & \begin{tabular}{c}
+63 \\
$\ldots 138$ \\
$\ldots \ldots \ldots$ \\
\hdashline-364
\end{tabular} & $\begin{array}{l}23.89 \\
26.74\end{array}$ & $\begin{array}{c}2.63 \\
5.16 \\
\cdots . . \\
10.90\end{array}$ \\
\hline
\end{tabular}

$35)$. The difference was $+131.9 \pm 15.7$ seconds, or 8.4 times the probable error. The 12 same-day broods for this period likewise gave a mean for the plus strain in excess of the minus strain (table 36 ). The difference was $+63 \pm 23.89$ seconds, 2.63 times the probable error.

For the seeond longer period (August 1915-July 1916) of the data for this line the means were 625.0 and 530.7 seconds for the plus and minus strains. The difference was $+94.3 \pm 14.2$ seconds. This difference was 6.64 times the probable error. Twelve same- 
day broods averaged 617 and 479 seconds, the difference being $+138 \pm 26.74$ seconds. A test series conducted in June 1916, and consisting of more than 1,300 individuals of each strain, gave a plus mean of 615.4 seconds and a minus mean of 591.6 seconds. The difference $(+23.8 \pm 8.9$ seconds) was 2.67 times the probable error. Thus the data for this line to August 1916 indicates a signifi-

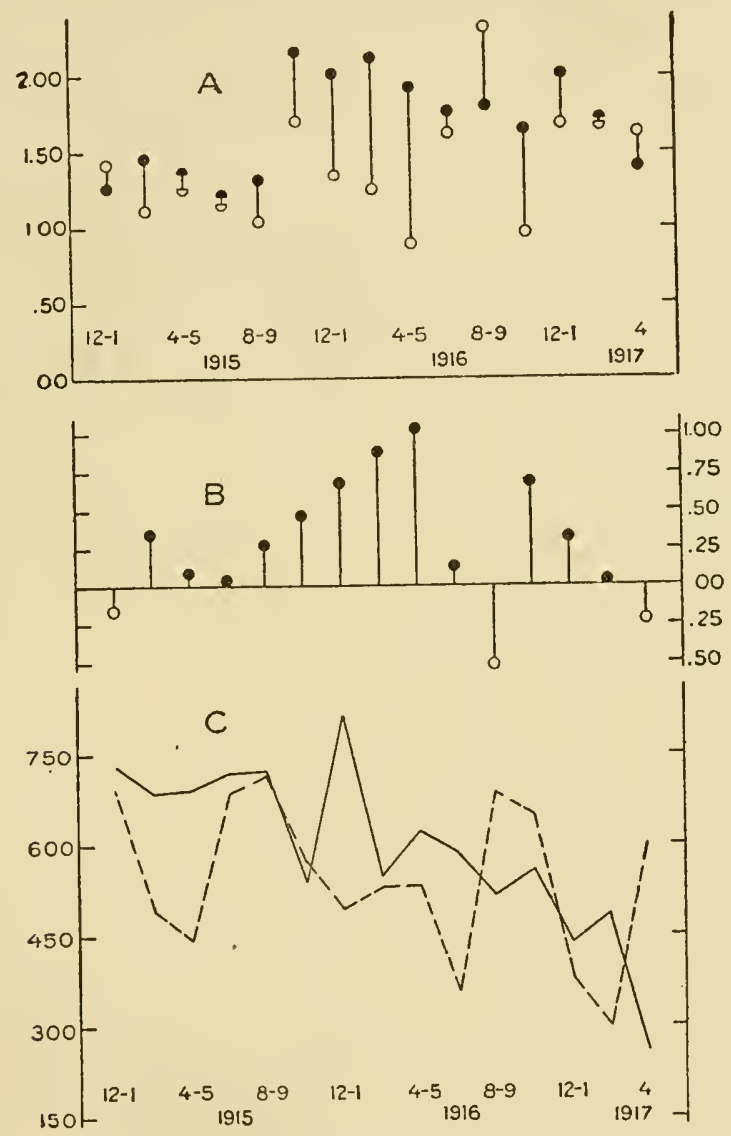

Figure 12.-Line 795.

A. Reproductive indices, actual values.

B. Reproductive indices, superiority.

C. Reaction-time curves.

cantly lower reactiveness on the part of the plus strain, a result opposite that of a selective effect.

For the following and final 9 months of selection with this line the plus strain averaged the more reactive; the means were 457.2 and 502 seconds, and the difference was $-44.8 \pm 17.6$ seconds, or 2.55 times the probable error. The 5 same-day broods gave as means 307 and 671 seconds. The minus same-day mean was more than double that for the plus strain, the difference being $-364 \pm 33.38$ seconds, 10.9 times the probable error. Of these 5 same-day broods, 
4 occurred in succession in April 1917 and constituted the final data for this line. The writer believes that considerable stress may be safely placed upon the same-day-brood data and is inclined to think that at the close of the experiment with Line 795 the plus strain was actually and significantly the more reactive.

It is quite possible to suppose that the considerably higher reaction-time of the plus strain during the early part of this experiment (whatever may have been the cause and meaning) was gradually reduced by selection and that at the close of the experiment the plus strain was actually the more reactive, due to the influence of selection. But in the absence of a test series at the close of the experiment, and without knowledge as to what the relative reaction-time means for the two strains would have been in later generations, with or without further selection, the supposition is not worth consideration.

It is not at all improbable, however, that the differences in different parts of the curves for the two strains represent merely low and high points in the reactiveness of the two strains due to nongenetic influences, the plus strain being relatively slightly reactive and the minus strain unusually reactive during the early period, while the reverse was true during the later part of the experiment. Such fluctuations in the reactiveness of the two strains of the same line for considerable periods are seen in several cases, notably in Line 695 (figure 2c) and Line 740 (figure 15).

In this line from June-July 1915 to April-May 1916 there was a general rise in the reproductive index for the plus strain and a general fall in the reproductive index for the minus strain. The result was a wide divergence in reproductive indices for the two strains culminating in April-May 1916, when the reproductive index for the plus strain was nearly twice that for the minus strain (figure 12A). This may be thought a result of selection acting in a cumulative way upon the vigor of the 2 strains, but there was no relaxation in or change in the method of selection, and yet the minus strain later reached as high a point in reproductive index as it had attained at any earlier time (though in general it remained lower than the plus strain).

While the reproductive indices indicate (figure $12 \mathrm{~A}$ ) that the plusstrain was in general very much the more vigorous of the two strains, one fails to find (as always) any direct relation between reproductive index and reaction-time. The generally much higher reproductive index for the plus strain, associated as it is during most of the experiment with a considerably higher reaction-time mean for this strain, in itself serves as a general denial of an association in this line between vigor and reactiveness to light.

LINE 796.

This was a sister line to Lines 794 and 795 . Sclection was begun at the same time and continued for the same period as with those 
lines (29 months), representing 95 generations in the plus and 91 generations in the minus strain. The data are given in tables 37 and 38 and figure 13.

The courses of the reaction-time curves are extremely irregular, although in a general way the curves follow each other in a manner to suggest environmental influence upon reaction-time. It is obvious that there was no effect of selection.

TABLE 37.-Selection summary for Line 796.

\begin{tabular}{|c|c|c|c|c|c|c|c|c|c|c|c|c|c|c|c|}
\hline Time period. & Strain. & 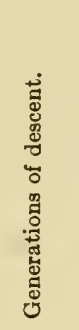 & 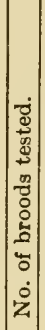 & 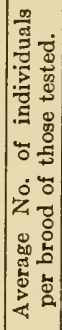 & 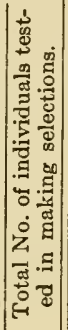 & 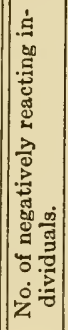 & 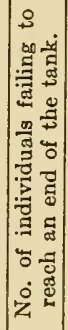 & 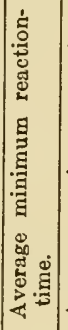 & 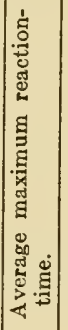 & 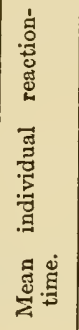 & 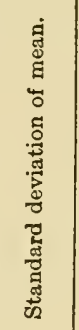 & 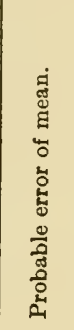 & 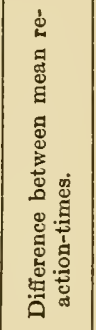 & 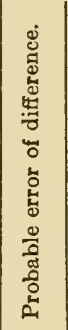 & 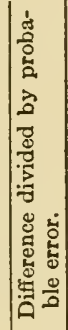 \\
\hline $\begin{array}{l}\text { Dec. 25, 1914- } \\
\text { July } 31,1915 \\
\text { Aug. 1, 1915- } \\
\text { July } 31,1916 \\
\text { Aug. } 1,1916- \\
\text { May } 1,1917 \\
\text { Test se ries. } \\
\text { Aug. } 1916,0 \\
\text { July } 1,1916- \\
\text { Sept. 30, 1916 }\end{array}$ & $\left\{\begin{array}{l}\text { Plus.... } \\
\text { Minus... } \\
\text { Plus..... } \\
\text { Minus... } \\
\text { Plus.... } \\
\text { MFinus... } \\
\text { Plus.... } \\
\text { Minus... } \\
\text { Plus.... } \\
\text { Minus... }\end{array}\right.$ & $\begin{array}{r}1-28 \\
1-2 \gamma \\
29-66 \\
28-61 \\
67-95 \\
63-90 \\
68 \\
64 \\
65-71 \\
61-68\end{array}$ & $\mid \begin{array}{r}28 \\
27 \\
38 \\
33 \\
22 \\
20 \\
20 \\
20 \\
7 \\
7\end{array}$ & $\begin{array}{l}12.3 \\
13.0 \\
15.9 \\
8.0 \\
13.7 \\
93.6 \\
33.1 \\
32.2 \\
16.6 \\
14.1\end{array}$ & $\begin{array}{r}343 \\
351 \\
604 \\
265 \\
302 \\
192 \\
662 \\
643 \\
116 \\
99\end{array}$ & $\begin{array}{r}4 \\
15 \\
13 \\
2 \\
5 \\
1 \\
15 \\
15 \\
8 \\
1 \\
9\end{array}$ & \begin{tabular}{r|r}
117 \\
147 \\
301 \\
175 \\
98 \\
49 \\
379 \\
362 \\
76 \\
28
\end{tabular} & $\begin{array}{l}244 \\
255 \\
364 \\
454 \\
220 \\
144 \\
256 \\
189 \\
346 \\
248\end{array}$ & \begin{tabular}{|l|}
876 \\
844 \\
857 \\
839 \\
692 \\
710 \\
900 \\
900 \\
828 \\
849
\end{tabular} & $\begin{array}{l}555.5 \\
604.8 \\
619.1 \\
697.5 \\
449.4 \\
393.7 \\
675.6 \\
653.7 \\
662.4 \\
458.8\end{array}$ & $\begin{array}{l}289.5 \\
290.9 \\
291.9 \\
299.2 \\
331.1 \\
31.9 \\
286.6 \\
302.8 \\
201.3 \\
319.9\end{array}$ & $\begin{array}{r}10.5 \\
10.5 \\
8.0 \\
12.3 \\
12.8 \\
14.1 \\
7.5 \\
8.1 \\
12.6 \\
21.7\end{array}$ & $\begin{array}{r}-49.3 \\
-78.4 \\
+55.7 \\
+21.9 \\
+208.6\end{array}$ & \begin{tabular}{|l|}
14.7 \\
19.1
\end{tabular} & 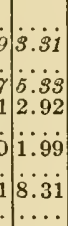 \\
\hline
\end{tabular}

TABLE 38.-Same-day broods. Summary of data for Line 796.

\begin{tabular}{|c|c|c|c|c|c|c|c|c|c|c|c|c|c|}
\hline Time period. & Strain. & 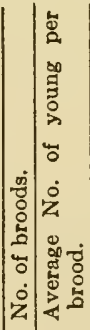 & 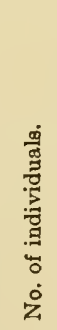 & 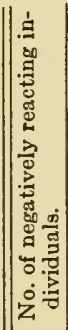 & 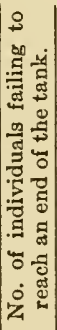 & 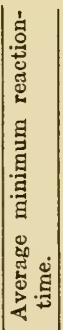 & 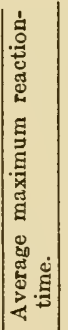 & 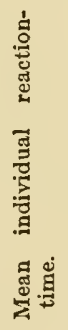 & 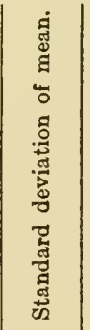 & 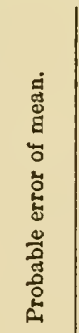 & 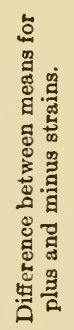 & 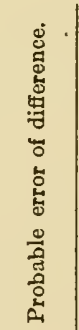 & 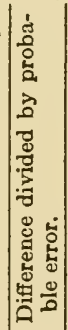 \\
\hline $\begin{array}{l}\text { Dec. } 25,1914- \\
\text { July } 31,1915 \\
\text { Aug. 1, } 1915- \\
\text { July } 31,1916 \\
\text { Aug. 1, } 1916- \\
\text { May } 1,1917\end{array}$ & $\begin{array}{l}\text { Plus.... } \\
\text { Minus... } \\
\text { Plus.... } \\
\text { Minus... } \\
\text { Plus.... } \\
\text { Minus. }\end{array}$ & \begin{tabular}{r|r}
7 & 8.4 \\
7 & 7.4 \\
10 & 13.9 \\
10 & 8.6 \\
4 & 17.0 \\
4 & 15.8
\end{tabular} & $\begin{array}{r}59 \\
62 \\
139 \\
85 \\
68 \\
63\end{array}$ & $\begin{array}{l}2 \\
5 \\
1 \\
1 \\
2 \\
3\end{array}$ & $\begin{array}{l}28 \\
14 \\
78 \\
52 \\
48 \\
19\end{array}$ & $\begin{array}{l}329 \\
194 \\
382 \\
492 \\
345 \\
161\end{array}$ & $\begin{array}{l}900 \\
797 \\
900 \\
864 \\
900 \\
810\end{array}$ & $\begin{array}{l}634 \\
523 \\
674 \\
680 \\
723 \\
503\end{array}$ & $\left|\begin{array}{l}283.10 \\
281.80 \\
176.68 \\
298.57 \\
291.84 \\
303.54\end{array}\right|$ & $\begin{array}{l}24.86 \\
26.36 \\
10.11 \\
21.84 \\
23.87 \\
25.79\end{array}$ & $\begin{array}{r}\cdots \\
+220 \\
+220\end{array}$ & $\begin{array}{l}24.0 \% \\
35.14\end{array}$ & $\begin{array}{l}0.24 \\
6.26\end{array}$ \\
\hline
\end{tabular}

The mean reaction-times for the first longer period (8 months) of the experiment were 555.5 and 604.8 seconds, the plus strain being the more reactive by a margin of $49.3 \pm 14.9$ seconds, a difference 3.31 times the probable error (table 37$)^{\circ}$. The 7 same-day broods for this period gave averages indicating greater reactiveness for the minus strain by a difference of $+111 \pm 36.23$ seconds, more than double the difference obtained from the entire data for this period and in the reverse direction (table 38). 
For the second longer period the reaction-time means were 619.1 and 697.5 seconds. The difference was $-78.4 \pm 14.7$ seconds, 5.33 times the probable error. The 10 same-day broods gave averages differing by only $-6 \pm 24.07$ seconds.

The data for the last longer period (August 1916 to the end of the selection experiment in April 1917) gave as means 449.4 and
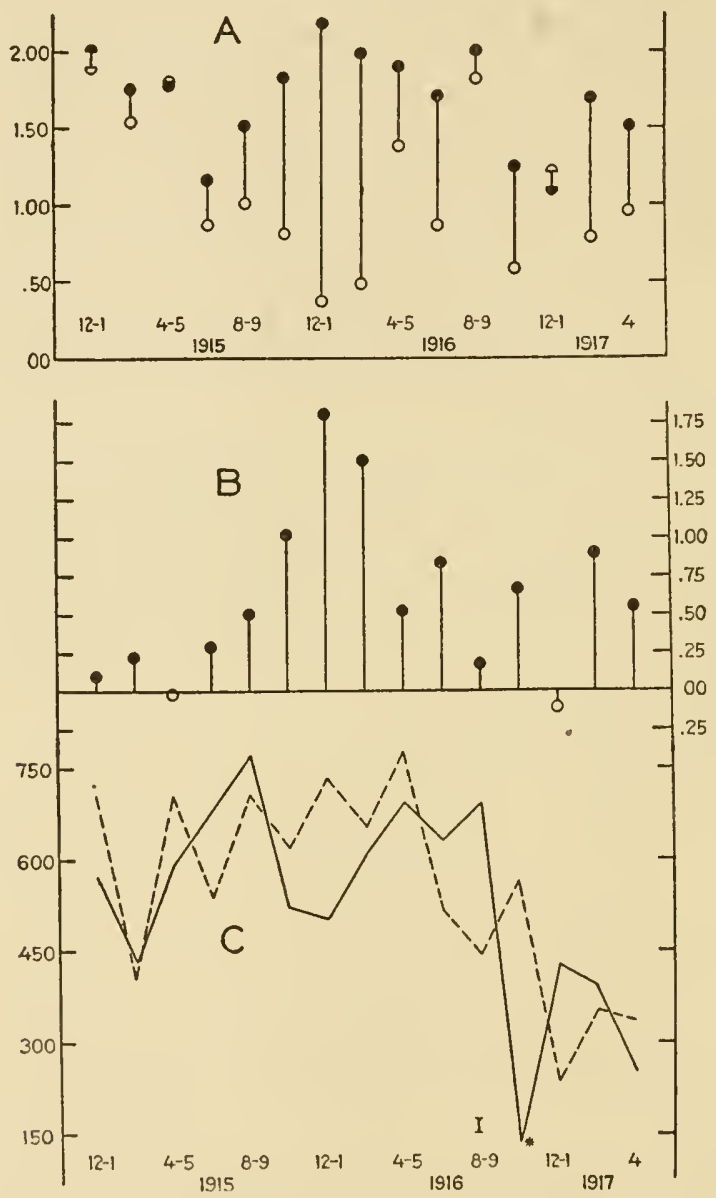

Figure 13.-Line 796.

A. Reproductive indices, actual values.

B. Reproductive indices, superiority.

C. Reaction-time curves. (The asterisk indicates a point established from insufficient data, only one brood.)

393.7 seconds. The minus strain was the more reactive by $55.7 \pm 19.1$ seconds, 2.92 times the probable error. The same-day-brood means (only 4 broods of each strain) differed by 220 seconds, the minus strain being the more reactive. A test series conducted during August 1916 consisted of 662 and 643 individuals in the two strains. 
The means were 675.6 and 653.7 seconds. The difference was $+21.9 \pm 11.0$ seconds, 1.99 times the probable error.

Hence, for the first 2 longer periods the means for the entire data gave higher reaction-times for the minus than for the plus strain. These differences $(-49.3$ and -78.4 seconds) were 3.31 and 5.33 times their probable errors, but the lack of confirmation of these differences from the same-day-brood data at once throws doubt upon a real significance for these differences; while for the final long period of the experiment with Line 796, the test series, the selection data as a whole, and the same-day-brood data confirm each other in indicating a greater reactiveness on the part of the minus strain.

The data for this line would seem to present these points of interest: a lack of selective effect, an effect of environmental influences upon reaction-time as indicated by the courses of the curves; they following each other in a general way, and the lack of any marked evidence of a relation between vigor and reaction-time in a case in which the two strains differed extremely in vigor. This last point may be worthy of a little further statement.

The plus strain was very much the more vigorous during most of the experiment, yet the differences in mean reaction-time were not such as to indicate, everything considered, a significantly higher reaction-time for the minus strain than for the plus strain. Indeed, the same-day-brood data quite fail to confirm any significant difference in reaction-time between the two strains for any part of the experiment. During the 3 two-month periods during which the difference in mean reproductive indices were greatest (figure $13 \mathrm{~B}$ ), the minus strain was less reactive, but for 2 of the 3 other periods (in which the inferiority in reproductive index for the minus strain was almost as great) the minus strain was actually the more reactive. There were altogether 9 periods of very low reproductive indices (about 1.00 or lower) for the minus strain, and these were periods during which the plus strain, with two exceptions, ran fairly high in vigor (reproductive index over 1.50), and hence the difference in vigor was marked; yet the minus strain, far from being markedly less reactive, was during 4 of these periods actually the more reactive. It was the less reactive, however, during the other 5 periods and in 3 cases the differences were large. Though in general the reproductive index for the minus strain of this line remained lower than that for the plus strain, it regained a high level (1.7) soon after this divergence in reproductive indices was most marked.

Thus, while in both Lines 795 and 796 there was an apparent cumulative effect of selection upon the vigor of the minus strain, in both cases the effect was lost and the minus strain later attained relatively high reproductive indices, although the method and procedure of selection were in no wise modified. 
LINE 740.

Line 740 was the first line of S. exspinosus subjected to selection. It was obtained in August 1912, from Pond IV, in which S. exspinosus occurs the year round. Selection was begun at once and continued for 181 and 184 generations, for a period of more than 56 months,

TABLE 39.-Selection summary for Line 740.

\begin{tabular}{|c|c|c|c|c|c|c|c|c|c|c|c|c|c|c|c|}
\hline Time period. & Strain. & 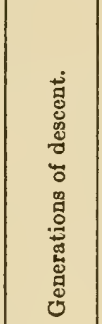 & 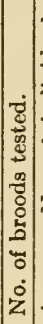 & 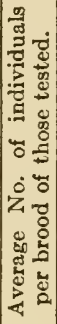 & 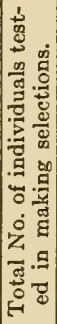 & 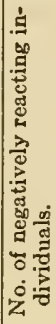 & 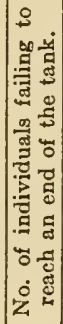 & 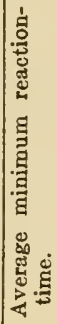 & 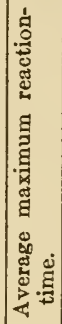 & 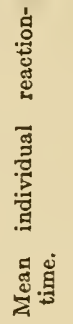 & 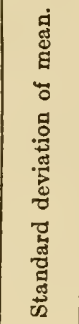 & 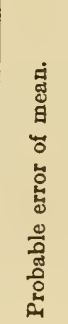 & 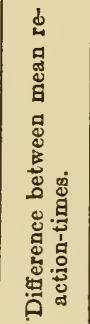 & 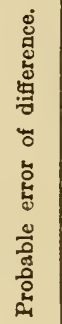 & 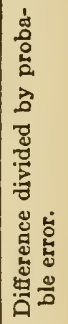 \\
\hline Aug. 27, 1912- & lus & $1-34$ & 37 & 11.5 & 427 & 0 & 291 & 384 & 872 & 735.2 & 266.0 & 8.7 & & & \\
\hline & & & the & & $\begin{array}{l}857 \\
094\end{array}$ & 5 & 259 & 999 & 884 & 757.0 & 244.7 & 8.7 & -21.8 & 12.8 & 1.77 \\
\hline $\begin{array}{l}\text { Augg } 1,1913- \\
\text { July } 31,1914\end{array}$ & $\begin{array}{l}\text { Pus... } \\
\text { Minus. }\end{array}$ & $\begin{array}{l}35-76 \\
95-79\end{array}$ & $40: 3$ & $\begin{array}{l}10.6 \\
10.7\end{array} \mid$ & $\begin{array}{l}424 \\
482\end{array}$ & $\begin{array}{l}5 \\
2 \\
2\end{array}$ & $\begin{array}{l}184 \\
275\end{array}$ & $\begin{array}{l}359 \\
416\end{array}$ & 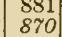 & $\begin{array}{l}597.1 \\
656.9\end{array}$ & $\begin{array}{l}298.7 \\
302.4\end{array}$ & $\begin{array}{l}9.8 \\
9.3\end{array}$ & -59.8 & $i \ddot{s} . \dot{5}$ & 4.49 \\
\hline Test serie 8, & Plus... & $\begin{array}{l}65 \\
66\end{array}$ & 23 & 28.4 & $\begin{array}{l}653 \\
614\end{array}$ & 1 & 358 & 173 & 900 & 666.4 & 294.6 & 7.8 & -45 & 10 & iij \\
\hline Mar.1914- & & $\begin{array}{r}61-68 \\
68\end{array}$ & 8 & $\begin{array}{l}20.9 \\
11.0\end{array}$ & $\begin{array}{r}1.4 \\
88\end{array}$ & $\frac{1}{1}$ & $\begin{array}{r}391 \\
36\end{array}$ & 347 & 870 & 569.2 & & & $\begin{array}{l}-40.0 \\
\ldots \ldots\end{array}$ & & \\
\hline & & $62-71$ & 10 & & 126 & 0 & 56 & 269 & 834 & 596.8 & & & -27.1 & & \\
\hline Au & & $77-118$ & 42 & & 452 & 16 & 244 & 305 & 886 & 642.5 & 307.6 & 9.8 & +34.8 & 13.8 & 2.52 \\
\hline & & $\mid \begin{array}{r}79-119 \\
119-153\end{array}$ & 40. & 11.4 & $\begin{array}{r}454 \\
4771\end{array}$ & $\frac{4}{2}$ & 208 & $\begin{array}{l}851 \\
303\end{array}$ & \begin{tabular}{|l|}
839 \\
828
\end{tabular} & & $\begin{array}{l}306.0 \\
335.6\end{array}$ & 9.7 & & & \\
\hline $\begin{array}{l}1915- \\
, 1916\end{array}$ & Minus & $\left|\begin{array}{l}119-153 \\
120-155\end{array}\right|$ & {$\left[\begin{array}{ll}30 \\
36\end{array}\right.$} & & $\left|\begin{array}{l}481 \\
519\end{array}\right|$ & 4 & 262 & \begin{tabular}{|l}
303 \\
290
\end{tabular} & 820 & $\begin{array}{l}574.6 \\
600.0\end{array}$ & $\begin{array}{l}335.6 \\
326.9\end{array}$ & $\begin{array}{r}10.4 \\
9.7\end{array}$ & -25.4 & 14.2 & 1.79 \\
\hline Test series, & Plus... & & 34 & & $\mid 1078$ & $\underset{7}{5}$ & $\begin{array}{c}628 \\
509\end{array}$ & 202 & 900 & $\begin{array}{l}641.6 \\
677.9\end{array}$ & \begin{tabular}{|}
324.6 \\
931.7
\end{tabular} & 6.7 & +63.7 & 9.5 & 6.71 \\
\hline & Plu & $139-146$ & & 17.9 & 143 & 2 & 82 & \begin{tabular}{|l|}
1750 \\
359
\end{tabular} & 900 & 653.8 & & & 712.0 & & \\
\hline & & $140-147$ & & & & & 81 & 348 & & & & & & & \\
\hline & & & 32 & & 1231 & & 199 & 113 & 817 & & & 6.1 & & & \\
\hline & & & 82. & & 1282 & & 243 & 127 & & & 468.5 & 8.8 & -105.5 & 10.3 & 10.24 \\
\hline $\begin{array}{c}\text { Ma a } 1916 \\
\text { July } 31,19\end{array}$ & $\begin{array}{l}\text { Minu } \\
\text { Minu }\end{array}$ & $\left|\begin{array}{l}147-153 \\
148-154\end{array}\right|$ & $\begin{array}{l}6 \\
6\end{array}$ & $\left|\begin{array}{l}14.3 \\
18.5\end{array}\right|$ & $\begin{array}{r}86 \\
111\end{array} \mid$ & $\begin{array}{l}0 \\
s\end{array}$ & $\begin{array}{l}45 \\
75 \\
\end{array}$ & 413 & 839 & $\begin{array}{l}57.7 \\
710.4\end{array}$ & & & -135.7 & & \\
\hline $\mathrm{Au}$ & & $\mid$ & 26 & & 252 & 3 & 27 & 113 & 631 & & 243.0 & 10.3 & & & \\
\hline & & & $\mid \begin{array}{l}24 \\
26\end{array}$ & & $\begin{array}{l}324 \\
756\end{array}$ & 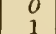 & $\begin{array}{l}88 \\
38 \\
8\end{array}$ & $\begin{array}{r}153 \\
79\end{array}$ & 669 & & $\begin{array}{l}334.0 \\
256.3\end{array}$ & $\begin{array}{l}12.5 \\
6.3\end{array}$ & -84.7 & 16.2 & 5.23 \\
\hline & & & 26 & & 756 & 0 & $\begin{array}{l}31 \\
31\end{array}$ & 106 & 678 & & 267.0 & 6.5 & -10.8 & 9.1 & 1.68 \\
\hline & & $175-181$ & 6 & 12.7 & 76 & 0 & & 102 & 560 & & 248.8 & 19.2 & +96.3 & 21.1 & 4.56 \\
\hline$y, 1918$ & & $178-184$ & & & & & & & 421 & 165.7 & 124.6 & & & & \\
\hline
\end{tabular}

TABLE 40.-Same-day broods. Summary of data for Line 740.

\begin{tabular}{|c|c|c|c|c|c|c|c|c|c|c|c|c|c|}
\hline Time period. & Btrain. & 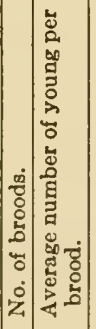 & 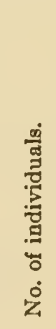 & 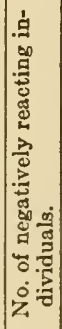 & 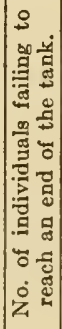 & 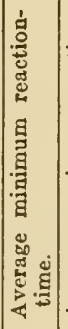 & 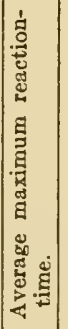 & 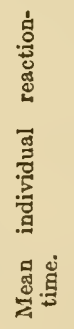 & 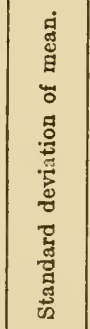 & 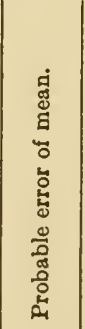 & 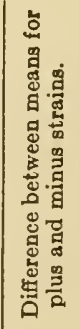 & 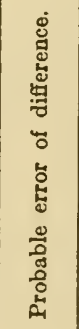 & 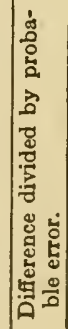 \\
\hline $\begin{array}{l}\text { Aug. } 1,1912- \\
\text { July } 31,1913 \\
\text { Aug. } 1,1913- \\
\text { July } 31,1914 \\
\text { Aup. } 1,1914- \\
\text { July } 31,1915 \\
\text { Aug. } 1,1915- \\
\text { July } 31,1916 \\
\text { Aug. } 1,1916- \\
\text { May } 1,1917\end{array}$ & $\left\{\begin{array}{l}\text { Plus..... } \\
\text { Minus... } \\
\text { Plus.... } \\
\text { Minus . } \\
\text { Plus.... } \\
\text { Mlinus... } \\
\text { Plus .... } \\
\text { Minus... } \\
\text { Plus..... } \\
\text { Minus. }\end{array}\right.$ & \begin{tabular}{r|r|}
6 & 10.0 \\
6 & 8.2 \\
9 & 10.8 \\
9 & 12.4 \\
3 & 12.3 \\
3 & 10.0 \\
14 & 15.4 \\
14 & 16.1 \\
4 & 10.5 \\
4 & 10.5
\end{tabular} & $\begin{array}{r}60 \\
49 \\
97 \\
112 \\
37 \\
90 \\
210 \\
226 \\
42 \\
42\end{array}$ & \begin{tabular}{l|}
0 \\
0 \\
1 \\
0 \\
0 \\
0 \\
0 \\
0 \\
0 \\
0
\end{tabular} & $\begin{array}{r}38 \\
29 \\
46 \\
54 \\
54 \\
31 \\
21 \\
99 \\
99 \\
193 \\
6 \\
2\end{array}$ & $\begin{array}{r}386 \\
382 \\
498 \\
412 \\
355 \\
529 \\
266 \\
324 \\
111 \\
75\end{array}$ & \begin{tabular}{|l|}
900 \\
900 \\
874 \\
789 \\
900 \\
900 \\
782 \\
806 \\
818 \\
736
\end{tabular} & $\begin{array}{l}713 \\
682 \\
607 \\
632 \\
834 \\
815 \\
558 \\
640 \\
358 \\
221\end{array}$ & 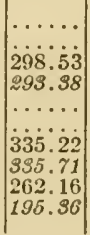 & $\begin{array}{l}15.38 \\
15.06 \\
27.29 \\
20.33\end{array}$ & $\begin{array}{c}\cdots \\
-88 \\
+137 \\
\ldots \ldots\end{array}$ & $\begin{array}{l}21.5 s \\
34.03\end{array}$ & $\begin{array}{l}3.80 \\
4.02\end{array}$ \\
\hline
\end{tabular}


until the experiment was completed. Both strains are still in our laboratory. ${ }^{1}$ The data are summarized in tables 39 and 40 and figures 14 and 15.

The first longer period of the experiment, approximately 11 months, contains the data for 37 and 36 broods of the two strains. The mean reaction-times (427 and 357 individuals) are 735.2 and 757 seconds (table 39$)$. The difference $(-21.8 \pm 12.3$ seconds) was 1.77 times the probable error. There were 6 same-day broods for this period (table 40) for which the mean reaction-times were 713 and 682 seconds, the difference being +31 seconds.

For the second year-period of selection with Line 740, the mean reaction-times (424 and 482 individuals) were 597.1 and 656.9 seconds. The difference was $-59.8 \pm 13.5$ seconds. This difference was 4.43 times the statistical probable error. The 9 same-day broods for this period gave as mean reaction-times 607 and 632 seconds, the difference being $-25 \pm 31.18$ seconds.

A test series was conducted in April 1914. There were 653 individuals of the plus strain and 614 of the minus strain. The mean reaction-times were 666.4 and 711.9 seconds. The difference was $-45.5 \pm 10.9$ seconds, or 4.17 times the probable error. There is a suggestion of an effect of selection for this year-period in that the data as a whole, the data for the same-day broods, and the testseries data all show higher reaction-times for the minus strain. But in view of the later data this evidence is overruled.

For the next year-period (August 1914-July 1915) the mean reaction-times (452 and 454 individuals) were 642.5 and 607.7. The difference $(+34.8 \pm 13.8$ seconds) is 2.52 times the probable error. Hence the difference is of statistical interest, but is opposed to an effect of selection. There were only 3 same-day broods for this yearperiod for which the mean reaction-times were 834 and 815 seconds. The difference was +19 seconds.

For the year-period (August 1915-July 1916) the mean reactiontimes (471 and 519 individuals) were 574.6 and 600.0 seconds. The difference $(-25.4 \pm 14.2$ seconds) is only 1.79 times the probable error. There were 14 same-day broods for this period, for which the mean reaction-times were 558 and 640 seconds. The difference was $-82 \pm 21.53$ seconds.

A test series was conducted during March 1916 and contained 1,078 individuals in the plus strain and 1,089 in the minus strain. The mean reaction-times were 641.6 and 577.9 seconds. The difference $(+63.7 \pm 9.5$ seconds $)$ is 6.71 times the probable error. This test series was conducted with great care, and the fact that the plus strain was the less reactive of the two by a margin of statistical significance largely counterbalances the small difference in the

${ }^{1}$ It was in one of the substrains of this line $(740$ - Special B) that the sex-intergrades were first discovered. 
opposite direction for the selection data as a whole and the larger difference in the opposite direction for the same-day-brood data for this year. Another test series was conducted during this period, during June 1916; it contained 1,231 individuals in the plus strain and 1,282 in the minus strain. The mean reaction-times were 420.2 and 525.7 seconds. The difference $(-105.5 \pm 10.3$ seconds $)$ is 10.24 times the probable error. The result of this test series, conducted only 3 months later than the earlier one, is quite contradictory to the result of the former.

The results of these test series are somewhat puzzling, but table 39 , giving the selection summary, shows that for the three-month period February-April 1916 (including the month in which the earlier test series was made and that just preceding and just succeeding) the mean reaction-time was much higher for the plus strain. The similar period of 3 months, May-July 1916, during which the June test series was conducted, shows a mean reaction-time in the minus strain 135.7 seconds greater than that for the plus strain. One sees, in these test series and the selection data for the contingent periods, that the relative reactiveness had changed here in a comparatively short time. Reference to the curve, figure 15, shows that for the two-month period, February-March 1916, the two curves met, but for the later two-month periods the minus strain for a considerable time was much less reactive than the plus strain.

For the final longer period of the experiment with Line 740 (August 1916 to the close of the experiment, May 1, 1917) the mean reaction-times were 311.1 seconds and 395.8 seconds for the two strains. The difference $(-84.7 \pm 16.2$ seconds) was 5.23 times the probable error. There were only 4 same-day broods, for which the mean reaction-times were 358 and 221 seconds, the difference being $+137 \pm 34.03$ seconds. Here the number of same-day broods was too small to be given serious consideration, but it is interesting to note that with these same-day broods the plus strain was so much less reactive than the minus, in opposition to the difference shown by the data as a whole for this period. Two of these 4 same-day broods, however, occurred during the final 3 months of the experiment, when the data as a whole showed that the minus strain was temporarily the more reactive.

Reference to the curves of the mean reaction-times (figure 15) shows that for 10 months (from April 1916 to January 1917, inclusive) the minus strain was the less reactive and that the margin of difference increased until in the December 1916 and January 1917 periods the reaction-time for the minus strain was more than double that for the plus strain. The data for a portion of this ten-month period was not very satisfactory. We were troubled with poor food conditions, and, at times, when the stock was not well nourished, the selections were not made by tests, but individuals were chosen at 
tween the two strains of Line 740 for the period April 1916-January 1917 is due to exceptionally high means for the minus strain during the period April-September and to exceptionally low means in the plus strain from October to the following January, both relative to the means for corresponding two-month periods for the other $S$. exspinosus strains (Lines 794, 795, and 796). The following of one of these two exceptional reaction-time periods just upon the other produces the long period of divergence which at first sight seems very suggestive of an effect of selection. Since it is seen in this case that neither the plus nor the minus strain of Line 740 is consistently different from the composite curve for the other plus and minus strain of lines of $S$. exspinosus throughout this ten-month period, it seems pretty evident that genetic change is not responsible for this divergence. It is believed that the explanation lies in the unavoidable differential treatment of the two strains of the same line (see pages $140-142$ ).

A final test series was conducted in April 1917. There were 756 individuals of each strain. The mean reaction-times were 314.5 seconds and 329.8 seconds. The difference $(-15.3 \pm 9.1$ seconds) was only 1.68 times the probable error. For the contingent twomonth period the plus strain was the less reactive by 96.3 seconds. This test series, fortunately conducted at the close of selection, showed conclusively that there was no effect of selection in this line; or, if there had actually been an effect of selection, that it had been lost. The selections were somewhat relaxed during the October-January period, but it does not seem probable that a real selective difference would have been lost so quickly. Hence, everything considered, the writer does not believe that the data for the ten-month period in which there was a consistent reaction-time difference between the two strains indicates an effect of selection.

Line 740 is somewhat unique among the lines of Cladocera for which the data for vigor has been worked out, in that the minus strain was on the whole more vigorous. Of the 29 two-month periods, the minus strain was the more vigorous as measured by the reproductive index for 18 periods and the plus strain was the more vigorous of the two for only 11 periods. The differences in favor of the plus strain average somewhat larger than those favoring the minus strain, however. Examining these data with reference to periods of superiority in the reproductive index on the part of the two strains, one fails to find any correlation between relatively greater reactiveness and greater vigor. For the 5 two-month periods during which the reproductive index for the plus strain was superior to that for the minus strain by 0.25 or more, the plus strain had a higher reactiontime twice and a lower reaction-time three times. For the 6 twomonth periods for which the reproductive index for the minus strain was superior to that for the plus strain by 0.25 or more, the reaction- 
time mean for the minus strain was higher four times and lower twice. Further detailed analysis fails to show any relation between mean reproductive index and mean reaction-time.

The curves for Line 740 indicate clearly a marked general effect of environmental conditions upon the reactiveness of these animals. There are irregularities in the curve, but in a general way the reactiontime curves for the two strains follow each other remarkably well.

It is possible that a mutation occurred in the minus strain of Line 740 in the forty-third generation of selection. A brood of 8 young on September 28, 1913, had the remarkably low reactiontime mean of 159 seconds. These were day-old young, however, and day-old young are sometimes abnormally reactive. Further, 4 of these 8 young were negative in their reactions, an unusual result, indicating unusual experimental conditions (see page 15). However, on the following day a brood of 8 from another mother of this strain had a mean of only 280 seconds.

Examination of the other selection data for the same days showed that the broods of the strains of $D$. pulex from which selections were made were unusually reactive. Fairly extensive tests of additional broods of 740 minus and other strains of S. exspinosus extending over several generations failed to show any consistently greater reactiveness in 740 minus, though certain descendants of the very reactive individuals of the minus strain of Line 740 produced broods some, but a minority, of which were very reactive.

The results of these tests and the fact of the unusual reactiveness of many of the broods of other strains tested during this period led to the conclusion that a mutation had probably not occurred and that the unusual reactiveness of the minus strain of Line 740 at that time had probably been caused by unusual experimental conditions.

If a mutation did occur it should have remained apparent (in the absence of segregation) at least for a considerable period, in spite of any effect of selection. But after the second generation the reaction-means for 740 minus were normal, running usually above 700 seconds.

\section{LINE 757.}

\section{Presentation of Data.}

The datafor Line 757 will be examined with great care, for with this line the result is different from that with most of the other lines used in these selection experiments, and it is desired to be conservative regarding any conclusions that may be reached regarding the effect of selection within this line.

The original mother of Line 757 was obtained October 19, 1912, from Pond I, the temporary surface-water pond. Selection was begun with her first laboratory brood of young and continued for 181 generations, covering a period of $41 / 2$ years. 
The tabulations of the data and the diagrams employed are practically identical with those used in presenting the data for Line 695 and the other lines to which rather careful treatment has been accorded. They are: tabulations of the data by broods for the 757 plus strain and the 757 minus strain (tables 41 and 42 ); tabulation by two-month periods (tables 43 and 44); a summary of the selection data, including the results of the test series (table 45); a tabulation of the data for the same-day broods (table 46); summary of data for more reactive individuals (table 47 ); figure $18 \mathrm{~B}$, showing graphically the mean reaction-times of the two strains by two-month periods; figure 19, showing the reaction-time curves by six-month periods; figure 16, showing the relative rates of descent of the two strains; figure $17 \mathrm{~A}$, representing the average brood-size for the two strains; figure $17 \mathrm{~B}$, showing average age of mothers at the time the first broods were produced; figure $17 \mathrm{c}$, giving the reproductive indices for the two strains; and figure 18A, showing graphically the differences in vigor of the two strains as indicated by the reproductive indices. Tables 48 and 49, comparing the data for Line 757 with that for the other S. exspinosus lines, are also presented, and the data in them are graphically presented in figures 15 and $18 \mathrm{~B}$.

Examination of tables 41 and 42 shows that in Line 757, as with all the lines subjected to selection, there are considerable fluctuations in the reactiveness of individual broods. During the first 5 months of selection the range in mean reaction-time by broods for the plus strain was from 472 to 900 seconds and for the minus strain from 586 to 900 seconds. The fluctuations in reaction-time means by broods were still large after the two strains became widely different in their reactiveness to light. For the last 5 months of selection with Line 757 the plus strain means ranged from 93 to 651 seconds and the minus strain means from 133 to 814 seconds.

Although brood-by-brood comparison (tables 41 and 42) shows clearly that in general, after the early part of the selection experiment with Line 757 , the minus broods were very much the less reactive, the rather wide fluctuations by brood averages made it desirable to treat the data by larger units.

Tables of the data by one-month periods were made. ${ }^{1}$ From the averages in these tables it was found that for the first 9 months of selection the plus strain of Line 757 was the more reactive for 7 months; for the second longer period (the year August 1913-July 1914) the plus was the more reactive during 10 months; for the third longer period the plus was the more reactive during 10 months; for the remaining 21 months of the experiment the plus was the more reactive during each month. After the first 5 months of selection

1 These are omitted from the paper for the sake of reducing the cost of publication and in favor of retaining in the paper the tables of data by broods in which the original data are given in sufficient detail to make possible their utilization by anyone who might wish to examine the data statistically. 
TABLE 41.-Summary of selection data by broods for Line 757 plus.

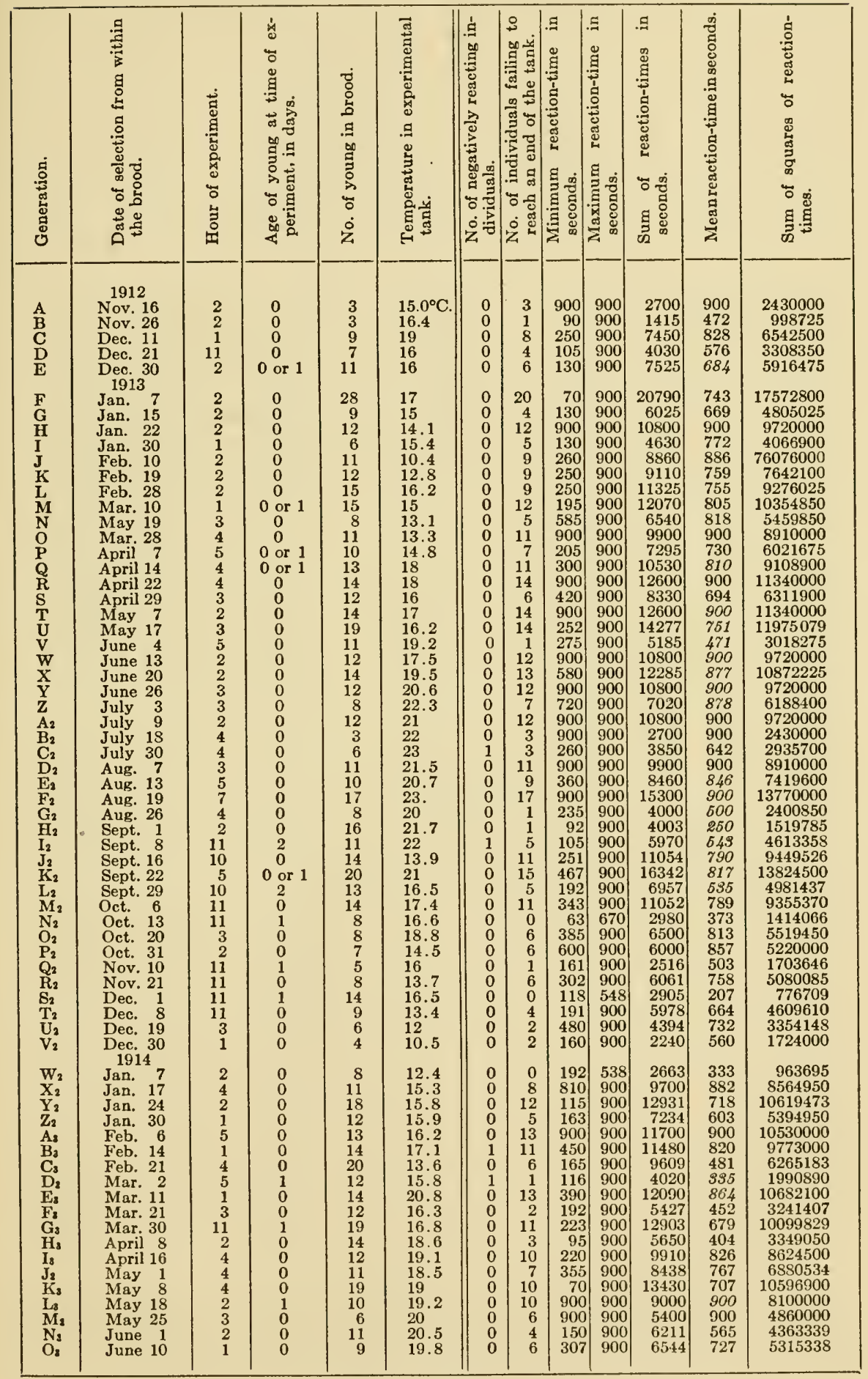


TABLE 41.-Summary of selection data by broods for Line 757 plus-Continued.

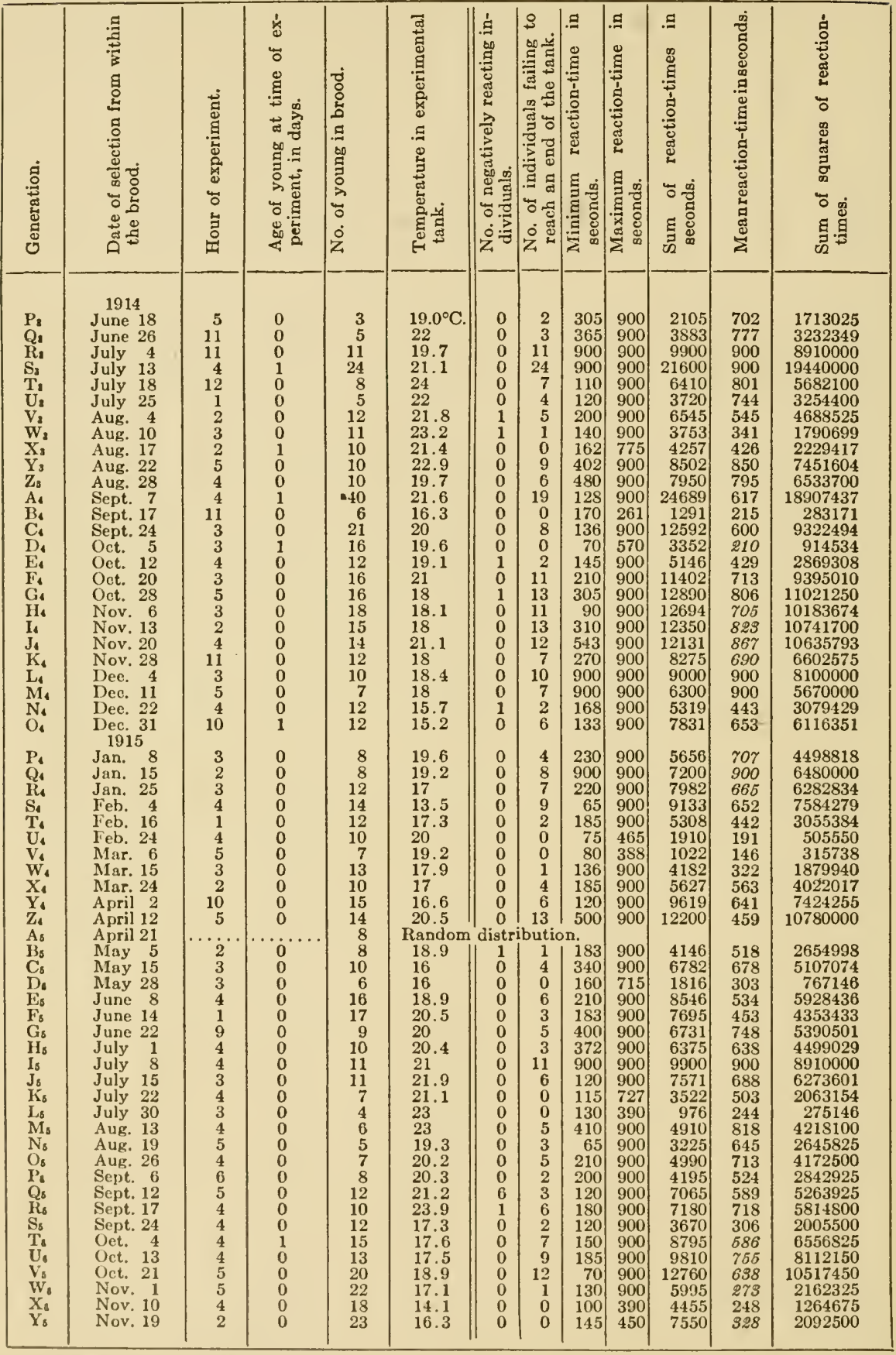

- Probably two broods, the first brood having been overlooked until the seeond appeared. Inammueh as the seeond brood (if there were two) was a day old before this test was made, the first brood must then have been near 72 hours old. Obviously data for three-day-old individuals is not strietly comparable to the other data, nearly all of which was obtained from individuals less than 24 hours old. Henee, much as the writer dialikes to eull his data in any manner, the data for this day's test is omitted. However, it may be added that this is the only instanee in the data of this publication in which any data bas been rejected. 
TABLE 41.-Summary of selection data by broods for Line 757 plus-Continued.

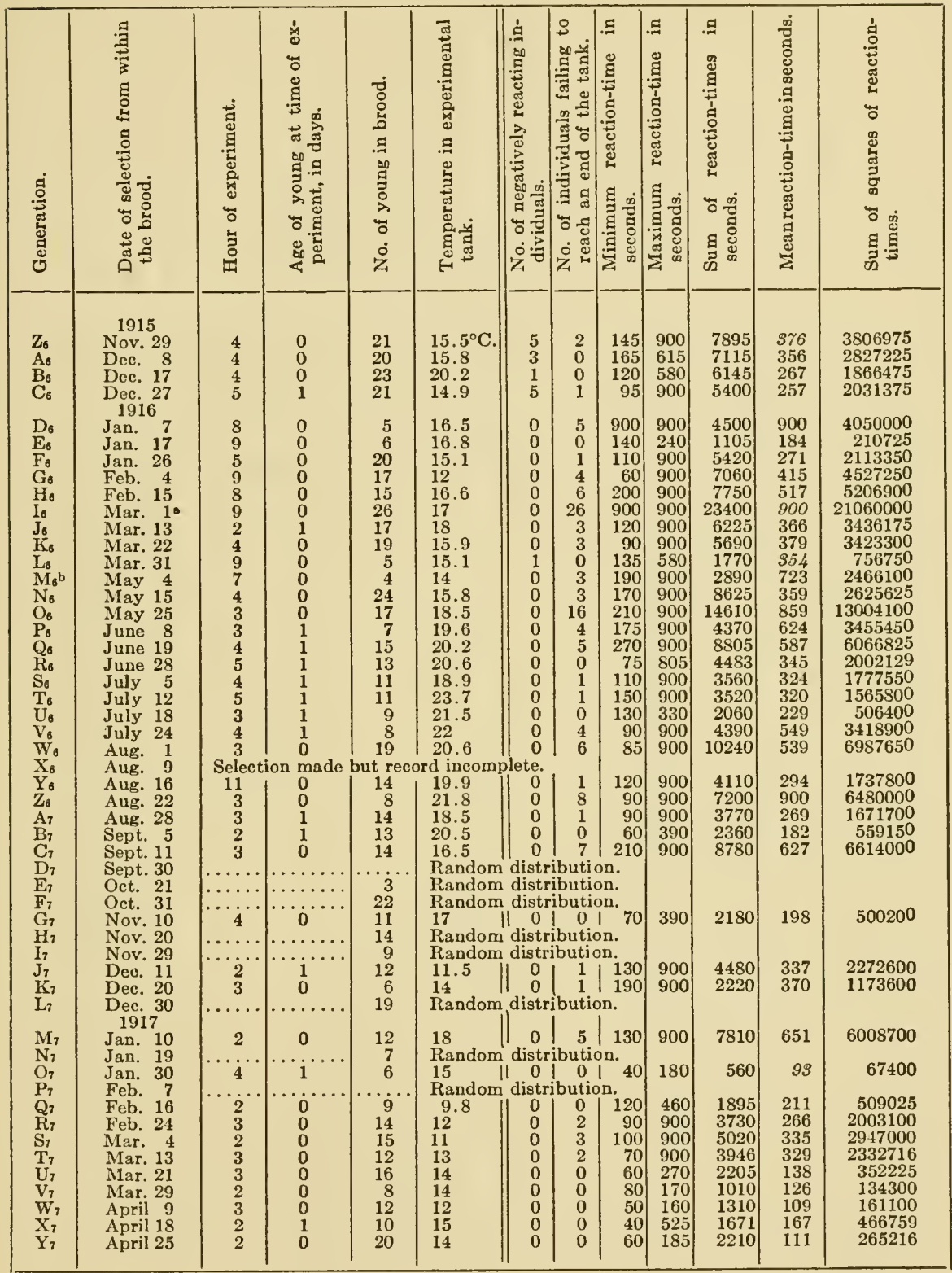

- Second brood from this mother.

b The $M_{6}$ generation was taken from a very late brood of the $\mathrm{L}_{6}$ generation which was used in conducting a test series. 
TABLE 42.-Summary of selection data by broods for Line 757 minus.

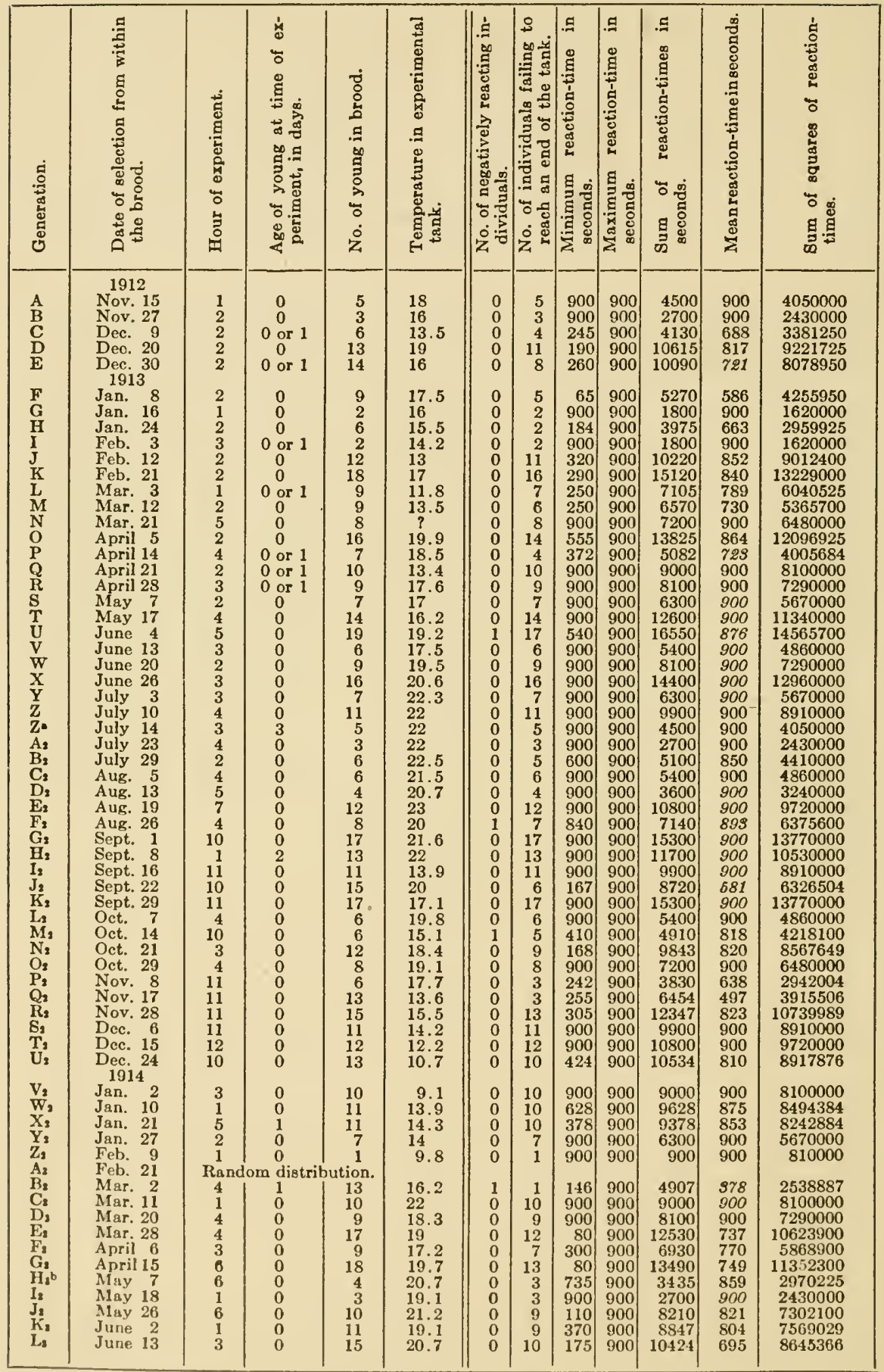

- Selection was repented from a later brood because of the loss of the earlier brood.

b Death lasses in this strain made this interval between generations unusually long. 
TABLE 42.-SUmmary of selection data by broods for Line 757 minus-Continued.

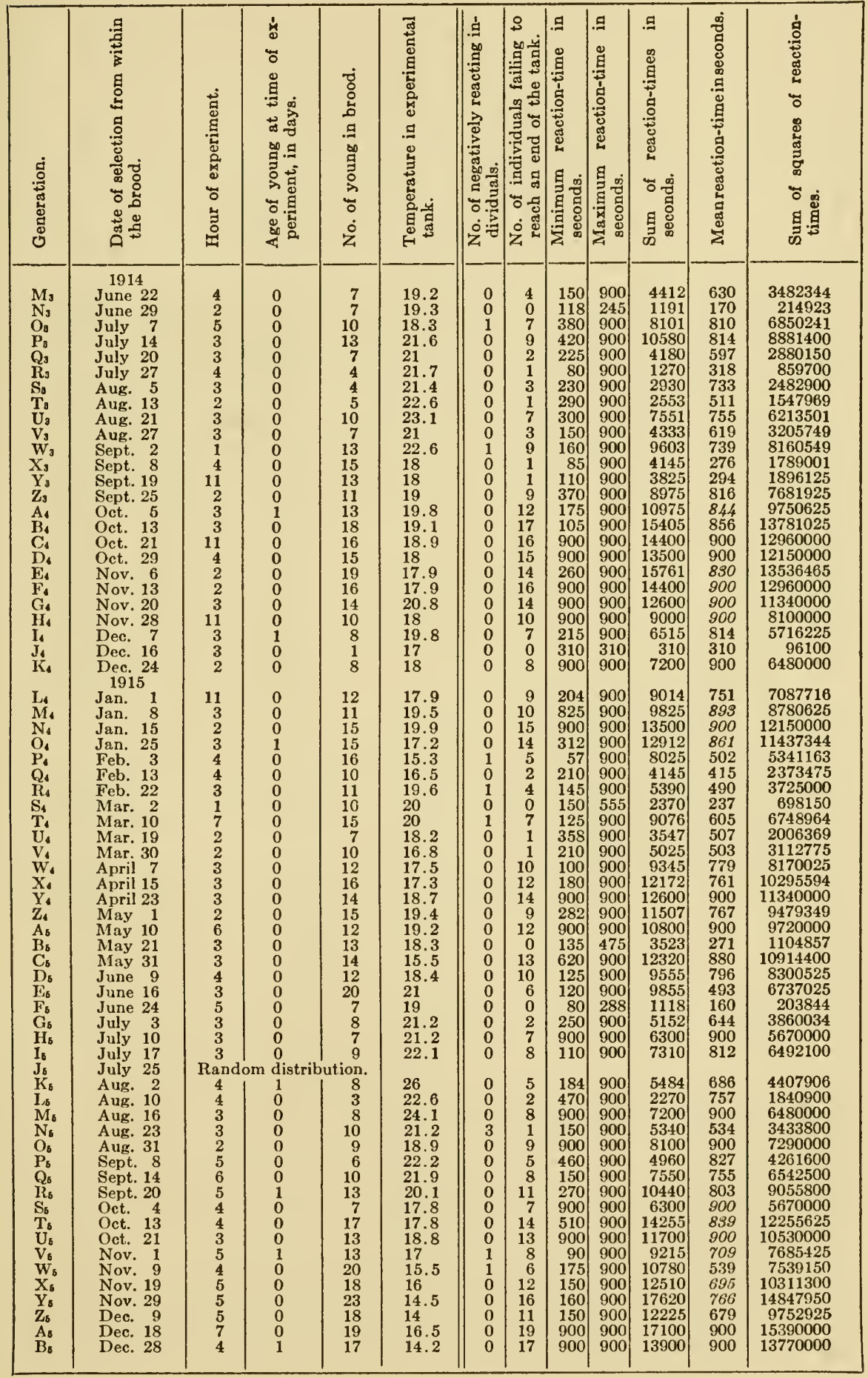


TABLE 42.-Summary of selection data by broods for Line 757 minus-Continued.

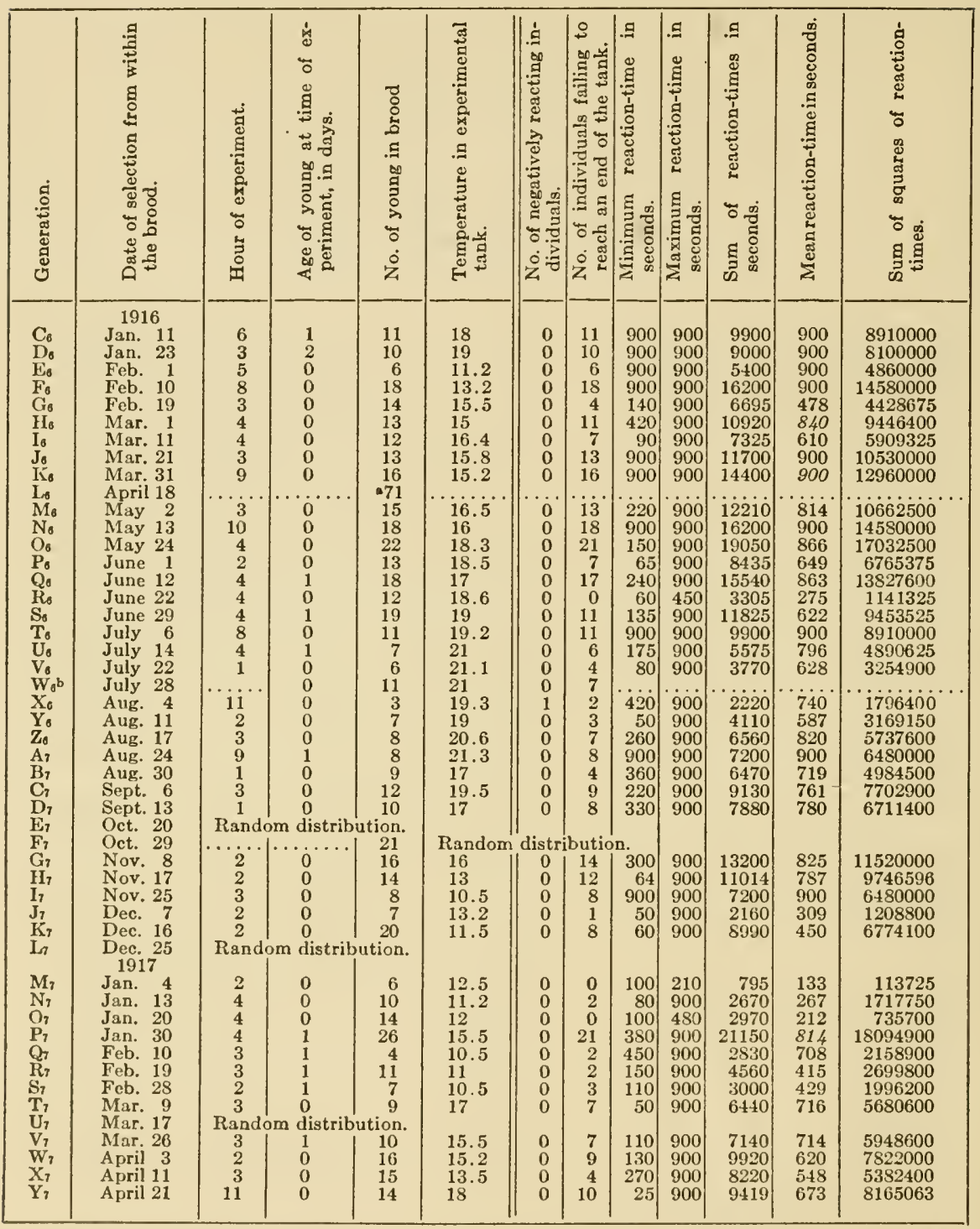

a This selection made from a fourth brood of 71 individuals constituting a part of a test series. Data not included here as not strictly comparable to other data of this table.

Selection made, but time of beginning of experiment insdvertently omitted.

the plus was the more reactive during every month exeept for 4 months during the period of irregularity in reactiveness in 1914 and 1915 (see pages 115-116 and table 44).

Averages of the data by two-month periods (tables 41 and 42), such as are given for Lines $695,689,711$, and 719 , serve still further to compensate for temporary irregularities in reactiveness and are used in the analysis of the data for line 757 and as a basis for the curves given in figure $18 \mathrm{~B}$. 
individual reaction-time records, respectively) were: for the plus strain 788.3 seconds, and for the minus strains 838.9 seconds (table 45). The difference $(-50.6 \pm 11.18$ seconds $)$ is 4.53 times the statistical probable error. These data include those for the 5 months at the beginning of the experiment, when selection was only slightly if at all effective. For this nine-month period there are 9 same-day broods, containing 114 and 99 individuals, with the reaction-time for the minus strain averaging $58 \pm 16.24$ seconds greater than that

TABLE 43.-Selection data summarized by two-month periods for Line 757 plus.

\begin{tabular}{|c|c|c|c|c|c|c|c|c|c|c|c|c|c|c|}
\hline Time period. & 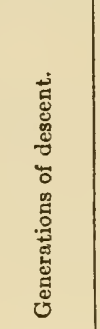 & $\begin{array}{l}\dot{8} \\
\dot{0} \\
0 \\
0 \\
\dot{0} \\
\dot{0} \\
\dot{0} \\
z\end{array}$ & 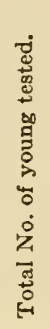 & 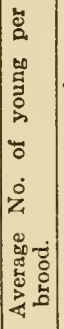 & 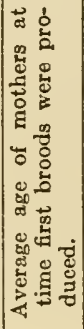 & 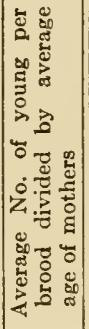 & 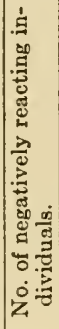 & 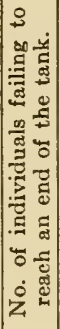 & 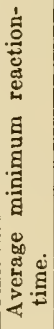 & 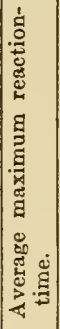 & 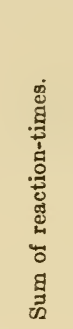 & 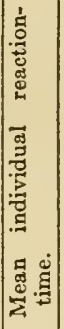 & 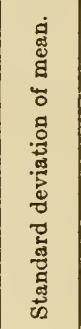 & 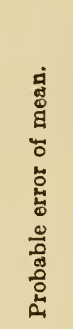 \\
\hline $\begin{array}{l}\text { Nov. 1912........ } \\
\text { Dec.1912-Jan.1913 } \\
\text { Feb.-Mar. 1913... } \\
\text { Apr.-May 1913... } \\
\text { June-July 1913... }\end{array}$ & $\begin{array}{c}1-2 \\
3-9 \\
10-15 \\
16-22 \\
23-20\end{array}$ & $\begin{array}{l}2 \\
7 \\
6 \\
6 \\
8\end{array}$ & $\begin{array}{r}6 \\
82 \\
72 \\
82 \\
78\end{array}$ & $\begin{array}{r}3.0 \\
11.7 \\
12.0 \\
13.7 \\
9.6\end{array}$ & $\begin{array}{r}13.7 \\
9.8 \\
9.7 \\
8.4 \\
7.4\end{array}$ & $\begin{array}{l}0.22 \\
1.19 \\
1.24 \\
1.63 \\
1.30\end{array}$ & $\begin{array}{l}0 \\
0 \\
0 \\
0 \\
1\end{array}$ & $\begin{array}{r}4 \\
59 \\
55 \\
66 \\
63\end{array}$ & $\begin{array}{l}495 \\
245 \\
407 \\
496 \\
679\end{array}$ & $\begin{array}{l}900 \\
900 \\
900 \\
900 \\
900\end{array}$ & $\begin{array}{r}4115 \\
61250 \\
57805 \\
65632 \\
63440\end{array}$ & $\begin{array}{l}685 \\
747 \\
803 \\
800 \\
813\end{array}$ & \begin{tabular}{|l|}
318.01 \\
274.69 \\
198.86 \\
208.50 \\
196.47
\end{tabular} & $\begin{array}{l}87.57 \\
20.36 \\
15.81 \\
15.53 \\
15.00\end{array}$ \\
\hline $\begin{array}{l}\text { Aug.-Sept. 1913 ... } \\
\text { Oct.-Nov. 1913...ं } \\
\text { Dec.1913-Jan.1914 } \\
\text { Feb.-Mar. 1914 ... } \\
\text { Apr.-May 1914... } \\
\text { June-July } 1914 \ldots\end{array}$ & $\begin{array}{l}30-38 \\
39-45 \\
46-52 \\
53-59 \\
60-65 \\
66-73\end{array}$ & $\begin{array}{l}9 \\
6 \\
8 \\
7 \\
6 \\
8\end{array}$ & $\begin{array}{r}120 \\
50 \\
82 \\
104 \\
72 \\
76\end{array}$ & $\begin{array}{r}12.3 \\
9.1 \\
9.7 \\
14.9 \\
12.0 \\
9.9\end{array}$ & $\begin{array}{l}6.4 \\
8.2 \\
8.8 \\
8.3 \\
8.2 \\
7.6\end{array}$ & $\begin{array}{l}1.92 \\
1.11 \\
1.10 \\
1.80 \\
1.46 \\
1.30\end{array}$ & $\begin{array}{l}1 \\
0 \\
0 \\
2 \\
0 \\
0\end{array}$ & $\begin{array}{l}75 \\
30 \\
33 \\
57 \\
46 \\
61\end{array}$ & $\begin{array}{l}389 \\
309 \\
279 \\
348 \\
423 \\
395\end{array}$ & \begin{tabular}{|}
900 \\
862 \\
811 \\
900 \\
900 \\
900
\end{tabular} & $\begin{array}{l}81986 \\
35109 \\
48045 \\
67229 \\
51828 \\
60373\end{array}$ & $\begin{array}{l}683 \\
702 \\
586 \\
646 \\
720 \\
794\end{array}$ & $\left|\begin{array}{l}301.07 \\
270.01 \\
309.38 \\
296.25 \\
266.32 \\
227.95\end{array}\right|$ & $\begin{array}{l}18.54 \\
25.76 \\
23.04 \\
19.59 \\
21.17 \\
17.64\end{array}$ \\
\hline 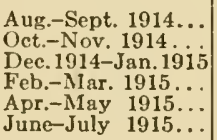 & $\begin{array}{c}74-81 \\
82-89 \\
90-96 \\
97-102 \\
103-108 \\
109-116\end{array}$ & $\begin{array}{l}7 \\
8 \\
7 \\
6 \\
5 \\
8\end{array}$ & $\begin{array}{r}80 \\
119 \\
69 \\
66 \\
53 \\
85\end{array}$ & $\begin{array}{r}13.3 \\
15.0 \\
10.2 \\
11.4 \\
11.0 \\
9.9\end{array}$ & $\begin{array}{l}7.1 \\
8.3 \\
8.2 \\
9.5 \\
9.7 \\
7.6\end{array}$ & $\begin{array}{l}1.87 \\
1.81 \\
1.24 \\
1.20 \\
1.13 \\
1.30\end{array}$ & $\begin{array}{l}2 \\
2 \\
1 \\
0 \\
1 \\
0\end{array}$ & $\begin{array}{l}29 \\
69 \\
44 \\
16 \\
24 \\
34\end{array}$ & $\begin{array}{l}241 \\
243 \\
493 \\
121 \\
261 \\
304\end{array}$ & $\begin{array}{l}791 \\
859 \\
900 \\
742 \\
863 \\
815\end{array}$ & $\begin{array}{l}44890 \\
78240 \\
49288 \\
27182 \\
34563 \\
51316\end{array}$ & $\begin{array}{l}561 \\
657 \\
714 \\
412 \\
652 \\
604\end{array}$ & $\left|\begin{array}{l}298.18 \\
303.13 \\
269.78 \\
305.76 \\
281.37 \\
281.06\end{array}\right|$ & $\begin{array}{l}22.47 \\
18.74 \\
21.91 \\
25.38 \\
26.07 \\
20.56\end{array}$ \\
\hline $\begin{array}{l}915-J a n .1916 \\
\text { Mar. } 1916 \ldots \\
\text { May } 1916 \ldots \\
\text { July } 1916 . . .\end{array}$ & $\begin{array}{l}117-123 \\
124-130 \\
131-136 \\
137-142 \\
143-145 \\
146-152\end{array}$ & $\begin{array}{l}7 \\
7 \\
6 \\
6 \\
3 \\
7\end{array}$ & $\begin{array}{r}60 \\
132 \\
95 \\
99 \\
45 \\
74\end{array}$ & $\begin{array}{l}10.0 \\
17.8 \\
17.8 \\
15.2 \\
17.8 \\
10.6\end{array}$ & $\begin{array}{r}7.4 \\
9.2 \\
9.8 \\
10.3 \\
9.8 \\
8.3\end{array}$ & $\begin{array}{l}1.35 \\
1.93 \\
1.82 \\
1.48 \\
1.82 \\
1.28\end{array}$ & $\begin{array}{l}0 \\
5 \\
9 \\
1 \\
0 \\
0\end{array}$ & $\begin{array}{r}26 \\
31 \\
7 \\
42 \\
22 \\
15\end{array}$ & $\begin{array}{l}187 \\
132 \\
255 \\
251 \\
190 \\
143\end{array}$ & $\begin{array}{l}900 \\
763 \\
689 \\
847 \\
900 \\
805\end{array}$ & $\begin{array}{l}35235 \\
57260 \\
29685 \\
51895 \\
26125 \\
31188\end{array}$ & $\begin{array}{l}587 \\
434 \\
312 \\
524 \\
581 \\
421\end{array}$ & $\begin{array}{l}323.40 \\
270.87 \\
200.72 \\
336.60 \\
255.24 \\
276.37\end{array}$ & $\begin{array}{l}28.16 \\
15.90 \\
13.89 \\
22.82 \\
25.66 \\
21.67\end{array}$ \\
\hline $\begin{array}{l}\text { Aug.-Sept. 1916... } \\
\text { Oet.-Nov. 1916 } \\
\text { Dec.1916-Jan.1917 } \\
\text { Feb.-Mar. 1917 ... } \\
\text { Apr. 1917. ....... }\end{array}$ & $\begin{array}{l}153-160 \\
161-165 \\
166-171 \\
172-178 \\
179-181\end{array}$ & $\begin{array}{l}6 \\
1 \\
4 \\
6 \\
3 \\
\end{array}$ & $\begin{array}{l}82 \\
11 \\
36 \\
74 \\
42\end{array}$ & $\begin{array}{l}13.7 \\
12.8 \\
10.4 \\
12.3 \\
14.0\end{array}$ & $\begin{array}{r}6.9 \\
11.0 \\
10.0 \\
8.8 \\
9.2\end{array}$ & $\begin{array}{l}1.99 \\
1.16 \\
1.04 \\
1.40 \\
1.52\end{array}$ & $\begin{array}{l}0 \\
0 \\
0 \\
0 \\
0\end{array}$ & $\begin{array}{r}23 \\
0 \\
7 \\
7 \\
0\end{array}$ & $\begin{array}{r}109 \\
70 \\
123 \\
87 \\
50\end{array}$ & $\begin{array}{l}815 \\
390 \\
720 \\
600 \\
290\end{array}$ & $\begin{array}{r}36460 \\
2180 \\
15070 \\
17806 \\
5191\end{array}$ & $\begin{array}{l}445 \\
198 \\
419 \\
241 \\
124\end{array}$ & $\begin{array}{r}309.23 \\
78.92 \\
298.80 \\
232.34 \\
77.53\end{array}$ & $\begin{array}{r}23.03 \\
16.05 \\
33.59 \\
18.22 \\
8.07\end{array}$ \\
\hline
\end{tabular}

for the plus strain. This difference is 3.59 times its probable error. Only one of these minus same-day broods had a mean reaction-time lower than that for the corresponding plus brood.

For the year August 1913-July 1914 (44 generations and 504 individual reaction-time records, and 42 generations and 412 individuals in the plus and minus strains, respectively), the mean reaction-times were 683.7 seconds and 783.0 seconds (table 45). The difference in mean reaction-time was $-99.3 \pm 11.77$ seconds, or 8.44 times the probable error. The 11 same-day broods for this period (145 and 123 individuals, table 46) gave a difference in reaction- 
time of $-135.0 \pm 21.74$ seconds. Because of the smaller total numbers of individuals of the same-day broods, the statistical probable error was relatively large, but the difference was still 6.31 times the probable error. In only one of these same-day broods was the reaction-time for the brood of the minus strain smaller than that for the plus strain. However, during one period, the last two-month period of this year, the minus strain had a reaction-time 132 seconds lower than that for the plus strain. This was a period of rather

TABLE 44.-Selection data summarized by two-month periods for Line 757 minus.

\begin{tabular}{|c|c|c|c|c|c|c|c|c|c|c|c|c|c|c|c|c|c|}
\hline Time period. & 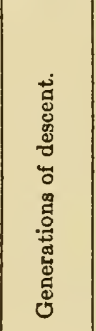 & 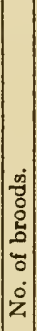 & 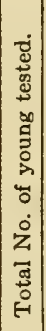 & 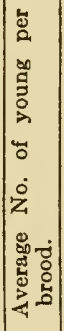 & 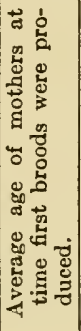 & 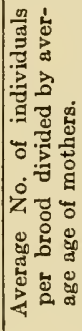 & 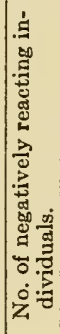 & 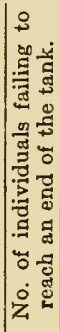 & 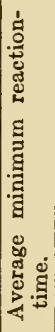 & 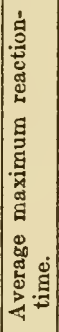 & 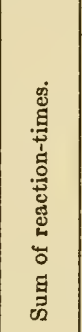 & 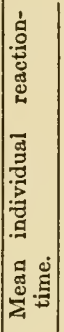 & 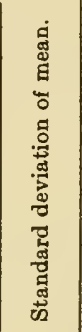 & 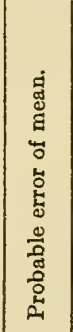 & 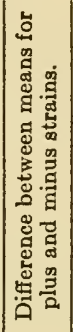 & 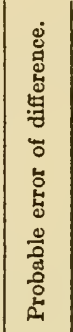 & 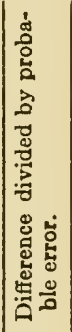 \\
\hline $\begin{array}{l}\text { Nov. 1912 ..... } \\
\text { Dec.1912-Jan.1913 } \\
\text { Feb.-Mar. 1913 ... } \\
\text { Apr.-May } 1913 . \ldots \\
\text { June-July } 1913 \ldots\end{array}$ & $\begin{array}{c}1-2 \\
3-8 \\
9-14 \\
15-21 \\
22-28\end{array}$ & $\begin{array}{l}2 \\
6 \\
6 \\
6 \\
9\end{array}$ & $\begin{array}{r}8 \\
50 \\
58 \\
63 \\
82\end{array}$ & $\begin{array}{r}4.0 \\
8.3 \\
9.7 \\
10.5 \\
8.3\end{array}$ & $\begin{array}{r}14.3 \\
9.9 \\
9.3 \\
9.5 \\
7.4\end{array}$ & $\begin{array}{l}0.28 \\
.84 \\
1.04 \\
1.11 \\
1.12\end{array}$ & $\begin{array}{l}0 \\
0 \\
0 \\
0 \\
1\end{array}$ & $\begin{array}{r}8 \\
32 \\
50 \\
58 \\
79\end{array}$ & $\begin{array}{l}900 \\
307 \\
485 \\
755 \\
827\end{array}$ & $\begin{array}{l}900 \\
900 \\
900 \\
900 \\
900\end{array}$ & $\begin{array}{r}7200 \\
35880 \\
48015 \\
54907 \\
72950\end{array}$ & $\begin{array}{l}900 \\
718 \\
828 \\
872 \\
890\end{array}$ & $\begin{array}{r}0.00 \\
274.60 \\
185.83 \\
101.83 \\
55.42\end{array}$ & $\begin{array}{r}0.00 \\
26.19 \\
16.46 \\
8.65 \\
4.13\end{array}$ & $\begin{array}{l}-214 \\
+\quad 29 \\
-25 \\
=72 \\
-77\end{array}$ & $\begin{array}{l}87.56 \\
33.18 \\
22.82 \\
17.78 \\
15.56\end{array}$ & $\begin{array}{l}2.45 \\
0.87 \\
1.09 \\
4.05 \\
4.94\end{array}$ \\
\hline $\begin{array}{l}\text { Aug.-Sept. 1913... } \\
\text { Oct.-Nov. } 1913 . . \\
\text { Dec.1913-Jan.1914 } \\
\text { Feb.-Mar. 1914 ... } \\
\text { Apr.-May } 1914 \ldots \\
\text { June-July } 1914 \ldots\end{array}$ & $\begin{array}{l}29-37 \\
38-44 \\
45-51 \\
52-57 \\
58-62 \\
63-70\end{array}$ & $\begin{array}{l}9 \\
7 \\
7 \\
5 \\
5 \\
8\end{array}$ & $\begin{array}{r}103 \\
66 \\
75 \\
50 \\
44 \\
74\end{array}$ & $\begin{array}{r}11.4 \\
9.4 \\
10.7 \\
10.0 \\
8.3 \\
7.7\end{array}$ & $\begin{array}{l}6.9 \\
8.3 \\
8.3 \\
9.1 \\
8.7 \\
7.5\end{array}$ & $\begin{array}{l}1.65 \\
1.13 \\
1.29 \\
1.10 \\
.95 \\
1.03\end{array}$ & $\begin{array}{l}1 \\
1 \\
0 \\
1 \\
0 \\
1\end{array}$ & $\begin{array}{l}93 \\
47 \\
70 \\
33 \\
35 \\
42\end{array}$ & $\begin{array}{l}812 \\
454 \\
719 \\
585 \\
425 \\
240\end{array}$ & \begin{tabular}{|}
900 \\
900 \\
900 \\
900 \\
900 \\
818
\end{tabular} & $\begin{array}{l}87860 \\
49984 \\
65540 \\
35437 \\
34765 \\
49005\end{array}$ & $\begin{array}{l}853 \\
757 \\
874 \\
709 \\
790 \\
662\end{array}$ & $\begin{array}{l}157.60 \\
242.21 \\
100.95 \\
291.54 \\
236.26 \\
306.09\end{array}$ & $\mid \begin{array}{r}10.47 \\
20.11 \\
7.86 \\
27.81 \\
24.02 \\
24.00\end{array}$ & $\mid \begin{array}{r}-170 \\
-55 \\
-288 \\
-63 \\
-70 \\
+132\end{array}$ & $\begin{array}{l}21.29 \\
32.67 \\
24.35 \\
34.02 \\
32.02 \\
29.79\end{array}$ & $\begin{array}{r}7.98 \\
1.68 \\
11.82 \\
1.85 \\
2.18 \\
4.43\end{array}$ \\
\hline $\begin{array}{l}\text { Aug.-Sept. 1914 ... } \\
\text { Oot.-Nov. 1914. } \\
\text { Dec.1914-Jan. } 1915 \\
\text { Feb.-Mar. } 1915 \ldots \\
\text { Apr.-May } 1915 \ldots \\
\text { June-July } 1915 \ldots\end{array}$ & $\begin{array}{c}71-78 \\
79-86 \\
87-93 \\
94-100 \\
101-107 \\
108-114\end{array}$ & \begin{tabular}{l|}
8 \\
8 \\
7 \\
7 \\
7 \\
6 \\
6
\end{tabular} & $\begin{array}{r}78 \\
121 \\
70 \\
79 \\
96 \\
63\end{array}$ & $\begin{array}{l}11.8 \\
16.0 \\
10.3 \\
11.7 \\
12.9 \\
10.8\end{array}$ & $\begin{array}{l}7.6 \\
8.1 \\
8.1 \\
9.3 \\
9.6 \\
7.8\end{array}$ & $\begin{array}{l}1.55 \\
1.98 \\
1.27 \\
1.26 \\
1.34 \\
1.38\end{array}$ & $\begin{array}{l}1 \\
0 \\
0 \\
3 \\
0 \\
0\end{array}$ & $\begin{array}{r}34 \\
114 \\
63 \\
20 \\
70 \\
33\end{array}$ & $\begin{array}{l}212 \\
630 \\
524 \\
179 \\
445 \\
264\end{array}$ & $\begin{array}{l}900 \\
900 \\
816 \\
851 \\
839 \\
798\end{array}$ & $\begin{array}{r}43915 \\
106041 \\
59276 \\
37578 \\
72267 \\
39290\end{array}$ & \begin{tabular}{|l|}
563 \\
876 \\
847 \\
476 \\
753 \\
624
\end{tabular} & $\begin{array}{l}325.30 \\
117.19 \\
171.25 \\
278.70 \\
262.89 \\
327.67\end{array}$ & $\left|\begin{array}{r}24.84 \\
7.19 \\
13.81 \\
21.15 \\
18.10 \\
27.85\end{array}\right|$ & $\mid \begin{array}{l}- \\
-219 \\
-133 \\
-64 \\
-101 \\
-20\end{array}$ & $\begin{array}{l}33.49 \\
20.07 \\
25.89 \\
33.04 \\
31.74 \\
34.62\end{array}$ & $\begin{array}{r}0.05 \\
10.91 \\
5.13 \\
1.93 \\
3.18 \\
0.57\end{array}$ \\
\hline $\begin{array}{l}\text { Aug.-Sept. } 1915 \ldots \\
\text { Oct.-Nov. } 1915 . . \\
\text { Dec.1915-Jan. } 1916 \\
\text { Feb.-Mar. } 1916 \ldots \\
\text { Apr.-May } 1916 \ldots \\
\text { June-July } 1916 \ldots\end{array}$ & $\mid \begin{array}{l}115-122 \\
123-129 \\
130-134 \\
135-141 \\
142-145 \\
146-153\end{array}$ & $\begin{array}{r}8 \\
7 \\
5 \\
7 \\
3 \\
7\end{array}$ & $\begin{array}{r}67 \\
111 \\
75 \\
92 \\
55 \\
86\end{array}$ & $\begin{array}{r}8.4 \\
17.1 \\
16.0 \\
11.9 \\
18.3 \\
12.8\end{array}$ & $\begin{array}{r}7.1 \\
9.7 \\
10.3 \\
10.2 \\
11.0 \\
8.2\end{array}$ & $\begin{array}{l}1.18 \\
1.76 \\
1.55 \\
1.17 \\
1.66 \\
1.56\end{array}$ & $\begin{array}{l}3 \\
2 \\
0 \\
0 \\
0 \\
0\end{array}$ & $\begin{array}{l}49 \\
76 \\
68 \\
75 \\
52 \\
56\end{array}$ & $\begin{array}{l}436 \\
412 \\
750 \\
607 \\
423 \\
236\end{array}$ & $\begin{array}{l}900 \\
900 \\
900 \\
900 \\
900 \\
836\end{array}$ & $\begin{array}{l}51344 \\
82380 \\
62125 \\
72640 \\
47460 \\
58350\end{array}$ & \begin{tabular}{|l|}
766 \\
742 \\
828 \\
790 \\
863 \\
678
\end{tabular} & $\begin{array}{l}243.39 \\
263.55 \\
244.04 \\
241.59 \\
155.04 \\
317.39\end{array}$ & $\begin{array}{l}20.06 \\
16.87 \\
19.01 \\
16.99 \\
14.10 \\
23.08\end{array}$ & $\begin{array}{l}-179 \\
-308 \\
-516 \\
-266 \\
-282 \\
-275\end{array}$ & $\begin{array}{l}34.57 \\
23.18 \\
23.54 \\
28.45 \\
29.28 \\
31.66\end{array}$ & $\begin{array}{r}5.17 \\
13.28 \\
21.92 \\
9.34 \\
9.63 \\
8.11\end{array}$ \\
\hline $\begin{array}{l}\text { Aug.-Sept. 1916 ... } \\
\text { Oct.-Nov. } 1916.917 \\
\text { Dec. 1916-Jan.1917 } \\
\text { Feb.-Mar. } 1917 \ldots \\
\text { April, 1917....... }\end{array}$ & $\begin{array}{l}154-160 \\
161-165 \\
166-172 \\
173-178 \\
179-181\end{array}$ & $\begin{array}{l}7 \\
3 \\
6 \\
5 \\
3 \\
\end{array}$ & \begin{tabular}{|l|}
57 \\
38 \\
83 \\
41 \\
45
\end{tabular} & $\begin{array}{r}8.1 \\
15.1 \\
13.3 \\
8.2 \\
15.0\end{array}$ & $\begin{array}{l}6.7 \\
9.0 \\
8.9 \\
9.5 \\
8.8\end{array}$ & $\begin{array}{l}1.21 \\
1.68 \\
1.49 \\
.86 \\
1.71\end{array}$ & $\begin{array}{l}0 \\
0 \\
0 \\
0 \\
0\end{array}$ & $\begin{array}{l}41 \\
34 \\
32 \\
21 \\
23\end{array}$ & $\begin{array}{l}363 \\
421 \\
128 \\
174 \\
142\end{array}$ & $\begin{array}{l}900 \\
900 \\
715 \\
900 \\
900\end{array}$ & $\begin{array}{l}43570 \\
31414 \\
38735 \\
23970 \\
27559\end{array}$ & $\begin{array}{l}764 \\
827 \\
467 \\
585 \\
612\end{array}$ & $\begin{array}{l}240.07 \\
216.57 \\
356.93 \\
330.26 \\
315.97\end{array}$ & $\begin{array}{l}21.45 \\
23.70 \\
26.42 \\
34.79 \\
31.77\end{array}$ & $\begin{array}{l}-319 \\
-629 \\
-48 \\
-344 \\
-488\end{array}$ & $\begin{array}{l}42.74 \\
39.27 \\
32.78\end{array} \mid$ & $\begin{array}{r}10.13 \\
21.97 \\
1.12 \\
8.75 \\
14.88\end{array}$ \\
\hline
\end{tabular}

severe losses by death in both strains and particularly in the plus strain. In general, however, there has been no obvious relation between losses by death and reaction-time, and it is doubtful if that was an influence at this time.

The test series corrducted during September of this year-period contained 14 broods of each strain, 322 individuals of the plus strain and 367 individuals of the minus strain. The means were 409.0 seconds for the plus strain and 859.7 seconds for the minus strain (table 45). Thus the mean for the minus strain was more than twice that for the plus strain. The difference $(-450.7 \pm 12.49$ seconds) 
was 36.08 times its probable error. In every case in this test series the plus brood had a lower reaction-time than the corresponding minus brood.

For the year August 1914-July 1915 (43 generations and 472 individuals, and 44 generations and 507 individuals, respectively)

TABLE 45.-Selection summary for Line $75 \%$.

\begin{tabular}{|c|c|c|c|c|c|c|c|c|c|c|c|c|c|c|c|}
\hline Time period. & Strain. & 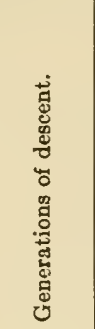 & 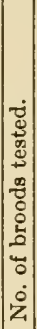 & 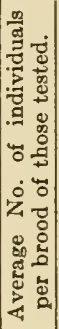 & 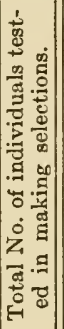 & 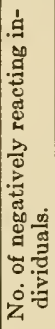 & 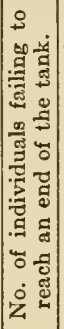 & 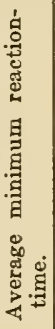 & 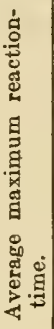 & 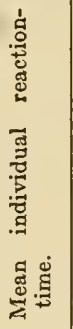 & 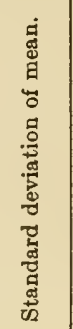 & 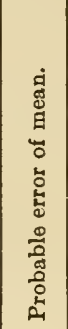 & 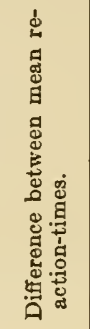 & 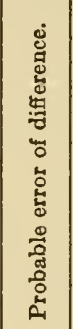 & 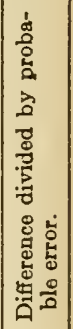 \\
\hline Nor & & $1-29$ & 29 & 11.0 & 320 & 1 & 247 & 468 & 900 & 788.3 & 226.8 & 8.57 & & & \\
\hline & & & 28 & 9.0 & 261 & 1 & 227 & 639 & 900 & & 171.9 & 7.18 & -50 & 11.18 & 4.69 \\
\hline Aug. $1,1913-$ & Plus & $30-73$ & 44 & 11.5 & 504 & 3 & 302 & 357 & 879 & 683 & 290.4 & 8.72 & & & \\
\hline July 31,1914 & & $\begin{array}{r}-70 \\
34\end{array}$ & $\begin{array}{l}41 \\
14\end{array}$ & $\begin{array}{l}10.0 \\
23.0\end{array}$ & $\begin{array}{l}412 \\
322\end{array}$ & $\frac{4}{7}$ & $\begin{array}{r}320 \\
74\end{array}$ & $\begin{array}{l}548 \\
112\end{array}$ & $\begin{array}{l}884 \\
823\end{array}$ & $\begin{array}{l}783.0 \\
409.0\end{array}$ & $\begin{array}{l}238.1 \\
301.7\end{array}$ & $\begin{array}{r}7.91 \\
11.34\end{array}$ & -99.8 & 11.77 & 8. \\
\hline Sept. 1913. & Minus & & $\begin{array}{l}14 \\
14\end{array}$ & 26.2 & 367 & 9 & s\$6 & 406 & 900 & 859. & 149.1 & $\begin{array}{r}11.04 \\
5.25\end{array}$ & -450.7 & $i 2.49$ & 36.08 \\
\hline Aug. 1, 1913- & & $30-42$ & 13 & 12.1 & 157 & 1 & 98 & 376 & 882 & & 292.0 & 15.72 & & & \\
\hline 31,1913 & & $29-41$ & 19 & 10.4 & 195 & 2 & 121 & & 900 & & 156.4 & 9.08 & -162.2 & 18.16 & 8.93 \\
\hline $1,1914-$ & Plus & $74-116$ & 41 & 11.5 & 472 & 6 & 206 & 282 & 829 & & 305.4 & 9.48 & & & \\
\hline & & & 43 & 11. & 507 & 4 & 394 & 380 & 854 & & 290.5 & 8.70 & -102.0 & 12.87 & 7.9 \\
\hline Aug. $1,1915-$ & & $117-152$ & 36 & 14.0 & 505 & 22 & 143 & 190 & 811 & & 294.7 & 8.84 & & & \\
\hline July 31,1916 & Minus. & $115-158$ & 37 & 12.9 & 486 & $\bar{\sigma}$ & 376 & 467 & 888 & & 260.7 & 7.98 & -312.0 & 11.91 & 26.20 \\
\hline Test & & & 12 & 54.3 & 652 & 0 & 433 & 172 & 900 & & & & & & \\
\hline & Minu & & 12 & 56.4 & 677 & 0 & 642 & 189 & 900 & & & 4.05 & -167.6 & 9.12 & 18.38 \\
\hline -Mar. $1,1916-$ & Plus & $140-145$ & 7 & 16.0 & 112 & 1 & 54 & 259 & 854 & & 314.9 & 20.08 & & & \\
\hline & & & 7 & & 109 & 0 & 99 & 511 & 90 & & & 12. & -277.9 & 29.43 & 11.86 \\
\hline Aug. $1,1916-$ & & $153-181$ & 20 & 12.3 & 245 & 0 & 37 & 94 & 632 & & & & & & \\
\hline May 1,1917 & Minus.. & $154-181$ & 24 & 11.0 & $264 \mid$ & 0 & 151 & 245 & 854 & 625.9 & 333.7 & 13.85 & -312.8 & 18.37 & 17.01 \\
\hline
\end{tabular}

TABLE 46.-Same-day broods. Summary of data for Line $75 \%$.

\begin{tabular}{|c|c|c|c|c|c|c|c|c|c|c|c|c|c|}
\hline Time period. & Strain. & 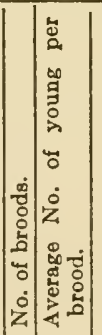 & 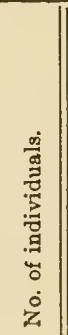 & 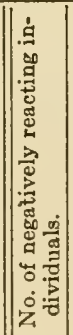 & 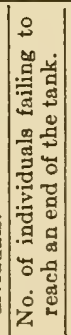 & 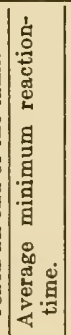 & 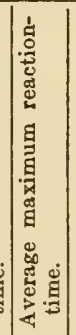 & 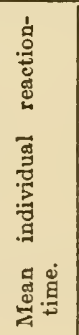 & 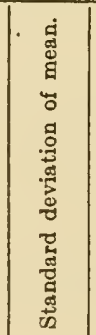 & 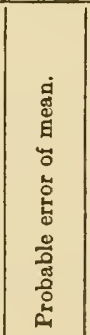 & 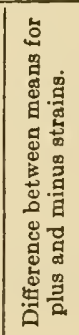 & 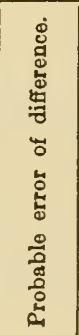 & 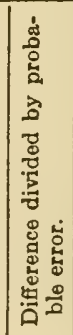 \\
\hline $\begin{array}{c}\text { Nov. 16, 1912- } \\
\text { July } 31,1913 \\
\text { Aug. } 1,1913- \\
\text { July } 31,1914 \\
\text { Aug. } 1,1914- \\
\text { July } 31,1915 \\
\text { Aug. 1, } 1915- \\
\text { July } 31,1916 \\
\text { Aug. } 1,1916- \\
\text { May } 1,1917\end{array}$ & 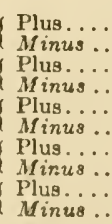 & $\mid$\begin{tabular}{r|r|}
9 & 12.7 \\
9 & 11.0 \\
11 & 13.2 \\
11 & 11.2 \\
8 & 12.9 \\
8 & 14.1 \\
8 & 18.1 \\
8 & 15.0 \\
1 & 6.0 \\
1 & 26.0
\end{tabular} & $\begin{array}{r}114 \\
99 \\
145 \\
129 \\
103 \\
119 \\
145 \\
120 \\
6 \\
66\end{array}$ & $\begin{array}{l}0 \\
0 \\
2 \\
2 \\
0 \\
0 \\
6 \\
1 \\
0 \\
0\end{array}$ & $\begin{array}{r}90 \\
80 \\
88 \\
101 \\
62 \\
105 \\
57 \\
97 \\
0 \\
21\end{array}$ & $\begin{array}{l}551 \\
725 \\
364 \\
759 \\
329 \\
647 \\
233 \\
504 \\
40 \\
380\end{array}$ & $\begin{array}{l}900 \\
900 \\
900 \\
900 \\
859 \\
900 \\
800 \\
900 \\
180 \\
900\end{array}$ & $\begin{array}{r}798.4 \\
856.8 \\
670.3 \\
805.4 \\
676.1 \\
875.9 \\
537.8 \\
807.7 \\
93.3 \\
813.5\end{array}$ & $\begin{array}{l}213.38 \\
133.47 \\
306.29 \\
219.47 \\
299.79 \\
109.76 \\
300.89 \\
218.56 \\
50.28 \\
184.86\end{array}$ & $\begin{array}{r}13.49 \\
9.05 \\
17.16 \\
13.95 \\
19.92 \\
6.96 \\
16.85 \\
13.09 \\
13.85 \\
24.45 \\
\end{array}$ & 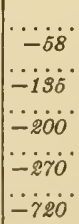 & $\begin{array}{l}16.24 \\
21.714 \\
21.11\end{array}$ & $\begin{array}{r}3.69 \\
\because 6.31 \\
3.46 \\
13.65 \\
12.65 \\
25.62\end{array}$ \\
\hline
\end{tabular}

the mean reaction-times differed by $-102.0 \pm 12.87$ seconds (table 45). This is a difference 7.93 times the probable error. None of the 8 minus same-day broods had a reaction-time lower than that for the corresponding plus brood. The mean reaction-time for these 
minus broods was $200.0 \pm 21.11$ seconds greater than that for the plus broods (table 46 ). This difference was 9.46 times the large probable error. There were rather striking fluctuations in the mean reaction-times for both strains (and especially the minus) during this year-period.'

While for 10 months of this year the minus strain, judged by the reproductive index, was slightly, though very slightly, the more

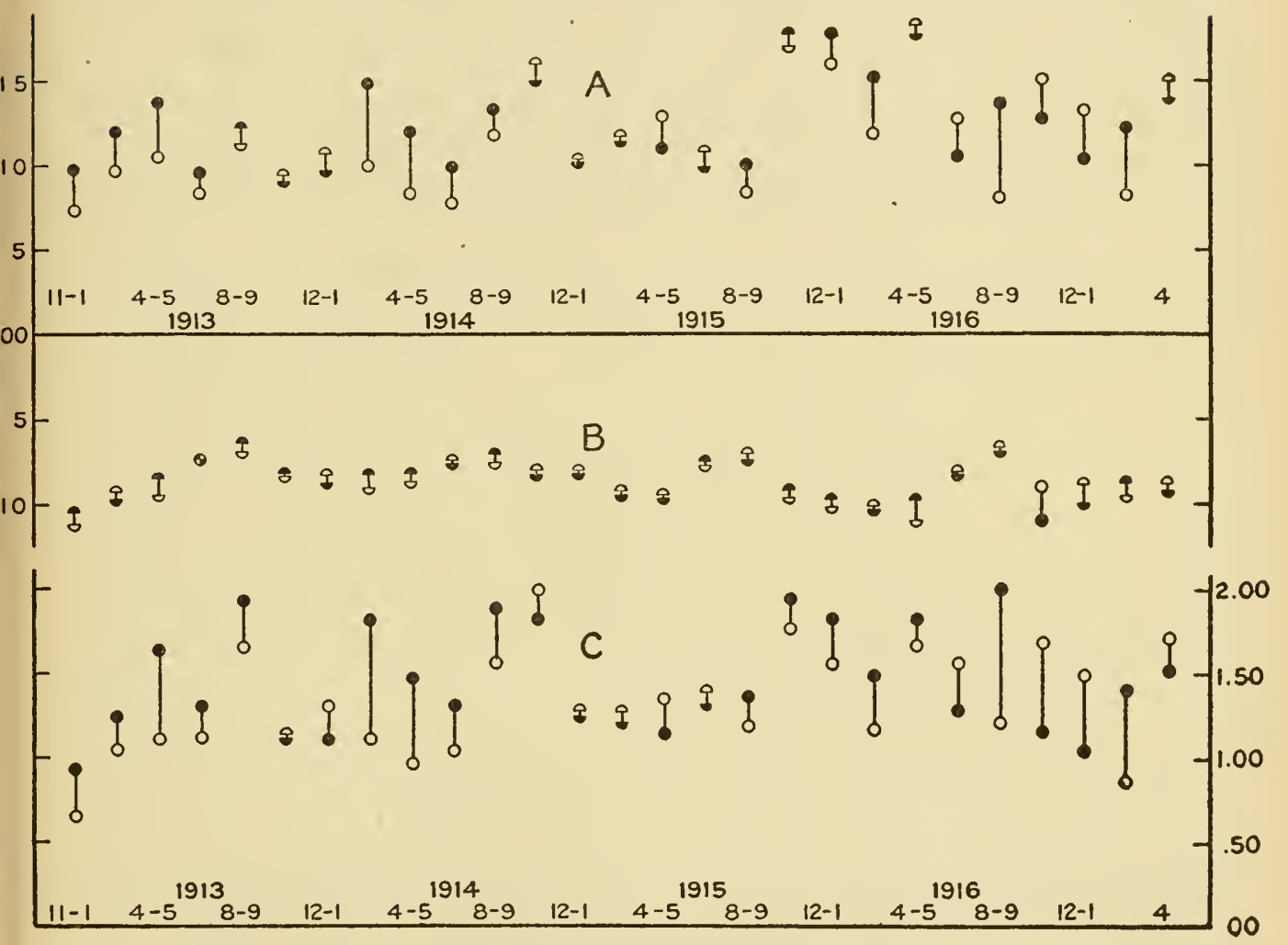

FIGURE 17.-Line 757. Reproductive vigor.

A. Average number in first brood for the two strains.

B. Average age of mother at time first brood was produced.

C. Reproductive indices, actual values.

vigorous of the two strains, it was the more reactive of the two during the only two-month period of this year in which it was the less vigorous of the two strains (see figures $18 \mathrm{~A}$ and $18 \mathrm{~B}$ ). The mean reaction-time for the minus strain was only 20 seconds greater than that for the plus strain during the last two-month period of this year.

1 These fluctuations in the means for the different two-month periods, so far as coincident in the two strains, are due to the same environmental influences; and so far as they are not coincident they are presumably due to the somewhat differential handling of the two strains (see pages 140-142). The material was handled with commendable care (mostly by an assistant) during this year-period. 
been conducted during any of the following months (under usual environmental conditions), when the plus strain was more reactive, the plus strain would have had a much lower mean and the minus strain possibly a somewhat, but probably not much, lower mean, so that the difference would have been much larger. ${ }^{1}$ It is interesting, however, to have this test series come at a time of relatively high

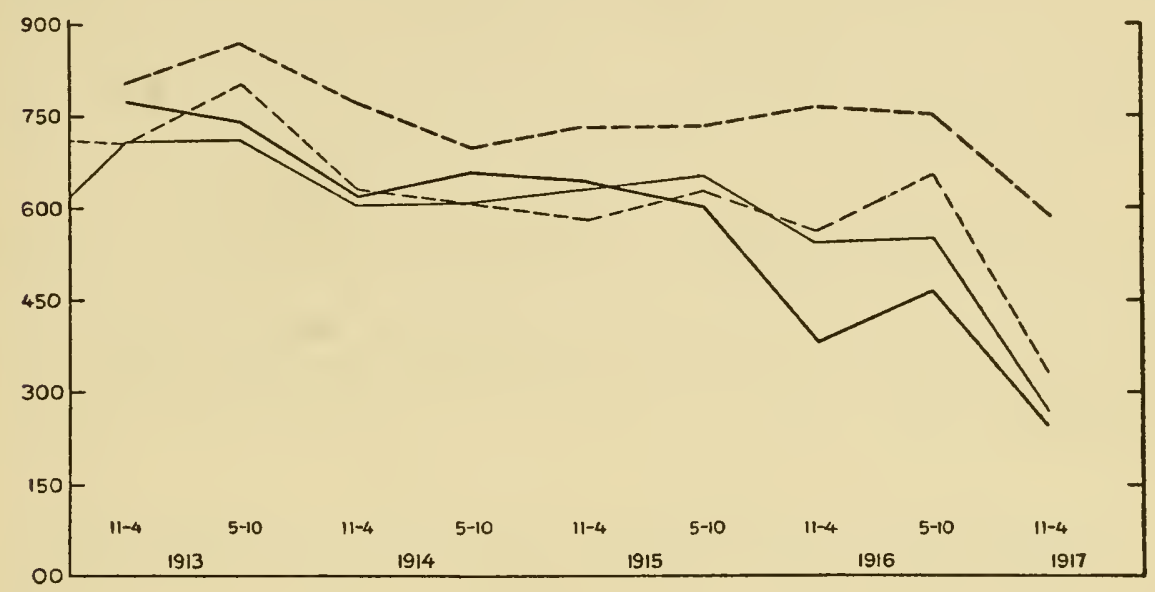

Figure 19.-Line 757.

Reaction-time curves by six-month periods with similar curves for Line 740 superimposed.

As noted on pages 87 and 88 , the minus strain of Line 740 was exceptionally slightly reactive compared with the other Simocephalus minus strains (Line 757 excepted) during the period from April to September 1916, while the 740 plus strain was exceptionally reactive during October 1916 to January 1917. Hence the point representing the mean for the minus strain for the " $5-10$ " 1916 period is exceptionally high, while the point for the plus mean for the " $11-4$ " period following is exceptionally low.

reaction-time for the plus strain and yet find the difference in means so markedly significant.

In the final nine-month period (August 1916-April 1917) of the experiment with Line 757 , the mean for the minus strain was double

1 The mean for the minus strain in this test series was only 5 seconds higher than during the earlier test series conducted $2 \frac{2}{3}$ years earlier (September 1913). On the other hand, the mean for the plus strain was 288 seconds higher in the later than in the earlier test series. Yet, in general, the plus strain during the latter part of the experiment was very much more reactive than during the earlier portion of the experiment. The explanation of these peculiar means compared with the means for the selection data lies in the following facts: (1) The plus strain of Line 757 was more reactive than normally during the first test series. This was, in part at least, due to local experimental conditions. Of the 15 broods tested in making selections (in the laboratory strains of the different species) during the period when this test series was conducted, the broods in 11 strains had lower reaction-time means than the combined means for the immediately preceding and next succeeding broods of the same strains and the differences were much larger than in the 4 cases in which the reverse relation held. Hence it is clear that the first test series for Line 757 was conducted at a time when local environmental conditions induced abnormally low reaction-time averages in most of the Cladocera strains. (2) During the second test series the plus strain of Line 757 was relatively slightly reactive. The test-series mean for the plus strain was 697 seconds, a larger mean than had occurred in the selection data for 14 months and larger than occurred at any later two-month period of the experiment. Two broods used in selection tests in 757 plus soon after this test series was conducted had sinilar averages, but of the other 27 broods of this strain tested during the remainder of the selection experiment only one had an average as high as that for this entire test series. It seems clear that the 757 plus strain was in a relatively slightly reactive condition at the time of the second test series. 
that for the plus strain. The means for both strains were lower than for any other longer period of the experiment (313.1 seconds for the plus and 625.9 seconds for the minus strain, table 45$)$. The difference was $-312.8 \pm 18.37$ seconds. The mean difference in reaction-time was slightly increased. Because of the much smaller total number of individuals, however, the probable error of the difference was larger, though the difference was still 17.01 times its probable error. There was only one same-day brood. Although from a single pair of broods little may wisely be assumed, it is interesting to note that the mean for the plus brood was 93 seconds, while that for the minus was 814 seconds, the latter mean being almost 9 times the former.

While the reaction-time curves by two-month periods (figure 18B) clearly show the wide and increasing divergence in reactiveness between the two strains of Line 757 , curves by six-month periods (November-April and May-October) are also given, together with similar curves for Line 740 for comparison with them (figure 19). Naturally these curves are less affected by local fluctuations and are smoother curves.

\section{Other features of the Data.}

Examination of other features of the data for Line 757 brings out similar evidence of a marked effect of selection. ${ }^{1} \quad$ The average minimum reaction-time ${ }^{2}$ for the two strains is a point on which their reactiveness may be compared. The average minimum reactiontime for the plus strain for the longer periods of the experiment was progressively lowered from 468 to $357,282,190$, and 94 seconds (table 45). For the minus strain there was likewise a lowering, though not so great nor so consistent. The minus strain average minima were $639,548,380,467$, and 245 seconds (table 45). For the plus strain the average minimum for the last long period was only one-fifth that for the first of the 5 longer periods; for the minus strain the minimum for the last period was two-fifths that for the earliest period. The average minima for the two strains show wide differences throughout the experiment, the differences being 171, $191,98,277$, and 151 seconds for the 5 longer periods. These differ-

1 In a single minor detail the data for a small portion of the time do not seem consistent with an effect of selection. This point is the relative numbers of negatively reacting individuals in the two strains. From August to December 1915 there were considerably more of the negatively reacting individuals in the plus (21) than in the minus (5) strain. This is of course contrary to one's expectation in a less-reactive strain. However, 19 of the 21 negatively reacting individuals in the plus strain for this period occurred in four broods. Since in all strains negatively reacting individuals are extremely irregular in their occurrence, and when they do occur are often relatively numerous within a single brood, it seems probable that these reactions are in large measure determined by environmental conditions and lenee are of little, if any, real significance ( $c f$. page 15). If, however, they were to be ascribed an important significance here, this data alone (and only a very limited portion of it) runs counter to the plain implication of all the rest of the data for Line 757. During the remainder of the experiment the plus and minus strains of Line 757 had approximately equal numbers of negatively reacting individuals (tables 43 and 44 ).

2 This, of course, inclucles the reaction-time of only a single individual (the most reactive one) of each brood. Like the data for the average maximum reaction-time, it has much less value as a measure of reactiveness than the mean reaction-time for all the individuals tested; nevertheless, it is highly significant. 
ences are more instructive if stated in percentages. The average minima are $37,54,35,146$, and 161 per cent higher for the minus than for the plus strain.

These differences clearly point to a marked and cumulative divergence in reactiveness of the most reactive individuals of the two strains, a divergence which became in the final period more than 3 times as great as the average minimum for the plus strain. It is a striking fact that for the last 9 months of the experiment the mean reaction-time for the plus strain was considerably lower than the average minimum reaction-time for the broods of the same strain for the first 21 months of the experiment.

A comparison of the average maximum reaction-times is less instructive, for a large percentage of the broods of $S$. exspinosus contain over-time individuals; but even here comparison indicates increasingly greater reactiveness for the least reactive individuals of the broods of the plus strain toward the end of the experiment. For the first 9 months every brood in the plus strain as well as the minus strain contained over-time individuals and the average maximum reaction-time for each strain is (the arbitrary) 900 seconds. For the longer periods of the entire experiment the maxima for the plus strain declined from 900 to $879,829,811$, and 632 seconds (table 45). There is a slight decline for the minus strain, the averages being 900 , $884,854,888$, and 854 seconds (table 45 ). The difference in average maximum reaction-time for the two strains increased from 0 to 5 , 25,77 , and 222 seconds. The average maximum reaction-times are $0,1,3,10$, and 35 per cent higher for the minus than for the plus strain. For the minus strain the total lowering of the average maximum reaction-time was only 46 seconds, or 5.1 per cent as compared with 268 seconds, or 29.8 per cent, for the plus strain.

The data for the same-day broods may be referred to again. They, too, show an interesting decline in the mean for the plus strain through the various periods (from 798 to $670,676,538$, and 93 seconds, table 46). The average for the last period is for a single brood and is abnormally low. The general trend is unmistakable, however. There is no marked lowering for the minus strain, the means being $857,805,876,808$, and 814 seconds (table 46). The increased divergence between the means for the two strains is strikingfrom 58 to $135,200,270$, and 720 seconds. Stated in percentages, these differences for the several longer periods of the experiment, compared with the mean for the plus strain, are 7.3, 20.2, 29.6, 50.1, and 774.2 per cent. Again, although allowing that the difference for the last period was obtained from too meager data, the divergence is marked and continuous, and these differences arise from the most strictly comparable data obtainable.

Considering the number of "over-time" individuals for the two strains in the different periods of the selection experiment is another 
method of checking up the data (table 47). This is a test of vital significance. The number of over-time individuals is extremely significant of the reactiveness of a strain. For the 5 longer periods of the experiment the figures for the plus strain are 247,302, 216, 143 , and 37 over-time individuals; for the minus strain $227,320,334$, 376 , and 151 individuals. These can be compared better on a percentage basis. The percentages of over-time individuals for the plus strain for the 5 longer periods of the experiment are $77.2,59.9$, $45.8,28.3$, and 15.1 per cent; for the minus strain $87,77.7,65.9$, 77.4 , and 57.2 per cent. Starting near equality (though the plus strain almost from the start had significantly fewer over-time individuals), the differences are $9.8,17.8,20.1,49.1$, and 42.1 per cent.

Hence the percentage of over-time individuals in the plus strain decreased throughout the experiment and particularly during the last 21 months of the experiment. The final percentage was less than one-fifth that for the earliest longer period. For the minus strain there was also a decrease, but it was less consistent, and in the end the percentage of over-time individuals was two-thirds as large as at the beginning (see table 47).

It is possibly worth while to consider the mean-reaction times of the more reactive individuals of the two strains of Line 757, omitting from consideration for a moment the over-time individuals. While this is a point of interest, the fact remains that the relative number of over-time individuals is in itself as good a measure of reactiveness as might be desired. The large influence of the arbitrary reaction-times of 900 seconds, assumed for the over-time individuals, does not ascribe too much influence in determining the mean reaction-time. In point of fact, the reverse is true. This arbitrary method of assuming 900 seconds as the reaction-time for the overtime individuals minimizes the rightful influence upon mean reaction-time of these relatively non-reactive individuals. The data are given in table 47 and show that there is a progressive reduction in the mean reaction-time for the more reactive individuals of both strains, considered by the longer periods of the experiment. This reduction for the minus strain is from 431 to $376,334,326$, and 260 seconds; but for the plus strain the reduction is larger, from 410 to $360,356,284$, and 209 seconds. The differcnces between the means for the two strains, with some irregularity, became larger, the plus strain having the lower reaction-time. These differences were as follows: $-21,-16,+22,-43$, and -51 seconds. The reduction in mean reaction-time for the plus strain in the final period as compared with the first period of the experiment was 201 seconds; for the minus strain, 171 seconds. The differences for the last two longer periods of the experiment have statistical significance, being respectively 2.97 and 4.2 times their probable errors. 


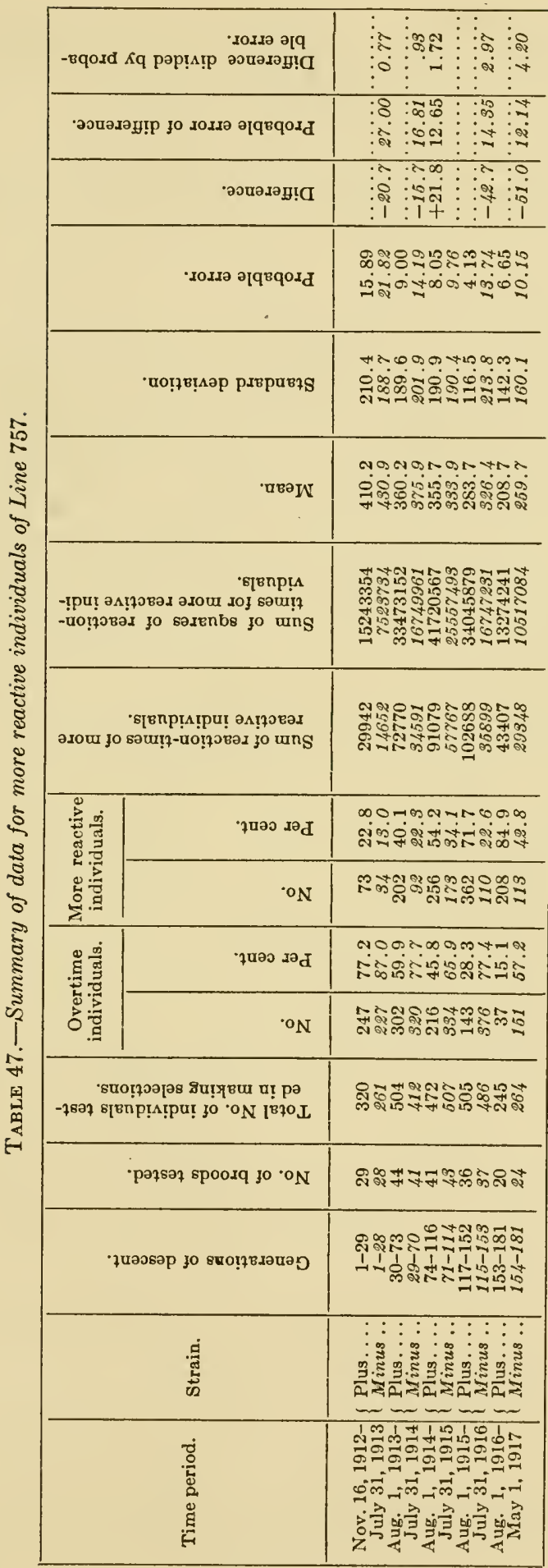


Thus, for the moment ignoring the data for the less reactive (over-time) individuals, one finds that the more reactive individuals of the plus strain showed greater reactiveness than the more reactive individuals of the minus strain. These differences are not large and are not all in the same direction, but on the basis of this portion of the data alone there is evidence for an effect of selection, though naturally it is not as decisive as that obtained from the complete data.

\section{Relation Between Relative Vigor and Mean Reaction-Time.}

There remains to be considered the relation, if any, between the relative vigor of the two strains and their relative reactiveness. This is an important point. While it has already been shown that with the other lines subjected to selection in connection with which this point was considered, there is little, if any, relation between reactiveness and the general vigor of the stock, it still remains desirable to know whether such is certainly the case with Line 757 .

There is to be noted with the minus strain of Line 757, as with the minus strains of many other lines of Cladocera subjected to selection, a somewhat lower reproductive vigor than with the corresponding plus strain. This is presumably the result of the individuals selected in the minus strains being somewhat below the average in vigor. That this at the same time has not operated materially to increase the mean reaction-time of the minus strain is evident enough in nearly every line. The data for vigor and mean reaction-time considered for the other individual lines (and for all the lines as a whole) seem to show conclusively that there is no relation between vigor and reaction-time. While this suggests that in Line 757 the result of selection is not due to less vigor in the minus strain, yet it does not preclude the possibility that it may have been a factor in the divergence in reactiveness in Line 757. Some attention will now be directed toward an analysis of the data on mean reactiontime as related to vigor in this line. The matter of concern is whether there is a relation between the relative vigor of the two strains and their mean reaction-times, and, if there is a relationship, to what extent it is operative. Several more or less disconnected considerations will be taken up in regard to this point before referring to the statistical correlations.

The two strains were compared as to general vigor as revealed by the measures applied to them (see page 42 ) and stated in terms of the reproductive index (tables 43 and 44 ).

1. The plus strain was on the whole the more vigorous of the two, as will be seen by reference to tables 43 and 44 and figure 18A. Of the 27 periods of 2 months each (except the first period of 3 months and the last period of 1 month) the plus strain was of superior vigor during 16 periods and the minus strain during 11 periods. The 
quantitative differences in favor of the plus strain averaged greater than those for the minus strain, so that on the whole the plus strain averaged somewhat higher in reproductive vigor. For the first 11 periods ( 23 months) this superiority in vigor in the plus strain was marked; but, during the remainder of the experiment (16 two-month periods) during which the divergence in mean reaction-time became very large, the average superiority of the plus strain in reproductive vigor was slight indeed, and, in fact, during 9 of these 16 periods the minus strain was the more vigorous. This at once throws serious doubt upon the possibility of explaining any portion of the divergence in mean reaction-time as a result of a difference in vigor.

2. Near the middle of the curve for 5 successive two-month periods the minus strain showed (see figure 18, $\mathrm{A}$ and $\mathrm{B}$ ) a slight superiority in reproductive vigor over the plus strain, and during this time the minus curve twice approached the plus curve, although in spite of its greater vigor the minus strain had a consistently higher reaction-time. Examination of the curves at this point might at first sight seem to suggest, however, that there was actually some effect upon mean reaction-time of the relatively greater vigor of the minus strain. At two points the curves covering this limited period are separated by spaces representing differences in reaction-times of only 64 and 20 seconds, but at the other three points the curves are separated by 219,133 , and 101 seconds (table 44 ). These last three divergences are larger than had occurred except in 3 of the 11 preceding periods of the experiment. The mean reaction-time for all the data for the plus strain during this ten-month period of superior vigor on the part of the minus strain was 613.7 seconds, 119.2 seconds (19 per cent) less than that for the minus strain, whose reproductive index during this time averaged 0.10 higher than that for the plus strain. This may be compared $(a)$ with similar averages for all data for Line 757 obtained previous to October 1914, during which the mean reaction-times differed by 68.7 seconds (10 per cent), the minus strain having the higher reaction-time and a less vigor by 0.25 ; $(b)$ with the period of 10 months immediately following the ten-month period of superior reproductive ability on the part of the minus strain, in which the plus strain was the superior in vigor by 0.19 and its reaction-time averaged 325 seconds (71 per cent) less; and $(c)$ with the final 6 periods (11 months), during which the plus strain had a lower reproductive index by only 0.08 and a lower mean reaction-time by 300.6 seconds (nearly 89 per cent). This shows that the rapidly increasing percentage difference between the mean reaction-times was quite independent of the relative vigor of the two strains.

Further, in the 2 two-month periods immediately preceding the 5 periods of superior vigor on the part of the minus strain just referred to, the minus strain showed a greater reactiveness to light 
than the plus strain in one case and a practically equal reactiveness in the other case-a thing which did not occur elsewhere in the experiment-and yet the plus strain was markedly superior in vigor.

3 . There were 10 two-month periods during which the vigor of the plus strain was quite above the average (figure $17 \mathrm{c}$ ) the reproductive index being more than 1.50. The mean reaction-time for these periods of high vigor was 546.8 seconds, 36 seconds less than the mean for the plus strain for the entire period of the experiment. There were 9 corresponding periods of high vigor for the minus strain, for which the mean reaction-time was 768 seconds, 23 seconds greater than the mean for the entire period for this strain. There were 9 two-month periods during which the plus strain had a reproductive index under 1.25, somewhat below the average. For these periods the general average reaction-time was 634.9 seconds, 52 seconds above the average for the entire experiment. For 12 periods of correspondingly low reproductive indices in the minus strain the mean reaction-time was 770.8 seconds, 26 seconds above the average for the whole experiment. Hence in 3 of these 4 comparisons the mean reaction-times varied in the direction to indicate some relation between actual vigor and mean reaction-time. In one case the reverse is true.

4. A fairer method of making a comparison between relative vigor and mean reaction-times is a detailed period-by-period examination of the data for reproductive index and the mean reactiontime. Comparing the mean reaction-time for the plus strain for the 10 periods of high reproductive indices (above 1.50) with the reactiontime means for the adjacent points in the curve (each representing two-month periods), it is seen (figures $17 \mathrm{c}$ and $18 \mathrm{~B}$ ) that in 2 cases the reaction-time means are higher than in the adjacent points in the curve, in 3 cases intermediate, and in 5 cases lower. For the 9 periods of like high reproductive indices for the minus strain, the mean reaction-times are higher than in the adjacent portions of the curves in 5 cases, intermediate in 1 case, and lower in 3 cases. A similar comparison for 9 periods of low reproductive index (below 1.25 ) in the plus strain shows that in 5 cases the mean reaction-time is higher than in adjacent points in the curve, and in 4 cases it is lower. For the 12 periods of like low reproductive indices in the minus strain the mean reaction-times are higher than in adjacent portions of the curve in 3 cases, intermediate in 5 cases, and lower in 4 cases. These comparisons indicate a possible slight relation between mean reaction-time and reproductive vigor for the plus strain, high vigor being more often associated with greater reactiveness and a lower reaction-time; but the reverse relation is more strongly indicated for the minus strain, higher reproductive vigor being more often associated with less reactiveness and a higher reaction-time. 
5. Arbitrarily selecting the 6 periods of highest reproductive indices for the plus strain, they have, as compared with adjacent parts of the curve, a higher reaction-time twice, an intermediate reaction-time once, and a lower reaction-time 3 times. The minus strain for its 6 highest reproductive indices has a higher reactiontime 4 times, an intermediate reaction-time once, and a lower reaction-time once. The 5 periods of lowest reproductive indices for the plus strain have, as compared with adjacent points in the curve, a higher reaction-time 3 times and a lower reaction-time twice. The similar periods for the minus strain have a higher reaction-time in one case, an intermediate reaction-time in 3 cases, and a lower reaction-time once.

The comparisons under (4) and (5) show some evidence of a relation between vigor and reaction-time in the plus strain, the mean reaction-time more often varying in the direction anticipated, if greater vigor is associated with greater promptness in reaction (and hence lower reaction-time) than in the reverse direction. But with the minus strain the differences are such as to indicate the reverse relation, i. e., greater vigor associated with less promptness in reaction (higher reaction-time). These small differences about neutralize each other and lead one to conclude, from this portion of the evidence, that there is probably no relation between vigor and reaction-time. ${ }^{1}$

6. For the two-month period during which the minus strain showed its greatest vigor (October-November 1914) its mean reactiontime was greater than at any other period except one, and much greater than the average for the succeeding 5 periods, during which its reproductive index was about 35 per cent lower.

7. It is worthy of note that 4 of the 6 high points in the curve of the reaction-times of the minus strain occur when the minus strain was superior in vigor to the plus strain. This, if considered alone, would seem to suggest a reverse relation between reproductive vigor and reaction-time, a relation which would seem not to have biological significance.

8. Attention may be directed to the two-month periods during which (even after the effect of selection appeared already to have become established) the minus strain had a reaction-time approximating or lower than that for the plus strain. For the period JuneJuly 1914, during which the minus strain was on the average the more reactive of the two, and the following two-month period during which the minus strain was the less reactive by only 2 seconds, the plus strain was markedly the more vigorous. For the FebruaryMarch 1915 period, when the minus strain was within 64 seconds of the plus strain, the minus strain was slightly the more vigorous.

1 These data, however, might be taken to offer slight corroboration of the puzzling results obtained from the correlations based upon this data (see page 113). 
For the following June-July period, during which the minus strain was within 20 seconds of being as reactive as the plus strain, it again was slightly the more vigorous. But it is noteworthy that in the period intervening between the two periods just referred to the minus strain was superior in vigor to the plus strain by a difference 3 times as great as in the other two periods, and yet the reaction-time for the minus strain was 101 seconds greater than that for the plus strain. For the last two-month period (December 1916-January 1917), in which the reaction-time mean for the minus approached that for the plus strain, the minus was considerably the more vigorous. It is noteworthy here, however, that in the period just preceding ${ }^{1}$ the minus strain showed greater superiority in vigor than at any other time, and yet its reaction-time differed from that for the plus by a larger margin (629 seconds) than for any other period of the experiment. This analysis might be prolonged further, but enough has been seen to make clear that there is at most a very slight relation between the reproductive index and the mean reaction-time.

Of the points discussed above, (3) and doubtfully (4) and (5) indicate a possible effect of vigor upon reaction-time in the plus strain (but not in the minus strain)-i. e., the greater the vigor the more reactive the individuals and the lower the reaction-time. But this bit of evidence is not very convincing, since the numerical differences in the comparisons made are small and the differences in averages are not all in the right direction to bear out such a relationship. On the other hand, (1), (2), and (8) fail to show the appearance of an effect of mean vigor upon mean reaction-time, while (5) (in part), (6), and (7) seem to indicate the reverse effect, that greater vigor is associated with lessened reactiveness and a higher reactiontime.

Obviously, the best method of determining the relation, if any, between reproductive vigor and mean reaction-time is by statistical correlation. The mean reaction-times and mean reproductive indices, both by two-month averages, were correlated for the data for the Line 757 strains, using as the terms of the correlation the reproductive index of the mother and the mean reaction-time of her first brood of offspring. The correlation is $-0.1109 \pm 0.127$ for the plus strain and $0.0612 \pm 0.129$ for the minus strain. In order to have a larger scries, the data for both strains of Line 757 were thrown together. ${ }^{2}$ The resulting correlation is $-0.12845 \pm 0.0902$. These correlations are low, and, judged by their probable errors, are not of statististical significance.

1 The numbers of individuals tested during this period were abnormally small, so that these averages are not as trustworthy as most of the others, but the major part of this difference can not be regarded as accidental.

${ }^{2}$ Since the two strains aro different in their reactiveness to light, this combination of data is open to criticism, although it is reasonable to suppose that variations in vigor should influence the reation-time in the two strains similarly. 
Correlations involving the individual reaction-times and the reproductive indices of the mothers were made. For the plus strain this data included every individual of Line 757 whose reaction-time was obtained in making the selections and the reproductive index of whose mother was known-a total of 1,992 individuals. The correlation was $-0.000828 \pm 0.0151$. For the minus strain (with 1,842 individuals) the corresponding correlation was $0.2154 \pm 0.0149$.

A negative correlation between vigor and reaction-time would have obvious biological significance, while a positive correlation would not, for it is difficult to see how less vigor would be causally associated with greater reactiveness (lower reaction-time). Both the correlations for the 757 plus strain are negative, but although suggestive, they are much too small to be statistically significant. The correlations for the 757 minus strain are both positive and the second, while not large, is 14 times its probable error. This is not convincing evidence, but on its face it indicates that in the minus strain of Line 757 the greater the vigor the higher the reaction-time; that is to say, a greater vigor is associated with less reactiveness and a lower vigor with greater reactiveness. Some possible corroboration of this anomalous state of affairs is seen under (4) and (5) above (page 110), ${ }^{i}$ but it is difficult to understand how this relation is possible.

Further analysis of the data for Line 757 was attempted. Correlations were made between age of the mother at the time of producing her first brood and the reaction-times of her young; between the number in the brood (size of brood) and their reactiveness, and between the age of the mother and the size of her first brood.

The correlations between the age of mothers and reactiveness of young were $-0.03865 \pm 0.0205$ for the plus strain (1,992 young) and $-0.01529 \pm 0.0157$ (1,842 young) for the minus strain. Between the number in the brood and their reactiveness the correlations were $-0.07619 \pm 0.0150$ for the plus strain and $0.01606 \pm 0.0157$ for the minus strain.

Other things being equal (temperature, food, etc.), the more vigorous mothers reproduce earlier and the less vigorous mothers later. Hence a correlation of obvious biological significance between age of mothers and reactiveness of young should be positive. Both the correlations obtained were negative, but they were very low, and neither was of statistical significance. A biologically significant correlation between size of brood and reaction-time should apparently be negative. The correlation obtained for the data for the plus strain was negative and was 5 times its probable error, but it is numerically so small $(-0.07619)$ that it at most indicates an extremely slight relation between size of brood and reaction-time. The

${ }^{1}$ Likewise, this fits with the observation recorded under (7) stated on page 111. 
correlation obtained for the same data for the minus strain is positive and is too small to be of statistical significance. ${ }^{1}$

Considered on all points, there is little in the data or the course of the curves to indicate any appreciable relationship between the relative vigor of the two strains and their mean reaction-times. The comparisons made and the correlations calculated show that there is at most only a possible slight relation between average vigor (reproductive index) and mean reaction-time. The relation (if actually significant) is so small, however, that when the data are examined in many detailed ways it usually quite fails to appear and statistical correlations do not establish it. This possible relation is large enough at most to account for only a small portion of the fluctuations of the curves and at best for only a small fraction of the divergence between the mean reaction-times of the two strains of Line 757. Hence it becomes clear that fluctuations of the mean reaction-time curves of the two strains were controlled neither in direction nor in amount (to any appreciable extent at any rate) by the relative vigor of the two strains. ${ }^{2}$

While the writer is convinced that in Line 757 there is at most only a very slight relation between vigor and reaction-time and has already laboriously presented the evidence on this point from the data for Line 757 itself, this conclusion is perhaps even better justified from consideration of the data for the plus and minus strains of the other Cladocera lines subjected to selection. Inspection of the curves showing mean reaction-times and reproductive indices for the other lines of Simocephalus exspinosus ${ }^{3}$ brings some crucial evidence to bear directly on this point.

The data for Line 794 (tables 33 and 34, and figures 11, A, B, and $\mathrm{c}$ ) show considerably greater reproductive superiority on the part of the plus strain (as compared with the corresponding minus strain) than in the plus strain of Line 757, yet the reaction-time means for the two strains of Line 794 run much nearer together than in Line 757.

The data for Lines 795 (figures 12, A, B, and C) and 796 (figures 13, $\mathrm{A}, \mathrm{B}$, and $\mathrm{C}$ ) show still greater differences in mean reproductive vigor of their plus and minus strains, yet there are no corresponding differences in mean reaction-time. The differences in mean reaction-time which occur in different parts of the curves for these lines do not at all lend

1 The eorrelations between age of mother and size of brood have no apparent bearing upon reactiveness, but they may be mentioned for their hiological interest. The correlations obtained are $-0.05785 \pm 0.0525$ for the plus strain and $-0.01732 \pm 0.0527$ for the minus strain. If one eliminates the data for mothers which did not produce their first broods until more than 11 days of age, thus eliminating the obviously weak mothers (sinee more than 11 days is an abnormally late reproductive age), the correlations are $0.11618 \pm 0.0531$ for the plus strain and $0.12409 \pm 0.0533$ for the minus strain.

${ }^{2}$ It is obvious that if the vigor of the stock were extremely low the mean reaction-times should hecome higher, but this stock was always maintained at the highest possible vigor and the varying reproductive indices merely indicate various degrees of the always (except for very limited periods) successful maintenance of high levels of reproductive vigor.

${ }^{3}$ See pages $44-45,60$ and 65 and figures $2, \mathrm{~B}$ and $\mathrm{C}, 3, \mathrm{~B}$ and $\mathrm{C}, 7, \mathrm{~B}$ and $\mathrm{C}$, and $8, \mathrm{~B}$ and $\mathrm{C}$. for treatment of this data for the $D$. pulex lines. 
themselves to explanation as due to differences in relative vigor. For example, during the period from October 1915 to May 1916, inclusive, the plus strains of Lines 795 and 796 were both greatly superior in reproductive vigor to the minus strains of the same lines (figures $12, \mathrm{~A}$ and $\mathrm{B}$, and $13, \mathrm{~A}$ and $\mathrm{B}$ ), yet during this time the plus strain of Line 795 was much less reactive than its minus strain, while the plus strain of Line 796 was more reactive than its minus strain.

The curves for Line 740 (figures 14B and 15) are also instructive on this point. In general, the minus strain averaged slightly less reactive than the plus, yet it was on the whole consistently the more vigorous.

It is obvious that reaction-time and reproductive vigor are on the whole, very slightly, if at all, related in S. exspinosus, and that differences in vigor do not explain the divergence in mean reactiontime so pronounced in Line 757.

Further, there is no basis for an assumption that the reactiontime differences which arose in Line 757 are due to differences in swimming ability. If the difference in reaction-time in Line 757 arose from differences in swimming ability, the results are fully as interesting from a genetic standpoint as though they were due to differences in reactiveness to the light per se. But differences in swimming ability were not the source of the differences in reactiontime between the two strains of Line 757. As compared with the plus strains, individuals of the minus strain less often showed any tendency to react to light, i. e., many more were immobile throughout the time of the test, and individuals of the minus strain which did reach an end of the tank in general did so after more and longer interruptions of swimming than occurred for individuals of the plus strain. It is not believed that anyone who observed the behavior of individuals of these two strains in the experimental tank and in the culture-bottles would countenance any suggestion that the differences between the two strains were due to differences either in general activity or in swimming ability.

\section{Special Features of the Reaction-Tme Curves.}

The approximation of the curves (figure 18A) for mean reactiontimes in Line 757, during 1914 and 1915, at first sight appears more significant than it really is. For 1 two-month period, June-July 1914 , the minus strain was more reactive than the plus strain, and for the following two-month period the difference was only -2 seconds, while for the June-July 1915 period the plus strain averaged only 20 seconds lower in reaction-time than the minus strain; but in the intervening February-March period, for which the curves appear so nearly to approach, there is a difference of 64 seconds, or 16 per cent. That such fluctuations are to be expected occasionally would seem to be indicated by the fact that during the last longer (nine- 
month) period of the experiment the mean for the minus strain for 1 two-month period (December 1916-January 1917) fell to within 48 seconds of that for the plus strain, yet, from consideration of the data for this line for the 21 months at the end of the experiment, no one would be inclined to question the validity of a real and large difference in reactiveness between the two strains. Further, periods of local shifts in reactiveness-changes which are believed to be purely environmental and non-genetic-are seen in other lines, e. g., Lines 695 and 740 (see pages 44 and 86), in which there is not evidence of an effect of selection. The approximation of the curves for the plus and minus strains during 1914 and again in 1915 seems to have been due to differential local environmental influences (see also pages 140-142).

There is an additional suggestive feature of the general course of the curve for the Line 757 selection data. It is in the marked general lowering of the mean reaction-time for both the plus and minus strains of Line 757. The curve starts at 743 seconds for the plus strain ${ }^{1}$ and at the close of the experiment ends at 124 seconds. $^{2}$

The average reaction-time for the plus strain for the first 9 months of selection was 788 seconds and for the last 9 months 313 seconds, while the intervening 3 year-periods of data show a progressive and consistent lowering of this reaction-time as follows: $684,605,458$. The form of the curve suggests that this lowering had not ceased, but was continuing when the experiment closed.

The curve shows a slight lowering of the reaction-time for the 757 minus strain, but the amount is small and the mean reactiontimes for the longer periods of the experiment do not indicate as large and consistent lowering in this as with the plus strain. The means for the minus strain for the longer periods are 839, 783, 707, 770 , and 626 seconds.

Extent of the Change in Reactiveness of the Line 757 Strains.

The lowering of the mean reaction-time for the 757 plus strain may be examined further. When it is recalled that a mean reactiontime of 788 seconds (that for the plus strain for the first longer period) means that by far the greater part of the individuals failed to react ${ }^{3}$ to the light stimulation during the test (actually 77.2 per cent of the individuals of the plus strain during the first nine-month period failed to reach an end of the tank) and that a mean reaction-time of 313 seconds indicates that a great preponderance of the individuals responded to the light stimulation (only 15.1 per cent, less than onetenth as many as during the earlier period, failed to respond during the final nine-month period) the decline in reaction-time from 788 seconds to 313 seconds takes a still greater significance. Not a

${ }^{3}$ That is, reach an end of the tank during the 15 -minute period of the test. 
single brood in the first longer period failed to contain individuals which did not respond during the 15 minutes to the test. In the final longer period nearly half the broods tested contained no overtime individuals. Of the last 10 broods tested, only 3 contained over-time individuals and the last 5 broods contained none. The change in reactiveness in this strain is also strikingly indicated by again referring to the average minimum reaction-times in the first and last periods. For the first nine-month period it was 468 seconds; in the last period 94 seconds. These figures, it will be recalled, refer only to the most reactive individuals of each brood, but when these have become 5 times as reactive as during the early period of the experiment, the fact can not fail to have considerable significance.

The change in responsiveness in the plus strain of Line 757 was in no other way as striking to an observer as the change in the general behavior of the animals in the experimental tank. Early in the history of this strain the young daphnids, on being released in the experimental tank, ordinarily behaved as follows: first they settled to the bottom in a rather close group; after 3 to 5 minutes a few (usually less than 30 per cent) moved a little-ordinarily toward the source of light, though many movements were indifferent to the light. (In about a third of the earlier selection tests of entire broods, there was no movement at all after the animals settled to the bottom of the tank, though these were vigorous individuals.) Of the small number swimming toward the light, about two-thirds, in spite of many pauses, made their way to the end of the tank within the period (15 minutes) of the test. Toward the close of the selection experiment with Line 757 , the behavior of the 757 plus strain was essentially as follows: the animals, on being released, ordinarily settled to the bottom as previously, but within a few seconds some of them began to swim toward the light and within a minute or two all were usually under way toward the positive end of the tank, which the majority reached with few interruptions of their swimming movements. In the earlier part of the experiment the animals frequently did not move a second time after once swimming for a moment and then settling to the bottom or holding fast to the surface film or the sides of the tank. At the close of the experiment the movements in the plus strain were not only more prompt and general, but were less often interrupted, and when interrupted were generally resumed rather promptly.

There was to the eye of the observer possibly some increase in reactiveness of the 757 minus strain as exhibited in its general behavior, but it was slight as compared with the change which occurred in the 757 plus strain.

The lowered mean reaction-times for the strains of 757 during the course of the selection experiment are in partial accord with the general lowering of the mean which occurred for all of the strains 
of Simocephalus during the course of the selection experiment. This general lowering of the mean is probably attributable to environmental conditions (see pages 137-139). ${ }^{1}$ But in the case of the 757 minus strain, and particularly during the final 11 months of the experiment, the mean was lowered much less than that for each of the other 9 selected strains of this species. Selection here seems to have operated to hold the mean much higher than it otherwise would have been.

Reactiveness of Both Strains of Line 757 Modified Through Selection.

Another method of checking up the effect of selection in Line 757 is by a detailed comparison of the mean reaction-times of the plus and minus strains of Line 757 with corresponding data for Line 740, with which it is most similar in point of time of beginning the selections and in duration of the selection experiment; and by a further comparison of the reaction-time means for the two strains of Line 757 with corresponding mean reaction-times for the plus and the minus strains of the other lines of the same species, Lines 794, 795, and 796 .

This comparison is given in detail in tables 48 and 49 and serves to show whether both the plus and minus strains of Line 757 became modified during the selection or whether the divergence between the two strains of this line resulted from a genetic change in reactiveness of the minus strain alone. This would seem to have an important bearing upon the question as to whether the results came from mutation or gradual change in Line 757. It would seem less easy to explain the result as due to larger mutations if both the plus and minus strains of Line 757 were affected, i. e., departed from the means for corresponding strains of the other lines of the same species, than if only one of the two strains of Line 757 was affected.

The comparison between the mean reaction-times of the Line 757 plus strain and the plus strains of the other $S$. exspinosus lines is the more crucial test, for it is obvious, by mere inspection and comparison of the figures (figures $11 \mathrm{c}, 12 \mathrm{c}, 13 \mathrm{c}, 15$, and 18c) showing the reaction-time curves for Line 757 and the other S. exspinosus lines, that the Line 757 minus strain became much less reactive than any of the other S. exspinosus strains. The following analysis seems to show, however, that the plus strain of Line 757 likewise became more reactive than the plus strain of Line 740 or than the plus strains of the other $S$. exspinosus lines.

The curves showing reaction-time means for the plus strain of Line 757 (figures $18 \mathrm{~B}$ and 19) are somewhat irregular, but their

${ }^{1}$ Possibly the general lowering of the means in both the plus and minus strains of all the lines of S. exspinosus is to be accounted for through a better handling of the material as the experiment progressed. No intentional changes in the handling of the material were made after about July 1912, however, and we were not conscious of any better manipulation as the experiments progressed. 
A PHysiological CHARACTER.

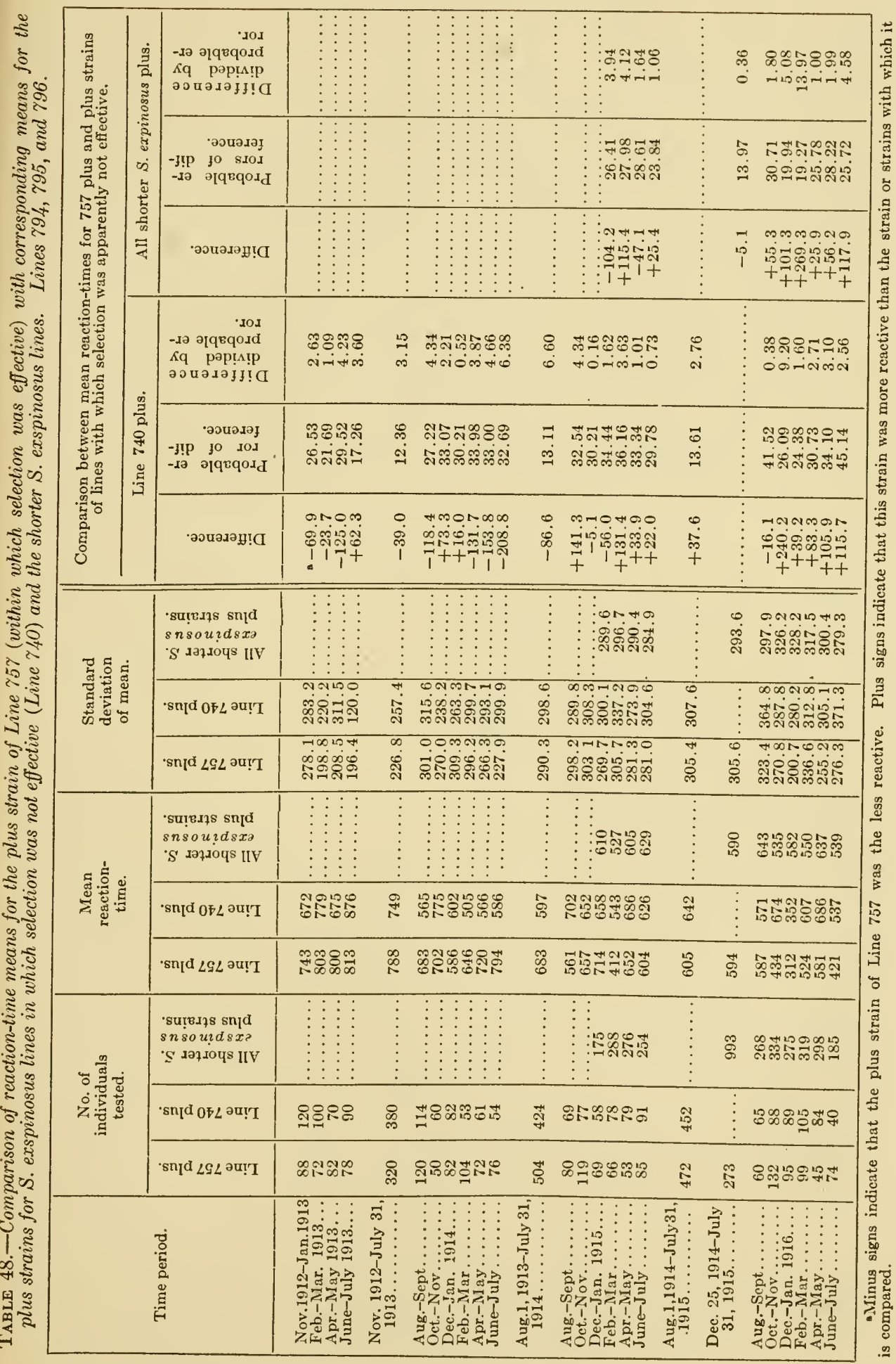




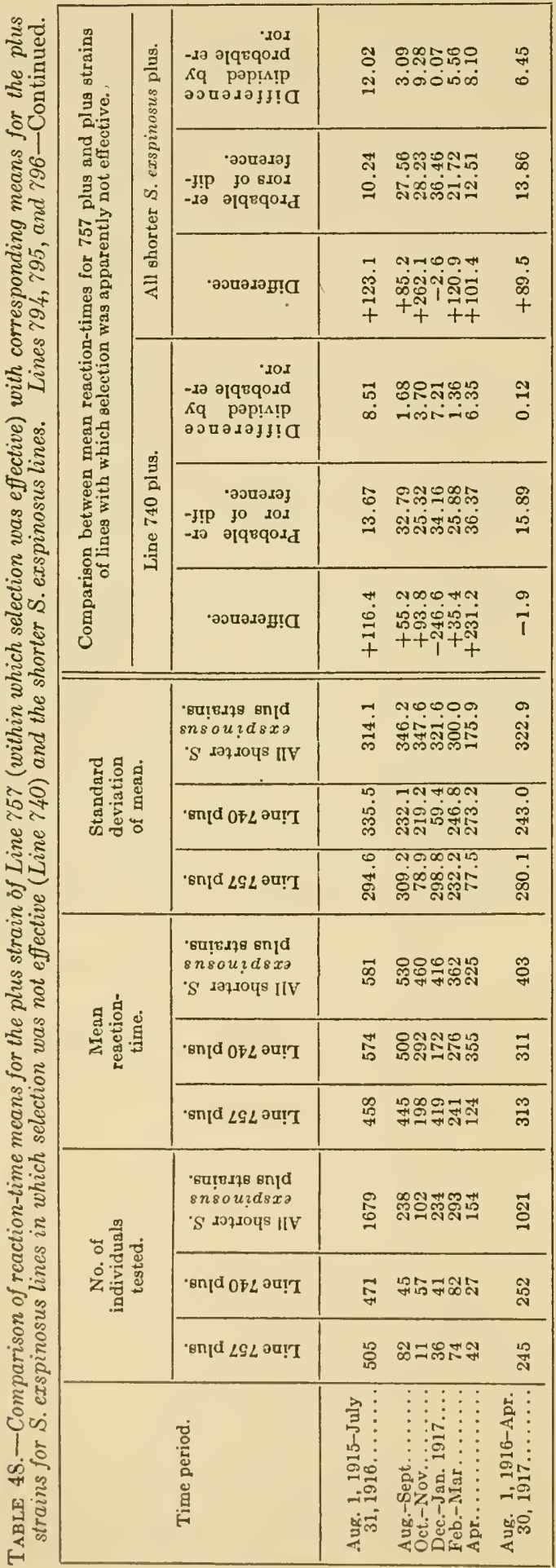




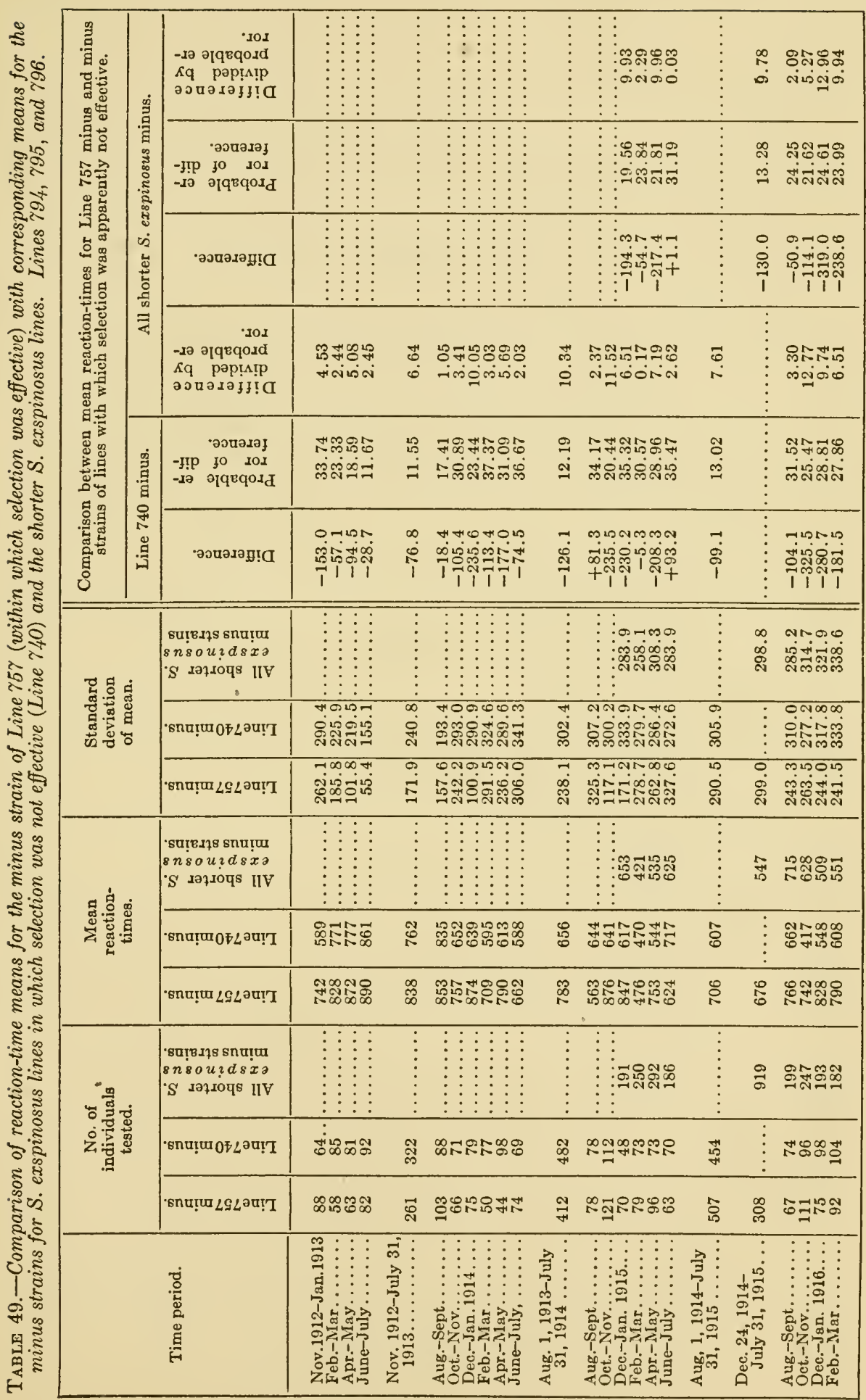




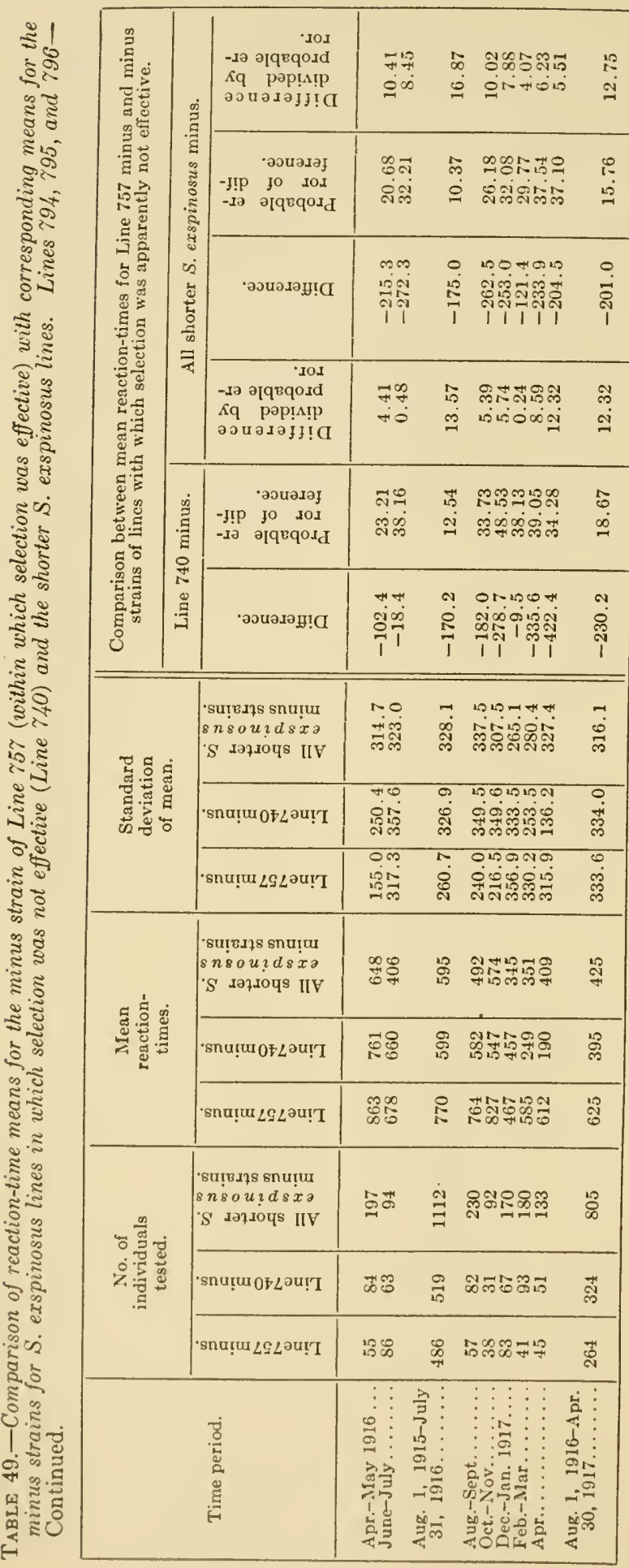


general trend is very nearly that of a straight line. This general form constitutes intrinsic evidence of the reliability of the curves as a whole.

The curve for Line 757 plus (figure 15) starts higher than the level attained by the Line 740 plus strain for the same period. This is probably. significant. The two-month period curve for the Line 757 plus strain held very closely to a level near 800 seconds for the first 9 months of selection. The curve for the plus strain of Line 740 , while prevailingly at a lower level for these periods, fluctuated from 672 seconds to 876 seconds. The mean difference between the plus strains of Lines 757 and 740 for this nine-month period is $39 \pm 12.36$ seconds, 3.15 times the probable error. Hence there is evidence that at the start the plus strain of Line 757 was less reactive than the plus strain of Line 740 .

During the first 31 months (to February 1915) of selection with Line 757 the plus strain in general had a higher reaction-time than the plus strain of Line 740 (table 48 and figure 15), which tends to strengthen one's conviction that at the start the plus strain of Line 757 was less reactive than the plus strain of Line 740 . But from February 1915 the fairly consistent differences between the plus strains of Lines 757 and 740 are striking and indicate that the plus strain of Line 757 had become the more reactive of the two. Of 14 two-month periods the plus strain of Line 740 was the more reactive only twice. One of these differences is slight ( $16 \pm 41.5$ seconds), the other is large $(246.6 \pm 34.2$ seconds); but this difference arises from the coincidence of an exceptionally low average for Line 740 plus (the lowest, by 104 seconds, of any two-month average for this strain) and an exceptionally high average for Line 757 plus. ${ }^{1}$ Averages by two-month periods are obtained from too few individual reaction-time records to be highly reliable when considered singly, so, while this difference is large, it must be considered in relation to the other averages and evaluated accordingly. For the other 12 two-month periods of the latter half of the experiment with those two lines, the plus strain of Line 757 was the more reactive as compared with the plus strain of Line 740 ; the differences were from 22 to 240 seconds, and were respectively $3.6,1.0,0.7,9.2,1.6,2.7$, $3.1,2.6,1.7,3.7,1.4$, and 6.4 times their probable errors (see table 45). That is to say, even when considered by shorter (two-month) periods, 12 of 14 differences indicate that the plus strain of Line 757 was more reactive than the plus strain of Line 740 , although, with their large probable errors due to relatively small numbers, only 7 of these differences are statistically significant.

The mean for the December 1916-January 1917 period for the plus strain of Line 757 was obtained from the reaction-time records of only 36 individuals of 3 broods. The corresponding mean for the 740 plus strain resulted from 41 individual reaction-time records. These numbers are scarcely more than half the usual numbers for two-month periods. 
Considered by longer periods, it is found that during the first (9 months) and second (12 months) longer periods of the experiment the plus strain of Line 757 was less reactive than the Line 740 pus strain by $39.0 \pm 12.36$ seconds and $86.6 \pm 13.11$ seconds, differences of statistical value, 3.15 and 6.6 times the probable errors. During the following year the plus strain of Line 757 became the more reactive, though the difference for the entire year-period was only $37 \pm 13.61$ seconds, or 2.76 times the probable error. During the next year, August 1915-July 1916, the difference is $116.4 \pm 13.67$ seconds, 8.51 times the probable error-the plus strain of Line 757 being the more reactive. The averages for the final ninemonth period of selection differ by $1.9 \pm 15.89$ seconds, the plus strain of Line 740 having the lower reaction-time. This on its face distinctly controverts the existence of a significant difference in reactiveness between the plus strains of lines 757 and 740 . But, as already noted, in one two-month period during this longer period there was an exceptionally low average for the plus strain of Line 740 and an exceptionally high average for the plus strain of Line 757 , and the striking influence of these two aberrant averages produces the difference noted above, a difference which is quite out of line with the general behavior for the latter part of this experiment of the two strains concerned.

The curves for Lines 740 and 757 by six-month periods (figure 19) show the plus strain of Line 757 the less reactive until the MayOctober 1915 periods, from which time the 757 plus strain is shown the more reactive for the remainder of the experiment. The exceptional reaction-time periods (December 1916-January 1917) for the two strains compared serve to cause the curves to approach for the last six-month period, but the plus strain of Line 757 maintains the lower level.

Hence it is seen that, whereas on the start the plus strain of Line 757 was fundamentally less reactive than the plus strain of Line 740, during the latter half (nearly) of the experiment there is fairly conclusive evidence that the plus strain of Line 757 was more reactive than the plus strain of Line 740 , which may fairly be considered as a check, since it was subjected to the same treatment as Line 757 and throughout a contemporaneous period of time.

Comparing the mean reaction-times by two-month periods for the plus strain of Line 757 with the means for the plus strains of the remaining lines of $S$. exspinosus subjected to selection, Lines 794 , 795 , and 796, the result is still more suggestive of a changed reactiveness of the plus strain of Line 757. The remaining 3 lines are lumped in this comparison, a procedure justified only in the interest of brevity and the securing of less fluctuating averages. The plus strain of Line 757 was less reactive than the combined plus strains of Lines 794, 795, and 796 in only 3 out of 15 two-month periods, the 
means for Line 757 plus being exceptionally high, in each of these periods. For the other 12 periods Line 757 plus was the more reactive, the differences varying from 25 to 269 seconds and being $4.1,1.1,1.8,5.1,14.0,1.0,2.0,4.6,3.1,9.3,5.6$, and 8.1 times the large statistical probable errors (table 48). Considered by longer periods, it is seen (table 48) that the differences are $-5.1 \pm 13.97$ seconds, $+123.1 \pm 10.24$ seconds, and $+89.5 \pm 13.86$ seconds, the plus sign indicating greater reactiveness on the part of the plus strain of Line 757 . Reference to figure $18 \mathrm{~A}$, which shows the reaction-time curves for Line 757 and combined reaction-time curves for all other S. exspinosus lines, Lines 740 (in part), 794, 795, and 796 , shows clearly to what extent the mean reaction-time for the plus strain of Line 757 is prevailingly lower than the combined means for all the other S. exspinosus plus strains. These curves show at a glance that the plus strain of Line 757 was essentially lower in its reaction-time than the other plus strains of the same species. The 3 two-month periods in which the reverse exists are there seen in their true light-as exceptionally high points in the reaction-time curve for 757 plus.

Thus, from examination of the data for mean reaction-times for contemporaneous periods, it is found that during the latter half of the experiment the plus strain of Line 757 is more reactive than the plus strains of the other $S$. exspinosus lines. That this is a result of selection is indicated by the fact that in the beginning of the experiments both strains of Line 757 were appreciably less reactive than the two strains of Line 740 , with which Line 757 may fairly be compared.

Comparison of the reaction-time means for the minus strain of Line 757 with the 740 minus strain (table 49 and figures 15 and 19) shows at once that the minus strain of Line 757 was from the beginning the less reactive of the two, and that as the experiment progressed the difference in reactiveness between the minus strains of the two lines increased until at the close of the experiment the divergence was fairly large. ${ }^{1}$ Of 27 two-month periods the minus strain of Line 757 had a lower reaction-time than Line 740 minus only 2 times, a remarkable uniformity of differences when the irregularities of the curves are considered. Of the 25 times when the minus strain of Line 757 was the less reactive, the differences were of statistical value 18 times, being $4.5,5.1,3.4,10.1,3.0,5.7$, $11.5,6.5,7.2,3.3,12.8,9.7,6.5,4.4,5.4,5.7,8.6$, and 12.3 times their probable errors (see table 49 ). Seven of the differences by shorter periods and the 2 differences in the reverse direction were not of statistical significance. Considered by longer periods, the mean

${ }^{1} \mathrm{As}$ is general, when comparing reaction-time means of two strains for contemporaneous periods, there is seen an obvious rough parallelism between the two curves; but the uniformity with which these two curves parallel each other is rather exceptional. 
differences were $77,126,99,170$, and 230 seconds. The difference for the middle period is influenced by the exceptionally low means for the Line 757 minus strain during 2 two-month periods. Otherwise the divergence consistently increased.

When the minus strain of 757 is compared with the shorter $S$. exspinosus lines (Lines 794, 795, and 796) the divergence between the minus strain of Line 757 and the minus strains of other lines which may serve as checks is even more marked (table 49 and figure 18B). The minus strain of Line 757 had a higher average than the combined averages for the minus strains of Lines 794, 795, 796 in 14 of 15 twomonth periods, the differences ranging from 51 to 319 seconds and all but two of them being from 4 to 13 times their probable errors. The one exceptional difference was a difference of only 1.1 seconds.

\section{Conclusion Regarding Effect of Selection in Line 757.}

It is seen, then, in Line 757 , that by all the tests applied and in spite of all the safeguards used in connection with these data, a marked effect of selection is indicated. This is shown by the course of the curves plotting the mean reaction-times of the two strains; by a progressively increased (though somewhat irregular and once interrupted) difference in mean reaction-time between the two strains, the plus strain having the lower reaction-time; by a decrease to 94 seconds in the average minimum reaction-time of the plus strain as compared with a decrease to 245 seconds in the minus strain; by a decrease of approximately one-third in the average maximum reaction-time in the plus strain, ${ }^{1}$ while at the same time the minus strain decreased only 5 per cent; by a decrease of four-fifths in the number of individuals of the plus strain which failed to respond to the light, while the decrease in this number in the minus strain was only onethird; by the results of the two test series applied to the strains of this line; by the data for the same-day broods; by every statistical test which was applied to the data; by a comparison with similarly treated strains of other lines of the same species; and, to the eyes of the observer, most of all by the greatly changed behavior in the experimental tank of the plus strain as compared with that of the minus strain.

There scems no escape from the conclusion that in Line 757 there is a marked effect of selection. This effect appeared in the early period of the experiment and with some fluctuation increased throughout its duration. The form of the curves would seem to indicate that the effect of selection was continuous and was still

${ }^{1}$ This decrense in the maximum reaction-time means more than a decrease of one-third suggests. At the beginning of selection with Line 757 some broods were left in the experimental tank for an hour or more, and those individuals which did not respond to the light within the period allotted for the experiment ( 15 minutes) often did not move at all within the much longer period. It seems probable that the maximum reaction-times for this carly period might readily have been near 3,600 , or even 10,800 seconds in many cases, if each of the selection tests had been continued for an hour or 3 hours. 
cumulative at the close of the experiment. The divergence in mean reaction-times is neither controlled nor noticeably influenced by the relative vigor of the two strains, nor does it appear to be explicable on any other grounds than as a divergence coming about through selection.

It is to be regretted that no return selection was attempted with Line 757 . The selection experiments were very laborious, and at the time when it was decided that they had been carried far enough, there did not seem sufficient justification for prolonging the experiment. Though it was then realized that the two strains of Line 757 were pronouncedly different in their reactiveness to light, the full significance of this difference, particularly as involving a changed reactiveness in both strains of Line 757 as compared with the corresponding strains of the other S. exspinosus lines, was not brought out until months later, when the extensive data were fully worked over. Time was not then available for again taking up the selection experiment.

A further fact of importance is that the effect of selection was permanent, or at any rate persisted, through a long series of generations. In December 1919 (32 months after selection had been discontinued) the selective effect still persisted and probably to as marked a degree as at the termination of selection. The two strains, meantime, had been propagated for 112 generations without any regard to their past history. The persistence of the effect of selection was demonstrated by testing a large number of broods of both strains. In extremely few cases did a brood of the plus strain fail to show more reactiveness to light than the corresponding brood of the minus strain, while in most cases the broods of the plus strain were markedly the more reactive. 


\section{ENVIRONMENTAL CONDITIONS AS AFFECTING REACTION- TIME AND VIGOR OF STOCK.}

Any relation between environmental influences and reactiveness to light is a fact of general biological significance and is a matter of importance in the present connection. In the light tests with Cladocera little-understood environmental influences were important factors in influencing reaction-time in all three species which were subjected to selection. These environmental influences are discussed under the following heads: (1) temperature influences; (2) influences of exhaled substances from the observer's breath; (3) relatively temporary chemical (?) differences in the water used in the experimental tank; (4) occurrence of negatively reacting individuals; (5) general influences operative through longer periods of time; (6) influence of vigor.

\section{Temperature Influences.}

The temperature of the water in the experimental tank was a minor factor influencing reaction-time. This influence was not marked enough to be evident to the observer in the tests day by day, but the somewhat lower reaction means during the winter periods indicate and correlation between temperature and reactiontime demonstrates that lower temperatures are to some extent associated with greater reactiveness and a lower reaction-time mean.

The temperature of the water in which the animals were tested was always near that of the basement room in which the tests were conducted. Fortunately this room was less affected by fluctuations in summer temperatures than the remainder of the building, but in winter temperatures ran fairly low, $-10^{\circ}$ to $15^{\circ} \mathrm{C}$., inasmuch as this room was not provided with much artificial heat.

Correlations between individual reaction-times (50-second classes) and temperature $\left(0.5^{\circ} \mathrm{C}\right.$. classes $)$ of the water for all the tested individuals of strains of $D$. pulex cover the following periods and give the following values:

\begin{tabular}{|c|c|c|c|c|c|c|c|c|c|}
\hline $\begin{array}{l}\text { Time } \\
\text { period. }\end{array}$ & $\begin{array}{l}\text { No. of } \\
\text { tested } \\
\text { young. }\end{array}$ & $r$ & $E$ & $r / E^{r}$ & $\begin{array}{l}\text { Time } \\
\text { period. }\end{array}$ & $\begin{array}{l}\text { No. of } \\
\text { tested } \\
\text { young. }\end{array}$ & $r$ & $E^{r}$ & $r / E^{r}$ \\
\hline Apr. 1911 & 194 & +0.0071 & 0.0454 & 0.15 & $\mathrm{Fel} .1915$. & 292 & +0.0142 & 0.0395 & 0.36 \\
\hline May 191.1 & 317 & -.2107 & .030 & 5. 82 & Mar. 1915. & 347 & -.0532 & .0361 & 1.47 \\
\hline June 191.1 & 175 & -.0019 & .0510 & 0.0 .4 & (Summer) & & & & \\
\hline July 1914 & 197 & $-.000 !$ & $.04 \$ 1$ & 0.02 & Apr.-Sept. & & & & \\
\hline Aug. 1914 & 205 & +.1238 & .0464 & 2. $(i 7$ & $1914 \ldots$ & 1,474 & -.0193 & .0175 & 1.10 \\
\hline Sept. 1914 & 386 & -.2442 & $.0: 322$ & 7.70 & (11"inter) & & & & \\
\hline Oet. 1:14 & 385 & +.2742 & .0318 & 8.62 & Oct $1914-$ & & & & \\
\hline Nov. 1914 & 438 & $+.06 ! !): 3$ & .0321 & 2.16 & Mar 1915. & 2,025 & $+.0 \cdot 1 \cdot 12$ & .0150 & 2.95 \\
\hline Dec. 1914 & 301 & $+0 \sin 1$ & $.03 \times 4$ & 2.20 & (Ye:ar) & & & & \\
\hline Jan. 1915 & 263 & +.0969 & $.0 \div 13$ & 2.35 & Аpr. 1911- & & & & \\
\hline & & & & & M:21. 1915 & 3,499 & +.1369 & .0112 & 12.22 \\
\hline
\end{tabular}


These correlations are small and of those for single month-periods only three or four can be credited with statistical value, those for the May, August, September, and October 1914 periods. Two of these are positive and two are negative correlations. Five of the correlations from March to September are negative and two of these are significant, both in numerical value and in comparison with their probable errors. One of the two positive correlations for the spring and summer period is very small, but the other is larger and of possible significance. The correlations for October-February are all positive, but only one is significant. The correlation for the sixmonth spring and summer period is $-0.0193 \pm 0.0175$; that for the six-month winter period is $+0.0442 \pm 0.0150$. These very limited data suggest that negative correlations are possibly general for the spring and summer months, while positive correlations are general for the late fall and winter months. The correlation for the year April 1914-March 1915, while only +0.1369, is 12.2 times its probable error.

These data cover the year-period of most consistent shifts in the composite reaction-time curves for the D. pulex strains (figure 10D) and probably show the changes in reaction-time associated with season and temperature at its maximum for D. pulex.

Correlations between temperature and reaction-time for $S$. exspinosus were confined to separate correlations for the strains of Line 757 covering in each case the selection data for 19 months from October 1915 to April 1917, the period during which occurred the greatest differences in reaction-time between the two strains. The correlations were, for the plus strain (689individuals), $+0.2428 \pm 0.0242$ and for the minus strain (683 individuals), $+0.2363 \pm 0.0244$. Each value is large enough to have a real meaning and is approximately 10 times its probable error.

Hence there is shown for both species, and particularly for S. exspinosus, Line 757, some significant correlation between reactiontime and the temperature of the water in the experimental tank. It is a question how much of this correlation, if any, represents a real direct temperature influence. If the temperature influence were direct, one would perhaps expect within the limited range of temperature occurring in the tests that higher temperatures would be associated with greater reactiveness and a lowered mean reaction-time, which would be indicated by negative correlations. Since the significant correlations are mostly positive, higher temperatures tend to be associated with less reactiveness and a higher reaction-time.

It is possible that the lowered reactiveness with higher temperatures is really due to reduced oxygen in the water used in the experimental tank. The water, when brought in the day it was to be used, was always at a lower temperature than the experimental room. As it warmed up, the excess gas in solution appeared as bubbles. The 
water was ordinarily used soon after it reached approximately the room temperature; hence it was probably near saturation for the principal gases which had been thrown out of solution. Whether the gases retained in solution were equally oxygen and other gases would of course depend upon the actual amounts of individual gases within the water when taken from the pond. Assuming that the pond-water was ordinarily near saturation for oxygen when brought into the laboratory, after it had given up a portion of its contained gases (as it always did) it would presumably be saturated for oxygen. Since the amount of oxygen at saturation at $25^{\circ} \mathrm{C}$. is about $26 \mathrm{per}$ cent less than at $10^{\circ} \mathrm{C}$, , this is a basis for the suggestion of an explanation for the greater reactiveness at the lower temperatures. No specific tests have been made to determine if this is the correct interpretation, and the results of the summer correlations for $D$. pulex do not fit in with this explanation.

There is also the possibility that temperature influenced reactiontime indirectly through its effect upon the food in the culture-water. The water used as culture-water went through the changes in temperature (and chemical constitutents) to which a shallow out-door pond is subject in the climate of Cold Spring Harbor and the development of the protista upon which the Cladocera feed is naturally influenced by temperature as well as other environmental factors. Before being used the culture-water (during its successive strainings) was kept for approximately 6 days indoors in jars surrounded by running water. The temperature of this running water varied with out-door temperatures, but was much less extreme. Hence there is also room for the assumption of influences of temperature upon the Cladocera stock, not directly as a temperature influence per se, but indirectly through the culture medium, which is a veritable microcosm.

\section{Influence of Substances Exhaled from Observer's Breath.}

That the amount of carbon dioxide was actually an important factor in influencing reaction-time is suggested by the fact that if several broods were tested successively in the experimental tank without change of water the later broods reacted markedly less promptly than the ones tested in the same water an hour earlier. ${ }^{2}$ The young Cladocera are so small as to be just visible in the illumination in the experimental tank, so that one must get the eyes at about reading distance from the water of the tank in order to observe the young animals. As a consequence, the exhaled air very largely

\footnotetext{
${ }^{1}$ The spring water is known to contain relatively a large amount of $\mathrm{CO}_{2}$.

${ }^{2}$ This was observed a number of times, after which the ptan of frequently changing the water in the experimental tank was adopted to obviate this disturbing influence. It seemed impracticable to change the water oftener than after testing each four broods, although it was sometines noted that the last brood or two of the four tested between changes of water wasless reactive than broods tested just after the change.
} 
struck the surface of the water. These differences in reactiveness were not due to temperature differences, since they occurred in cases where there were no temperature differences in the water. It is assumed that this difference in reactiveness was due to the accumulation of carbon dioxide from the observer's breath in the water contained in the tank, though exhaled volatile organic substances may have been wholly or partially responsible.

\section{Relatively Temporary Chemical Differences in Water used in Experimental TANK.}

Probably the environmental factor of greatest importance consisted in differences in the chemical content of the water used in the experimental tank, although this water was always obtained from the same pond and handled in the same fashion. Such chemical differences in the water would account for the pecularities in reaction-time which were so apparent in the reactions of all the broods tested on certain days. Not infrequently, between successive days or between periods of a few days' duration, considerable difference was noted in the general reactiveness of the stock as a whole. On one day the individuals tested would react fairly promptly, while on the following day they might react conspicuously less promptly. This clearly points to environmental influences operative temporarily but pronouncedly. These temporary differences in reactiveness, presumably due to differences in the water, are well illustrated in table 2 (page 18), showing in abbreviated form the data for the broods of Line 695, tested on August 29, 30, and 31, $1913 .{ }^{1}$

The data given in table 2 present an extreme case selected to show the environmental influence upon reaction-time (and upon the occurrence of negatively reacting individuals) at its maximum. The averages for the data for the two strains of Line 695 for the 3 days shown in table 2 are 401, 636, and 398 seconds, based upon 87, 190, and 50 individual reaction-times. The mean for the second of these days is 235 seconds or 58.6 per cent greater than that for the first day and 238 seconds or 59.8 per cent greater than that for the third day. The standard deviations and probable errors for these means were not determined, but obviously (from other experience in determining probable errors with such data) these differences are of large statistical value. As already noted, this is an extreme case (and it is doubtful if many as extreme could be found in any portion of the later data), but the factor operative here presumably was also operative to some extent in many of the tests conducted in making

1 These data were obtained with due regard to the necessity for changing the water in the experimental tank at frequent intervals and they fit the requirements of the present purpose very well. They are part of the data of the first test series conducted. As a test series this was not satisfactory, as the numbers of individuals in the corresponding plus and minus broods were not as nearly exactly the same as in later test series. Also, the broods were not always paired here, i. e., in the usual course a plus brood was always tested just before or immediately after a minus brood of the same age and containing the same number (within one or two) of individuals. 
selections; but this effect was probably the same with all the individuals of the plus and minus strains and could not have interfered with the choosing of the proper individuals or affected the experiment as a whole, except that it added to the irregularity of the reactiontime records. If, however, this disturbing influence did sometimes prevent the making of the proper selections, that would only render the selections less effective and would not confuse any results obtained.

\section{Occurrence of Negatively Reacting Individuals.}

The data shown in table 2 also serve to illustrate the irregular occurrence of negatively reacting individuals. There were 3 negative ones of a total of 87 individuals, or 3.5 per cent, August 29; 3 out of 190 , or 1.6 per cent, August 30 ; and 14 of 50 , or 28 per cent, August 31 . While these numbers are not large, the widely differing percentages indicate very well the relatively spasmodic occurrence of negatively reacting individuals on August 31 (see also page 15). There is great irregularity in the occurrence of negatively reacting individuals in general, so that while the illustration taken from table 2 is somehwat extreme, it is not unique. ${ }^{1}$

These illustrations, (1) to (4), bring to notice relatively temporary disturbing factors which are a matter of concern, but for which no way of complete elimination was found; yet they do not serve to discount the selection data as a whole. This is clear for two reasons: (1) these factors, which in the long run presumably must have affected the plus and minus strains in a similar way, could not often have interfered with making the proper selections and could contribute only to the fluctuations in reaction-time; (2) the consistent and convincing results with Line 757 could not have come about if these disturbing factors had seriously interfered with the course of the selection experiment as a whole.

5. General Influences Operative Through Longer Periods of Time.

The general relation between mean reaction-time and environmental conditions is obvious in the curves plotting mean reactiontimes by two-month periods. This relation is seen in that reactiontime curves for the plus and minus strains of the same line in a general way move upward and downward together to some extent and at times the nearly coincidental courses of the curves for the two strains are very striking. This was not due to any large extent to temperature differences in the water used in the experimental tank, although temperature differences in this water were sometimes a factor (see pages 128-130). Temperature influences fail to explain many of the broad fluctuations of the reaction-time curves, e. g., the high levels obtaining for the curves for D. pulex (figure 10D) during December

${ }^{1}$ It chances in this case that the lowest percentage of negatively reacting individuals falls upon the day of higlest mean reaction-time. This is a mere coincidence. 
1913-March 1914, a winter period during which relatively low levels are generally seen.

It is not difficult to believe that these environmental factors may have been in part chemical differences in the pond-water, gradual changes in carbon-dioxide or oxygen content, or other chemical differences, since the effects observed are operative through longer periods of time than the temporary environmental effects already considered. Such gradual changes in the water of a pond are well known, and the water used for culture-water and in the experimental tank during these tests was pond-water. We know nothing about the precise specific character of the changes involved in the present case.

\section{Coincident Changes in Reactiveness.}

The curves for Line 695 (figure 2c) show these general environmental effects to a marked degree, particularly in the relatively low levels of the curves for October 1912-November 1913 and in the higher level from December 1913-September 1914. The general coincidence of level of the two curves does not end here, but it is not so marked through the later course of the experiment because of the relatively wide fluctuations of the curve for the minus strain. The correlation between the mean reaction-times of the plus and minus strains of this line by two-month periods is $0.4962 \pm 0.0979$. With Line 689 (figure 3c) the environmental effect is observable throughout the course of the curves. In Line 691 (figure 4), while the curve for the minus strain is quite irregular, the general course of the curves is very similar. The same may be said for Line 711 (figure 5). In Line 713 (figure 6), in spite of the very irregular curve for the plus strain, the curves in general follow each other remarkably closely. The correlation for the two strains of this line is $0.6982 \pm 0.0773$. With Line 714 (figure $7 \mathrm{c}$ ) the curves are unusually irregular for strains of Daphnia pulex, yet the environmental influence is obvious from the general course of the curves. The correlation is $0.5027 \pm 0.0971$. In Line 719 (figure $8 \mathrm{c}$ ), again, the curve for the plus strain is very irregular, yet the general coincidence of the curves is obvious.

Line 751 (figure 9) shows the same general coincidence of the curves. This line, within which selection was begun in November 1912 , is the only $D$. pulex line with which selection was begun later than March 1912. It is interesting to note that the curves for this line start at virtually the same level as was attained by the other $D$. pulex strains during the same two-month period (December 1912January 1913) and closely follow the composite curves for the other D. pulex strains (see figure 10D).

The curves (figure 10, A and $\mathrm{B}$ ) for the relatively short experiments with Lines 762 and 766, both Daphnia longispina, show the same general indication of a parallel effect of environment upon the 
mean reaction-times of the plus and minus strains. Likewise, with the other $D$. longispina line, Line 768, the curves (figure $10 \mathrm{c}$ ) for the two strains, despite irregularities, follow the same general course.

With the S. exspinosus material the general influence of environment upon the mean reaction-times of the two strains of the same line is less conspicuous than with the lines of the two species of Daphnia, but it is evident in most of the curves and is particularly clear for the curves for the final several months of the experiments.

The curves for Line 794 (figure 11c) show this influence to a marked degree, in spite of the irregular portions of the curve for the minus strain. Because of the unusually irregular curve in Line 795 (figure 12c), the environmental influence is less in evidence, but there probably is a small positive correlation between the reactiontime means for the two strains by the two-month periods of the experiment. In Line 796 (figure 13c) the curves follow each other in a general way.

With Line 740 (figure 15) the curves on the whole follow each other to a remarkable degree. A clearer demonstration of the effect of environmental influence working through relatively long periods would be hard to find. The correlation between the mean reaction-times for the plus and minus strain by two-month periods is $0.6437 \pm 0.0733$. The relatively shorter range of the up-and-down movements of the curves for this line renders this correlation smaller than one would otherwise expect from the relatively close parallelism of the two curves, but, considering the limited number of terms involved in the correlation, it is very large.

In Line 757 (figure 18B) the environmental effect is somewhat in evidence in the courses of the two curves, but naturally it is obscured by the marked effect of selection, particularly during the last 21 months of the experiment; yet, even in this latter period, in spite of the wide divergence of the curves, there is an evident relation between the two which seems intelligible only as an effect of environmental influence. The correlation for the reaction-time means for the two strains is $0.4283 \pm 0.1041$.

A composite curve plotting the mean reaction-times for all the plus strains and another for all the minus strains of $D$. pulex is shown in figure 10D. The courses of the curves for the strains of any single D. pulex line, despite irregularities, strikingly resemble the corresponding portions of this composite curve. Likewise, the few reaction-time curves for strains of $D$. longispina (see figure 10, A, B, and c) to some extent follow the same course as the composite reaction-time curve (figure 10D) for the $D$. pulex strains.

A composite curve of the reaction-time means for all the plus strains and one for all the minus strains of S. exspinosus (except Line 757) is shown in figure $18 \mathrm{~B}$. The environmental influence is well shown in the generally fairly coincidental courses of the two curves, 
and, as with the lines of $D$. pulex, there is a striking resemblance between the curves for any one of the strains and the composite curve for all the corresponding strains of S. exspinosus.

There is some tendency for the composite reaction-time curves for strains of $D$. pulex to follow the same course as the curves for $S$. exspinosus, but this is seen to a limited extent and in only a few places, such as in a general rise for both species for June-July 1913 (figures 10D and 15) and in a general rise followed by a pronounced drop in the period from April to November 1915 (figures 10D and 18). While in general the physiology of these two species is much the same, there are still such specific physiological differences that any coincidental changes in reaction-times bespeak pronounced contemporaneous effects of environment.

Seasonal Changes in Reactiveness.

There is some tendency observable in the reaction-time curves for a drop in the curves, indicating greater reactiveness during the winter than the summer months. The composite curves for the $D$. pulex lines (figure 10D) in general show lower portions of the curves for the October-March periods, but this does not hold for the winter period for 1913-1914. Seasonal changes are seen to some extent for the winter and summer periods in the composite reaction-time curves for the $S$. exspinosus lines (figure 18B) and in the six-month curves for Lines 740 and 757 (figure 19).

The seasonal (winter and summer) differences are possibly due largely to temperature influences, but there is no certainty that this seasonal shift is due to temperature alone or even to temperature as indirectly working through the oxygen or other content of the water used in the experimental tank and through the culture medium, yet it seems probable that these influences may be a large factor in these seasonal effects.

\section{Contemporaneous Shifts in Reaction-Time Means.}

Contemporaneous shifts in the reaction-time curves for the strains of different lines of the same species are seen. There are a few shorter time-periods in the data for which there are really remarkable contemporaneous changes in the curves for the different strains of the same species. For the August-September 1912 period the $14 D$. pulex strains, with two exceptions, showed drops in the reaction-time curves. All but one of these drops were considerable in extent. The two strains which did not show drops in this period and the one which showed a slight drop in this period showed profound drops in the next two-month period, while most of the strains showed further drops in this later two-month period. Temperature influences ${ }^{1}$ were not the factors determining these drops in the

\footnotetext{
1 Temperature is referred to frequently because the data include temperature records, whil 3 for the other environmental factors no definite measurements are available.
} 
curves. In general, the temperature of the water in the experimental tank was very much the same for August-September 1912 as for June-July preceding. It is interesting to note that this AugustSeptember period, because of poor food conditions, was a period of great difficulty in maintaining our stock; mortality was high; most broods were excessively small, usually 1 to 3 individuals; and sterility was relatively common. Yet this is one of the periods of the greatest drops in the curves (decrease in reaction-time) which occurred at any part of the experiment with $D$. pulex.

A second interesting contemporaneous change in the reactiontime curves was a marked rise for all of the ten strains of $D$. pulex for December 1913 to January 1914. Though the temperatures were somewhat lower for this period than for the preceding period, it should be noted that the reaction-time curves for $D$. pulex strains remained very close to this high level for 8 months, namely, from December 1913 to July 1914 (from early winter to midsummer). Hence it seems impossible to attribute this fluctuation in the $D$. pulex curves for the December 1913-January 1914 period to temperature influences.

Another local drop is seen in every one of the 10 curves for $S$. exspinosus strains for the February-March 1915 period. This drop is very large for 5 of these strains. Temperatures for this twomonth period were in general slightly lower than during the preceding and succeeding periods, but as compared with other periods these are comparatively slight temperature differences and the drops in the curves can not be considerd primarily, if at all, due to the slight temperature differences between these two periods.

It is worthy of note that the contemporaneous shift in the reaction-time curves affecting every one of the 10 strains of $D$. pulex for December 1913-January 1914 period is not markedly reflected in the 4 S. exspinosus strains (see figures 15 and 18B) and that the profound drop in the curves for strains of Simocephalus for the last period mentioned above is not in evidence for the strains of $D$. pulex. This in itself would seem to indicate clearly enough that the effect is not due to temperature influences per se. ${ }^{1}$

One might be tempted to assume that the first and third of these profound shifts in the reaction-time curves were due to some improvement in Cladocera stock due to favorable laboratory conditions, inasmuch as the first appears after 4 months of selection in the D. pulex lines and the third after 2 months of selection in 3 of the $S$. exspinosus lines, except for the facts that (1) the D. pulex lines had been under laboratory conditions for $3 \frac{1}{2}$ months before selection began and hence a total of $71 / 2$ months before these drops occurred, and further, that they did not maintain these lower levels; (2) that

1 The lack of contemporaneous shifts in the eurves for strains of D. pulex and S. exspinosus is in line with physiologieal differences between the two species observed in other connections. 
Lines 740 and 757 had been in the laboratory for more than 2 years before these fluctuations occurred in the S. exspinosus lines; (3) that no such improvement is shown in the reproductive indices. ${ }^{1}$

While with the older lines of $D$. pulex subjected to selection the reaction-time means decreased markedly almost from the beginning of selection, and the means for these lines reached a low point in the curves (see figures 10D, 2c, 3c, 4, 5, 6, 7c, and $8 \mathrm{c}$ ) within 8 months, they afterward fluctuated upward and downward through the same general range, so that there is no ground for assuming that this early fluctuation was anything other than one of the wide general fluctuations of the curves. This decrease in mean reaction-time was due to environmental conditions, $i . e$., factors in the environment which made for changed conditions under which the animals were tested in the experimental tank.

Further, comparison of the curves for mean reaction-times for Line 751 (figure 9) with the curves for the other $D$. pulex lines shows that the reduced reaction-time means, which occurred with all the older $D$. pulex lines simultaneously soon after selection was begun, were not attributable to any improvement in the general vigor or quality of the daphnid stock due to its possibly being subjected to more advantageous conditions in the laboratory than in the ponds from which the stock was obtained. This is clear because the curves for the two strains of Line 751 not only do not show a drop soon after laboratory culture was begun, but start at very nearly the same level as was attained during the same months (December 1912January 1913) by the other D. pulex lines (figures 2 to 8) which had previously been subjected to laboratory culture for about 11 months and selection for approximately 7 months; and these curves for Line 751 follow the same general course as those for the older lines (during the same two-month periods) regardless of the fact that Line 751 had been under laboratory culture for a period 11 months shorter than that for the older lines.

General Increase in Reactiveness of Simocephalds exspinosus.

With the $S$. exspinosus lines, Lines 740 and $757,,^{2}$ there is a slight simultaneous increase in reactiveness of both the plus and the minus strains beginning after the June--July 1913 period (figure 15) and continuing, with fluctuations, throughout the rest of the experiment. This increase is more marked after the August-September 1915 period (figures 18B, 11c, 12c, 13c, and 15), where it appears in all the $10 \mathrm{~S}$. exspinosus strains, though to a less degree in the minus strain of Line 757 . The curves for $S$. exspinosus strains

\footnotetext{
${ }^{1}$ Not only is there no improvement reflected in the reproductive indices, but those indices for the $D$. pulex lines are abnormally low (indicating reduced vigor) for the very months (in the sutumn of 1912) during which this increase in reactiveness is most marked.

${ }^{2}$ No other Simocephalus lines were then in the laboratory. Lines 794, 795, and 796 were begun in December 1914.
} 
previous to August-September 1913 period show fairly consistent rises in reaction-time, but henceforth, in spite of fluctuations, somewhat lower levels are usually maintained.

It is extremely improbable that these general increases in reactiveness in the $S$. exspinosus strains are due to improvement in the stock due to better conditions in the laboratory than in the outdoor ponds from which the material was obtained. The increased reactiveness does not appear soon enough after selection was begun with Lines 740 and 757 to render this interpretation probable, and there was an actual decrease in reactiveness for approximately 12 months (Line 740) and 9 months (Line 757) after laboratory culture was begun. Then, too, the increases in reactiveness for Lines 740 and 757 are simultaneous, in spite of the fact that Line 740 had been in the laboratory for about 12 months and Line 757 for only 9 months. Further, Lines 794, 795, and 796 were in the laboratory for 10 months before a pronounced general tendency to increased reactiveness is evident (figure 18B).

Again, with the 3 lines of Simocephalus (Lines 794, 795, and 796), with which selection was begun more than 2 years later than with the older S. exspinosus lines (Lines 740 and 757), the reactiontime curves (figures 11c, 12c, and 13c) start at near the same levels as were attained by the two older lines (figures 15 and 18B) for the same months, regardless of the fact that the older lines had already lived under laboratory conditions and undergone selection for approximately 28 and 25 months. ${ }^{1}$ The striking decrease in reactiontime means which occurred during the last few months of selection (except to a lesser degree in the minus strain of Line 757) is likewise as pronounced with the newer as with the older $S$. exspinosus lines.

A further and (to the writer's mind) a fatal criticism to the assumption (to explain decreased reaction-time) of a progressive improvement in the stock due to favorable laboratory conditions lies in the fact that there are not changes in reproductive indices coincident with changes in reaction-time and that there is no progressive increase in reproductive index.

To explain the result within Line 757 as due to a differential physiological improvement requires several assumptions: (1) that such improvement is not shown in the reproductive index; (2) that Line 757 was more susceptible to such improvement than the other S. exspinosus lines; (3) that not only was the plus strain of Line 757 subjected to greater improvement than the minus strain, but to greater improvement than the other S. exspinosus plus strains; (4)

${ }^{1}$ Omitting the minus strain of Line 757 - which because of the effect of selection had 8 considerably higher mean for this period, 829 seconds (47 individual records)-the mean reaction-time for the period December 11, 1914, to January 15, 1915, for the older S. exspinosus strains was 645 seconds (124 individual reaction-time records). For the same period, the period during which the selection was begun with the newer lines of S.exspinosus, the mean for the newer lines was 658 seconds (319 individual records). 
that the minus strain of Line 757 through the selection was very little, though somewhat improved; (5) that this improvement was permanent, or at least persisted for 32 months after the close of selection.

The writer challenges the first of these assumptions as contrary to fact. 1 Further, at no time was there any observable difference in the general activity of the two strains of Line 757 , except when subjected to directive light stimulation in the experimental tank. To the second, third, and fourth assumptions the writer makes no objection, except the general objection that there is no obvious advantage derived through them and they seem uncalled for; further, there is no obvious reason for assuming an obscure physiological effect rather than genetic changes. The last of these assumptions appears tantamount to the assumption of a permanent extra-chromosomal inheritance or at least an extra-genetic transmission-an extremely precarious assumption.

It is possible to assume that the increase in reactiveness as the experiment progressed was due to a better handling of the material, such as to affect the reactiveness (but not the reproductive index), but the author was not conscious of any better manipulation.

The logical explanation would seem to be that the pond-water which was used in testing these animals was undergoing a progressive change. This pond is fed by a spring and has considerable overflow. It is a dying pond, rapidly filling with silt. At the close of the experiment the spring-water was flowing through a pond which then had probably less than one-third the water-content which it had at the beginning of the experiment. The water was always taken at the outlet. Consequently, as the experiment progressed, the water used in the experimental tank had remained for shorter and shorter periods of time in the pond from which it was obtained. It is reasonable to suppose that this water was progressively changed in some of its constituents (carbon dioxide, oxygen, substances obtained from the silt, or in other constituents). This explanation also seems plausible in view of the fact that reaction-time is clearly closely related to the condition of the water in which the young daphnids are tested. ${ }^{2}$

Whatever may have been the cause for the generally reduced reaction-time for $S$. exspinosus strains during the latter part of the experiment, it should be borne in mind that except for the practice of selection all strains were treated as nearly alike as possible and that there is apparently no ground for the assumption of a possible continued differential effect due to selection other than such as came about through genetic changes.

1 The validity of the reproductive index as a measure of vigor (including general muscular activity) is discussed on page 143 .

${ }^{2}$ Local influences, presumably due to changes in the water, have been frequently referred to (see table 2, pages 17-18, and elsewhere). 
Independent Shifts in Reaction-time Means.

Throughout this experiment every effort was made to treat alike all the lines, and particularly the two strains of a line, as regards food, temperature, light, method of handling stock, making of transfers, etc. However, the two strains of the same line did not usually reproduce on the same day, and consequently transfers were generally made into culture-water of different collections from the outdoor pond. Such variations as occurred in food and chemical content of the culture-water, and temperature, light, etc., in the laboratory, impinged upon different periods of the life of the new generations. Such unavoidable differential treatment can scarcely be conceived to be without influence upon the physiology of these organisms. ${ }^{1}$

In spite of the somewhat differential treatment of the two strains of a line, there has been seen in general a fairly close correlation between the reaction-time means for the two strains of most of the lines throughout their entire history. In so far as there are differences in reactiveness between the two strains of the same line, where they are temporary and hence are presumably non-genetic, they are believed to be due to this unavoidable differential environmental treatment.

Pronounced independent shifts in the reaction-time curves covering considerable periods for the two strains of the same line are seen in several cases. Three such shifts relative to each other are seen in the reaction-time curves for the two strains of Line 695: (1) September 1912 to January 1913, in which the minus strain is consistently higher than the plus strain and higher than the composite curve (figure 10D) for the minus D. pulex strains for this period; (2) September 1914 to May 1915, in which the minus strain is consistently, though only slightly, lower than the plus strain and lower than the composite curve for the period; (3) February-September 1916, during which the two strains differed consistently by a widening margin due to the plus curve running sharply upward. None of these three periods of consistent differences in reactiveness for periods of 6 months or longer are considered to have genetic significance (see pages 44-45).

Two shifts are seen in the curves for Line 691, September 1912January 1913 , during which the plus curve runs lower than the minus curve and lower than the composite curve (figure 10D), and JuneSeptember 1913, during which the minus curve runs abnormally high. This last shift may have genctic significance, since the minus curve tends to run slightly higher than the Line 691 plus and the composite curves during the remainder of the experiment, but its genetic significance is extremely doubtful.

In Line 713 the plus-strain curve is particularly fluctuating, there being 3 main periods of differences in reaction-time: December

\footnotetext{
It is obvious that temperature and character of the food affect the reproductive index.
} 
1912-October 1913, when in general the plus curve was low (see figures 6 and 10D); December 1913-July 1914, when the plus curve was relatively high; and October 1914-July 1915, when the plus curve again was relatively low, compared in each case with the composite curve (figure 10D). The minus curve fluctuated similarly, but to a less degree.

In Line 714 the minus curve shows 3 parts where it is quite separated from the plus curve (figure 7c): (1) April-September 1912, when it is high; (2) June-September 1913, when it was low; AprilJuly 1914, when it was high. None of these cases has apparent genetic significance.

Line 794 shows (figure 11c) 2 fluctuations, each consisting of 3 two-month periods. During the first (December 1914-May 1915) the minus strain was low, and during the second (June-November 1915) it was high, both relative to the plus strain of Line 794 and the composite curves for the other $S$. exspinosus strains (figure 18B).

Line 795 shows two similar periods for the minus strain (figure 12c): February-May 1915 and December 1915-July 1916, during which this strain was lower relative to the plus strain of this line and the composite curves for the other $S$. exspinosus strains (figure 18B).

Line 740 shows 3 periods of 6,10 , and 10 months, during which the two strains differed consistently in reaction-time. The first 2 periods, February 1914-July 1914 and September 1914-May 1915, are apparently due principally to fluctuations in the plus strain. There were no sufficient other strains of this species in the laboratory during this time to make adequate comparisons. During a third period, April 1916-January 1917, the minus strain ran higher than the composite curve for the other minus strains (except Line 757 , see figure 18B). For the latter part of this period the plus strain of line 740 ran abnormally low. The two fluctuations produced a relatively large difference between the reaction-time curves for the two strains of this line. The later history of the two strains, especially the test-series data obtained at the close of selection with this line, indicated that this divergence had no genetic basis.

Line 757 shows a period, June 1914-July 1915, in which 4 of the 7 two-month periods show relatively low points in the curve for Line 757 minus (figure 18B). While the effect of selection within this line is such that the minus curve drops below the plus curve at only one point, it is believed this clearly represents a period, or two periods (the October 1914-January 1915 period shows the minus curve relatively high), which are in every way similar to these just referred to (for the other lines) and that non-genetic influences served to mask the effects of selection during this portion of the experiment.

The outstanding fact regarding local fluctuations in reactiontime means of the two strains in Line 757 is that they produce relatively so little reduction or interruption of the difference between 
those means. This fact would seem a further confirmation of the effect of selection within Line 757.

Fluctuations for single two-month periods are common in the data. They are presumably due to the same factors which produce the fluctuations in reaction-time for longer periods. It is also true that the number of reaction-time records for single two-month periods is not sufficient to obtain highly reliable averages, and hence fluctuations for single two-month periods are less significant than those covering 3 or more such periods.

Purely local differences in reactiveness might be expected to be seen occasionally in results obtained from the different test series, and such proves to be the case. The first test series for Line 695 gave a mean reaction-time for the plus strain 32 seconds greater than that for the minus strain. The second test series (9 months later) gave a mean for the minus strain 62 seconds the greater. The other 2 test series for Line 695 were in consecutive months, yet the difference in one was -1 second and the other +51 seconds. Such local differences lend caution to one's interpretation of the result of test series, and the results of test series are given credit only when they show pronounced agreement and there is other confirmatory evidence.

In the first test series for Line 757 the mean for the plus strain is 282 seconds lower than the mean for the selection data for the threemonth period during which this test series was conducted (table 45); while during the second test series the mean for the plus strain was 133 seconds higher than that for the selection data for the contingent three-month period. It is extremely probable that if another test series had been conducted within a few weeks after the first one, the mean for the plus strain would have been more nearly within the range of the selection data for the plus strain for that period, and that another test series conducted a few weeks after the second test series would have given a much lower mean for the Line 757 plus strain. The reaction-time differences between the two strains of Line 757 are so large, however, that a wide departure from the usual reactiveness of a strain still leaves a large difference in mean reactiveness between the two strains. ${ }^{1}$

\section{Whether "Depression Periods" Occur.}

These periods of relatively temporary drops or rises in the reaction-time curves are probably in no case due to genetic influences. In cases in which the reaction-time curves rise, the large and somewhat continuous lifts in the level of the curves may be ascribed by

${ }^{1}$ For the benefit of any who (in view of the fact that local environmental effects are seen even in test series) might be inclined to wonder if additional test series would have shown such large divergences between the two strains of Line 757 , it may be added that in July 1919 and again in December 1919 (27 and 32 months after selection was discontinued) extensive test series were conducted in Line 757 , each covering a period of and consisting of material from three generations. In extremely few cases in these large series did a brood of the plus strain fail to show markedly greater reactiveness than the corresponding brood of the minus strain. 
some workers to "depression periods" in the Cladocera stock. This explanation is rejected for the following reasons:

1. These periods of local drops or rises in individual reactiontime curves are extremely irregular in their occurrence and do not affect all the strains or the two strains of the same line equally.

2 . There is no coincidence between changes in reaction-time and reproductive index and no demonstrable relation between reactiontime and the vigor of the stock, as measured by the reproductive index.

3. Cases such as Lines 714, 794, and 795, in which these nongenetic differences appeared immediately upon the beginning of selection (figures $7 \mathrm{c}, 11 \mathrm{c}$, and $12 \mathrm{c}$ ), can scarcely be attributed to depression periods, inasmuch as the two strains of each of these lines had just been derived from the same progenitor.

4. Males or ephippial females were not found in this stock at any time during the selection experiments, either in periods of unusually low or high reproductive indices or unusually slight or great reactiveness; yet if males or ephippial females occurred in any appreciable numbers (particularly the latter) they would have been detected.

5. Depression periods as such are not seen in the stock bred in the laboratory.

The writer believes that these fluctuations are merely reflections of relatively local environmental influences upon the individual strains concerned.

6. Environmental Conditions as Affecting Vigor of Stock.

Obviously vigor is closely related to environmental factors. As to the Cladocera reared in this laboratory, there is reason to think that their vigor, with most of the species at any rate, is completely controlled by environmental influences and is not affected by internal factors, such as the effect of long-continued parthenogenetic reproduction.

\section{Reuiability of the Reproductive Index.}

The reproductive index is a safe criterion to use as a measure of general vigor and, it is believed, of general muscular activity as well. During times of lowered reproductive activity (appearing in decreased numbers in first broods and in increased age of mothers when first broods are produced), such as frequently affected several or all of our strains of the same species at the same time, there was high mortality, more sterility, more cases of failure to produce a second brood, and frequently, with the Daphnia species, a noticeable decrease in general muscular activity so far as swimming movements were concerned. ${ }^{1}$

\footnotetext{
${ }^{1}$ It seems surprising that this is not reflected in increased reaction-time means, but (as is shown elsewhere) there is extremely little evidence of a relation between vigor and reaction-time. During part of the time, when the stock was low in reproductive vigor, selections were omitted.
} 
Conversely, when the reproductive index is high, mortality is low, sterility is extremely rare, there are few failures to produce a second brood, and swimming activity is at its maximum.

Coincident Fluctuations in Vigor.

If vigor is related to environmental conditions, coincident fluctuations in reproductive indices for the two strains of the same line and for the strains of different lines should be in evidence. They are present and most conspicuous when the two strains of the same line are compared.

In the data for Line 757 (figure $17 \mathrm{c}$ ) for example, the reproductive indices for the two strains, compared in each case with the reproductive index for the preceding period, rise or decline together 16 times and move in reverse directions only 10 times. Of these 16 coincident fluctuations, 13 are large enough to have a probable real meaning, while only 4 of the 10 independent fluctuations are large enough to be considered significant.

There is not more coincident fluctuation in reproductive index in Line 757 than with most of the other lines (see figures $1 \mathrm{c}, 3 \mathrm{~A}, 7 \mathrm{~A}$, $8 \mathrm{~A}, 11 \mathrm{~A}, 12 \mathrm{~A}, 13 \mathrm{~A}$, and $17 \mathrm{c}$ ), so that in general there is a rather close correlation between the reproductive indices of the two strains of a line. This was clearly seen to be a reflection of environmental influences in some cases, e. g., the August-November 1912 period (see page 135), and it is believed to have been equally due to environmental influences where the precise character of the environmental influences was not recognized.

Coincident fluctuations in reproductive indices are likewise seen between the different lines of the same species and also between lines of $D$. pulex and $S$. exspinosus.

With the $D$. pulex lines there is a remarkable agreement in the occurrence of low reproductive indices for the August-November 1912 period (figures 1c, 3A, 7A, and 8A). Line 740 (S. exspinosus) likewise shows extremely low points for this period (figure 14A). There are some early data for Line 757 (figure 17c), another line of $S$. exspinosus, culture of which was begun during the month of November 1912, which show very low reproductive indices. This is a striking fact, as showing that whether the lines had been in the laboratory for nearly a year (as in the case of the Daphnia pulex lines), for 4 months (Line 740), or had just been introduced into the laboratory (Line $757)$, low reproductive indices occurred. As has been stated before (page 136), this was a period of particularly poor food conditions and it involved the loss of much laboratory stock.

During June-July 1913, 7 of 8 strains of $D$. pulex (figures 1c, 3A, $7 \mathrm{~A}$, and $8 \mathrm{~A}$ ) show lowered reproductive indices. This was again a period of not very successful feeding and of considerable loss of 
strains of the $D$. pulex stock, but it scarcely affected the two $S$. exspinosus strains (figures $14 \mathrm{~A}$ and $17 \mathrm{c}$ ). ${ }^{1}$

During August-September 1913 all the D. pulex strains and all the $S$. exspinosus strains show relatively high reproductive indices. Again, for October-November 1914 all the strains of $D$. pulex and 2 (of 4) strains of $S$. exspinosus have high reproductive indices. These are particularly marked for the $D$. pulex strains. For the period immediately following, December-January 1915, most of the strains of both species show considerably lowered though not particularly small reproductive indices (figures $1 \mathrm{c}, 7 \mathrm{~A}, 8 \mathrm{~A}, 11 \mathrm{~A}, 12 \mathrm{~A}, 13 \mathrm{~A}, 14 \mathrm{~A}$, and $17 \mathrm{c}$ ). In October-November 1915 all the 4 strains of $S$. exspinosus and 3 of the 4 strains of $D$. pulex have high reproductive indices. Still other periods of more or less coincident fluctuations in reproductive indices may be seen in the curves.

Mean reproductive indices for all the $D$. pulex strains and for all the $S$. exspinosus strains were determined, and it was found that the coincident high and low points in reproductive index as given above were clearly reflected in these means.

These fluctuations in reproductive indices are in two cases (August-November 1912 and June-July 1913) clearly related to poor food, and perhaps to other unfavorable conditions, and it is believed the other coincident fluctuations are likewise associated with environmental factors.

\section{Independent FldCtUations in Vigor.}

Vigor is closely related to environmental conditions and many coincident fluctuations in vigor have just been referred to; but because of the necessarily somewhat differential treatment (see page 140) of the two strains of the same line (and of the different lines), independent fluctuations are much in evidence in the figures showing reproductive index (figures $1 \mathrm{c}, 3 \mathrm{~A}, 7 \mathrm{~A}, 8 \mathrm{~A}, 11 \mathrm{~A}, 12 \mathrm{~A}, 13 \mathrm{~A}, 14 \mathrm{~A}$, and 17c).

For example, in figure $17 \mathrm{c}$, showing reproductive indices for the two strains of Line 757, conspicuous instances in which the changes in reproductive index for the two strains of this line are in reverse directions (as compared with the preceding period) are seen in the February-March 1914, August-September 1916, October-November 1916, and February-March 1917 periods. Six other less conspicuous fluctuations (in reverse directions) are seen in this same figure. Some of these small fluctuations are probably due to the reproductive indices for the two-month period, having been derived from a relatively small amount of data; but this is not believed to be the case in general and can scarcely be assumed to account for

${ }^{1}$ It has been found in other observations that while the physiology of these two species of Cladocera is fundamentally very similar, yet physiological differences not infrequently appear. The lack of a pronounced lowering of the reproductive indices for the two $S$. exspinosus lines for this period is an illustration of these physiological differences between the two species. 
the wide fluctuations in the four periods enumerated above; certainly it is not true for consistent differences in reproductive index between the two strains of a species for several months in succession, such as are seen in four different periods for Line 757 (figures 17c and $18 \mathrm{~A}$ ) and in parts of the data for nearly every line for which reproductive indices are given.

Such independent fluctuations are believed to be due to the somewhat differential treatment resulting from the transfer of young of the two strains of a line on different days and into culture-water of different collections. The cumulative effect of continued transfers into somewhat different culture media seems very readily to account for local differences in reproductive vigor between the two strains of a line.

Some of these independent fluctuations are capable of explanation as due to variations in an internal cycle which most workers believe exists in Cladocera. But differences in environmental conditions explain these cases so readily, some of the contemporaneous changes are associated with recognized changes in environmental conditions, and it is well known that such culture media do have great variation, so that any assumption of an internal cycle seems quite unnecessary. Further, in Line 689 (figure $3 \mathrm{~A}$ and $\mathrm{B}$ ) the plus strain, which had much the higher reproductive index for the first two months of selection, had a considerably lower reproductive index for the following 2 months. This would seem a short time for the internal cycles of these two sister strains to have diverged. The minus strain of Line 714 (figure 7 , A and $\mathrm{B}$ ) had a reproductive index nearly three times as large as that for the plus strain for the first two-month period. Can these strains just derived from the same individual have immediately passed into different periods of an internal cycle? There are other cases (less striking, however) of significantly different reproductive indices immediately or very soon after the origin of related strains.

However, in spite of the unavoidably somewhat dissimilar treatment of the two strains of a line and the consequent local differential changes in reproductive indices, there is in general a very close correlation between the reproductive indices of kindred strains, a result to be ascribed, in large part at least, to the general influence of similar environmental conditions.

Differences between Reproductive Indices during Different Parts of Experiment.

The reproductive indices for the two strains of the different lines in general differed somewhat less at the beginning of selection (for the first 4 months), when the two strains had just been separated, than during the later parts of the experiment, after the two strains had been separate for considerable periods of time (figures $1 \mathrm{c}, 3 \mathrm{~A}$, $7 \mathrm{~A}, 8 \mathrm{~A}, 11 \mathrm{~A}, 12 \mathrm{~A}, 13 \mathrm{~A}, 14 \mathrm{~A}$, and $17 \mathrm{c})$. This is explainable as due to 
the fact of the identity of environmental conditions before selection was begun and the diversity of environmental conditions as affecting the two strains later (or as due to their being in different portions of their cycles at the same time later). However, some of the strains, e. g., Lines 695 and 689 , on the whole show greater differences in reproductive indices during the first 4 months than later (see figures $1 \mathrm{C}$ and $3 \mathrm{~A})$.

Is the Increased Reactiveness for Lines of S. exspinosus Associated with INCREASED VIGOR?

In view of the increase in reactiveness in the S.exspinosus lines during the course of the experiments, it is of interest to examine the reproductive indices to see if similar or other changes are seen in them.

With the 4 lines of Daphnia pulex (Lines 689, 695, 714, and 719) for which reproductive indices are worked out, there are in general reproductive indices somewhat below the average for the first 2 two-month periods, very low reproductive indices for the following 2 periods (during the obviously poor food conditions), and thereafter the reproductive indices are somewhat fluctuating, but in general fall about slightly higher means throughout the remainder of the experiment (figures $1 \mathrm{c}, 3 \mathrm{~A}, 7 \mathrm{~A}$, and $8 \mathrm{~A}$ ). Hence with the lines of $D$. pulex the reproductive index increased somewhat during the course of the experiment.

The reproductive indices for Line 740 show marked increases for the two-month periods just following the first 4 months of selection. These early low reproductive indices are clearly related to the poor food conditions prevalent during the early months of selection with this line and reflected even more strongly in the $D$. pulex lines which had been in the laboratory for several months previously. There is also a rise in reproductive index for Line 757 after the first 2 months, and this rise is only partly coincident with recognized differences in food conditions in the laboratory. This rise is capable of explanation as due to the cumulative effect of better food conditions in the laboratory than in the outdoor ponds, but practically the maximum rise in reproductive index for this line was realized at once (figure $17 \mathrm{C})^{1}$ and there is no evidence for a cumulative effect of better food conditions. The reproductive indices for Line 795 are much higher during the latter part of the experiment than earlier (figure $12 \mathrm{~A}$ ), but the reverse is true for Line 796 (figure 13A). On the whole, the reproductive indices for $S$. exspinosus do not show any general increase or decrease during the course of the experiment.

Thus it is seen that reproductive indices for the $D$. pulex strains increase somewhat during the course of the experiment, while re-

\footnotetext{
1 The general level for the plus strain was not higher for the remainder of the experiment, though the general level for the minus strain increased somewhat further.
} 
action-time means are neither increased nor decreased. On the other hand, reaction-time means are decreased for $S$. exspinosus lines, while there are no consistent general changes in reproductive indices.

Perhaps no better evidence bearing on the relation between reproductive vigor and reaction-time can be had (or desired) than that obtained from the following data: The total numbers of individuals tested in making the selections in all the plus strains of $D$. pulex for the entire series of the experiments was 6,991 ; the mean reaction-time of these 6,991 individuals was 343.76 seconds. The corresponding figures for all the minus strains of $D$. pulex were 6,973 individuals, with a mean reaction-time of 345.92 seconds. The difference was only 2.16 seconds. For the S. exspinosus plus strains (except Line 757 plus), the total number of individuals was 4,722 and the mean reaction-time 531.56 seconds. For the $S$. exspinosus minus strains (except 757 minus) the figures were 3,943 individuals and 532.55 seconds. The difference is 0.99 second.

Since in both species the plus strains in general were somewhat more vigorous than the corresponding minus strains, these negligible differences in reaction-time means for the entire series of experiments indicate a lack of relation between reproductive index and reactiontime.

Possible Divergence in Vigor between the Two Strains of a Selected Line.

The effect of selection on the basis of reaction to light might conceivably result in plus strains of greater vigor and minus strains of reduced vigor. It would indeed seem possible that the minus strains might become very much reduced in vitality and perhaps eventually die out if selection were continued long enough. In view of this theoretical possibility it is interesting to note that of the selection experiments discontinued because of loss of one or both of the strains (see table 1, column 8), 2 lines were discontinued because of the loss of both strains within a few days of each other, 1 line suffered the loss of the minus strain only, and 5 lines suffered the loss of the plus strain only. ${ }^{1}$ Hence this significant bit of data does not indicate reduced vitality in the minus strains as compared with the corresponding plus strains.

Column 9 of table 1 likewise throws light upon a point intimately associated with the general vitality of corresponding plus and minus strains, the relative numbers of generations of descent of the plus and corresponding minus strains. This column shows the total number of generations of descent of the different strains at the close of selection within the different lines. In 8 lines the plus strain had descended for a greater number of generations than the corresponding minus strains; in 7 the minus had descended farther; and in 1 line

${ }^{1}$ Two of the last were lost through accident, however, rather than because of gencral weakness or poor food conditions, and one of the minus strains suffered the accidental loss of part of its stock, except for which it might have survived. 
the 2 strains had descended an equal number of generations. The plus strains which had descended a greater number of generations averaged an advance of 2.9 generations ahead of their respective minus strains; the minus strains which had descended farther than their corresponding plus strains averaged an advance of 4.3 generations beyond the plus strains. The $D$. pulex and S. exspinosus lines were pretty well divided as to whether the plus or minus strains had descended the greater number of generations. In all the $D$. longispina lines, however, the plus strain had descended farther-by a single generation in two of the lines, but by 5 generations (almost 11 per cent) in one. Hence, there was possibly some real loss of vigor in the minus strains of $D$. longispina as compared with their respective plus strains (though three lines are too small a number from which to reach a safe conclusion). But with $S$. exspinosus and $D$. pulex there was no loss in vigor of the minus as compared with their respective plus strains, so far as was revealed by their total numbers of general tions of descent. In fact (so far as this point is concerned), the minus strains in 5 of the $8 \mathrm{D}$. pulex lines descended farther and by larger margins (an average of 5.2 generations as compared with 3.7 generations for the plus strains), which affords almost as much ground for assuming that the plus strains of the $D$. pulex lines became of inferior vigor compared with the corresponding minus strains as is afforded for the opposite conclusion with reference to the D. longispina lines.

Some effect of the selections upon the general vigor of the corresponding plus and minus strains is evident, however, in some cases in the generally lower reproductive indices for some of the minus strains as compared with their corresponding plus strains. In only 1 (Line 740) of the 8 lines for which the reproductive indices have been worked out was the minus strain in general conspicuously the more vigorous of the 2 strains of the same line (figure 14B). It is significant, however, that (except possibly for parts of the data for Lines 795 and 796 , and these differences were not maintained) the differences in vigor of the two strains of the same line were not cumulative; and in no case were they greater during the later than during the early portions of the experiments, except for the very first months of selection. It would seem, then, that in some cases there was a tendency for the selected individual (the most reactive individual) in the plus strain to be more vigorous than the selected individual (the least reactive individual) in the corresponding minus strains, but that this difference is neither universal, uniform, nor cumulative in its effect. As is shown elsewhere, differences in reproductive indices, even when relatively large, are not associated with corresponding differences in reaction-time. ${ }^{1}$

1 The lack of relation between reproductive index and reaction-time has been referred to in several places (see pages $40-45,49,60,65,72,76,80,83,88-89$, and 108-115) and need not be further discussed here. 


\section{STATEMENT OF RESULTS OF SELECTION.}

The results of this series of experiments may be stated briefly:

With two lines, Lines 689 and 719, there were found reactiontime differences in the reverse of selection. These differences were so consistent as to suggest real genetic differences affecting reactiveness in the two strains of these two lines, though line 689 was carried for a relatively short period of time. In the case of Line 719 the reaction-times differed less toward the end of the experiment, and it is suggested that selection may have operated to produce this effect.

The results with Line 689 and Line 719 suggest that in addition to genetic differences in the direction sought in selection genetic changes may occur in the opposite direction. This is strongly suggestive of mutation. It does not, however, obviate the theoretical difficulty of explaining by mutation the plural genetic changes in Line 757.

Lines $695,713,714,751,766,768$, and 796 show no evidence (or slight evidence as in Line 713) of significant differences in reactiveness between their plus and minus strains. Some of these lines were carried for relatively short periods of time, but Lines 695, 713, 714, and perhaps 768 and 796 were subjected to selection for what would seem adequate periods of time.

Line 691 shows a possible effect of selection, though such an effect is not fully supported by the last year's data and may therefore be disregarded. Selection was conducted for 27 months, 84 and 85 generations in the two strains.

Line 711 apparently shows an effect of selection, but the differences are small and the evidence is not entirely conclusive, though the case is as convincing as the result in the opposite direction for Lines 689 and 719 . Selection was continued for 45 and 46 generations, covering a period of about 16 months.

Line 762 gave a possible effect of selection during the last two months of the experiment. In view of the wide fluctuations in the reaction-time curves of many of the lines, this is not sufficient data upon which to base a conclusion, but the entire consistency in the differences between broods of the plus and minus strains during this late portion of the experiment is unusual enough to be highly suggestive. However, in view of the local differences in reactiveness seen in other lines (see pages 140-142), an effect of selection in Line 762 must be considered problematical. The plus strain was lost, thereby terminating the experiment after 36 and 35 generations of selection.

Line 794 may have undergone a divergence in reactiveness during selection. For the first 6 months the differences were in the reverse of selection, but the remaining 12 two-month periods gave differences in the opposite direction, with 3 exceptions, and 8 of these differences 
were relatively large. The single test series, however, quite fails to lend support to a difference in reactiveness between the two strains, and this case likewise remains doubtful.

Line 795 clearly shows a lack of selective effect during most of the experiment. 'The last month's data is very suggestive of significant reaction-time differences, but the data are too slight in amount to receive serious consideration.

A mutation possibly occurred in the minus strain of Line 740, causing it to be more reactive to light. The case was critically examined (page 89) and the conclusion was reached that the unusual reactiveness of a few broods of this strain was probably due to peculiar local environmental conditions.

None of the above possible cases of differences in reactiveness between the two strains of a line is well enough supported by the evidence to be considered proven. The cases best supported by the evidence are in Lines 689, 719, and 711. In Lines 689 and 719 the differences are in the reverse of selection. With Line 719 the difference was slight during the latter portion of the experiment. Line 689 was lost before enough evidence was obtained to convince one that the difference was necessarily genetic. Line 711 shows consistent differences in accordance with an effect of selection, but, like Line 689 , was lost before enough evidence was obtained to convince one that the difference was certainly genetic.

With Line 757, on the other hand, a marked effect of selection is attested by every significant bit of evidence which the data for this line provide. The divergence in mean reaction-times began to appear after the first 3 months at the beginning of the experiment (for which the two strains had the same reaction-time means). For the second (two-month) period the means differed by $-25 \pm 22.82$ seconds, and the means for the following two-month period differed by $-72 \pm 17.78$ seconds, a difference of statistical significance $(4.05$ times the probable error), in spite of the small numbers and consequently large probable error. This is followed by 6 two-month periods, during which the differences are all in the same direction and 3 of which (even for the shorter periods) are of large statistical significance, though the differences of $-55,-63$, and -70 seconds were not of statistical value because of large probable errors. For the two-month period June-July 1914 the minus strain was the more reactive and the difference was $132 \pm 29.79$ seconds, a difference 4.4 times the probable error. For the following two-month period the difference is only -2 seconds. From this period on, all the 16 differences (by two-month periods) indicate greater reactiveness in the plus strain. With 3 exceptions the differences were large and of statistical value, even when considered by two-month periods. One of these smaller differences, which was not of statistical value, occurred within 3 
months of the close of the experiment, when the effect of selection was at its height. ${ }^{1}$

Considering the data by longer periods, those from the beginning of the experiment to July 1914 show significant differences in mean reaction-time, though the early differences were generally not large. Following this was a period during which both strains, and particularly the minus strain, fluctuated widely, though the difference for this longer period is significant of a real difference in reactiveness between the two strains. During the latter part of 1915 the disturbances due to environmental factors became less marked and the divergence in mean reaction-time appeared to increase greatly and, with a single fluctuation, continued very large during the remainder of the experiment. During the final 9 months of the experiment the mean for the plus strain was only one-third that for the minus strain. The form of the curves (figure 18B) suggests that the divergence in reactiveness was still increasing at the close of the experiment.

Points of importance in connection with the results with Line 757 are that both the plus and minus strains became modified during selection and that the divergence was permanent or at least persisted for 112 generations. It is also important to note that there is nothing to distinguish the two strains other than the difference in behavior of the strains in the experimental tank in response to directive stimulation by light, and a somewhat higher reproductive index for the plus strain during most but not during the concluding months of the experiment.

\section{DISCUSSION OF RESULTS.}

Consistent differences in reactions to light of animals of the same or closely related stocks appear not to have been frequently found.

McEwan (1918) presents a conclusive case of differences in phototropism which are clearly genetic. A certain mutant strain, "tan," of Drosophila melanogaster, unlike most of this species, showed very little response to light. Tan is a very variable character and can not always be distinguished by inspection of the flies. The differences in phototropism between tan and normal flies were so striking that it was found (and proven by breeding tests) that the slight phototropism of tan stock was a more reliable means of diagnosing tan than inspection of the flies. The character was shown to be a recessive sex-linked character. McEwan found differences in

1 Such a marked reduction in the difference between the means, coming at a time when according to all eriteria the two strains were so different in their reactiveness to light, seems certainly due to unequal local environmental influences, which may also account for the relatively wide fluetuations in the reaction-time curves for the period from June 1914 to July 1915 (see pages 141 and 159-160). While during this earlier period the minus strain for 1 two-month period had the lower reaction-time mean, this fact need perhaps exeite no more surprise than the fact that the mean for the minus strain was so near that for the plus strain at the later period when the general reactiveness of the two strains was so widely different. 
phototropism of other types of Drosophila, but these were associated with differences in the color or other conditions of the eye itself. In the tan mutant, on the other hand, no peculiarities could be discovered in the eye.

The writer has considerable (unpublished) data tending to show that the amphipod Eucrangonyx gracilis, living in the surface streams near Bloomington, Indiana, is less negatively phototropic than the same species which lives in Mayfield's Cave, near at hand. The differences in reaction are not large and consistent enough to be very conclusive. In this species those inhabiting caves and those inhabiting the open are indistinguishable morphologically, except for differences in pigmentation, the former having fully pigmented eyes, but no body pigment.

In asexually reproducing forms ${ }^{1}$ Jennings $(1908,1909)$ with Paramecium, Agar (1913, 1914) with Cladocera, Ewing (1914) with aphids, Hanel (1908) and Lashley (1915, 1916) with Hydra, and other workers have failed to obtain hereditarily diverse strains by selection within the uniparental progeny of single individuals.

On the other hand, Middleton (1915) in Stylonychia, Stout (1915) with Coleus, Jennings (1916) with Difflugia, Root (1918) in Centropyxis, and Hegner $(1918,1919)$ with Arcella seem to have found genetic variation wherever they sought it.

Stocking (1915), studying abnormalities in Paramecium, found that of 122 strains containing abnormal individuals, in which the character was clearly hereditary, 97 were persistently abnormal races, i. e., they presumably were not subject to genetic variation in this regard; and 25 strains were subject to genetic variation, i. e., selection was effective in 25 strains. That is to say, about 20 per cent of the strains studied by her, in which the character was inherited, were subject to genetic variation.

The results of selection with Protozoa are open to certain objections which Jennings (1916, p. 523) outlines somewhat as follows: (1) that the results may be due to cytoplasmic influences and hence may not be of real genetic significance; (2) that the result may be due to nuclear recombination between the active nucleus and nuclear material within the cytoplasm (chromidia); and (3) that nuclear recombination may occur between different nuclear masses in the same individual. Professor Jennings (1916, p. 525) believes that these possibilities have "no claim to greater probability than their negatives, so far as our knowledge of the facts is concerned." The opinion of different workers as to the validity of these objections differs greatly.

\footnotetext{
${ }^{1}$ In view of the many excellent historical accounts which have appeared it does not seem desirable to review any considerable portion of the vast amount of work on selection within the pure line. Excellent discussions of this literature are given by Jennings (1910, 1917), Pearl (1917), and Sturtevant (1918).
} 
Cladocera material has the advantages for a selection experiment possessed by protozoa in that it is (under controlled conditions) exclusively uniparental in inheritance. It has additional advantages in that the germ-plasm is less bound up with the soma than in protozoa and the very great advantage that (so far as our knowledge goes, at any rate) there are no complications of chromidia or separate nuclear masses within the germ-cell, recombination of which might conceivably produce the results attained by selection in protozoa.

So far as known, there is no mechanism within the germ-cells of Cladocera through which a segregation or recombination of nuclear material is to be expected in parthenogenesis. In the production of the parthenogenetic egg there is a single maturation division (Weismann, 1886; Kühn, 1908), in which the chromosomes behave as in any ordinary cell-division, i. e., each chromosome is merely divided into two theoretically equal parts, equal quantitatively and qualitatively. Hence the objections offered to results of selection with protozoa do not apply to the present material. Any results obtained from selection in such material (parthenogenetic and without reduction) should have a crucial bearing on the problem of selection.

In experiments having to do with the variability of organisms it does not seem necessary to suppose that all apparently similar material should be found similarly subject to genetic variation. In Stocking's (1915) Paramecium, about 20 per cent of the strains in which an abnormality was hereditary showed genetic variation. In the Cladocera material used in selection, Line 757 alone has certainly shown such genetic variation with regard to the characteristic studied, though the possible (but doubtful) mutation in the minus strain of Line 740 and the somewhat consistent differences in mean reaction-times between the two strains of Lines 689,691 , $711,719,762,794$, and 795 are suggestive of differences of genetic significance. Allowing that the case is proven for Line 757 alone (though some of the other cases are very suggestive), genetic variation was found in only one of the 15 distinct lines of Cladocera studied. This is approximately only 7 per cent.

The effects of selection in Line 757 may be assumed to be either (1) of a nature of general physiological changes, possibly changes in metabolism or some kindred effect, or (2) direct genetic changes. ${ }^{1}$

If the former interpretation is favored, the question arises as to what is the basis of such physiological effects. If they are considered not strictly genetic, the apparently permanent nature of the change is a matter of especial importance. Cases of transmission

${ }^{1}$ In this discussion genetic variations, in metazoa at least, are assumed to concern genebic factors confined to the chromosomes. The carrying over from one generation to another of cytoplasmic inclusions and the transmission of variations or modifications which affect only one or two generations are assumed to concern the cytoplasm alone and are considered not strictly genetic. 
not really genetic and some of which are clearly cytoplasmic are well known. If Sudan III is fed to fowls some of the dye is deposited in the egg-yolk (Riddle, 1908) and reappears in certain of the tissues of the chick (Gage and Gage, 1908). This is merely the carrying over of a cytoplasmic inclusion. Other cytoplasmic inclusions, the plastids of plants, parasitic or symbiotic bacteria and protozoa, are carried over in the cytoplasm of the egg; but these are mere inclusions and this is not true inheritance. Starving occasionally causes the production of young of small size. The effect would seem probably due to reduced quantity of food material (or to deleterious substances) in the egg cytoplasm. Later generations are not affected. The effects of immunization are transmitted by the mother and not by the father. The effects are not permanently transmitted and are presumably cytoplasmic. Agar (1913) was able to produce young Cladocera with carapace gaping open by keeping the mothers in a particular food medium. This peculiarity was transmitted for one generation by affected stock when reared in the usual culture medium, but the abnormality rapidly decreased and ceased to appear after one generation. This transmission may readily have been cytoplasmic, but it is clearly not a case of real inheritance. The substances carried over in the egg cytoplasm (if there were such) were rapidly dissipated and lost.

These are typical cases of cytoplasmic transmission, and one may conclude with Conklin (1920) that "in the present state of our knowledge there is not sufficient evidence to conclude that modifications of the cytoplasm of germ-cells are ever really inherited or that they are ever the initial steps in evolution."

To assume that the changes in phototropism in the present case were not really genetic would seem to place them in the class of cytoplasmic transmissions and to assume a permanent cytoplasmic or extra-genetic transmission which in our present state of knowledge would seem unwarranted.

Aside from its theoretical difficulty, there does not seem to be any evidence favoring the assumption of general and purely physiological changes as accounting for the divergence in reactiveness of the two strains of Line 757, since these two strains are indistinguishable, except in their reactiveness to light.

However, it is of course possible to assume that a non-chromosomal inheritance occurs and to apply this interpretation to the present results, though the writer can see no reason for favoring such an interpretation. If, however, this should prove to be the correct interpretation a practically new phase of inheritance is opened up, and in any case the importance of the present results as bearing upon selection within the pure line is not lessened.

If, on the other hand, physiological changes having a genetic basis be assumed to explain the present results of selection, the nature of the factorial changes involved is still the pertinent question. 
If the variations are considered direct genetic changes (or general physiological changes having a genetic basis), they may be thought of as having been due to segregation, ${ }^{1}$ to larger mutations, or to many small genetic changes.

It would seem that the effect of selection here obtained can not be explained as due to recombination or segregation unless segregation occurred rather generally in Line 757 under conditions in which it is not known and is theoretically not supposed to occur. It is conceivable, however, that segregation may occur on rare occasions in Cladocera in the germ-tract previous to maturation, in the one maturation division (even though that is a non-reduction division), or in cleavage or later somatic divisions. But this explanation for the result with Line 757 encounters certain difficulties: (1) Such factorial recombination, if large quantitatively, should at once produce an obvious effect. (2) If, on the other hand, the factorial recombination produces only a slight effect, the result obtained with Simocephalus Line 757 is explicable only as the result of several of these exceptional factorial changes. (3) The effect is in both high and low selection strains.

Since with Line 757 the effect is extensive, is in both strains, and appears gradually and not by a sudden increment (except possibly, but doubtfully, at one point in the minus strain), this sort of explanation would call for more than a single factorial recombination. Probably many more genetic changes occurred, but at least three such genetic recombinations are required to explain the case on this basis. Such might possibly be located as follows: one in the minus strain early in its laboratory history, one in the plus strain, possibly about January 1915, and one in the minus strain about August 1915 (figure 18B). But the points at which these three or more hypothetical recombinations occurred are not indicated in the data by broods (tables 41 and 42) and can be doubtfully and only approximately located (assuming that they were masked for a time by environmental conditions) by reference to the averages by two-month periods (tables 43 and 44 and figure $18 \mathrm{~B}$ ). Yet presumably these, at least the third one $\mathrm{e}^{2}$ (assuming a minimum of three genetic modifications), must have been genetic changes of large moment, considering the wide differences in reactiveness between the two strains during the latter portion of the experiment. Since these factorial changes must have come about under exceptional conditions, three or more such occurrences affecting two strains of the same line within a limited period seem unlikely of attainment.

Noтw.-There is another possible suggestion coneerning segregation in this material: that notwithstanding parthenogenesis and the presumed lack of segregation in maturation there may be a mechanism in Cladoeera by which changes in genetic constitution may,

${ }^{1}$ Including the phemomena of erossing-over and non-disjunction.

${ }^{2} \mathrm{As}$ shown on page 159 , there is strong probability that no large genetic change occurred at this point. 
in certain cases, be readily brought about in parthenogenetic reproduction. 'This is not indicated by the cytological evidence, so far as known, and would seem to call for quite a novel type of cytological behavior for which there is no direct genetic or cytological evidence in parthenogenetic organisms. But should there prove to be such a segregation in Simocephalus, then the effects of selection in this experiment with Cladocera readily yield to explanation in conformity with the chromosome interpretation of the pure-line hypothesis. Otherwise the writer does not see how the results can be satisfactorily made to conform with this theory. The Cladocera material deserves a critical cytological analysis. The writer would gladly cooperate in providing material for such a study by a cytologist who could give ample time to the problem.

It is just possible, however, that there may be an unusual or at any rate virtually unknown type of chromosomal behavior in Cladocera, permitting segregation more frequently than would otherwise be expected in material in which segregation seems improbable. Wenrich's (1916) observations on Phrynotettix are most suggestive in this connection. He found reduction occurring in a single chromosome and apparently not affecting the other chromosomes in that division. Crossing-over and non-disjunction (which Bridges and others have demonstrated and utilized so successfully in interpreting genetic results with Drosophila and other forms) may be appealed to as affording possible vehicles for such genetic changes, assuming that several genetic factors are involved in the reactiveness to light in Cladocera and that Line 757 was originally heterozygous for certain of these factors. In view of such known irregularities in chromosome behavior, one is led to consider the possibility that a partial segregation may occur in the one maturation division in parthenogenetic reproduction in Cladocera. Nabours (1919) found segregation in parthenogenetic reproduction in one of the grouse locusts, Apotettix. However, judging from the very limited cytological evidence presented, it would seem that in this case reduction was fully accomplished, as in sexual reproduction.

However, there is no cytological evidence that reduction or segregation of any sort occurs in the one maturation division of parthenogenetic eggs of Cladocera and, even assuming that such a partial segregation may occur in the single maturation division in Cladocera, there is still the theoretical difficulty of accounting for such frequent genetic change as seems to have occurred in Line 757. For it is hard to see how, even with assumed partial reduction in Cladocera (which lack the complicated features of protozoan nuclei), the rate of genetic change should so greatly have exceeded that so carefully worked out for Drosophila. This is not necessarily a fatal objection, however. Even though Cladocera are probably very little subject to genetic change, once genetic change occurs, for any thing we know to the contrary, it may proceed at a rapid rate.

This possible explanation has a certain appeal to the writer, not only because it offers an explanation (in accord with the explanation offered for most results of selection) for the results attained in the present study of the effects of selection on the basis of reactiveness to light, but also because certain other (unpublished) results of study of Cladocera material may in part be explained on this basis.

Explanation of the result with Line 757 by larger mutations encounters considerable difficulty: (1) the necessity for assuming at least three mutations, at least one of which must have been quite large; (2) the lack of definite points at which mutations may be presumed to have occurred; and (3) the occurrence of an additional mutation or mutations effective in the same direction as an earlier one. Further, the mutations in the two strains must have occurred in opposite directions, rendering the plus strain more reactive and the minus strain less reactive.

In general, in uniparental inheritance mutation may perhaps be expected to be only half as frequent as in biparental inheritance, since in the former a single germ-cell is involved in the production of each individual offspring. Bridges (1919) states evidence tending to show that in Drosophila mutations may occur in oogonial (or spermatogonial) divisions and in the zygote "immediately after fertiliza- 
tion," although he states that in the much-mutating Drosophila the bulk of the mutations occur "at or very near the maturation stage." In parthenogenetic reproduction in Cladocera, with only one maturation division (and that a non-reduction division) the probability of mutation would seem further greatly reduced. Hence, so far as one may judge, mutations in Cladocera should be expected to be much less frequent than in Drosophila. In the latter, Muller and Altenburg (1919) state that mutation in a particular factor is infrequent. From their data, ${ }^{1}$ mutation in a particular factor occurs about once in 50,000 generations. Yet this is the much-mutating Drosophila. Hence, if one may judge from the evidence from Drosophila, mutation in parthenogenetic reproduction in Cladocera should be very rare.

The selection experiment with Line 757 covered 181 generations. If larger mutations (affecting reactiveness to light) occurred, there must have been one (at least) in the plus strain and two (at least) in 181 generations in the minus strain, a surprisingly high incidence. It is possible that several genetic factors are concerned in the phototropism of Simocephalus, though McEwan (1918) found that a single mutant factor in "tan" Drosophila profoundly modified its phototropism. But even if several factors are concerned in the present case, at the rate of one mutation in a particular factor in 50,000 generations (for which Muller and Altenburg give data for Drosophila), the rate of assumed mutation in Line 757 would seem most excessive. If one disregards the possible, though improbable, mutation in the plus strain of Line 740 , and the possible, though unproven, genetic modifications in Lines 689, 691, 711, 719, 762, 794, and 795, of the Cladocera lines subjected to selection, Line 757 alone showed mutation. If larger mutations are to account for the result with Line 757, mutation must have been extremely frequent in this line and rare in the other Cladocera lines studied.

It seems, then, that there is difficulty in explaining so many genetic changes as must have occurred in Line 757 during a relatively short period as due to larger mutations, such as have been worked out for Drosophila.

If one seeks in the curves (figure 18B) for possible points of occurrence of larger mutations, three points at which such seem more nearly possible than elsewhere are seen in the curves, about April 1913 for the minus strain, about January 1915 for the plus strain, and about August 1915 for a second possible mutation in the minus strain. But the data by broods do not indicate points at which any mutation seems to have occurred. It is possible, of course, that the rather widely fluctuating averages by broods might tend to mask the occurrence of a mutation, but even so one would

1 Conklin criticizes Muller and Altenburg's statement regarding the frequency of mutation, but even if this statement is unwarranted it will still readily be granted that mutation in a particular factor is infrequent. 
expect a mutation of considerable import to appear evident very quickly in the brood averages and one would seem justified in expecting a mutation of considerable import to produce a marked and immediate change in the two-month curve for the strain affected. But such marked and immediate shifts are not found in the curves (figure 18B), except possibly in the Line 757 minus curve following August 1915, and even there a mutation seems not to have occurred (see below).

Since under the influence of the first two larger mutations provisionally assumed to have occurred (but for which no satisfactory locations can be found) the curves do not show great divergence, in comparison with their later divergence, the wide divergence between the curves for the two strains during the latter part of the experiment seems to call for a mutation of large moment if the result is to be explained by larger mutations. The divergence in the curves after the third point (August 1915), at which a larger mutation may possibly have occurred, seems somewhat pronounced, but does not appear abrupt enough to have been due to the influence of a single genetic change, unless the influence of this mutation was masked for a time by a pronounced influence of environmental factors. It is, of course, possible that this may have been the case.

If, however, it is necessary to concede a marked influence of environmental factors, a more logical explanation of the curve for the minus strain would seem to lie in the interpretation that the irregularities in the curve for the minus strain during the period June 1914-August 1915 were due entirely to marked local environmental influences. There seems no logical objection to this explanation.

Evidence that this is the correct interpretation is seen in the wide fluctuations, parallel for the most part to those for the minus strain, in the Line 757 plus strain for the same period. ${ }^{1}$ Further evidence that this may be the correct interpretation is seen in the fact that fluctuations similar to those found in the strains of Line 757 during the period under discussion are seen during certain periods in other strains, e. g., in strains of Lines 695 and 740, in which genetic changes obviously had not occurred and in which only local environmental influences seem to account for the facts.

During this time of great fluctuation in mean reaction-times in the two strains of Line 757, there were three relatively very low points in the Line 757 minus curve. Except for these low points, the curve for the minus strain is seen to have held to a fairly consistent course throughout the entire experiment (except for one two-month period, December 1916-January 1917, in which local

1 Except for the June-July 1914 period the fluctuations in the curves for the two strains of Line 757 are remarkably similar, though it is obvious that the Line 757 minus strain was somewhat more influenced by environmental factors than the plus strain (figure 18B). It is interesting to note that this June-July 1914 period is the only period of the entire experiment in which the minus strain of Line 757 appeared more reactive than the plus strain. 
environmental influences obviously were the determining factor). If, assuming that environmental influences are responsible for the fluctuations during parts of 1914 and 1915, one momentarily disregards entirely the curves for the Line 757 strains during this period of irregularities, the curves for the two strains following this period are seen to be mere resumptions of the courses of the curves previous to this period.

Hence it is seen that if it is necessary to assume that environmental factors exercised a determining influence, they may account in full for the deviations in the curves from their general courses during parts of 1914 and 1915, and there seems no necessity for, nor ground for, the assumption of a large mutation in the minus strain of Line 757 about August 1915; and, although this is the only point in the curves at which a mutation of considerable moment may seem to have occurred, the writer believes that another interpretation more logically accounts for the facts of the case.

It therefore appears that the point of occurrence of any really large mutation can not be satisfactorily located. Since the divergence in reactiveness between the two strains of Line 757 became very large and mutations of considerable moment can not be located, larger mutations do not seem to account for the result in Line 757 . When one considers the further fact that a minimum of three larger mutations would be required to explain the case on this basis, and that, by analogy with the Drosophila case, this would call for an extremely high rate of mutation, the plausibility of this explanation still further decreases.

The data for Line 757 readily permit of the interpretation of the result as having been due to imperceptibly ${ }^{1}$ small changes ${ }^{2}$ resulting, through selection, in cumulative effects in definite directions. The result as shown in the curves (figures 18B and 19) readily lends itself to this explanation, assuming that the writer's interpretation is correct and that the irregular portions of the curves (during parts of 1914 and 1915) are really due to disturbing en-

1 At any rate, their occurrence was unperceived. Reaction-time in this study is read off in seconds. The character studied, reactiveness to light, would seem ideal for detecting minute genetic changes in that the smallest changes in reaetiveness to light should presumably be detected. But the profound infiuenco of environment upou reactiveness proved extremely disturbing and only by averaging large numbers of individual reaction-times could modifications in reactivoness be detected. This was a distinct disappointment. In this study, because of these fluctuations in reaction-time, every case in which there seems any reasonable doubt as to an effect of selection is refused credit in conclusions favoring an infuence of selection, but in $\mathrm{n}$ case are the full experimental results withheld from the reader.

${ }^{2}$ These changes, one belioves, arose quite independently of selection, but were utilized through selection in building up the differences in reactiveness between the plus and minus strains. Selection does not cause genetic chango. It merely seizes upon modifications of the character used in selection as they occur, and in the case of plural genetic ehanges may build up differences between selected strains. Howevor, retention (through selection) of an hereditarily changed charactor, in so far as it preserves the material which may undergo further genetic variation, makes possible a furtler change in the same direction in the same character. Selection, although not a eause of variation, thus enables a deviation to be built up in the character utilizod in selection if genetic clianges occur in the direction sought. 
vironmental influences as the peculiar results for the December 1916January 1917 period clearly are.

Except for the fluctuations in the curves for the period mentioned, the curves for the two strains of Line 757 diverge rather gradually and somewhat uniformly. There are considerable irregularities in the curve for the plus strain, both during the period when irregularities occurred in the minus strain and elsewhere, but despite irregularities the general appearance of this curve strongly suggests that its true course is approximately a straight line. The general course of the curve for the minus strain less strikingly appears to be a straight line, but, aside from the irregularities already pointed out and accounted for, this curve is as regular as most curves based upon similar biological material.

The courses of the curves at the end of selection are such as to suggest that the divergence in reactiveness between the two strains was still increasing when the experiment closed.

Many workers would prefer to call these small genetic changes mutations, but they are indistinguishable from continuous gradual changes and must have occurred with a frequency quite unknown in forms in which the points of occurrence of definite mutations have been recognized. Jennings (1916, p. 526) applies the term mutation to such frequent small changes in morphological characters in protozoa, and Hegner (1919) calls such small structural changes (arising in his Arcella) mutations. But the complicated and less well-known conditions of the nuclear material in protozoa and the direct continuity between the cytoplasm, which one may think of as soma, of the parent and that of offspring lead one to feel that at least there is no positive assurance that conditions in protozoa are entirely comparable with metozoa.

In parthenogenetic Cladocera, without the reduction maturation division and apparently lacking in unequal distribution of nuclear elements, such as may occur in division in protozoa (Hegner, 1919), frequent mutation would not seem to be expected, since such frequent mutation as would be called for in the present case has not been recognized in metazoa and the mutations which have been most frequent have generally appeared to be associated with maturation. So many mutations through a lapse of only 181 generations would call for mutations at a truly phenomenal rate. However, the matter of a name for the genetic change merely turns upon one's definition of a mutation. The facts of the present case are in nowise altered, whether the small changes in character are termed mutations or given other designation. It is possible that modifications of genes are frequently of a low order and consequently not generally recognized; further, that although they are not to be found wherever sought, once such genetic change is initiated, such variations may be frequent in occurrence. 
The explanation of the results of selection in this material as having been due to many small genetic changes is suggested with extreme caution. There is the objection that such an explanation runs counter to the most acceptable explanation for most cases of effective selection within the pure line and that many cases for which this explanation has been invoked have later yielded to analysis on the basis of demonstrable mutation or genetic segregation. But the objections to explanation of the present case as due to segregation or larger mutations seem even more weighty (unless one assumes a novel and quite unknown type of segregation in this material), and it is believed that gradual modification of the factor or factors involved in the present case must receive serious consideration.

Since changes in a character seem to occur with such frequency in some clones of Cladocera, material in which because of uniparental inheritance and lack of reduction frequent genetic changes would seem not to be expected, one wonders if this type of organism is unique among metazoa and if such genetic changes may not likewise be found to occur elsewhere. In other words, may not selection be found equally successful in some other material and may not the case for selection be more hopeful than is generally supposed? In any material in which improvement or change in a character is sought, genetic variation may (or may not) be encountered. If genetic variation occurs in the character studied and in the direction sought, selection (though not a cause of the variations) may be a means of utilizing the variations in accomplishing the end sought.

The pure-line concept, set forth by Jordan and elaborated by Johannsen and his followers, has been extended until it has been shown to have wide application. Whether it may become universal in its application remains to be seen. The writer believes that such cases as the present are crucial in their relation to the universal validity of the theory, and that if they are not (or until they are) brought into line this concept can not attain the dignity of a law. It is for this reason that the present case has been presented in so much detail.

Whatever explanation one finds acceptable, the facts are that the effects of selection within Line 757 are due both to an increased reactiveness in the plus strain of Line 757 and a decreased reactiveness in the minus strain of the same line (both relative to the corresponding strains of the other lines of Simocephalus), the two modifications working together to produce a large difference in reactiveness between the two strains of Line 757; and that this difference was permanent or at least persisted for 112 generations after selection was discontinued. 


\section{SUMMARY.}

1. In experiments undertaken to get additional data on the effects of selection within the pure line, Cladocera material was chosen because of certain advantages: $(a)$ it reproduces rapidly, $(b)$ is readily handled in the laboratory, $(c)$ under controlled conditions it is exclusively parthenogenetic, and $(d)$ in its parthenogenetic reproduction there is a single maturation division without reduction, so that presumably it presents none of the complications present in material in which segregation occurs during maturation and in which fertilization occurs.

2. Selection was based upon a physiological character: reactiveness to directive light stimulation.

3. The material consisted of three species: Daphnia pulex, D. longispina, and Simocephalus exspinosus, collected at different times from three ponds at Cold Spring Harbor.

4. The animals were reared in 200-c. c. wide-mouthed bottles with about 100 c. c. of culture-water which was ordinarily unchanged from the time a young female was placed in the bottle until she produced young.

5. Selections were made during the first day of life of the young daphnids. The plus and minus strains of each line came from a single progenitor.

6 . The selections were conducted with light intensities of approximately 120 candle-meters.

7. Environmental factors modified reaction-time; but, presumably, these were horizontal influences equally operative in both strains and with all the individuals tested in making each selection, and hence did not influence the selections per se.

The relation between environmental conditions and both reaction-time and vigor is considered in some detail.

(a) There are shown to be low correlations between the temperature of the water in the experimental tank and reaction-time of young daphnids. These correlations are generally positive, meaning that reactiveness is decreased with increase in temperature. This result was not anticipated. It is suggested that where this relation holds it may be due to greater oxygen-content in the water of the experimental tank with lower temperatures.

(b) Some substance exhaled from the observer's breath, presumably $\mathrm{CO}_{2}$, influences reactiveness. Frequent changes of the water in the experimental tank reduced this influence to a minimum.

(c) Relatively temporary chemical (?) differences in the water used in the experimental tank sometimes influences reaction-time to a marked degree. 
(d) Negatively reacting individuals appear under circumstances suggesting that their occurrence is the result of peculiar local environmental conditions affecting the water of the experimental tank.

(e) Broad up-and-down movements in the reaction-time curves are presumably largely reflections of underlying (as distinguished from more temporary) changes in content of the pond-water, though in some cases temperature influences are contributory. More local contemporaneous changes are clearly produced by factors other than temperature, presumably changed constituents of the culture-water and the water used in the experimental tank.

(f) Slight seasonal (winter and summer) changes in reactiveness are attributed to direct temperature influences and to the indirect influence of temperature as affecting the content of the culture-water as well as the water used in the experimental tank.

(g) Following July 1913, and extending throughout the remainder of the experiment, there was a gradual increase in the reactiveness of all the strains of Simocephalus. That this is not due to the cumulative effect of favorable conditions in the laboratory is indicated: (1) by the fact that for several months after selection was begun with the older lines of Simocephalus there was a general decrease in reactiveness; (2) that the increase in reactiveness affected all strains at the same time, though they had been in the laboratory for different periods of time; and (3) that the reaction-time curves for the newer Simocephalus lines (Lines 794, 795, and 796) start at and follow approximately the same levels as were attained by the older lines for contemporaneous two-month periods.

(h) Because of the fact that the two strains of a selected line ordinarily reproduce on different days, culture-water from different collections was usually used with the two related strains. This unavoidably somewhat differential treatment is believed to account for some of the independent shifts in reaction-time means affecting the two strains of the same line. One such shift, for a time, materially cut down the difference in reaction-time means between the two strains of Line 757.

(i) Relatively local environmental influences are believed to explain certain abrupt shifts in the reaction-time curves and in reproductive indices which some workers with Cladocera might be inclined to ascribe to "depression periods."

\section{Cladocera.}

(j) Environmental conditions obviously influence the vigor of

(k) The "reproductive index" is believed to be a safe measure of general vigor and probably of general muscular activity as well.

(l) Similar effects of environmental conditions are seen in many coincident fluctuations in vigor of the two strains of the same line, of all or most of the strains of the same species, and even of many of the strains of both Simocephalus and Daphnia. 
$(m)$ Independent fluctuations in vigor, like the independent fluctuations in reaction-time affecting related strains, are believed to be due to the somewhat differential treatment of the material.

(n) This factor is also believed to account for the generally greater divergence between the two strains of a line during later periods than at the beginning of selection.

(o) There is not a generally increased reproductive index in $S$. exspinosus to correspond with the increased reactiveness of this species.

$(p)$ Selection did not produce plus strains of increasingly greater vigor as contrasted with minus strains of less vigor, either when measured by the numbers of plus and minus strains which died out, by the total numbers of generations of descent, or by the reproductive index.

8. Sometimes the plus and minus strains of the same line reproduced on and were tested on the same day. The "same-day-brood" data is more trustworthy, because of more uniform environmental conditions, than data not simultaneously obtained, and is given separate treatment.

9. Reaction-time means were obtained of large numbers of young from mothers of each of the two strains of a line reared simultaneously and tested on the same day. These "test" series gave averages obtained from several hundred individuals reared and subjected to stimulation by light under as nearly uniform conditions as possible, and served to check up the effect or lack of effect of selection within individual lines.

10. Reaction-time is slightly, if at all, correlated with reproductive vigor. This is a point of interest, since the minus strains in general had a somewhat lower reproductive index than the corresponding plus strains.

11. The possibility that the method of selection might have been inadequate is discussed and evidence given which it is believed vindicates the method used. Were the method of selection greatly at fault the results obtained with some of the lines, particularly with Line 757, could not have been possible.

12. In general, the plus strains showed somewhat greater reproductive vigor (measured by reproductive indices) than the corresponding minus strains. But this effect was not cumulative and selection did not result in plus strains of increasingly greater vigor than corresponding minus strains.

13. There are differences between the behavior of the different species in the experimental tank. S. exspinosus was generally relatively slightly reactive compared with the two species of Daphnia. Many individuals of this species (and a few of the species of Daphnia) failed to reach either end of the experimental tank during the 15minute period of the selection test. 
14. The data for the over-time individuals presented a serious difficulty. In many cases, especially with the Simocephalus lines, they constituted a considerable portion, and a most significant portibn, of the reaction-time data. Over-time individuals were arbitrarily assigned a reaction-time of 900 seconds and treated as though they had reached an end of the tank within the period of the test. This expedient really minimized the rightful influence of these relatively slightly reactive but highly significant individuals.

15. Negatively reacting individuals were very irregular in occurrence and of doubtful significance. They were utilized in selection in the minus strains under the assumption that a genetic change might occur rendering an individual fundamentally negative in its reactions to light.

16. Many of the data are published for the benefit of workers who might wish to go over the analysis or make further analysis.

In the treatment of the data for the different lines the following results are recorded:

17. For Line 695 there was not an effect of selection. A marked general influence of environmental factors upon reaction-times is observed, as is true with most of the other lines.

18. In Line 689 selection was not effective. On the contrary, there was a persistent, though slight, difference tending to indicate that the minus strain was the more reactive.

19. In Line 691 there was no certain effect of selection, though part of the data suggests such an effect.

20. In Line 711 a selective effect is strongly suggested, though not fully supported by the same-day-brood data. The evidence for a genetic difference between the two strains is, however, as good or better than that suggesting a genetic difference between the two strains of Line 689.

21. The data in part suggest an effect of selection in Line 713, but it is improbable that such actually occurred.

22. Some of the early data for Line 714 suggest an effect of selection, but the later data show clearly that such had not occurred.

23. In Line 719 , as in Line 689 , there is a generally higher reaction-time for the plus strain. The different periods of the data, in spite of considerable fluctuations, rather consistently bear out this interpretation, and genetic differences in opposition to selection are believed to have arisen. Selection possibly operated to reduce this difference, which was less marked during the latter part of the experiment.

24. There was no effect of selection in Line 751 .

25. Some of the final data for Line 762 suggest an effect of selection, but the data are not sufficient to be at all convincing. 
26. In the short experiment with Line 766 (derived from Line 762) there was no effect of selection.

27. There was no effect of selection in Line 768 .

28. Most of the data for Line 794 suggest an effect of selection, though the test series did not support this conclusion and effect of selection must remain in doubt.

29. Effect of selection is strongly indicated for the final data for Line 795, but in view of the earlier differences in the opposite direction and the small amount of the data which indicate an effect of selection, the result is questionable.

30. There is clearly no effect of selection in Line 796 .

31. Certain portions of the data for Line 740 seem to indicate consistent differences in reaction-time for the two strains. A possible mutation early in the course of the experiment was examined, but ruled out as improbable. For 14 months preceding the final 3 months of the experiment, the plus strain was somewhat more reactive. However, the data for the final 3 months of the experiment, together with a large test series, indicate a lack of selective effect.

32. A large effect of selection is clearly indicated for Line 757:

(a) This conclusion is consistently attested by every check which was applied to the data.

(b) The effect was due both to an increased reactiveness of the plus strain and a reduced reactiveness in the minus strain (relatively to the other plus and minus strains of Simocephalus).

(c) The divergence between mean reaction-times became large.

(d) The divergence in reactiveness was permanent, or, at any rate, still existed 32 months (112 generations) after selection was discontinued.

(e) Except for the difference in reactiveness to light, and a slightly lower reproductive index (which was not in evidence during the latter part of the experiment) in the minus strain, there is nothing to distinguish the two strains.

33. It is not believed that general physiological differences or cytoplasmic transmission can be appealed to as explaining the result, particularly in view of the apparently permanent nature of the changes in reactiveness.

34. The effect is presumably not due to genetic segregation (unless there is assumed a novel method of segregation, for which there is no evidence) inasmuch as at least three such segregations seem necessary to explain the result on this basis and there is no chromatic reduction in the maturation of parthenogenetic eggs of Cladocera.

35. A possible novel method of segregation is suggested. Such an assumption would explain the results with Line 757 in accord with 
the pure-line hypothesis, but there is no evidence for the occurrence in Cladocera of such unusual chromatic behavior.

36 . The divergence in reaction-time may be explained as due to larger mutations. But the data do not show points, with one possible exception, at which such mutations may presumably have occurred, and, assuming a minimum of 3 mutations, each mutation must have produced its maximum effect long after its occurrence, a fact not consistent with the current conception of a mutation in such material. Further, the mutations must have occurred in both strains, and since three and probably more mutations are required, this would call for a high rate of mutation in this line.

37. The result may be explained as due to a gradual modification, many small changes (mutations?), in the genetic factor or factors involved. 
AgAr, W. E.

\section{REFERENCES.}

1913. Transmission of environmental effects from parent to offspring in Simocephalus vetulus. Phil. Trans. Roy. Soc. London, B, 203, p. 319-350.

Banta, A. M.

1914. Experiments on inheritance in parthenogenesis. Phil. Trans. Roy. Soc. London, B, 205, pp. 421-489.

1913. Selection within pure lines in Daphnia. Science, n. s., 37, p. 272.

1919. The results of selection with a Cladocera pure line (clone). Proc. Soc. Exp. Bridges, Calvin B. Biol. Med., 16, pp. 123-124.

1919. The developmental stages at which mutations occur in the germ-tract. Proc.

Conkuin, E. G. Soc. Exp. Biol. Med., 17, pp. 1-2.

1920. The mechanism of evolution. VI. The cellular basis of evolution. William Ellery Hale Lectures before the National Academy of Sciences, April 1917.

Ewing, H. E. Sci. Mont., May 1920, pp. 496-515.

1914. Pure-line inheritance and parthenogenesis. Biol. Bull., 26, pp. 25-35.

GAGE, S. H. and S. P.

1908. Sudan III deposited in the egg and transmitted to the chick. Science, n. s., 28 , pp. 494-495.

HaNel, Ezsie.

1908. Vererbung bei ungeschlechtlicher Fortpflanzung von Hydra grisea. Jena. Zeitschr., 43, pp. 321-372.

HEGNER, R. W.

1918. Variation and heredity during the vegetative reproduction of Arcella dentata.

Proc. Nat. Acad. Sci., 4, pp. 283-288.

1919. Heredity, variation, and the appearance of diversities during the vegetative reproduction of Arcella dentata. Genetics, 4, pp. 95-150.

1920. The relations between nuclear number, chromatin mass, cytoplasmic mass, and shell characteristics in four species of the genus Arcella. Jour. Exp.

JENNINGS, H. S. Zool., 30, pp. 1-95.

1908. Heredity, variation, and evolution in protozoa. II. Heredity and variation of size and form in Paramecium, with studies of growth, environmental action, and selection. Proc. Amer. Phil. Soc., 47, pp. 393-546.

1909. Heredity and variation in the simplest organisms. Amer. Nat., 43, pp. 321-337.

1910. Experimental evidence on the effectiveness of selection. Amer. Nat., 44, pp. 136-145.

1916. Heredity, variation, and the results of selection in the uniparental reproduction of Diflugia coronata. Genetics, 1, pp. 407-534.

1917. Observed changes in hereditary characters in relation to evolution. Jour. Wash. Acad. Sci., 7, pp. 281-301.

KüHN, ALFred.

1908. Die Entwicklung der Keimzellen in den parthenogenetischen Gerenationen der Cladoceren Daphnia pulex De Geer und Polyphemus pediculus De

LASHLEY, K. S.

Geer. Arch. Zellforsch., 1, pp. 538-586.

1915. Inheritance in the asexual reproduction of Hydra. Jour. Exp. Zool., 19, pp. 157-210.

1916. Results of continued selection in Hydra. Jour. Exp. Zool., 20, pp. 19-26.

McEwan, R. S.

1918. The reactions to light and to gravity in Drosophila and its mutants. Jour.

MiddLETON, A. R. Exp. Zool., 25, pp. 49-106.

1915. Heritable variations and the results of selection in the fission rate of Stylonychia pustulata. Jour. Exp. Zool., 19, pp. 451-503. 
Muller, H. J., and E. Altenburg.

1919. The rate of change of hereditary factors in Drosophila. Proc. Soc. Exp. Biol.

NABOORS, R. K.

$$
\text { Med., 17, pp. 10-14. }
$$

1919. Parthenogenesis and crossing-over in the grouse locust A potettix. Amer. Nat., 53, pp. 131-142.

Pearl, Raymond.

1917. The selection problem. Amer. Nat., 51, pp. 65-91.

Riddle, Oscar.

1908. The rate of growth of the egg-yolk in the chick, and the significance of white

Root, F. M. and yellow yolk in the ova of vertebrates. Science, n. s., 27, p. 945.

1918. Inheritance in the asexual reproduction of Centropyxis aculeata. Genetics,

Stocking, RUth J. 3, pp. 174-206.

1915. Variation and inheritance in abnormalities occurring after conjugation in

Stout, A. B.

Paramecium caudatum. Jour. Exp. Zool., 19, pp. 387-449.

1915. The establishment of varieties in Coleus by the selection of somatic variations.

Sturtevant, A. H.

Carnegie Inst. Wash. Pub. No. 218, 80 pp.

1918. An analysis of the effects of selection. Carnegie Inst. Wash. Pub. No. 264,

Weismann, Adgust. $68 \mathrm{pp}$.

1886. Richtungskörper bei parthenogenetischen Eiern. Zool. Auz., 9, pp. 570-573. WENRICH, D. H.

1916. The spermatogenesis of Phrynotettix magnus, with special reference to synapsis and the individuality of the chromosomes. Bull. Mus. Comp. Zool.,

WOLTERECK, R. 60 , pp. 57-133.

1909. Weitere experimentelle Untersuchungen über Artveranderung, speziell über des Wesen quantitativer Artunterschiede bei Daphniden. Verh. Deut. Zool. Gesell., 1909, pp. 110-173. 









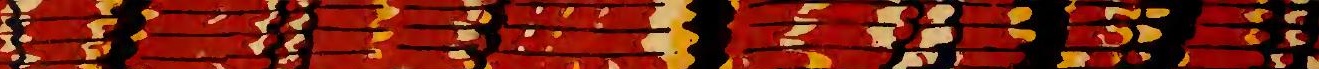

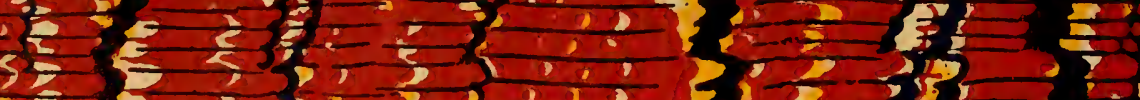

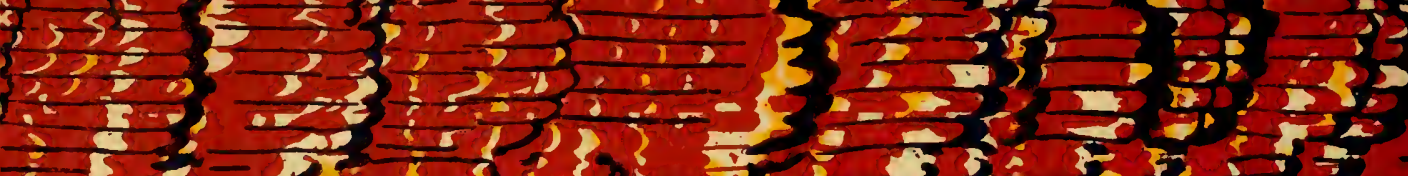

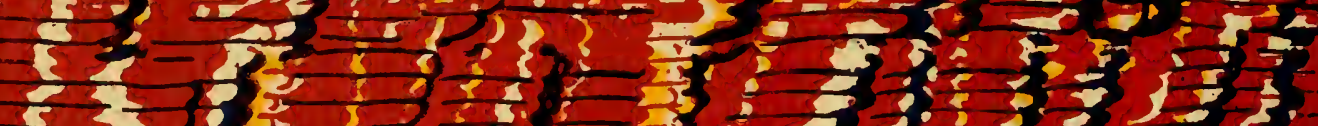

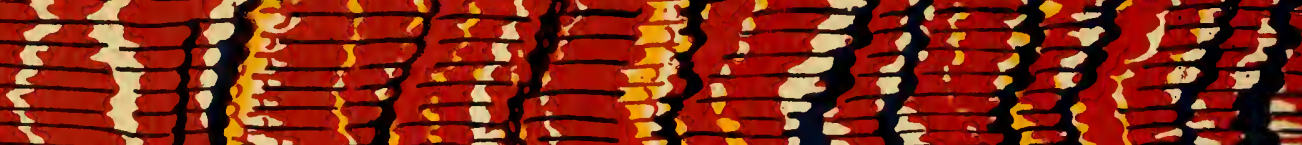

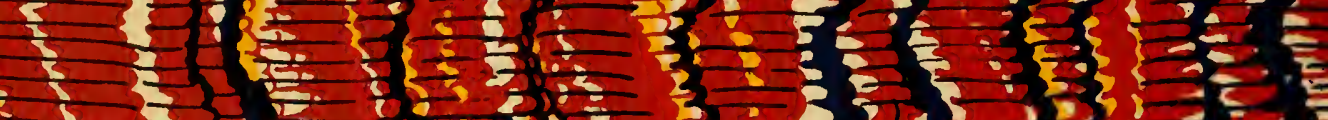

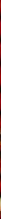

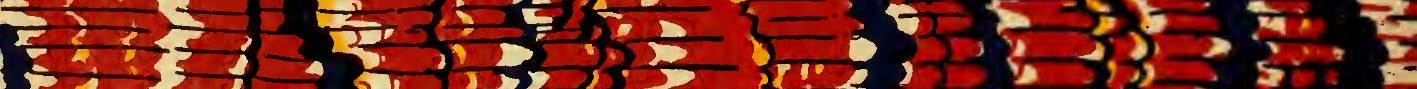

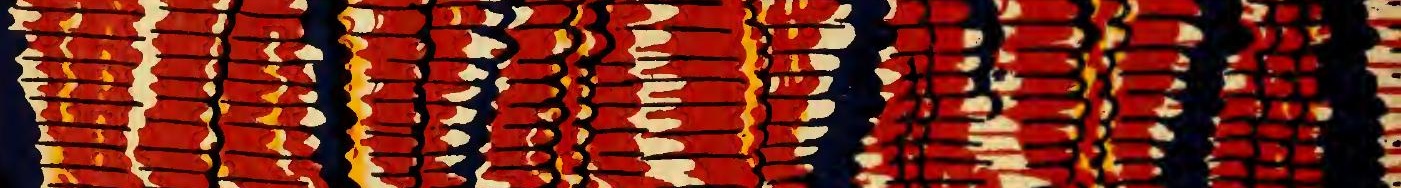

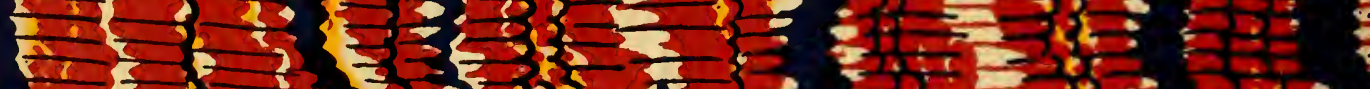

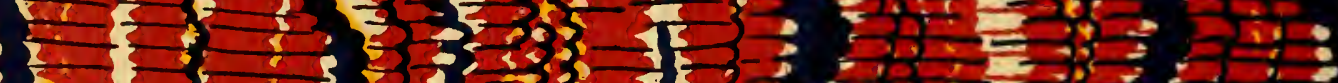

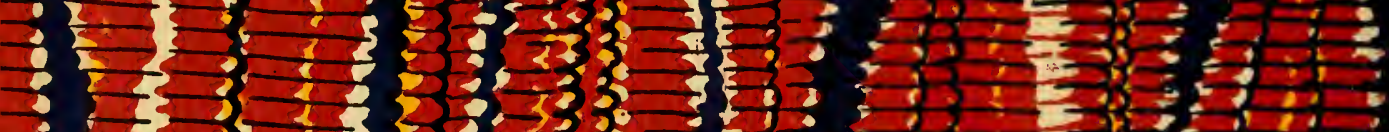

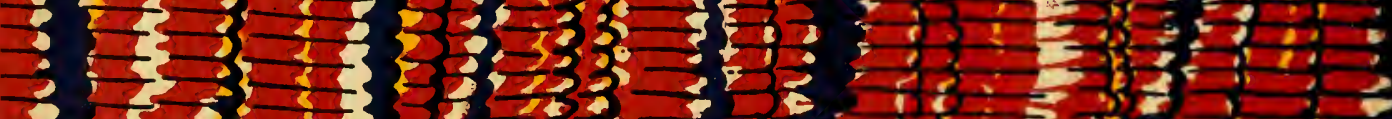

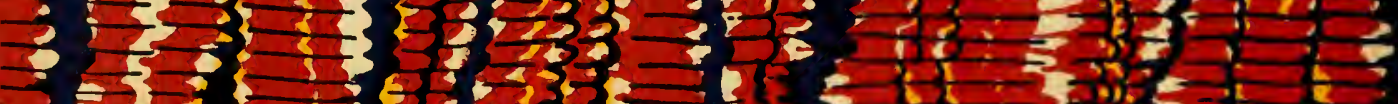

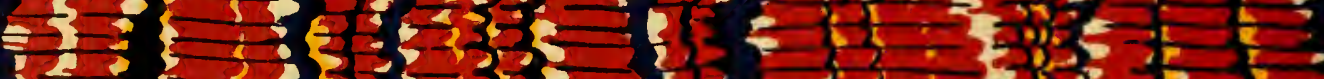

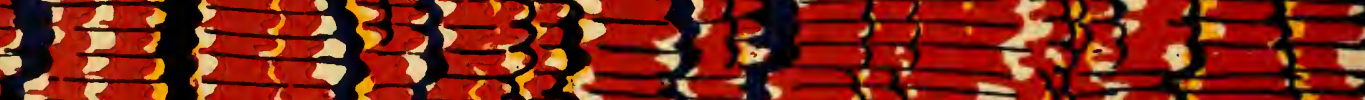

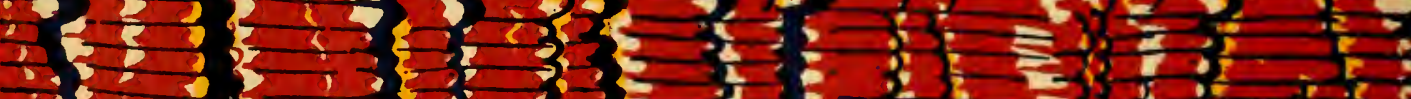

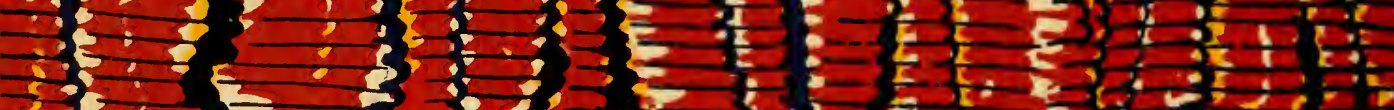

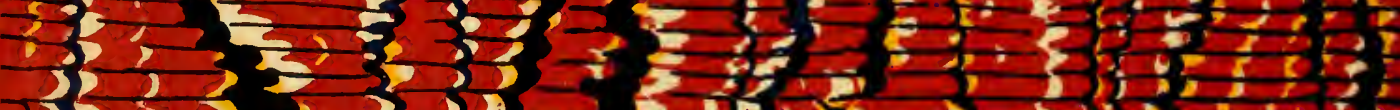

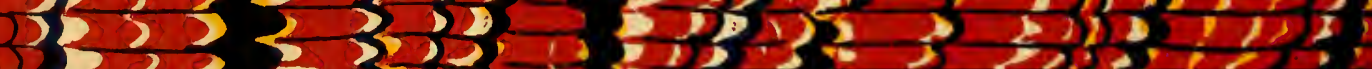

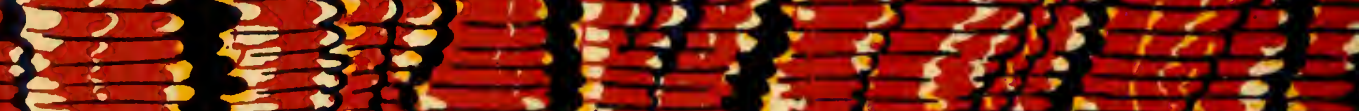

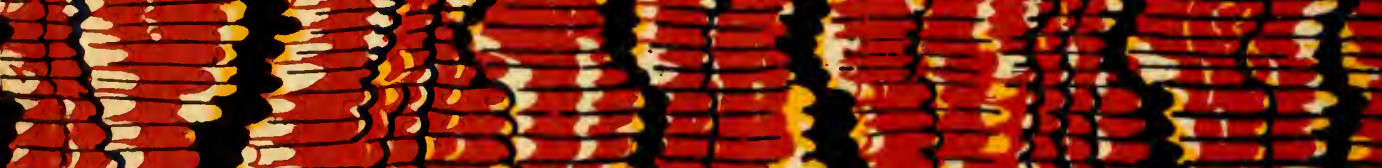

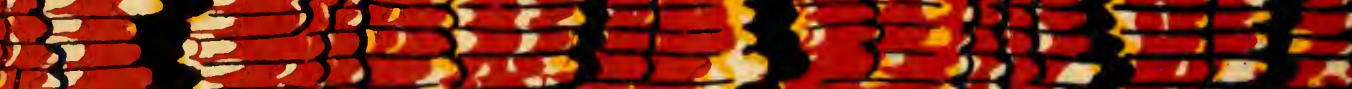

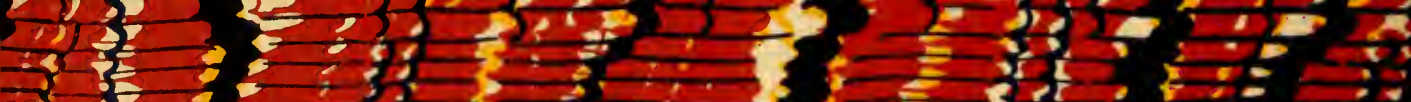

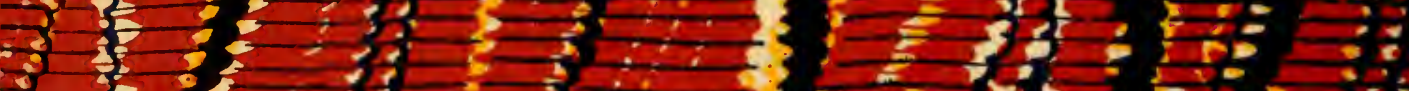

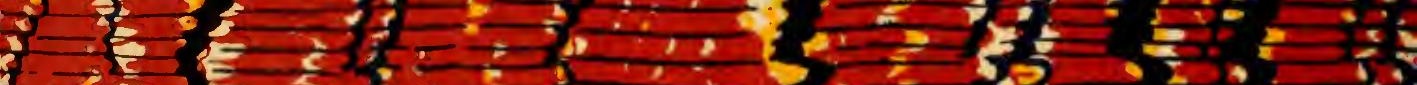

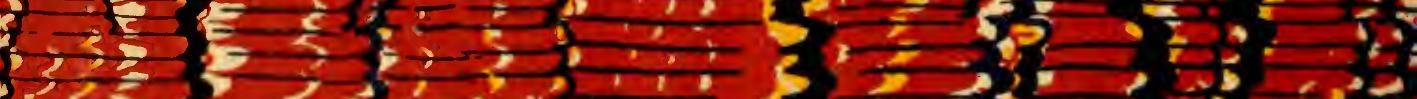

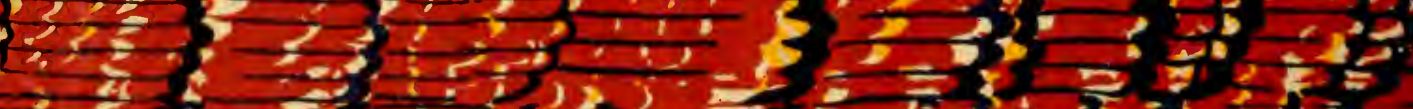

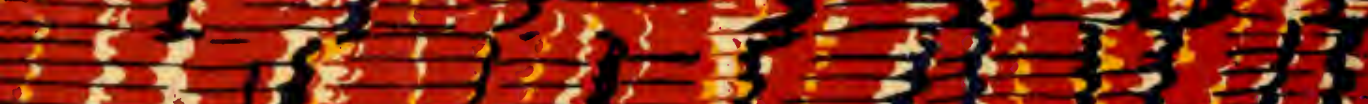

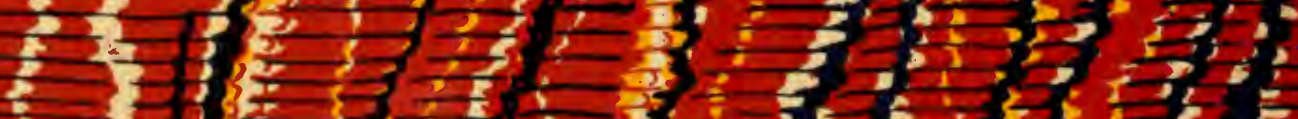

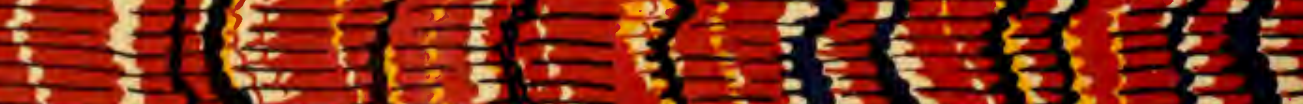

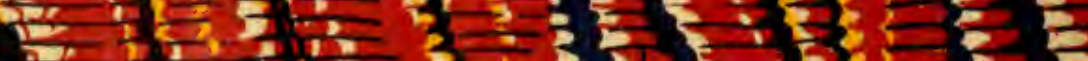




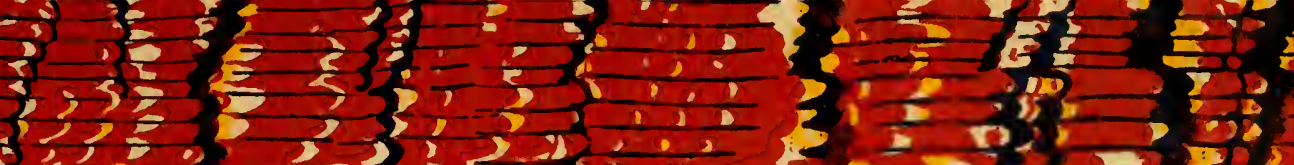

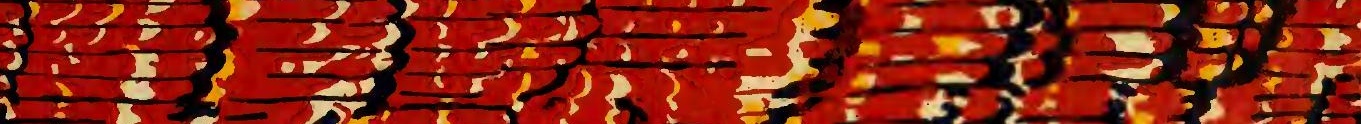

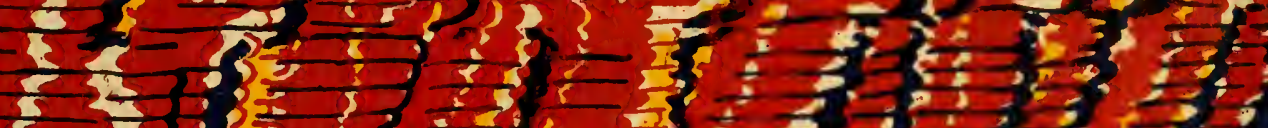
is 154035

$\frac{1}{5}$ in

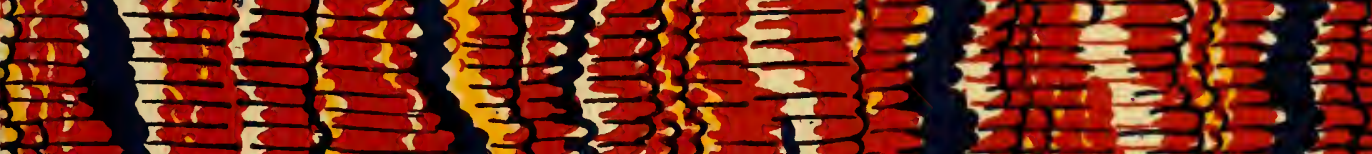

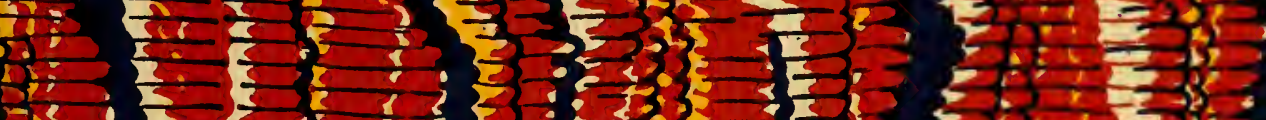

6. s $\{3,3,3\}$

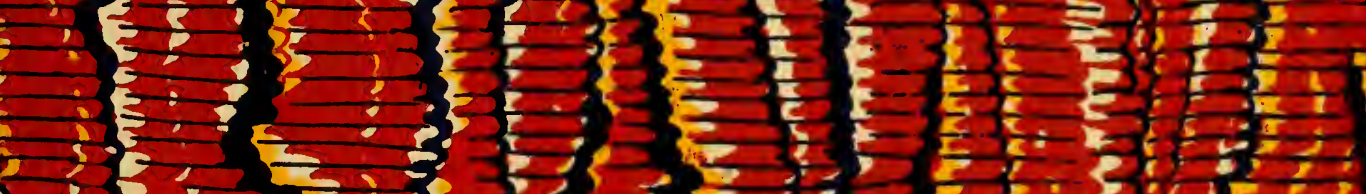

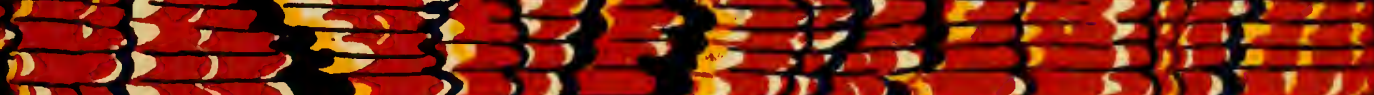

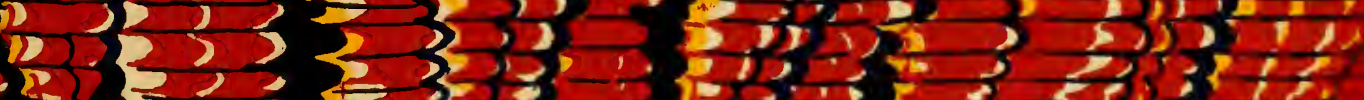

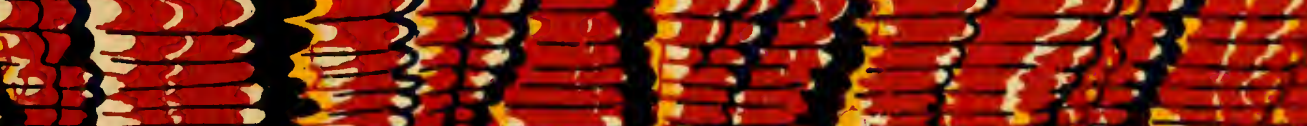
S

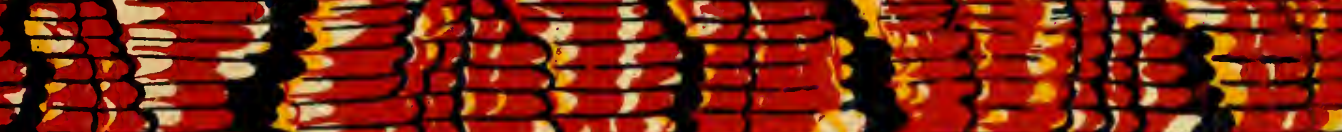

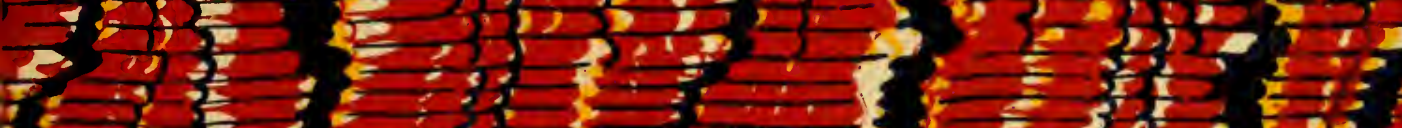

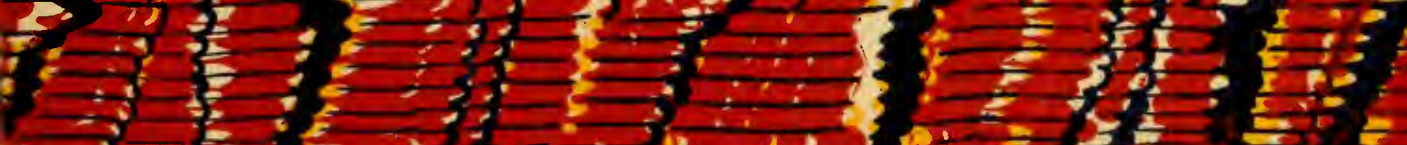

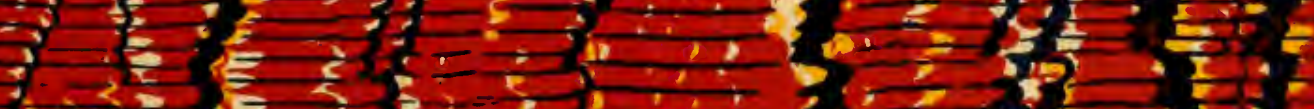

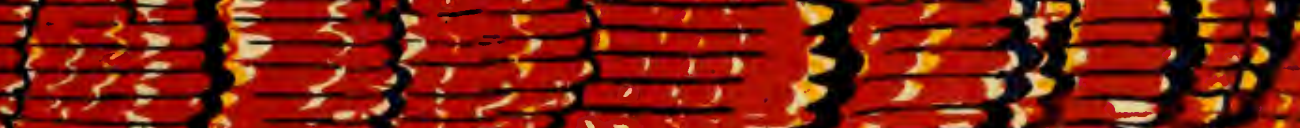
tots 
